\title{
SHEATH INSULATOR FINAL TEST REPORT TFE VERIFICATION PROGRAM
}

\author{
Prepared under \\ CONTRACT DE-AC03-86SF16298 \\ FOR THE SAN FRANCISCO OPERATIONS OFFICE \\ DEPARTMENT OF ENERGY
}

GENERAL ATOMICS PROJECT 3450

JULY 1994 


\section{DISCLAIMER}

This report was prepared as an account of work sponsored by an agency of the United States Government. Neither the United States Government nor any agency thereof, nor any of their employees, make any warranty, express or implied, or assumes any legal liability or responsibility for the accuracy, completeness, or usefulness of any information, apparatus, product, or process disclosed, or represents that its use would not infringe privately owned rights. Reference herein to any specific commercial product, process, or service by trade name, trademark, manufacturer, or otherwise does not necessarily constitute or imply its endorsement, recommendation, or favoring by the United States Government or any agency thereof. The views and opinions of authors expressed herein do not necessarily state or reflect those of the United States Government or any agency thereof. 


\section{DISCLAIMER}

\section{Portions of this document may be illegible in electronic image products. Images are produced from the best available original document.}


SHEATH INSULATOR

FINAL TEST REPORT

TFE VERIFICATION PROGRAM

1. INTRODUCTION

1.1 Objective of TFE Verification Program 1

1.2 Technical Approach 1

1.3 Organization of the Program 4

1.4 Structure of Test Program 4

1.4.1 Conceptual Design 7

1.4.2 Converter Performance 7

1.4.3 Insulator Seals

1.4.4 Sheath Insulators

1.4.5 Fueled Emitters

1.4.6 Cesium Reservoir and Interconnective Components 8

1.4.7 TFEs

1.5 Semiannual Progress Reports 8

1.6 Final Reports 8

1.7 Westinghouse Hanford Company Reports on Sheath Insulator 9

2. OBJECTIVES OF THE TEST PROGRAM 13

2.1 Function of the Sheath Insulator 13

2.2 Goals of the Test Program 13

2.3 Requirements of the Sheath Insulator 13

2.4 Development Approach/Logic 16

3. FABRICATION DEVELOPMENT 19

3.1 Original Test Matrix 19

3.2 Fabrication 21

3.2.1 Graded Trilayer Sheath Insulator 21

3.2.2 Cermet Trilayer Sheath Insulator 22

3.3 Process Qualification 24

3.4 Fabrication Results 24

4. EX-REACTOR TEST PROGRAM 29

4.1 Objective 29

4.2 Test Equipment and Test Assembly 29

4.3 Test Procedure $\quad 29$

4.4 Test Results 32

4.4.1 Yttria Sheath Insulators 33

4.4.2 YAG Sheath Insulators 33

4.4.3 Alumina Sheath Insulator 34 
5. IN-REACTOR TEST PROGRAM 37

$\begin{array}{lll}5.1 & \text { Objective } & 37\end{array}$

$\begin{array}{lll}5.2 & \text { Requirements } & 37\end{array}$

$\begin{array}{lll}5.3 & \text { Test Description } & 37\end{array}$

5.3.1 Uninstrumented In-Reactor Test 37

5.3.2 Instrumented In-Reactor Test 38

5.4 Postirradiation Examination 43

5.5 Test Results 44

5.5.1 UCA-1 45

$\begin{array}{lll}5.5 .2 \\ \text { UCA-2 } & 48\end{array}$

5.5 .3 UCA-3 $\quad 56$

$\begin{array}{lll}5.5 .4 & \text { H-Series } & 56\end{array}$

6. INSULATOR SEAL SPECIFICATION 61

$\begin{array}{lll}6.1 & \text { Materials/Design } & 61\end{array}$

6.2 Fabrication Process Description: Reference Sheath Insulators 61

6.2.1 Materials $\quad 62$

6.2.2 Processing 62

6.2.3 Acceptability of Sheath Insulators 63

7. REFERENCES 64

APPENDIX A - Resistance Requirement

APPENDIX B - Cermet Fabrication Development Report

APPENDIX C - TFE Sheath Insulator Test Procedures

APPENDIX D - Sheath Insulator Ex-Reactor Test Summary 


\section{INTRODUCTION}

\subsection{Objective of TFE Verification Program}

The program objective was to demonstrate the technology readiness of a Thermionic Fuel Element (TFE) suitable for use as the basic element in a thermionic reactor with electric power output in the 0.5 to $5.0 \mathrm{MW}$ (e) range, and a full-power life of 7 years. A TFE for a megawatt class system is shown on Figure 1-1. Only six cells are shown for simplicity; a megawatt class TFE would have many more cells, the exact number dependent on optimization trade studies.

\subsection{Technical Approach}

The TFE Verification Program (TFE-VP) built directly on the technology and data base developed in the 1960s and early 1970s in an AEC/NASA program, and in the SP-100 program conducted in 1983, 1984 and 1985. In the SP-100 program, the attractive features of thermionic power conversion technology were recognized but concern was expressed over the lack of fast reactor irradiation data. The TFE-VP addressed that concern.

The technical approach followed to achieve the program objective is shown on Fig. 1-2. Five prior programs form the basis for the TFE-VP:

1) AEC/NASA program of the 1960s and early 1970s.

1) SP-100 concept development program (Ref. 1-1).

3) SP-100 thermionic technology program (Ref. 1-2).

4) Thermionic irradiations program in TRIGA in FY-86 (Ref. 1-3).

5) Thermionic Technology Program in 1986 and 1987 (Refs. 1-4, 1-5).

These programs provided both the systems and technology expertise necessary to design and demonstrate a megawatt class TFE.

A TFE was designed that met the reliability and lifetime requirements for a 2 MW(e) conceptual reactor design. Analysis showed that this TFE could be used over the range of 0.5 to 5 megawatts. This was used as the basis for designing components for test and evaluation. The demonstration of a 7-year component lifetime capability was through the combined use of analytical models and accelerated, confirmatory tests in a fast test reactor. Iterative testing was performed where the results of one test series led to evolutionary improvements in the next test specimens.

The TFE components underwent screening and initial development testing in ex-reactor tests. Several design and materials options were considered for each component. As screening tests permitted, down selection occurred.

In parallel with ex-reactor testing, and fast reactor component testing, components were integrated into a TFE and tested in the TRIGA test reactor at General Atomics (GA). Realtime 


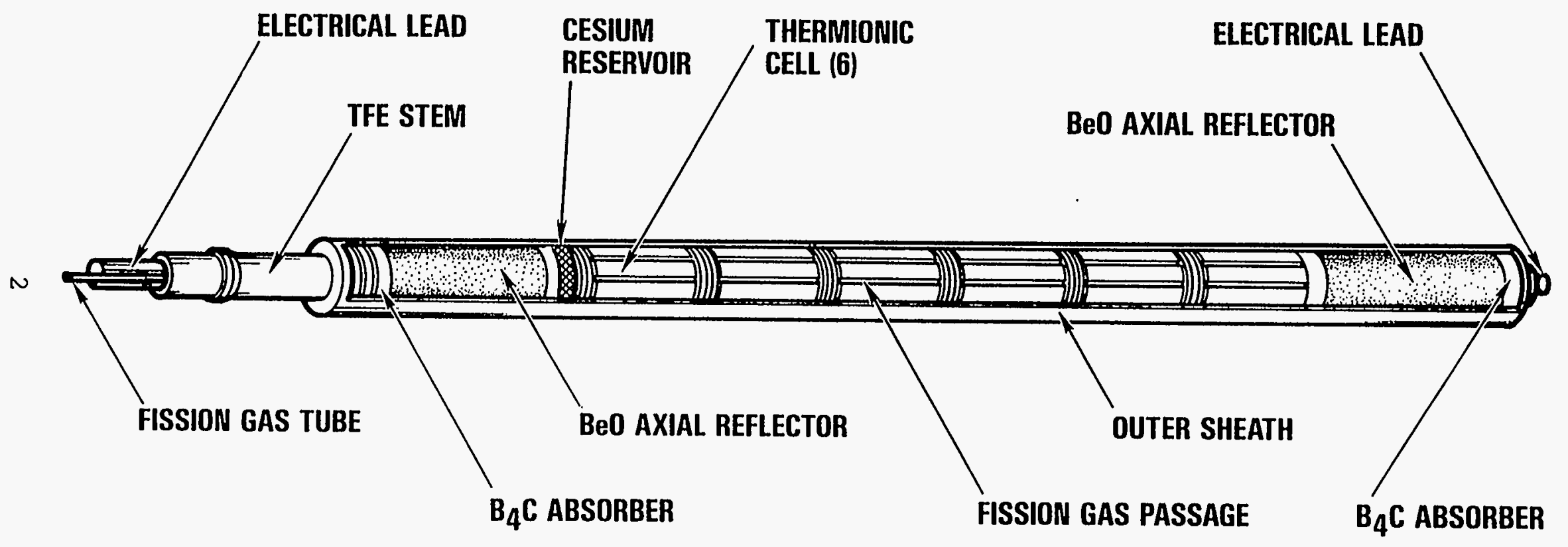

Figure 1-1. TFE for Megawatt Class System 


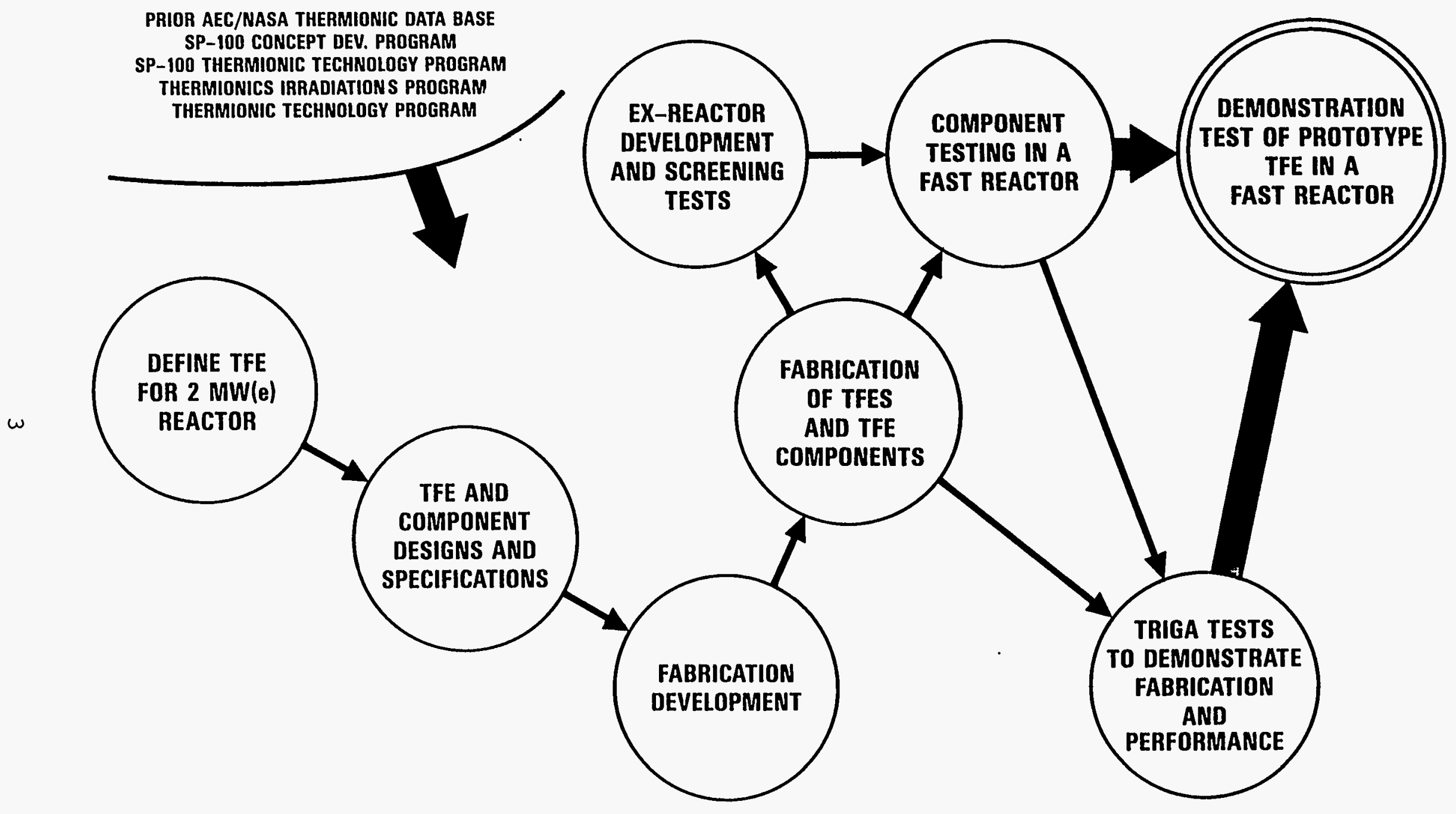

Figure 1-2. Logic to Demonstrate Technology Readiness of Megawatt Class TFE 
testing of partial length TFEs was used to test support, alignment and interconnective TFE components, and to verify TFE performance in-reactor with integral cesium reservoirs. Realtime testing was also used to verify the relation between TFE performance and fueled emitter swelling, to test the durability of intercell insulation, to check temperature distributions, and to verify the adequacy over time of the fission gas venting channels.

Predictions of TFE lifetime rested primarily on the accelerated component testing results, as correlated and extended to realtime by the use of analytical models.

\subsection{Organization of the Program}

Contracting Agency: Department of Energy, San Francisco Operations Office

Prime Contractor: General Atomics (GA)

Subcontractors:

ThermoTrex Corporation (TTC), a subsidiary of Thermo Electron Corporation

Rasor Associates, Incorporated (RAI)

Space Power Incorporated (SPI)

Fast reactor testing manager:

Westinghouse Hanford Corporation (WHC)

Fast reactor facilities:

Fast Flux Test Reactor (FFTF), with testing managed by WHC.

Experimental Breeder Reactor-II (EBR-II), with testing managed by Argonne National Laboratory-West (ANL-W)

Technical oversight for DOE: Los Alamos National Laboratory (LANL).

\section{$1.4 \quad$ Structure of Test Program}

The TFE-VP was broken down into 7 tasks, generally corresponding to the components of a TFE. Figure 1-3 shows a thermionic cell with the various components identified.

Figure 1-4 shows a one cell TFE fabricated for test in the program. A multi-cell TFE has 2 or more cells in series.

When compared to Figure 1-1, it is clear that this test article is not quite prototypical. The test conditions dictate the design to some extent. Also, the test approach is to first test simple TFEs and then gradually test TFEs more prototypic.

For each component, the work involved: 


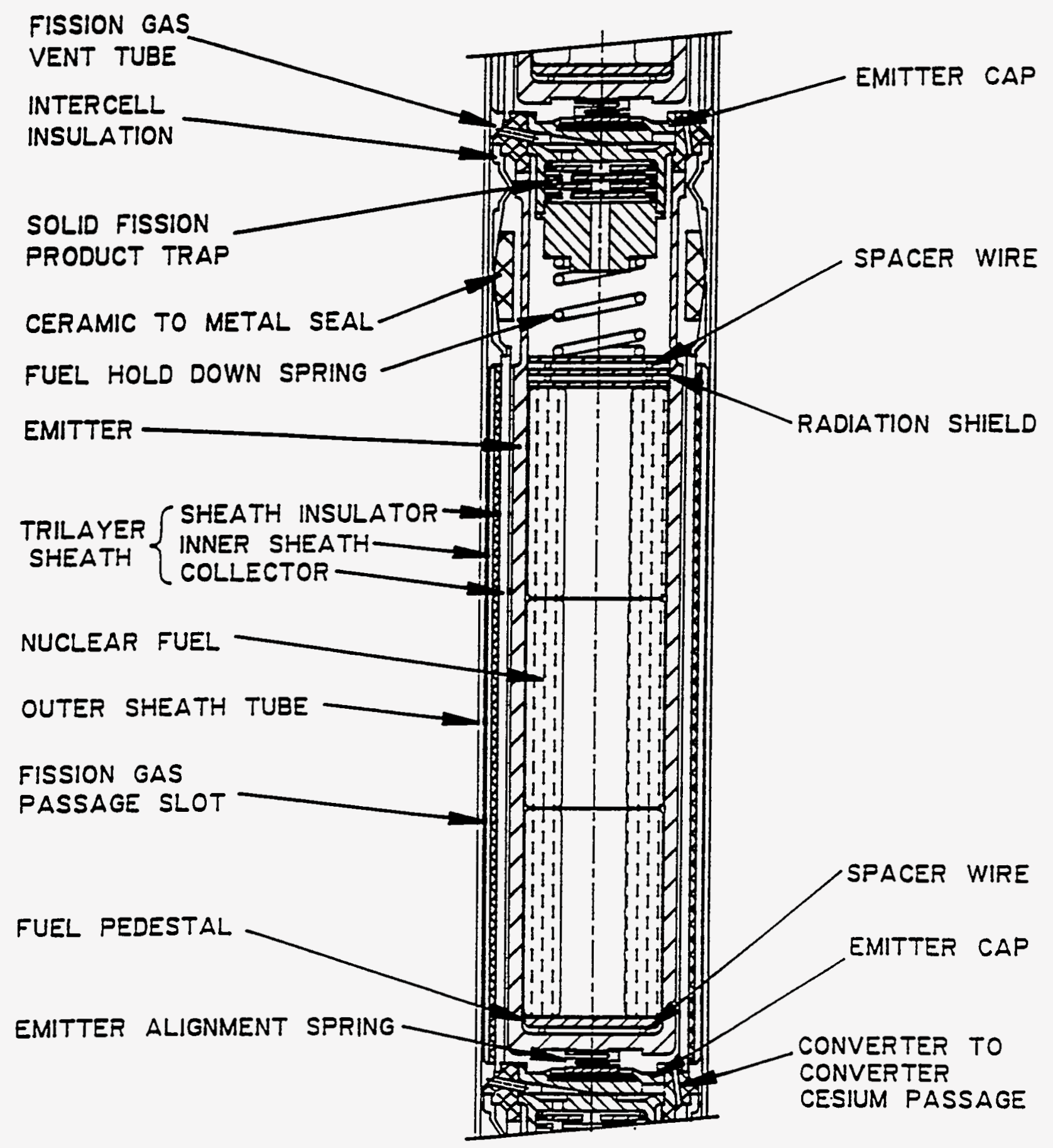

Figure 1-3. Thermionic Cell 


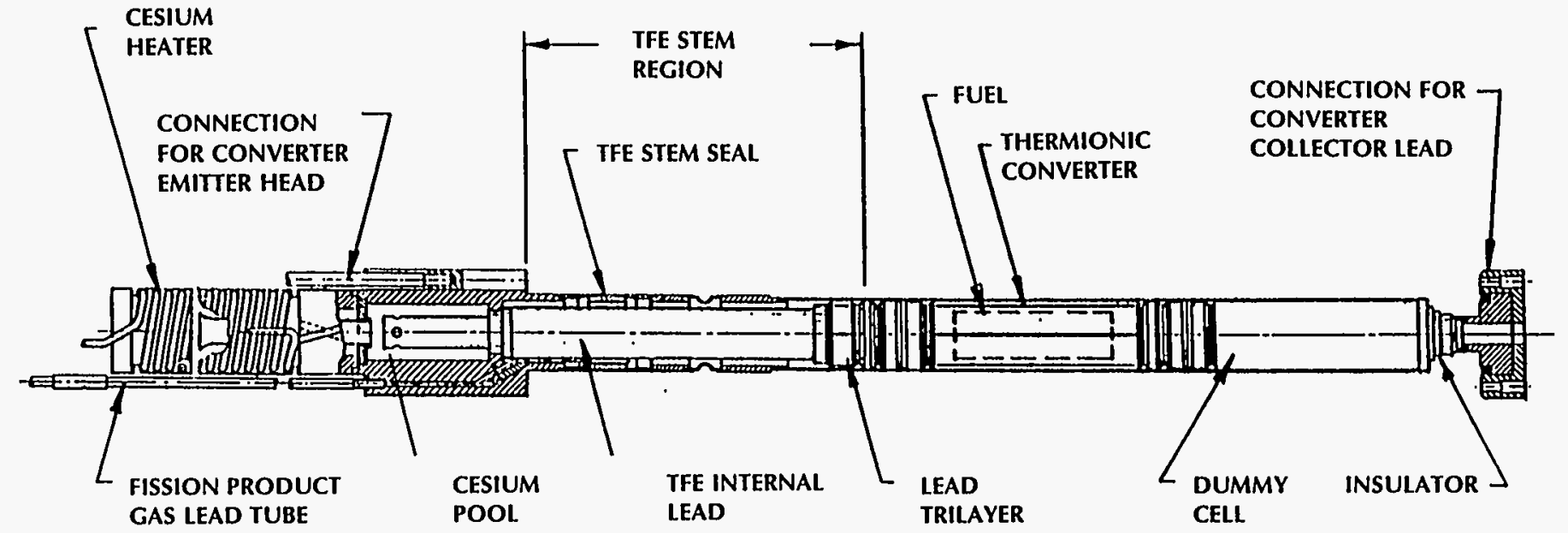

Figure 1-4. One Cell TFE Test in TFE Verification Program 
1) Component design and analyses

2) Materials evaluation and selection

3) Performance testing

4) Life testing, both accelerated and real time.

In addition, performance models were developed for converter performance, fueled emitters and cesium reservoirs.

A brief description of each task is given below. For each of the component tasks, fabrication process specifications were developed and materials were chosen.

1.4.1 Conceptual Design. A TFE optimized for a $2 \mathrm{MW}$ (e) system was designed. Its scalability over the range of $500 \mathrm{~kW}$ to $5 \mathrm{MW}$ was demonstrated.

1.4.2 Converter Performance. The performance of converters of interest for megawatt class systems was measuredd and existing models on converter performance were refined.

1.4.3 Insulator Seals. The insulator seal isolates the space filled with gaseous fission products from the cesium filled interelectrode gap. It also assures that electrons flow from the collector of one cell to the emitter of an axially adjacent cell.

1.4.4 Sheath Insulators. The sheath insulator is a structure composed of 3 layers:

o The inner layer is the collector.

- The middle layer is an insulator electrically isolating the collector from the reactor coolant and structure. It also must conduct reject heat to the reactor coolant.

o The outer metallic layer assures the structural integrity of the sheath.

1.4.5 Fueled Emitters. The fueled emitter is the emitter component inside of which are the following components:

- $\quad \mathrm{UO}_{2}$ fuel.

- Fuel holddown device to prevent damage to the cell during launch and ascent.

o Fission product trapping components to prevent solid and condensable fission products from exiting the cell.

o Heat shields to protect the upper and lower parts of the emitter from the high temperatures of the $\mathrm{UO}_{2}$ fuel. 


\subsubsection{Cesium Reservoir and Interconnective Components}

The cesium reservoir provides cesium vapor to the interelectrode gap. A graphite cesium reservoir was demonstrated in the program.

Interconnective components are those metal parts and insulators which are necessary to attach one cell in series with another.

\subsubsection{TFEs}

The TFE is an axial series of one or more cells. It also contains a cesium reservoir. TFEs with one, three and six cells were fabricated and tested.

The TFEs fabricated under the TFE-VP are designated the " $\mathrm{H}$ " series TFEs, being the next series following the "E", "F" and "G" series which were studied in the 1960s and 1970s. The E-series TFEs had an emitter diameter of 0.625 inch; the F-series, 1.1 inches; and the $\mathrm{H}$ series, 0.5 inches.

A specific TFE has a designation $x H y$, the " $x$ " being the number of cells in the TFE and the "y" being the specific TFE in question. For example, the TFEs fabricated and tested in the program were:

TFE-1H1, the first of the 1-cell TFEs.

TFE-1H2, the second of the 1-cell TFEs.

TFE-1H3, the third of the 1-cell TFEs.

TFE-3H1, the first of the 3-cell TFEs.

TFE-3H5, the fifth of the 3-cell TFEs. Numbers 2, 3 and 4 were eliminated early in the program.

TFE-6H1, the first of the 6-cell TFEs.

\subsection{Semiannual Progress Reports}

Semiannual progress reports provide a running account of technical progress which reflects the work done at GA, TTC, RAI and SPI. These reports also summarize the status and results of the irradiation program at WHC, ANL-W and LANL.

Table 1-1 shows a complete list of all semiannual progress reports.

\section{$1.6 \quad$ Final Reports}

Final test reports give details on each of the major components outlined in Section 1.4. A list of these final reports is given in Table 1-2. It is assumed in these reports that the reader is familiar with thermionic technology and the structure and operation of thermionic fuel elements and their components. 


\subsection{Westinghouse Hanford Company Reports on Sheath Insulators}

WHC issued several reports dealing with the testing and postirradiation examination of sheath insulators. These are listed in Table 1-3. The reader is referred to these reports for detail on the irradiation of cesium reservoirs and their subsequent postirradiation examination (PIE). 
Table 1-1

SEMIANNUAL PROGRESS REPORTS

\begin{tabular}{|l|l|c||}
\hline \multicolumn{1}{|c|}{ Period Ending } & \multicolumn{1}{|c|}{ Date Issued } & Report Number \\
\hline March 31, 1987 & April 1987 & GA-A18780 \\
September 30, 1987 & March 1988 & GA-A19115 \\
April 30, 1988 & June 1988 & GA-A19269 \\
October 31, 1988 & January 1989 & GA-A19412 \\
April 30, 1989 & September 1989 & GA-A19666 \\
September 30, 1989 & March 1990 & GA-A19876 \\
March 31, 1990 & July 1990 & GA-A20119 \\
September 30, 1990 & January 1991 & GA-A20335 \\
March 31, 1991 & April 1991 & GA-A20493 \\
September 30, 1991 & December 1991 & GA-A20804 \\
March 31, 1992 & April 1992 & GA-A20911 \\
September 30, 1992 & January 1993 & GA-A21210 \\
March 31, 1993 & May 1993 & GA-A21326 \\
September 30, 1993 & January 1994 & GA-A21511 \\
\hline
\end{tabular}

Table 1-2

FINAL TEST REPORTS OF TFE VERIFICATION PROGRAM

\begin{tabular}{||l|c|}
\hline Report Title & Document No. \\
\hline Conceptual Design & GA-A21590 \\
Converter Peformance Final Test Report & GA-A21591 \\
Insulator Seal Final Test Report & GA-A21592 \\
Sheath Insulator Final Test Report & GA-A21593 \\
Fueled Emitter Final Test Report & GA-A21594 \\
Cesium Reservoir and Interconnective Components Final Test Report & GA-A21595 \\
TFE Performance Final Test Report & GA-A21596 \\
TFE Design Package & GA-A21597 \\
Fabrication Process Specifications & GA-A21734 \\
\hline
\end{tabular}


Table 1-3

WESTINGHOUSE HANFORD COMPANY REPORTS ON SHEATH INSULATORS

\section{Test Documentation}

1. Williams, L. S., "Test Design Description for the Materials Open Test Assembly HM115 (MOTA-1E)", Experiment Description - Volume II, HEDL-TC-2851, July 1986.

2. Williams, L. S., "Final Data Package As-Built Documentation for the Installation of the Test Train into the Materials Open Test Assembly Vehicle - HM115 (MOTA1E)", HEDL-TC-2855, July 1986.

3. Williams, L. S., "Test Design Description for the Materials Open Test Assembly HM116 (MOTA-1F)", Experiment Description - Volume II, WHC-SP-0028, August 1987.

4. Williams, L. S., "Final Data Package As-Built Documentation for the Installation of the Test Train into the Materials Open Test Assembly Vehicle - HM116 (MOTA-1F)" WHC-SP-0085, September 1987.

5. Engineering Test Plan for EBR-II Tests UFAC-2B and UFAC-3, WHC-SP-0469, May 1989.

6. Experiment Description and Safety Analysis for EBR-II Tests UFAC-2B and UFAC3, WHC-SP-0470, July 1989.

6. Supporting Analysis for UFAC Tests in EBR-II, WHC-SD-SP-DA-002, December 1989.

7. Engineering Test Plan (ETP) for UCA-3, WHC-SD-SP-DB-001, August 1990.

8. QA and As-Built Data Package for UCA-3 Experiment (Capsule SC3-3), WHC-SDSP-DP-001, November 1991.

9. QA and As-Built Data Package for UCA-3 Experiment (Capsule SC3-4, SC3-5 and SC3-6), WHC-SD-SP-DP-002, April 1991.

\section{Test Data Reports}

1. Lawrence, L. A., N. S. Cannon and K. E. Ard, "Irradiation and Examination of the Thermionic Fuel Element (TFE) Verification Program UCA-1 Samples", WHC-SP0585, May 1990. 
2. Lawrence, L. A., K. E. Ard and D. M. Paxton, "Irradiation and Examinations of the Thermionic Fuel Element (TFE) Verification Program UCA-2 Samples", WHC-SP0656, June 1991.

3. Lawrence, L. A. and D. M. Paxton, "Irradiation and Examinations of the Thermionic Fuel Element (TFE) Verification Program UCA-3 Samples", WHC-SP-1055, September 1993.

4. Paxton, D. M. and L. A. Lawrence, "Irradiation and Nondestructive Examination (NDE) of the Thermionic Fuel Element (TFE) Verification Program UFAC SC3-2 Seal Insulator Samples", WHC-SP-0674, June 1991.

5. Paxton, D. M. and L. A. Lawrence, "Irradiation and Metallography of the Thermionic Fuel Element (TFE) Verification Program UCA-2 Samples", WHC-SP0658, February 1991.

6. Cannon, N. S., "Thermal Property Measurements of Unirradiated Thermionic Fuel Element (TFE) Sheath Insulators", WHC-SP-0711, November 1991. 


\section{OBJECTIVES OF THE TEST PROGRAM}

\subsection{Function of the Sheath Insulator}

The sheath insulator in a thermionic cell has two functions. First, the sheath insulator must electrically isolate the collector from the outer containment sheath tube that is in contact with the reactor liquid metal coolant. Second, the sheath insulator must provide for high uniform thermal conductance between the collector and the reactor liquid metal coolant to remove away waste heat. Figure 2-1 shows the types and location of the different insulators used in a thermionic cell.

\subsection{Goals of the Test Program}

The goals of the sheath insulator test program were to demonstrate that suitable ceramic materials and fabrication processes were available, and to validate the performance of the sheath insulator for TFE-VP requirements. In particular the goals were:

1) Produce designs for the sheath insulator.

2) Develop required fabrication processes for the sheath insulator design and document with process specifications.

3) Fabricate sheath insulators for ex-reactor testing to determine their electrical characteristics.

4) Fabricate sheath insulators for un-instrumented (UCA-1, UCA-2, and UCA-3) and instrumented (IFAC-SI) in-reactor testing.

5) Verify the performance characteristics and lifetimes associated with sheath insulators by means of ex-reactor and in-reactor testing. Perform postirradiation examinations of the sheath insulators and use the test results to improve on the sheath insulator design.

6) Develop an analytical model of the performance and lifetime of the sheath insulator and validate the model with test data.

\subsection{Requirements of the Sheath Insulator}

The TFE-VP placed the following requirements on the sheath insulator:

1) Insulator operating temperature:

2) Nominal fast fluence, $\mathrm{E}>0.1 \mathrm{MeV}$ :

3) Nominal applied voltage: Maximum applied voltage:
$1070 \mathrm{~K}$

$2.7 \times 10^{22} \mathrm{n} / \mathrm{cm}^{2}$

5.9 volts

7.5 volts 


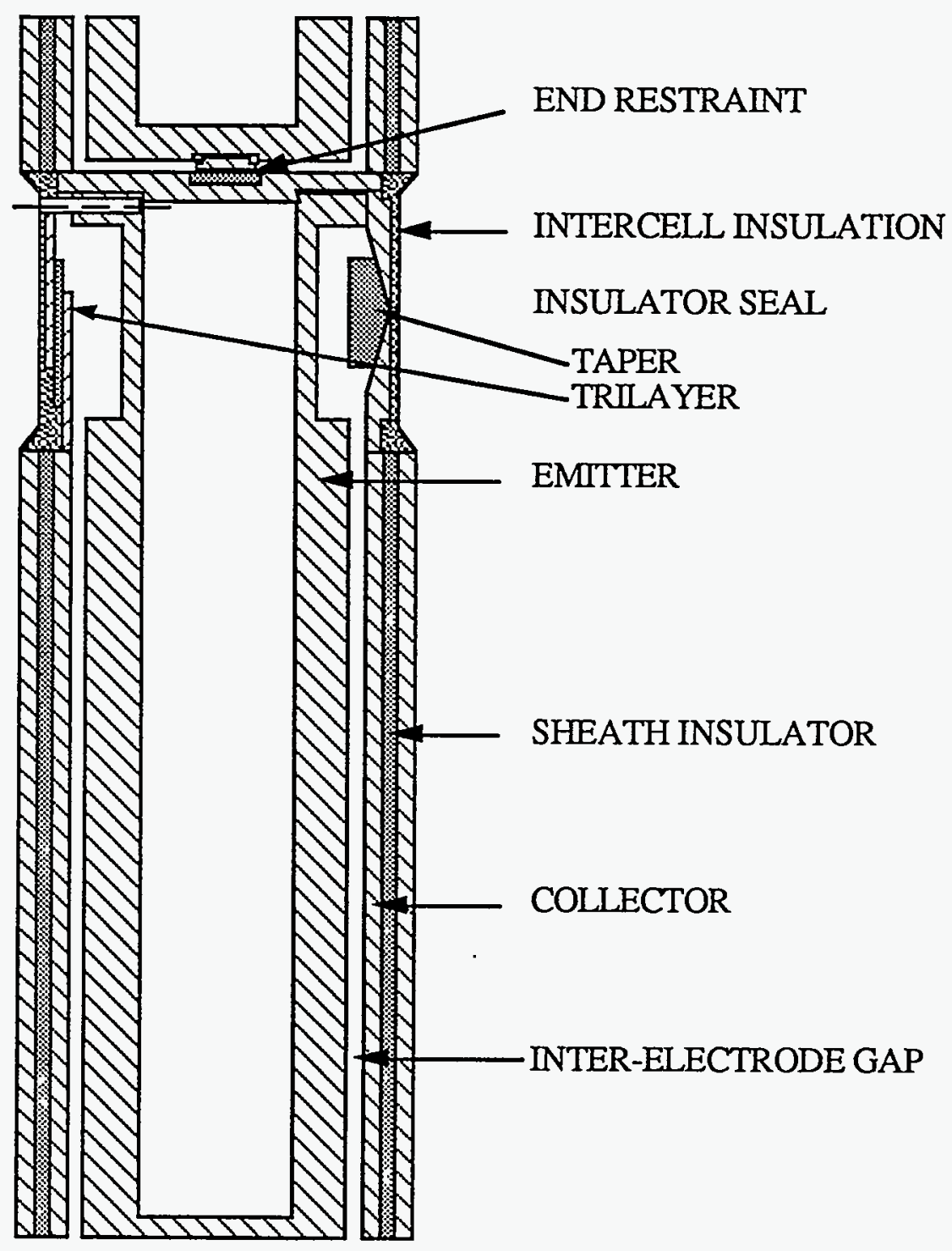

Figure 2-1. Thermionic Cell Showing Insulator Locations 
4) Operating environment:

5) Electrical resistance:

6) Thermal conductivity:

7) Lifetime:
1-3 torr Cs and fission gases

$>1000$ ohms $(1070 \mathrm{~K})$

$>0.03 \mathrm{~W} /(\mathrm{cm}-\mathrm{K})$

$\geq 7$ years

The sheath insulator resistance requirement calculations are given in Appendix A. A sheath insulator with a $1000 \mathrm{ohms}$ resistance will limit the power dissipated in the sheath insulator to less than $0.1 \%$ of the total TFE power. One thousand ohms translates into a resistivity of $5.9 \times 10^{5} \mathrm{ohms}-\mathrm{cm}$ at $1070 \mathrm{~K}$.

A thermal conductivity of $0.03 \mathrm{~W} /(\mathrm{cm}-\mathrm{K})$ at $1070 \mathrm{~K}$ corresponds to a temperature drop across the sheath insulator of $34 \mathrm{~K}$ for a heat flux of $25 \mathrm{~W} / \mathrm{cm}^{2}$ and an insulator thickness of $0.041 \mathrm{~cm}$. The thermal conductance of unirradiated sheath insulator was measured by TTC for the candidate materials (Ref. 1-2). Results showed that the temperature difference through the insulator was less than $5 \mathrm{~K}$ with a heat flux of approximately $20 \mathrm{~W} / \mathrm{cm}^{2}$. Furthermore, the local thermal conductivity was uniform, important for avoiding hot spots on the collector.

The following additional requirements derive from those listed above:

1) Minimal neutron damage effects. The fast neutron fluence should lead to minimal changes in the electrical properties of the sheath insulator. In addition, the sheath insulator should remain structurally intact. This condition implies that the volumetric swelling of the insulator should be low.

2) Electrical breakdown field. The sheath insulator should withstand a potential difference of 7.5 volts without exhibiting electrical breakdown. The electrical breakdown field of alumina at $1150 \mathrm{~K}$ is $\approx 3 \times 10^{4}$ to $2 \times 10^{5} \mathrm{~V} / \mathrm{cm}$ (Ref. 2-1). This corresponds to a breakdown voltage for an insulator thickness of $0.041 \mathrm{~cm}$ of 1200 to $8000 \mathrm{~V}$, considerably more than the maximum operating voltage of $7.5 \mathrm{~V}$.

Data for high temperature breakdown fields of yttria and YAG are not available, therefore, estimates were made assuming that the breakdown voltage scales as:

$$
\mathrm{V}_{\mathrm{B}} \propto \sqrt{\mathrm{K} / \sigma}
$$

where $\mathrm{K}$ is the thermal conductivity and $\sigma$ the electrical conductivity of the insulator. Taking $\sigma$ for yttria and YAG from Table 3-1 and using a value for $\mathrm{K}$ of $0.04 \mathrm{~W} /(\mathrm{cm}-\mathrm{K})$ for yttria and YAG (Ref. 2-2) and $0.07 \mathrm{~W} /(\mathrm{cm}-\mathrm{K})$ for alumina, the breakdown voltages for yttria and YAG were estimated using the following relation:

$$
\mathrm{V}_{\mathrm{B}}=\sqrt{\mathrm{K} / \sigma} \times \sqrt{\sigma_{\text {alumina }} \times K_{\text {alumina }} \times V_{\mathrm{B} \text { alumina }}}
$$

The breakdown voltage for yttria is between 90 and $600 \mathrm{~V}$ and between 290 and 1200 $\mathrm{V}$ for YAG, values well in excess of maximum TFE operating voltage of $7.5 \mathrm{~V}$. 
4) Chemical compatibility and Stability. The sheath insulator should be chemically compatible with its adjacent metallic electrode material. The sheath insulator can come into contact and should be compatible with both cesium and fission gases.

5) Minimal electrolytic degradation. Electrolysis of the insulator should be negligible. An insulator which exhibits and ionic conductivity of $<10^{-10}(\mathrm{Ohm}-\mathrm{cm})^{-1}$ at $1070 \mathrm{~K}$ will exhibit minimal electrolytic degradation.

6) Acceptable Vapor Pressure/Melting Point. The insulator melting temperature and its vapor pressure at $1070 \mathrm{~K}$ should be compatible with the design requirements. A melting point in excess of $2000 \mathrm{~K}$ and a vapor pressure at $1070 \mathrm{~K}$ of $<10^{-10}$ torr are expected to be sufficient.

\subsection{Development Approach/Logic}

The overall development approach/logic for the sheath insulator program is shown in Fig. 2-2. Solid boxes represent sheath insulator activities while supporting activities are indicated by dashed boxes. Initial sheath insulator requirements were established to define materials and designs. Data from previous fast neutron irradiation tests and previous sheath insulator design experience were also used. Test specimens were fabricated for ex-reactor and in-reactor testing and for actual incorporation and testing in the $\mathrm{H}$-series TFEs. If the ex-reactor and in-reactor testing results indicated that the properties of the sheath insulator were acceptable, then further specimens were prepared for more extensive testing. Materials and designs with unacceptable properties were dropped.

The major outputs from the development work were insulator materials, fabrication processes, and performance characteristics.

The in-reactor test program was composed of several batches of test specimens, as shown in Table 2-1. Uninstrumented Component Accelerated (UCA) tests were conducted in FFTF in a Materials Open Test Assembly (MOTA). UCA tests were also run the in EBR-II test reactor.

Two fabrication approaches were followed in developing a sheath insulator:

1) The graded trilayer approach in which ceramic and niobium powders are plasma sprayed in such a way as to produce a gradation from pure niobium to pure ceramic and back to pure niobium. The composite is contained within two niobium metal components. The gradation accommodates the differential thermal expansion between niobium and the ceramic.

2) The cermet trilayer approach in which ceramic and niobium powders are mixed together forming a composite which is contained within two niobium metal components. The niobium powder adds strength to the ceramic and accommodates the differential thermal expansion between niobium and the ceramic. 


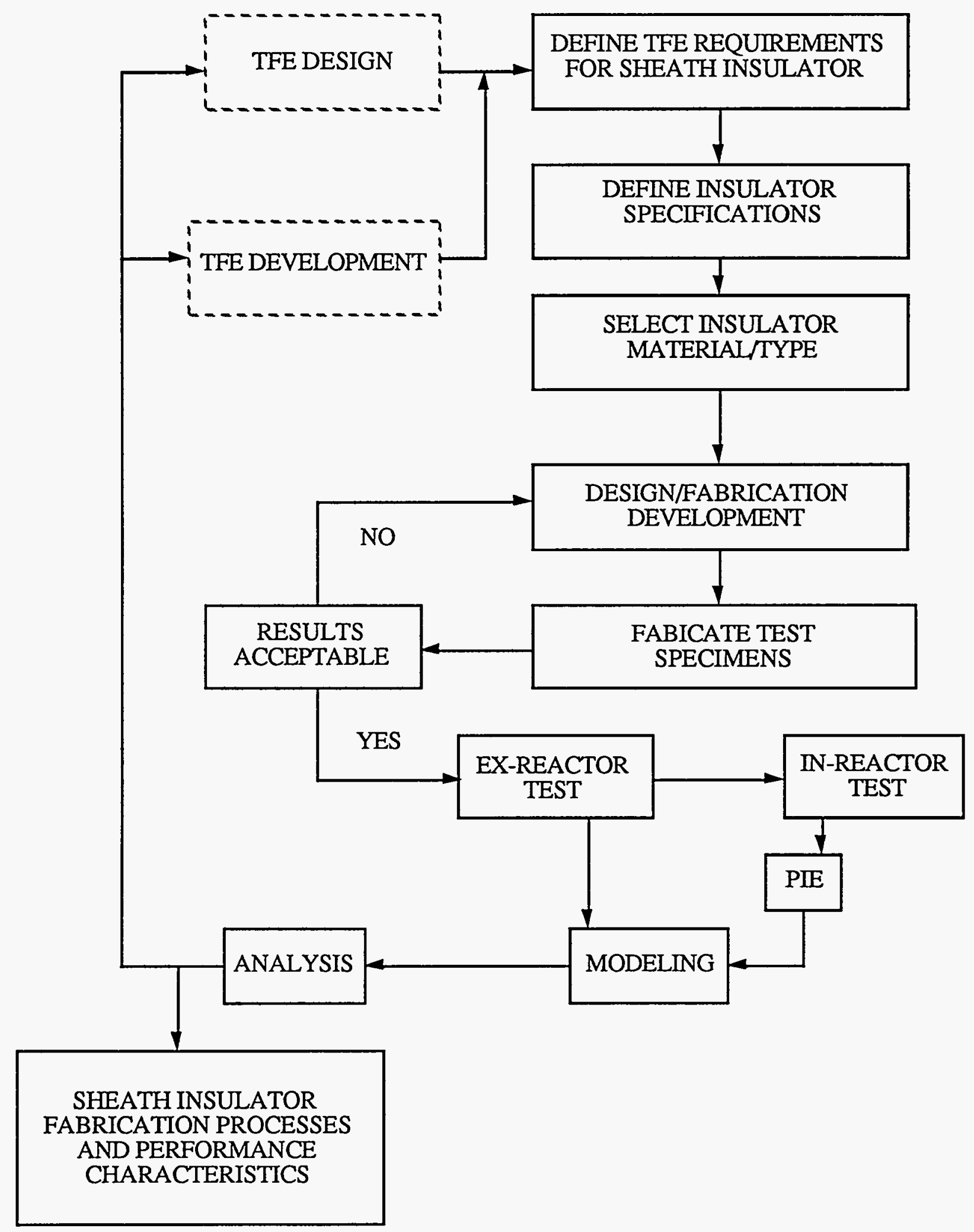

Figure 2-2. Development/Approach Logic for Sheath Insulators 
Table 2-1

IN-REACTOR TEST STRATEGY

\begin{tabular}{|c|c|c|c|}
\hline Test Designation & Test Reactor & Test Objective & Maximum Fluence \\
\hline $\mathrm{UCA}-1$ & FFTF & First screening test & $7.0 \times 10^{22} \mathrm{n} / \mathrm{cm}^{2}$ \\
\hline UCA-2 & FFTF & Second screening test & $6.2 \times 10^{22} \mathrm{n} / \mathrm{cm}^{2}$ \\
\hline UCA-3 Batch B & EBR-II & Third screening test & $1.8 \times 10^{22} \mathrm{n} / \mathrm{cm}^{2}$ \\
\hline IFAC-SI & EBR-II & $\begin{array}{l}\text { Sheath insulator performance } \\
\text { with an applied voltage }\end{array}$ & * \\
\hline
\end{tabular}

*This test was not run.

A brief description of both processes is included herein. A more complete discussion of the cermet process is given in Appendix B. 


\section{FABRICATION DEVELOPMENT}

\subsection{Original Test Matrix}

Ceramic materials that were the focus of sheath insulator development were:

1) Aluminum oxide (alumina - $\mathrm{Al}_{2} \mathrm{O}_{3}$ ), single crystal and polycrystalline

2) Yttrium oxide (yttria $-\mathrm{Y}_{2} \mathrm{O}_{3}$ ), polycrystalline

3) Yttrium aluminum garnet $\left(\mathrm{YAG}-\mathrm{Y}_{3} \mathrm{Al}_{5} \mathrm{O}_{12}\right)$, polycrystalline.

The choice of ceramic materials was guided by the requirements outlined in Section 2.3. YAG was the initially preferred material, for tolerance to neutron fluence and good electrical properties, but fabrication had to be demonstrated. Yttria was the baseline choice because it also had good neutron tolerance, appeared to have acceptable electrical properties, and was easily fabricated. Alumina was the backup choice since it swells under neutron irradiation. Data on the volumetric swelling of alumina suggests that the mechanical stability can be affected over the seven year lifetime. Properties of interest for the three selected materials are given in Table 3-1.

Table 3-1

PROPERTIES OF CANDIDATE SHEATH INSULATOR MATERIALS

\begin{tabular}{|c|c|c|c||}
\hline Material & $\begin{array}{c}\text { Volumetric Swelling } \\
\%\end{array}$ & $\begin{array}{c}\text { Coefficient of } \\
\text { Thermal Expansion } \\
\left(10^{-6} / \mathrm{K} \text { at 1150 K) }\right.\end{array}$ & $\begin{array}{c}\text { Resistivity } \\
(\text { Ohm-cm) at 1150 K }\end{array}$ \\
\hline Alumina & $3-10^{*}$ & 9.5 (Ref. 3-3) & $10^{9}$ (Ref. 3-5) \\
Yttria & $0.5-1.5^{*}$ & 8.9 (Ref. 3-3) & $10^{7}$ (Ref. 3-6) \\
YAG & $<0.5^{*}$ & 8.0 (Ref. 3-7) & $10^{8}$ (Ref. 3-4) \\
Niobium & & 8.7 (Ref. 3-3) & \\
\hline
\end{tabular}

"Irradiation to $1-2 \times 10^{22} \mathrm{n} / \mathrm{cm}^{2}$ at 925 and $1100 \mathrm{~K}, \mathrm{E}>0.1 \mathrm{MeV}$ (Ref. 3-2).

Single crystal alumina (sapphire) was considered for sheath insulator material based on encouraging work done at TTC in 1971 (Ref. 3-1). A niobium-sapphire trilayer sheath was fabricated and irradiated to a fluence of $0.9 \times 10^{21} \mathrm{n} / \mathrm{cm}^{2},(E>1 \mathrm{MeV})$ at a temperature of $800^{\circ} \mathrm{C}$ in EBR-II. After 3207 hours of irradiation there was no indication of cracking or metal-ceramic bond separation. This irradiation test did not meet the TFE-VP requirements for lifetime and fluence so single crystal alumina was also studied further.

All the insulators listed have resistivities above that required for acceptable performance. Electrolytic degradation is minimal because of the low ionic conductivity, high resistivity, of the candidate materials. 
The cesium compatibility was identified as the sole feasibility issue in the SP-100 Thermionic Technology Program (Ref. 1-2). The effort concentrated on establishing cesium compatibility in accelerated tests at higher than design temperatures and cesium pressures. Samples of single crystal alumina, polycrystalline yttria and polycrystalline YAG were exposed to 60 torr of cesium vapor for 200 hours at 1100,1250 and $1400 \mathrm{~K}$. None of the samples showed any evidence of being attacked by cesium.

The design for the sheath insulator is the trilayer where the insulator is sandwiched between two niobium cylinders. This design is shown schematically in Fig. 3-1.

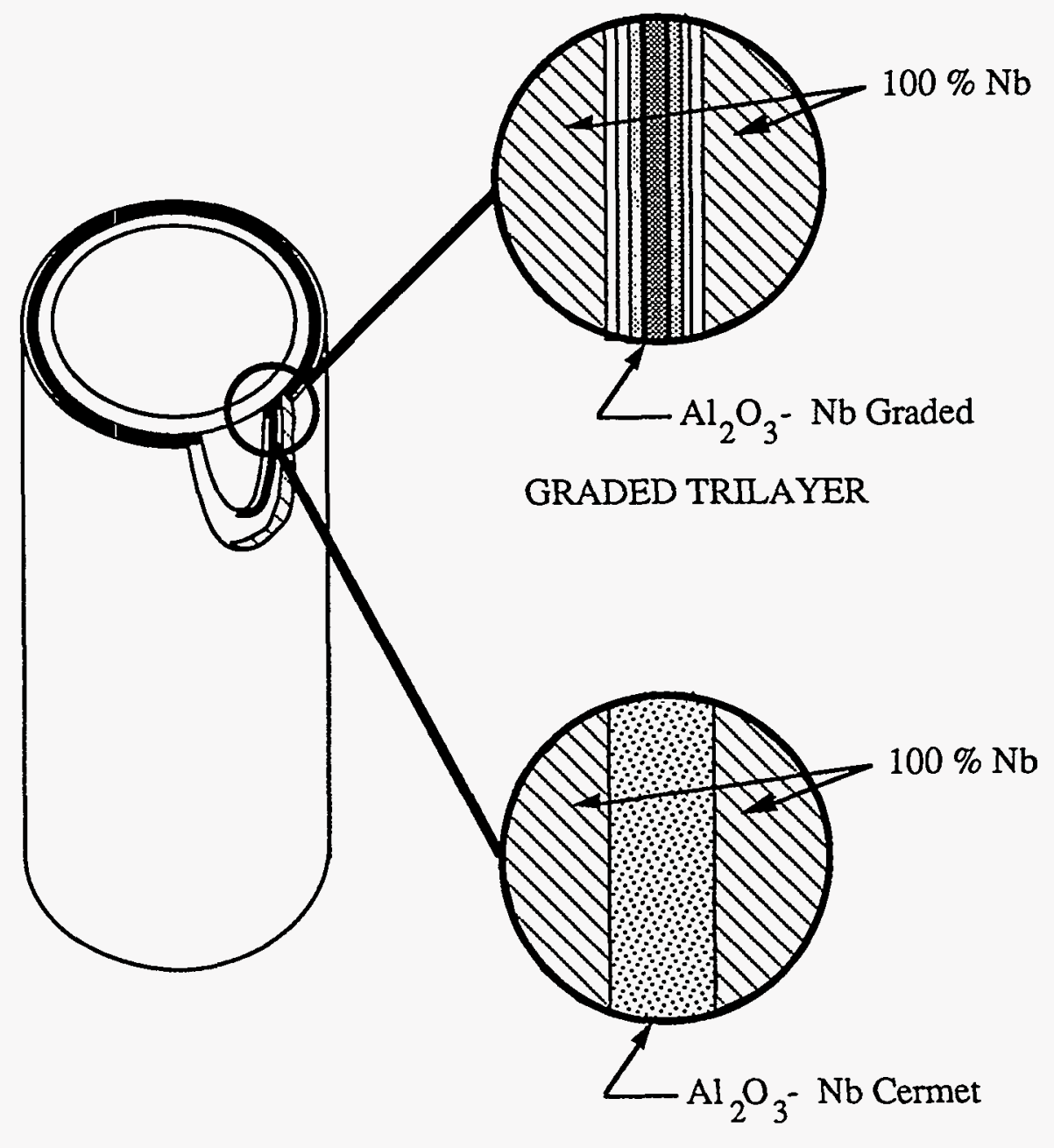

CERMET TRILAYER

Figure 3-1. Sheath Insulator Trilayer Configuration 
Two methods for fabricating the sheath insulators were studied:

1) Graded: Plasma spray graded (niobium-ceramic) layers onto a niobium mandrel followed by gas pressure bonding to a niobium sleeve.

2) Cermet: Slip cast niobium-ceramic tube and gas pressure bonding to a niobium mandrel and sleeve.

\subsection{Fabrication}

\subsubsection{Graded Trilayer Sheath Insulator}

Figure 3-2 shows the major steps in the fabrication of the graded trilayer sheath insulator. The starting ceramic materials, alumina, yttria or YAG, are high purity oxide powders. The sheath insulator is fabricated by plasma spraying niobium powder and ceramic powder onto a niobium mandrel. To match the difference in coefficient of thermal expansion between the niobium mandrel and ceramic, the ceramic and niobium powders are plasma-sprayed in such a way as to produce a gradation from pure niobium at the mandrel interface to pure ceramic in the center and back to pure niobium. A niobium sheath is placed over the last plasma sprayed layer of niobium and the assembly is gas pressure bonded at $1550^{\circ} \mathrm{C}$ and $10,000 \mathrm{psi}$. This bonding step densifies the graded structure and bonds it to the niobium mandrel and sheath. The resulting structure is then machined to the sheath insulator configuration.

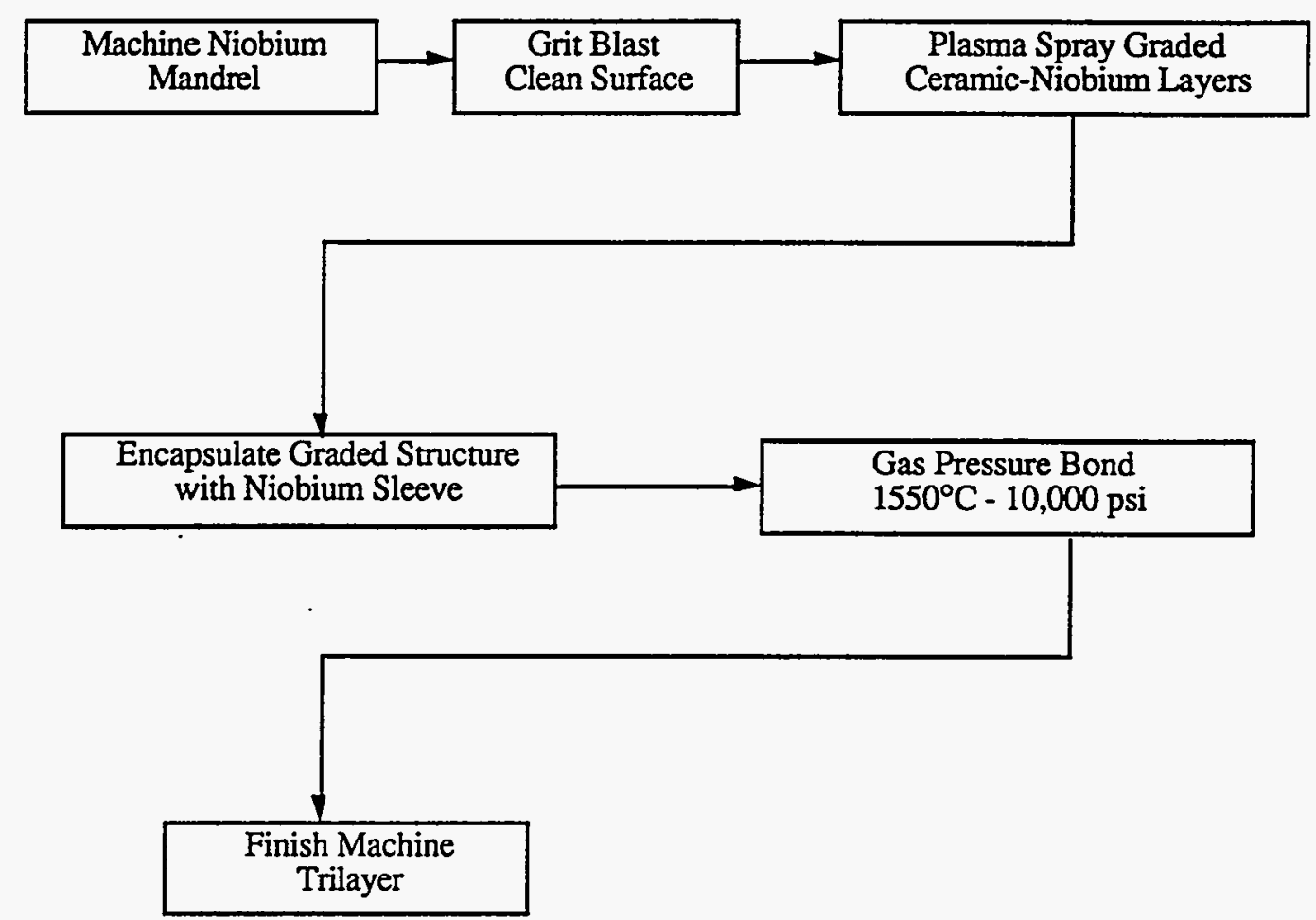

Figure 3-2: Graded Trilayer Fabrication Sequence 


\subsubsection{Cermet Trilayer Sheath Insulator}

Figure 3-3 shows the major steps in the fabrication of the cermet trilayer sheath insulator, a process developed by TTC. The high purity ceramic powder, alumina, yttria or YAG, is mixed with 5 to 10 volume percent niobium powder and slip cast into a free standing tube. The tube is sintered and machined to a uniform thickness of 0.020 in. The tube is encased with niobium sleeves inside and outside and the assembly is gas pressure bonded at $1550^{\circ} \mathrm{C}$ and $10,000 \mathrm{psi}$. This bonding step densifies the cermet and bonds it to the niobium sleeves. The resulting structure is then machined to the sheath insulator configuration.

Addition of niobium to the ceramic to form a metal-ceramic matrix composite has three purposes. First, the addition of the metal particles increases the fracture strength of the ceramic. Second, the metal particles help with the bond between the ceramic and the niobium sleeve. Third, the cermet better matches the coefficient of thermal expansion of niobium. Calculations have shown that about 15 volume percent niobium can be added to the ceramic matrix and still be below the percolation threshold limit thus minimizing the possibility of electrical shorts (Ref. 3-8).

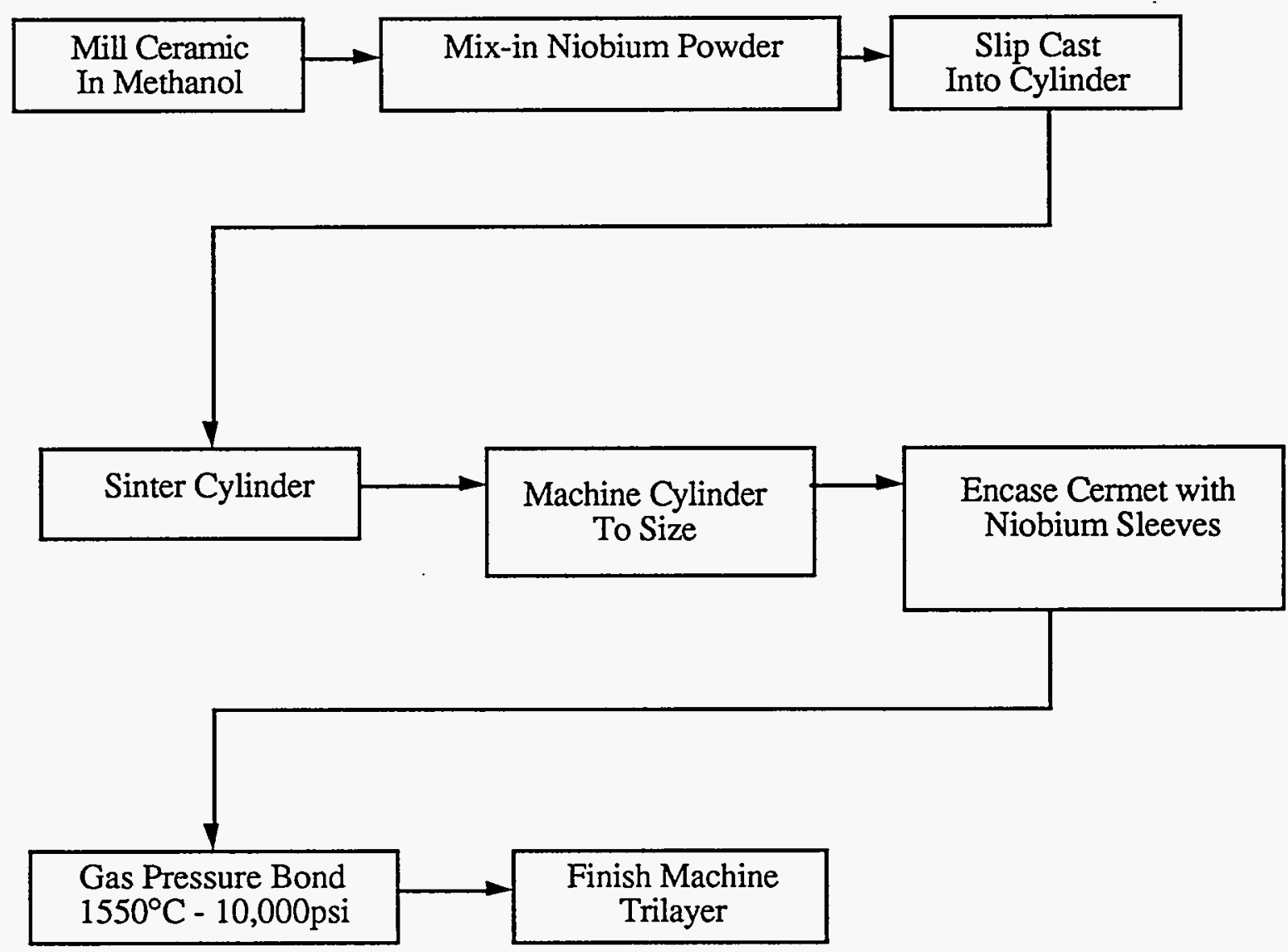

Figure 3-3. Cermet Trilayer Fabrication Sequence 
Successful cermet sheath insulators were developed in thermionic reactor programs during the 1960 s and early 1970 . These sheath insulators incorporated 30 volume percent niobium metal into the ceramic matrix. The cermets were composed of large (30 to 50 micrometer) niobium spheres in a matrix of fine alumina particles. Niobium powder was first spheroidized by passing though a plasma torch in an argon atmosphere. The irregular particles were removed and the remaining spheres tumbled in a wax-coated jar. The waxed niobium particles were then mixed with fine alumina powder to coat them totally. The resulting mixture was then isostatically pressed into tubes which were fired, machined, encapsulated in niobium and finally gas pressure bonded to form trilayer sheath insulators. The key to this fabrication process was to find the combination of wax and alumina powder which would assure that the niobium particles were well coated with alumina particles. The Thermionic Technology Program (TTP) attempted to recover this technology (Ref. 3-9) for applications in programs such as the TFEVP. The criticality of properly coating the spheres with the alumina particles was never consistently reproduced during the TTP effort. This work concluded that slurry processing was a better approach to achieve the goal of highly dispersed niobium particles within the cermet, and this was the approach taken by TTC in fabricating cermet trilayer sheath insulators for the TFE-VP.

The enhancement in strength and toughness by the incorporation of niobium partilces in the ceramic matrix is illustrated in Table 3-2. The table lists the strength and toughness for alumina cermets with various amounts of niobium spheres as well as sub-ten micrometer niobium powder. Disk specimens were fabricated and fractured by a multiple point bending method. The difference between the spheres and the irregular particles is striking. Addition of large sherical particles enhances neither the strength nor the toughness, while the fine powder doubles the strength with $10 \%$ or more addition. The increase in fracture toughness is even more dramatic.

Table 3-2

MECHANICAL PROPERTIES OF ALUMINA CERMET

\begin{tabular}{|c|c|c||}
\hline Composition & Strength & Toughness \\
\hline $0 \% \mathrm{Nb}$ & $29,200 \mathrm{psi}$ & $2.87 \mathrm{MN} / \mathrm{m}^{3 / 2}$ \\
$5 \% \mathrm{Nb}$ spheres & $32,400 \mathrm{psi}$ & $3.10 \mathrm{MN} / \mathrm{m}^{3 / 2}$ \\
$10 \% \mathrm{Nb}$ spheres & $29,850 \mathrm{psi}$ & $2.58 \mathrm{MN} / \mathrm{m}^{3 / 2}$ \\
$15 \% \mathrm{Nb}$ spheres & $30,050 \mathrm{psi}$ & $2.79 \mathrm{MN} / \mathrm{m}^{3 / 2}$ \\
$20 \% \mathrm{Nb}$ spheres & $33,040 \mathrm{psi}$ & $2.71 \mathrm{MN} / \mathrm{m}^{3 / 2}$ \\
$5 \% \mathrm{Nb}$ powder & $45,680 \mathrm{psi}$ & $8.13 \mathrm{MN} / \mathrm{m}^{3 / 2}$ \\
$10 \% \mathrm{Nb}$ powder & $63,130 \mathrm{psi}$ & $12.35 \mathrm{MN} / \mathrm{m}^{3 / 2}$ \\
$15 \% \mathrm{Nb}$ powder & $57,760 \mathrm{psi}$ & $9.01 \mathrm{MN} / \mathrm{m}^{3 / 2}$ \\
$20 \% \mathrm{Nb}$ powder & $55,870 \mathrm{psi}$ & \\
\hline
\end{tabular}

Success in the fabrication of taper seals from sapphire led to the evaluation of using sapphire as the insulating layer for the sheath insulator. TTC fabricated sheath insulators with sapphire. 


\subsection{Process Qualification}

All fabricated sheath insulators were qualified according to the following tests, and those that met the process qualification were used for testing:

1) Resistance check (room temperature) $>1,000,000 \mathrm{Ohms}$

2) Crack count $<25$

Normally insulators with high room temperature resistance are characterized by a high resistance at elevated temperatures. The crack count was selected based on the average number of cracks normally found in alumina sheath insulators fabricated with thick niobium mandrels.

The room temperature electrical resistance was found to be an excellent indicator of cracked specimens. Cracked specimens tended to polarize, that is, the resistance would change with time. The magnitude of this effect was largest when the samples had been recently cleaned and rinsed but perhaps not thoroughly dried. The polarization was not seen when the sample was at room temperature in an evacuated electrical test stand. This suggested that the effect was due to moisture in the cracks.

\subsection{Fabrication Results}

The fabrication of graded and cermet sheath insulators is characterized by a fully dense insulator and a good metal to insulator bond. The yttria sheath insulators were fabricated without any cracks in the insulator, while alumina and YAG sheaths insulators were not always crack free. The cracks are radial in nature, with YAG having the largest number of cracks. Cracking of the insulator was also a problem when fabricating the sapphire sheath insulators.

Stress analysis indicated that the cracking was caused by the mismatch in the thermal expansion coefficient between the ceramic and niobium, and it occurs during the cooldown step of the gas pressure bonding cycle. To resolve the cracking problem, several approaches were tried and included:

1. Blend alumina and YAG, and alumina and yttria powders to change the effective coefficient of thermal expansion of the ceramic mixture.

2. Change the grading scheme and the metal content in the cermet.

3. Use alternate mandrel/collector materials which more closely match the coefficient of thermal expansion of the ceramic.

4. Change the gas pressure bonding cycles to reduce the tensile stresses in the ceramic on cooldown. 
5. Change the niobium mandrel/collector design: e.g., stress analysis showed that a thin mandrel design can reduce the gas pressure bonding cycle stresses.

6. Remove surface flaws on the sapphire.

Sheath insulators were fabricated using blends of alumina with YAG (46\% and $85 \%$ YAG) and alumina with yttria (55.4\% yttria), to match the coefficient of thermal expansion of niobium. The number of cracks decreased when compared to pure alumina and YAG but the number was still significant.

YAG sheath insulators were fabricated with different grading schemes to minimize fabrication induced stresses. Sheath insulators were fabricated with 3, 7 and 11 graded layers. Increasing the number of layers reduced the number of cracks but did not eliminate the cracking problem. The grading schemes employed with the YAG sheath insulators are defined in Table 3-3. Going to a graded structure with more than 11 graded layers is time consuming, not economical, and there are physical limitations on how thick that graded structure can be in a sheath insulator.

Table 3-3

GRADING SCHEME FOR YAG SHEATH INSULATORS

\begin{tabular}{||c|c|c||}
\hline \hline 3 Layers & $\begin{array}{c}\text { Weight \% YAG } \\
\text { 7 Layers }\end{array}$ & 11 Layers \\
\hline 50 & 25 & 16 \\
100 & 50 & 35 \\
50 & 75 & 62 \\
& 100 & 78 \\
& 75 & 91 \\
& 50 & 100 \\
& 25 & 91 \\
& & 78 \\
& & 62 \\
& & 35 \\
\hline
\end{tabular}

Changing the source of the starting material was also investigated. Several commercial sources as well as in-house sol-gel derived oxide powders were tested. Different sources of materials have different particle sizes. Finer particles produce stronger, denser, and finer structures that can withstand better the stresses developed during processing. The source material had no effect on the cracking problem. 
The mandrel/collector was changed from niobium to molybdenum in an effort to reduce cracks, since molybdenum better matched the coefficient of thermal expansion of alumina. This strategy was not successful.

Elastic-creep analysis of a typical sheath insulators was performed to evaluate the probable cause of cracking during the gas pressure bonding process. The results indicated that improving the pressure/temperature cycle during gas pressure bonding and reducing the thickness of the inner niobium mandrel would reduce stresses to levels where cracking should not occur. During the heatup/pressurizing cycle, the ceramic is subjected to compressive stresses. Creep relaxes the stresses very rapidly during the high temperature/high pressure part of the cycle. On cooldown, the differential expansion places the ceramic in tension causing the ensuing tensile stresses to lead to cracking. By modifying the gas pressure bonding process and by minimizing the thickness of the inner niobium mandrel, the final tensile stresses in the ceramic could be reduced. Three different gas pressure bonding cycles were tested; the time-temperature-pressure for each are given in Table 3-4. There was no difference in microstructure or number of cracks among the three different gas pressure bonding cycles. However the predicted improvement in cracking with a thin mandrel design was clearly seen in the alumina sheath insulators. With the thin mandrel design alumina sheath insulators were finally fabricated without cracks. The thin mandrel design had outer and inner diameters of 0.580 inches and 0.500 inches, respectively; the standard design values were 0.580 inches and 0.190 inches.

Table 3-4

GAS PRESSURE BONDING CYCLES

\begin{tabular}{|l|l|l|l||}
\hline & Battelle & TTC Standard & TTC Modified \\
\hline Pressure & $12,000 \mathrm{psi}$ & $10,000 \mathrm{psi}$ & $10,000 \mathrm{psi}$ \\
Temperature & $1650^{\circ} \mathrm{C}$ & $1550^{\circ} \mathrm{C}$ & $1550^{\circ \mathrm{C}}$ \\
Time at Temperature & 3 hours & 3 hours & 3 hours \\
Pressure During Cooldown & Off & Off & On \\
\hline
\end{tabular}

Work on YAG sheath insulators was stopped because the cracking problem was never solved, and as will be shown in Section 4 the ex-reactor electrical resistance was several orders of magnitude lower than that for alumina.

During metallographical examination of yttria test samples, a number of dark regions/ spots in the ceramic were uncovered. Scanning Auger analysis of one of these samples indicated that the dark spot contained a significant amount of carbon. The starting ceramic materials were bought from several different sources as typically 99.99 percent or better ceramic. Carbon content of the ceramic powders is not commonly reported by the manufacturers. Carbon is an impurity associated with the fabrication and purification of high purity ceramic powders. Carbon contamination is a problem because during high temperature fabrication, and under applied voltages during subsequent electrical tests, the carbon particles react with the ceramic. The reaction zone around each particle enlarges with time and eventually can extend across the 
total thickness of the ceramic and cause a short. Carbon contamination had a dramatic effect on the electrical properties of yttria. Fabricating high resistivity yttria sheath insulators depended on using carbon-free yttria powder.

Subsequent to this finding, carbon content analyses of all starting ceramic powders were initiated. Results indicated that the carbon contamination ranged from 50 to $1500 \mathrm{ppm}$ depending on the vendor, with the lowest carbon content found in the in-house sol-gel derived powders. The carbon contamination was reduced to less than $50 \mathrm{ppm}$ by heating the starting powders to $1300^{\circ} \mathrm{C}$ for 18 hours in a pure oxygen environment.

Cermet fabrication processes investigated in the TFE-VP included dry pressing, filter pressing and slip casting. The dry pressing effort was discontinued early-on because of difficulties in obtaining a uniform dispersion of the metal powder, which resulted in many electrically continuous pathways being formed. Slip casting and filter pressing are two methods of forming cylinders directly from aqueous suspensions. After it became apparent that filter pressing offered no advantage over slip casting, the process was abandoned in favor of slip casting. A number of ceramic powders were tested for their ability to form suitable slips. Different powders were found to behave very differently when forming aqueous suspensions. After the mechanical advantage of adding irregular niobium powder rather than spheres became clear, all cermets were produced incorporating niobium powder and the spheroidization and separation process was abandoned. The particle size of the niobium powder was critical to the performance of the trilayers. The best alumina cermets were produced using the finest niobium powder $(<10 \mu \mathrm{m})$. A very effective particle size distribution is shown in Fig. 3-4.

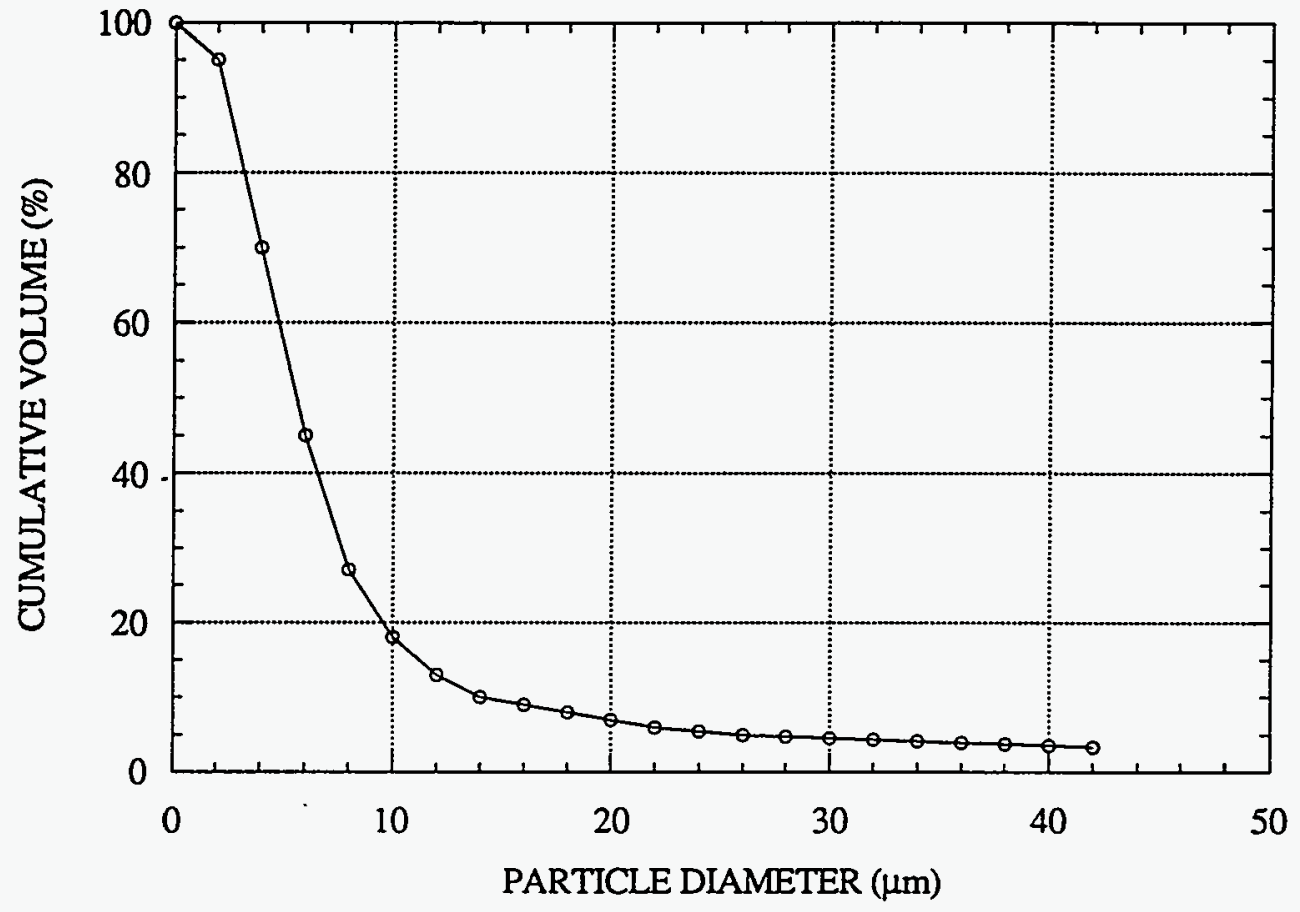

Figure 3-4. Optimum Niobium Particle Size Distribution 
After the initial fabrication development effort ceramic tubes containing 5 to 14 volume percent niobium powder were slip cast and bonded to niobium sheaths. When vacuum fired to $1250^{\circ} \mathrm{C}$, the cast cermet tubes were about 65 to $79 \%$ dense and could be machined into thin walled tubes using carbide tools. Cermets fabricated with $10 \%$ niobium powder were crack free. At five percent niobium addition, the results were mixed. A fraction (roughly $40 \%$ ) of the samples contained between one and five cracks, a result of the bonding, grinding or heat treatment processing. A limited number of $7.5 \% \mathrm{Nb}$ cermets indicated that this composition survives the bonding process uncracked. Cermets containing $14 \%$ niobium particles were crack free but had multiple conduction paths in each trilayer.

Developmental work was performed on the fabrication of sheath insulators using sapphire in the form of tubes as the insulator material. Examination of the tubes after gas pressure bonding indicated the presence of an unacceptable number of cracks and having a shattered appearance. LANL suggested that the cracking could be a result of the inner mandrel first making contact with the sapphire tube and exceeding the tensile strength of the sapphire. Also the presence of surface flaws from the grinding-to-size step was also contributing to subsequent cracking. A batch of sapphire sheaths was fabricated with a reduced inner mandrel diameter so that the outer niobium sleeve would bond first to the sapphire during processing placing the sapphire in compression. However this process step, even when coupled with the removal of surface flaws, by etching with molten borax, did not solve the cracking problem. The bonding cycle was changed to determine what bonding pressure could be tolerated by the sapphire. Samples were gas pressure bonded to $2000 \mathrm{psi}$ and $300 \mathrm{psi}$. In all cases the sapphire was severely cracked after bonding. All developmental work was then stopped on the sapphire sheath insulators.

A number of materials beside the original three condidates were fabricated for testing as sheath insulators at TTC. Many of these were ceramic/ceramic composites. The goal was to reinforce a ceramic matrix by inclusion of a second ceramic phase (powder or fibers) much the same way as the niobium particles strengthen the cermet matrices but without the potential electrical side effects of the inclusions of conduction particles. The results of much of this work are summarized in the final report for the Thermionic Technology Program (Ref. 3-10). The addition of chromium oxide (chromia, $\mathrm{Cr}_{2} \mathrm{O}_{3}$ ) to YAG greatly strengthened the material, but crack-free composite trilayers were never produced. Some of the strongest materials tested were alumina with silicon nitride $\left(\mathrm{Si}_{3} \mathrm{~N}_{4}\right)$ added. This material was not pursued strongly in the TFEVP due to probable incompatibility of the silicon containing material with the cesium vapor environment.

Aluminum oxynitride (AlON) was considered to be promising due to its spinel structure which tends to be very resistant to radiation damage. This material was found to need a platinum barrier between itself and the niobium sheaths in order for it not to break down during electrical testing. The AlON layer often shattered during the bonding cycle leading to abandonment of this material as possible sheath insulators. 


\section{EX-REACTOR TEST PROGRAM}

\subsection{Objective}

The ex-reactor test program had the dual purpose of providing data to aid in the selection of specimens for the in-reactor tests and to assist in the understanding of any degradation mechanisms that are dominant in the insulator at the TFE-VP operating conditions. The tests were divided into screening and life tests. The screening tests were short term tests designed to identify insulators with incipient failures. The life tests included long term tests at nominal operating conditions and accelerated tests at higher temperatures and applied potentials. These later would provide data on dominant degradation mechanisms. The ex-reactor test equipment requirements were:

1) Temperature: Room temperature to $1400 \mathrm{~K}$

2) Voltage: Zero to \pm 100 Volts

\subsection{Test Equipment and Test Assembly}

Screening testing to determine which types of specimens warranted long term testing was performed by TTC. Life testing of the sheath insulators was performed by RAI. The test stand used in the long term measurements consisted of three high temperature furnaces, an ultra high vacuum pumping system, and a computerized data acquisition system. The data acquisition system consisted of an electrometer, a voltage source, a temperature measuring device, and a computer. A schematic of the test stand is shown in Fig. 4-1. A typical test sample is shown in Fig. 4-2. The samples had guard rings to eliminate end and surface conduction artifacts, and is standard when examining highly resistive materials.

The electrical resistance of the sheath insulator test samples was determined by applying a DC voltage across the inner and outer niobium sheaths/electrodes. The resulting current was measured with an electrometer and the resistance calculated as the ratio of the voltage and current. The body and guard electrodes were held at the same potential.

Six samples could be tested within each oven by vertically stacking the samples. The samples were separated by niobium spacer rings that acted as a common ground for the inner niobium sheaths but isolated the outer sheaths. Four thermocouples were attached to these spacer rings at various positions along the length of the heater to monitor the temperature profile. Current and voltage probes were attached to the body and guard electrodes to measure the applied voltage and resulting current. A detail description of the test stand, sample installation and current and voltage measurements is given in Appendix C "TFE Sheath Insulator Test Procedure."

\subsection{Test Procedure}

The rationale for the screening test was to determine the initial electrical properties of 


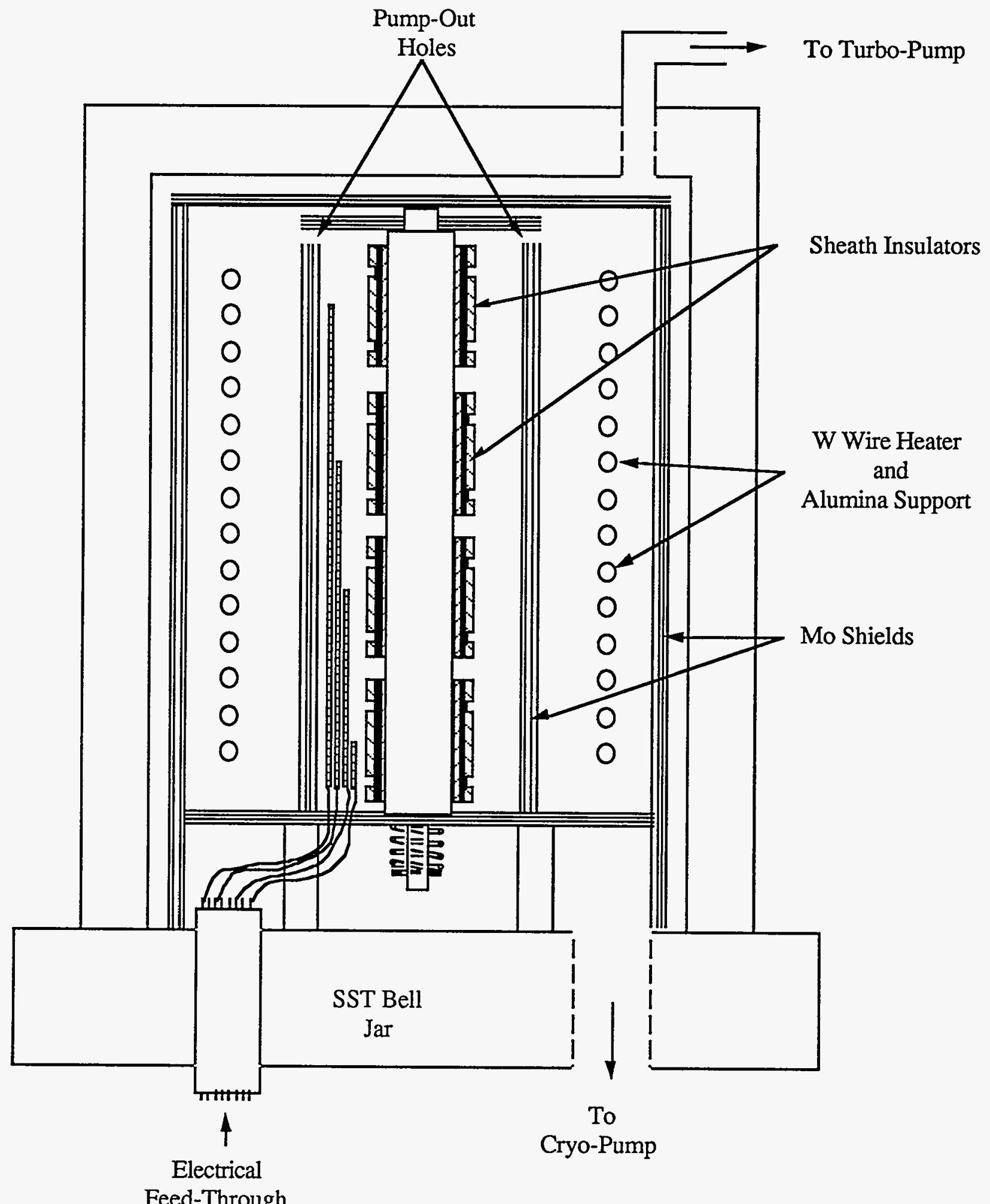

Figure 4-1. Sheath Insulator Ex-Reactor Test Stand 


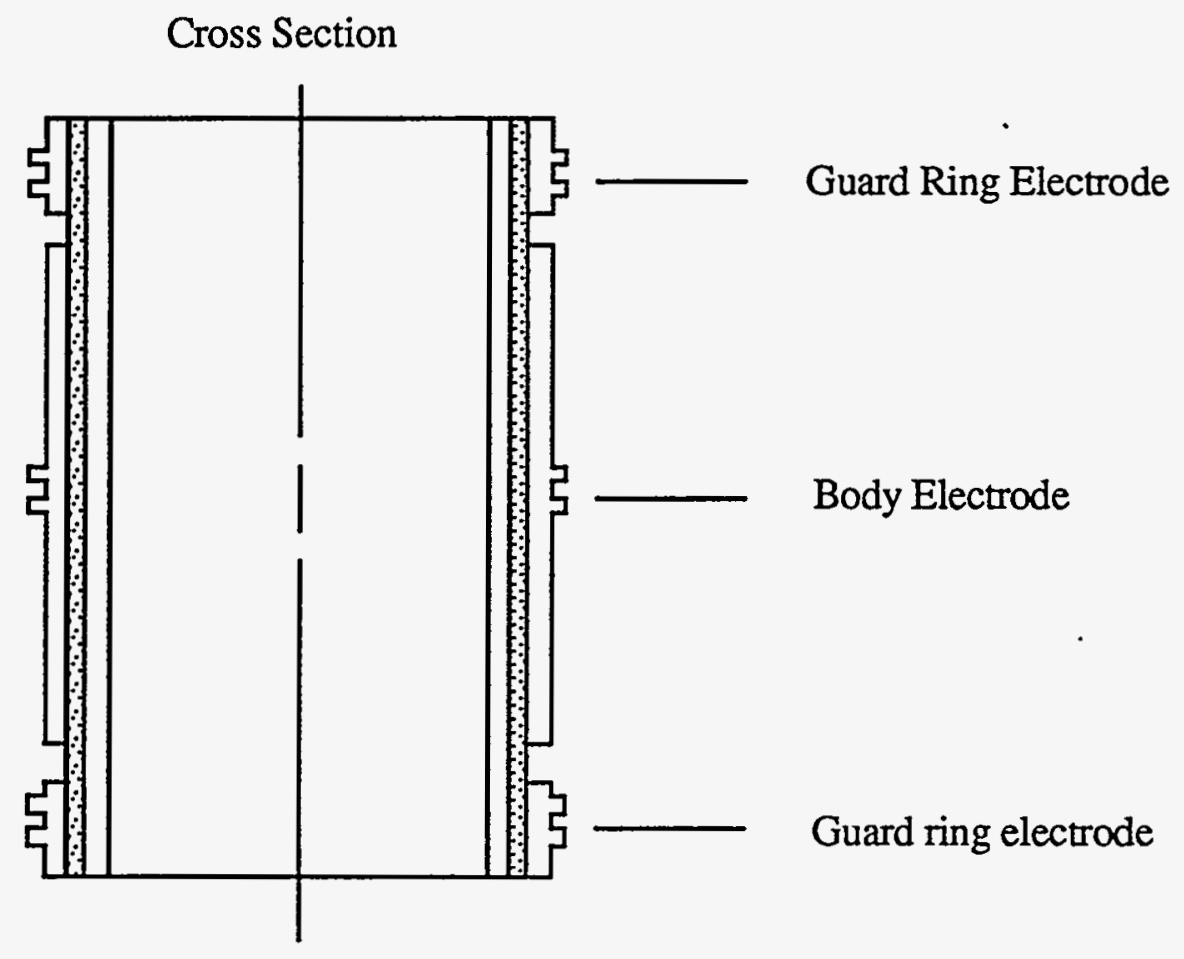

Figure 4-2. Ex-reactor Test Sample Configuration

the sheath insulators and make sure the samples were qualified for the life testing. The resistance was measured as a function of temperature, applied potential, and time. By measuring the resistance of the sheath insulator from 900 to $1400 \mathrm{~K}$ the activation energy for electrical conduction can be determined. Changes in the activation energy with time would indicate a deterioration of the electrical properties of the insulator. The activation energy was also used to determine the conditions needed to perform any subsequent accelerated testing.

The goal of the accelerated tests was to approximate the lifetime behavior of the material in a short time. This phase of the testing consisted of two parts: First, by elevating the temperature it would accelerate those processes that are temperature dependent. Second, by increasing the applied potential would accelerate those processes that are voltage dependent. The data should indicate variations in degradation rates at various potentials and temperatures.

A justification of the accelerated testing required the consideration of simple models for the ionic conductivity of the sheath insulator. The electrolytic stability can be modeled by considering the number of ions transported out of the insulator:

$$
\mathrm{N}=\sigma_{\mathrm{i}} \mathrm{VAt} / \mathrm{Lq}
$$




$\begin{array}{llll}\text { where } & \mathrm{N} & = & \text { number of ions, } \\ & \sigma_{\mathrm{i}} & = & \text { ionic conductivity, } \\ \mathrm{V} & = & \text { applied voltage, } \\ \mathrm{A} & = & \text { cross sectional area of insulator, } \\ \mathrm{t} & = & \text { time, } \\ \mathrm{L} & = & \text { thickness of insulator, } \\ \mathrm{q} & = & \text { charge of an ion, } \\ & \sigma_{\mathrm{i}} & = & \mathrm{n}_{\mathrm{i}} \mathrm{q} \mu_{\mathrm{i}} \\ \text { and } & \mathrm{n}_{\mathrm{i}} & = & \text { ionic concentration, } \\ \text { where } & \mu_{\mathrm{i}} & = & \text { ionic mobility }\end{array}$

If ion transport for a set of conditions is to be accelerated in time, then a higher temperature and/or voltage must be used. If the reference temperature is $T_{1}$, an accelerated temperature $T_{2}$ can be determined by equating the number of ions to be transported out of an insulator at temperatures $T_{1}$ and $T_{2}$, specifically

$$
\begin{aligned}
& \mu_{\mathrm{i}}\left(\mathrm{T}_{1}\right) \mathrm{V}_{1} \mathrm{t}_{1}=\mu_{\mathrm{i}}\left(\mathrm{T}_{2}\right) \mathrm{V}_{2} \mathrm{t}_{2} \\
& \mu_{\mathrm{i}}=\mu_{\mathrm{o}} \exp -\Delta \mathrm{E}_{\mathrm{o}} / \mathrm{kT}
\end{aligned}
$$

then

$$
\exp \left(-\mathrm{E}_{\mathrm{o}} / \mathrm{kT}_{1}\right) \mathrm{V}_{1} \mathrm{t}_{1}=\exp \left(-\Delta \mathrm{E}_{\mathrm{o}} / \mathrm{kT}_{2}\right) \mathrm{V}_{2} \mathrm{t}_{2}
$$

where $\Delta \mathrm{E}_{\mathrm{o}}$ is the ionic activation energy determined experimentally.

Assume the reference conditions are

$$
\begin{aligned}
& T_{1}=1070 \mathrm{~K} \\
& V_{1}=7.5 \text { volts } \\
& t_{1}=61,320 \text { hours }(7 \text { years }) .
\end{aligned}
$$

For an accelerated test with $V_{2}=15$ volts and $t_{2}=504$ hours, equation 5 can be solved to determine the required accelerated temperature. Aluminum oxide with an activation energy $\left(\Delta \mathrm{E}_{\mathrm{o}}\right)$ of about $3.5 \mathrm{eV}$ (Ref. 4-1), requires that the accelerated testing be done at $1200 \mathrm{~K}$.

\section{$4.4 \quad$ Test Results}

A summary of all the ex-reactor tests performed on sheath insulators in the TFE-VP is given in Appendix D. 


\subsubsection{Yttria Sheath Insulators}

Measurements of the electrical characteristics of yttria sheath insulators both graded and cermet have shown resistance values ranging form $10^{5} \mathrm{ohms}$ at $1100 \mathrm{~K}$ to unstable conditions characterized by rapid degradation and electrical shorting. The initial poor performance of the yttria sheath insulators was traced to carbon contamination. The electrical behavior of yttria sheath insulators fabricated from starting powders that had low carbon content $(<50 \mathrm{ppm})$ improved over the high carbon content samples but the samples were still shorting during accelerated testing at the higher temperatures and voltages. At the higher temperatures and voltages the ionic conductivity is dominant and the insulator was failing by electrolytic degradation. The literature (Ref. 3-5) indicate that doping alumina with a tetravalent oxide (donor) can reduce the ionic conductivity by many orders of magnitude. Yttria sheath insulators were fabricated with small additions of $\mathrm{CeO}_{2}$ and $\mathrm{ZrO} 2$ to act as donors in the yttria ionic structure. Doping did not change the electrical characteristics of yttria. Yttria was finally dropped as an insulator material for the sheath insulators. Table 4-1 summarizes the yttria sheath insulators ex-reactor testing.

Table 4-1

YTTRIA SHEATH INSULATORS EX-REACTOR TESTING

\begin{tabular}{|c|c|c|c|c|c|l||}
\hline $\begin{array}{c}\text { Number } \\
\text { Samples } \\
\text { Tested }\end{array}$ & $\begin{array}{c}\text { Fabrication } \\
\text { Process }\end{array}$ & $\begin{array}{c}\text { Temperature } \\
\text { Range (K) }\end{array}$ & $\begin{array}{c}\text { Voltage } \\
\text { (Volts) }\end{array}$ & $\begin{array}{c}\text { Duration of } \\
\text { Test (Hours) }\end{array}$ & $\begin{array}{c}\text { End of Test } \\
\text { Resistance } \\
(\Omega)\end{array}$ & \multicolumn{1}{||}{ Test Results } \\
\hline 10 & Graded & $995-1270$ & $7.5 \& 10$ & $16-838$ & $<100$ & $\begin{array}{l}\text { Failed due to low resistance } \\
\text { from carbon contamination }\end{array}$ \\
11 & Graded & $1050-1250$ & $7.5 \& 30$ & $312-3696$ & $\begin{array}{l}\text { Typica: }<100 \\
\text { Some:<3000 } \\
\text { Most failed due to low } \\
\text { resistance }\end{array}$ \\
6 & $\begin{array}{c}\text { Slip cast } \\
\text { Slip cast } \\
10 \% \text { Nb cermet }\end{array}$ & 1250 & 7.5 & $1253-2496$ & $<100$ & Failed due to low resistance \\
$<100$ & 7.5 & $<100$ & Failed due to low resistance \\
\hline
\end{tabular}

\subsubsection{YAG Sheath Insulators}

YAG sheath insulators had resistance values between $10^{3}$ and $10^{4} \mathrm{ohms}$ at $1100 \mathrm{~K}$. This was better than yttria but it did not compared with alumina that was three to four orders of magnitude higher. YAG was dropped from the list of insulator materials primarily because of fabrication problems. YAG sheath insulators could not be fabricated without cracks.

Cracking is a problem when the intended use is a trilayer seal; leak tightness is a requirement. Also, heat transfer from the collector to the reactor liquid metal coolant can be 
adversely affected by the presence of too many cracks and thus affect the thermionic performance of the converter. As will be shown in the next section, in-reactor testing of alumina sheath insulators was very encouraging, and alumina became the reference material. The incentive to develop YAG decreased as a result. Table 4-2 summarizes the YAG sheath insulators ex-reactor testing.

Table 4-2

YAG SHEATH INSULATORS EX-REACTOR TESTING

\begin{tabular}{||c|c|c|c|c|c|c||}
\hline \hline $\begin{array}{c}\text { Number } \\
\text { Samples } \\
\text { Tested }\end{array}$ & $\begin{array}{c}\text { Fabrication } \\
\text { Process }\end{array}$ & $\begin{array}{c}\text { Temperature } \\
\text { Range (K) }\end{array}$ & $\begin{array}{c}\text { Voltage } \\
\text { (Volts) }\end{array}$ & $\begin{array}{c}\text { Duration of } \\
\text { Test (Hours) }\end{array}$ & $\begin{array}{c}\text { End of Test } \\
\text { Resistance } \\
(\Omega)\end{array}$ & Test Results \\
\hline 4 & Graded & $1020-1120$ & 10 & $24-6931$ & $2000-11,000$ & $\begin{array}{l}\text { Marginal resistance } \\
\text { One sample was used in UCA-2 } \\
\text { Marginal resistance }\end{array}$ \\
\hline 1 & Slip cast & 1090 & 7.5 & 1100 & 2100 & \\
\hline
\end{tabular}

\subsubsection{Alumina Sheath Insulators}

Alumina sheath insulators both graded and cermet had excellent electrical characteristics. Samples were tested to voltages and temperatures 13 times and 200 degrees higher than nominal with no indications of electrical degradation. A graded alumina and an alumina 5\%-Nb cermet sheath insulator were tested for 377 days at the accelerated condition of 100 volts and $1270 \mathrm{~K}$. The resistivity as a function of time, temperature, and voltage for these two sheath insulators is shown in Fig. 4-3.

Cermet alumina sheath insulators with niobium contents greater than 5\% were also tested as part of the sheath insulator test program. Sheath insulators with $10 \%$ niobium were tested at nominal and accelerated conditions (Fig. 4-4). At the nominal condition of 7.5 volts and nominal and accelerated temperatures of $1070 \mathrm{~K} 1170 \mathrm{~K}$ and $1270 \mathrm{~K}$ the resistance as a function of time was constant with no indication of electrical degradation. Increasing the applied voltage to an accelerated condition of 100 volts resulted in failure from electrical breakdown. An examination of the microstructure of this type of cermet showed that the mean distance between niobium particles was only about $20 \mu \mathrm{m}$. The electric field associated with this dimension is $5 \times 10^{4} \mathrm{~V} / \mathrm{cm}$. The literature report (Ref. 3-8) an electrical breakdown field for alumina between $3 \times 10^{4}$ to $2 \times 10^{5} \mathrm{~V} / \mathrm{cm}$ at $1150 \mathrm{~K}$. Cermets with niobium contents equal to or less than $10 \%$ makes good insulators for sheath insulators, but accelerated testing must be limited to voltages that do not exceed the electrical breakdown field for alumina. Table 4-3 summarizes the alumina sheath insulators ex-reactor testing. 


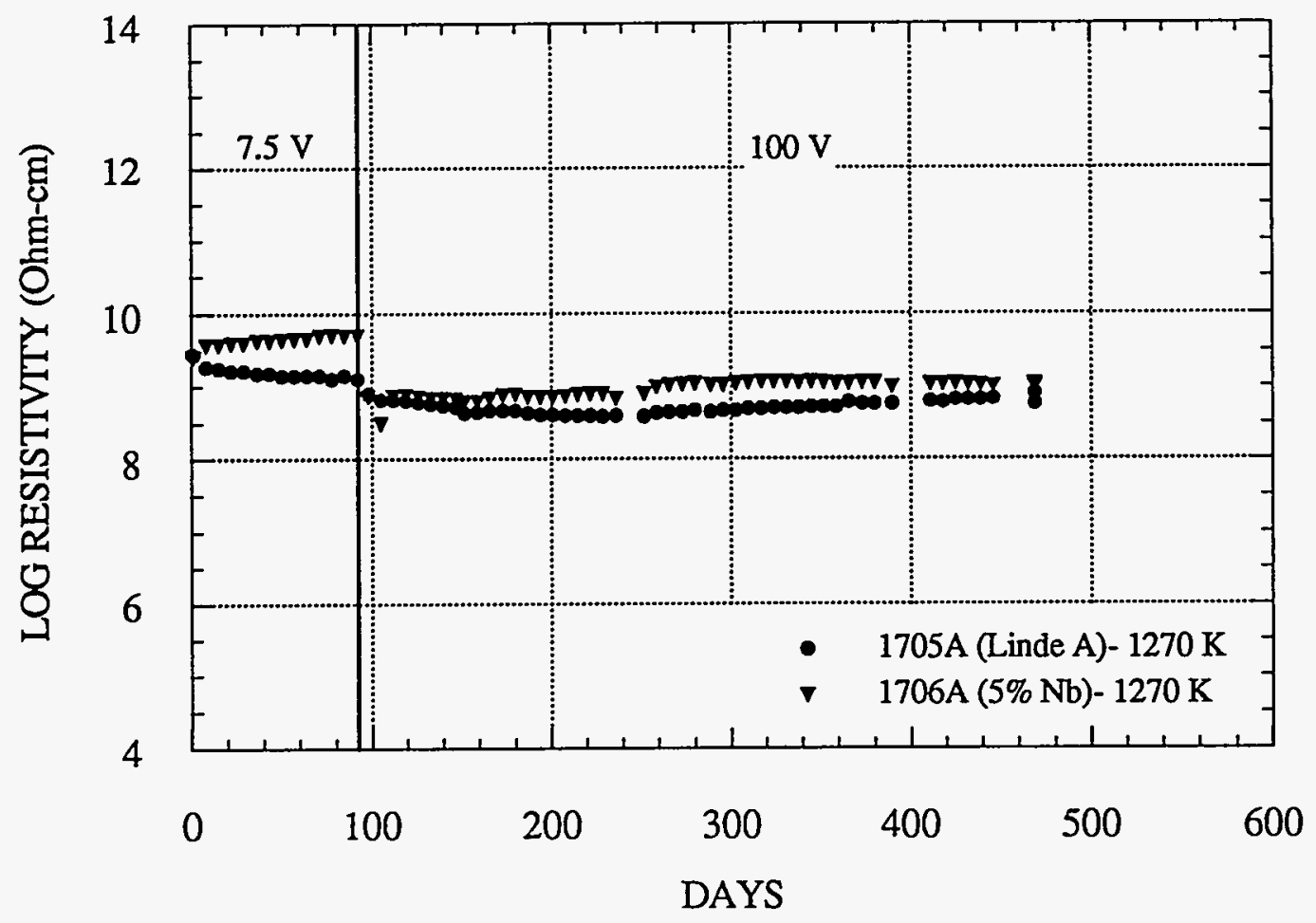

Figure 4-3. Electrical Resistivity vs Time for Graded Alumina and Alumina Cermet $(5 \%-\mathrm{Nb})$ Sheath Insulators

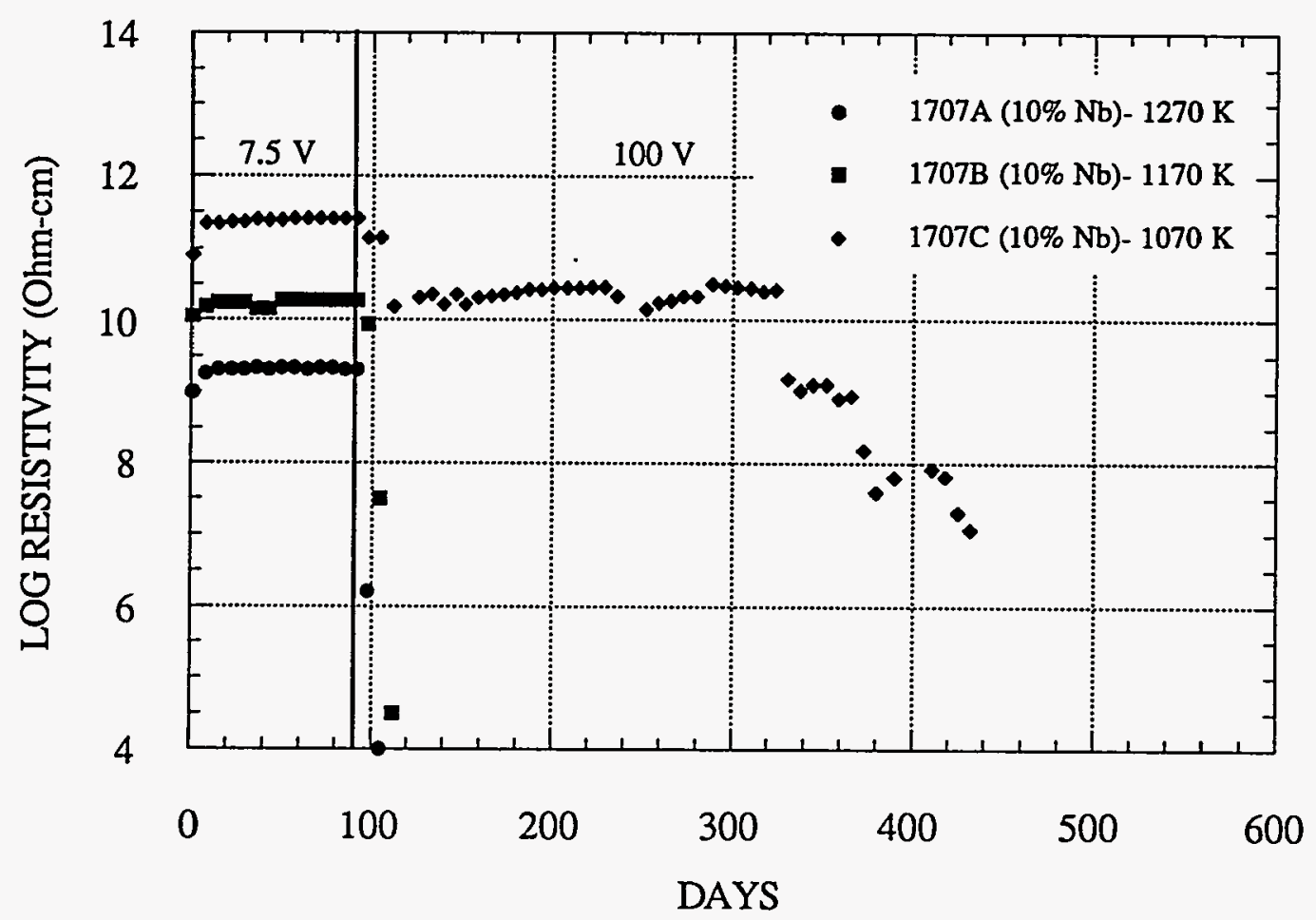

Figure 4-4. Electrical Resistivity vs Time for Alumina Cermet (10\%-Nb) Sheath Insulators 
Table 4-3

ALUMINA SHEATH INSULATORS EX-REACTOR TESTING

\begin{tabular}{|c|c|c|c|c|c|c|}
\hline $\begin{array}{c}\text { Number } \\
\text { Samples } \\
\text { Tested }\end{array}$ & $\begin{array}{c}\text { Fabrication } \\
\text { Process }\end{array}$ & $\begin{array}{c}\text { Temperature } \\
\text { Range }(\mathrm{K})\end{array}$ & $\begin{array}{l}\text { Voltage } \\
\text { (Volts) }\end{array}$ & $\begin{array}{l}\text { Duration } \\
\text { of Test } \\
\text { (Hours) }\end{array}$ & $\begin{array}{l}\text { End of Test } \\
\text { Resistance } \\
(\Omega)\end{array}$ & Test Results \\
\hline 31 & Graded & $1070-1270$ & $\begin{array}{l}7.5,10,30 \\
50, \& 100\end{array}$ & $24-9048$ & $>10^{7}$ & Results good \\
\hline 2 & $\begin{array}{c}\text { Slip cast } \\
15 \% \mathrm{Nb} \text { cermet }\end{array}$ & $1100-1130$ & 7.5 & $24-150$ & $<100$ & Failed due to low resistance \\
\hline 30 & $\begin{array}{c}\text { Slip cast } \\
10 \% \mathrm{Nb} \text { cermet }\end{array}$ & $1070-1300$ & $\begin{array}{l}7.5,10, \& \\
100\end{array}$ & $1-8160$ & $<100$ & $\begin{array}{l}\text { Some failed due to low resistance } \\
\text { Some failed due to electrical } \\
\text { breakdown at high voltage } \\
\text { Some results were good }\end{array}$ \\
\hline 20 & $\begin{array}{c}\text { Slip cast } \\
5 \% \mathrm{Nb} \text { cermet }\end{array}$ & $1070-1300$ & $\begin{array}{l}7.5,10,30 \\
50, \& 100\end{array}$ & $72-9048$ & $>105$ & Results good \\
\hline 2 & Sapphire & 1250 & 7.5 & 750 & $>10^{6}$ & Results good \\
\hline
\end{tabular}




\section{IN-REACTOR TEST PROGRAM}

\subsection{Objective}

The objectives of the in-reactor test program were to determine the material stability, electrical resistance and thermal conductivity of selected sheath insulator under fast neutron irradiation. The in-reactor test program consisted of two series of tests, the Uninstrumented Component Assembly (UCA) that investigated the effect of time at temperature and fluence, and the Instrumented Fast reactor Accelerated Component-Sheath Insulator (IFAC-SI) that investigated the additional effect of an applied voltage. The IFAC-SI test was never completed because of budgetary constraints.

\subsection{Requirements}

The UCA test program had four requirements:

1) Irradiate the sheath insulators to a nominal fast neutron fluence ( $\mathrm{E}>0.1 \mathrm{MeV}$ ) of $2.7 \times 10^{22} \mathrm{n} / \mathrm{cm}^{2}$ at a temperature of $1070 \mathrm{~K}$.

2) Measure the electrical resistance of the sheath insulator after irradiation up to a temperature of $1070 \mathrm{~K}$.

3) Measure the thermal conductivity of selected sheath insulators after irradiation up to a temperature of $1070 \mathrm{~K}$.

4) Perform metallography of selected sheath insulator after irradiation.

The IFAC-SI test program had four requirements:

1) Irradiate selected sheath insulators to a nominal fast neutron fluence ( $\mathrm{E}>0.1$ $\mathrm{MeV}$ ) of $2.7 \times 10^{22} \mathrm{n} / \mathrm{cm}^{2}$.

2) Measure the electrical resistance of the sheath insulators during irradiation at the nominal potential of 7.5 volts and up to an accelerated condition of 30 volts.

3) Measure the electrical resistance of the sheath insulator during irradiation at the nominal temperature of $1070 \mathrm{~K}$ and up to an accelerated temperature of $1170 \mathrm{~K}$.

4) Perform metallography of selected insulator seals after irradiation.

\subsection{Test Description}

\subsubsection{Uninstrumented In-reactor Test}


The UCA-1, UCA-2, and UCA-3 were a series of accelerated sheath insulator tests performed in fast neutron spectrum reactors. The UCA-1, and UCA-2 tests took place in FFTF at WHC. The UCA-3 test took place in EBR-II at ANL-W. The tests were conducted in MOTA for FFTF and in the standard B-7A capsule for EBR-II. Temperature control was achieved by means of gamma heaters and/or $\mathrm{He} / \mathrm{Ar}$ gas mixtures.

The first of the tests, UCA-1, was irradiated in FFTF Cycle 9. Irradiation testing began on September 11, 1986, and ended in October 10, 1987. The irradiation lasted 341.1 effective full power days (EFPD). The accumulated fast fluence (neutron energy $>0.1 \mathrm{MeV}$ ) was between $2.5 \times 10^{22} \mathrm{n} / \mathrm{cm}^{2}$ and $7.2 \times 10^{22} \mathrm{n} / \mathrm{cm}^{2}$.

UCA-2 was the second in the series of in-reactor component tests. Irradiation started in Cycle 10 of the FFTF that began on November 24, 1987, and ended January 9, 1989, with a total of 355 EFPD. End of test fluence ranged from $3.6 \times 10^{22} \mathrm{n} / \mathrm{cm}^{2}$ to $6.5 \times 10^{22} \mathrm{n} / \mathrm{cm}^{2}$.

UCA-3 was the last in the series of uninstrumented in-reactor component tests. It incorporated results from ex-reactor tests as well as results from the postirradiation examination of UCA-1 and UCA-2 sheath insulators. UCA-3 consisted of two batches, A and B. Seal insulators were tested in batch A and B while sheath insulators were only tested in batch B. Batch B started irradiation in Cycle 157 and irradiation was completed at the end of Cycle 158 January 19, 1992. The batch B capsule accumulated 110.1 EFPDs of irradiation with an estimated total fast fluence of $1.8 \times 10^{22} \mathrm{n} / \mathrm{cm}^{2}$.

The sheath insulator uninstrumented in-reactor test matrix is shown in Table 5-1.

\subsubsection{Instrumented In-reactor Test}

The IFAC-SI test was initially scheduled for irradiation June 1990 in FFTF in a modified MOTA test vehicle. In early 1990 the instrumented test was moved from FFTF to EBR-II. The MOTA type design developed for FFTF (shown in Fig. 5-1) consisted of individually encapsulated sheath insulator specimens with an on-line temperature control using a gas insulating gap and He/Ar gas mixture. This could not be accommodated in EBR-II because of space limitations. Instead a design consisting of a heat pipe and made out of the sheath insulators was adopted. This design is shown in Fig. 5-2. A properly designed heat pipe would create an isothermal condition with little uncertainty in temperature. The heat pipe design, however, precluded using temperature as a test variable, since its operating point cannot be changed during the test. Test samples were prototypic TFE sheath insulators with guard rings. Figure 5-3 shows the proposed measuring system that included provisions for a floating lead to measure the inherent noise and lead losses in the system. Irradiation was scheduled to start in the middle of 1993. In late 1992 a decision was made to stop all work on IFAC-SI. The completed Instrumentation and Control (I\&C) System and all pertinent hardware were placed in storage. An initial test matrix was developed for IFAC-SI and is shown in Table 5-2. Samples were fabricated and electrically tested at $1300 \mathrm{~K}$ for a week. All the samples showed resistivity values greater than $10^{8} \mathrm{ohm}-\mathrm{cm}$ at temperature. 
Table 5-1

UCA SHEATH INSULATOR IN-REACTOR TEST MATRIX

\begin{tabular}{||c|l|l|c|l||}
\hline \hline Test & \multicolumn{1}{|c|}{ Test Specimen } & & & \\
Identification & \multicolumn{1}{|c|}{ Design } & Number & \multicolumn{1}{|c||}{ Material } \\
\hline UCA-1 & Al-1,-2,N-1,H-1 & Stress relief & 3 & Graded alumina \\
& AA-1,-2,N-1 & Alternate stress relief & 3 & Graded alumina \\
& AlH-1 & Square end & 1 & Graded alumina \\
& Y-1,-2,-3 & Square end & 3 & Graded yttria \\
& TEA-1,-2,-3 & Restrain end & 3 & Alumina cermet 25\% \\
& TEYAG-1,-2,-4 & Square end & 3 & YAG cermet 25\% \\
\hline UCA-2 & 317,336 & Step end & 2 & Graded alumina \\
& 345,346 & Step end & 2 & Graded yttria \\
& 333,334 & Step end & 2 & Graded YAG \\
& TA8, TA9 & Step-square end & 2 & Alumina cermet 10\% \\
& TY2, TY5 & Step-square end & 2 & Yttria cermet 10\% \\
\hline UCA-3B & 1280,1383 & Step end & 2 & Graded alumina \\
& $065-1,065-4$ & Step end & 2 & Alumina cermet 10\% \\
& $066-2,066-3$ & Step end & 2 & Alumina cermet 5\% \\
\hline
\end{tabular}

Table 5-2

INITIAL IFAC-SI SHEATH INSULATOR IN-REACTOR TEST MATRIX

\begin{tabular}{|c|c|c|c|}
\hline Test & Design & Number & Materials \\
\hline IFAC-SI & Step end & 2 & Graded alumina \\
& Step end & 2 & Alumina cermet 5\% \\
& Step end & 2 & Alumina cermet 10\% \\
\hline
\end{tabular}

The IFAC-SI test had the following requirements:

o Materials Alumina (graded and cermet)

o $\quad$ Test temperature $1070 \mathrm{~K}$ (nominal)

$1170 \mathrm{~K}$ (accelerated)

- Test voltage $\quad 7.5$ volts (nominal)

15 volts (accelerated)

30 volts (accelerated)

o Irradiation Three 90 day cycles $\left(\sim 1.25 \times 10^{22} \mathrm{n} / \mathrm{cm}^{2}\right.$ per cycle) 


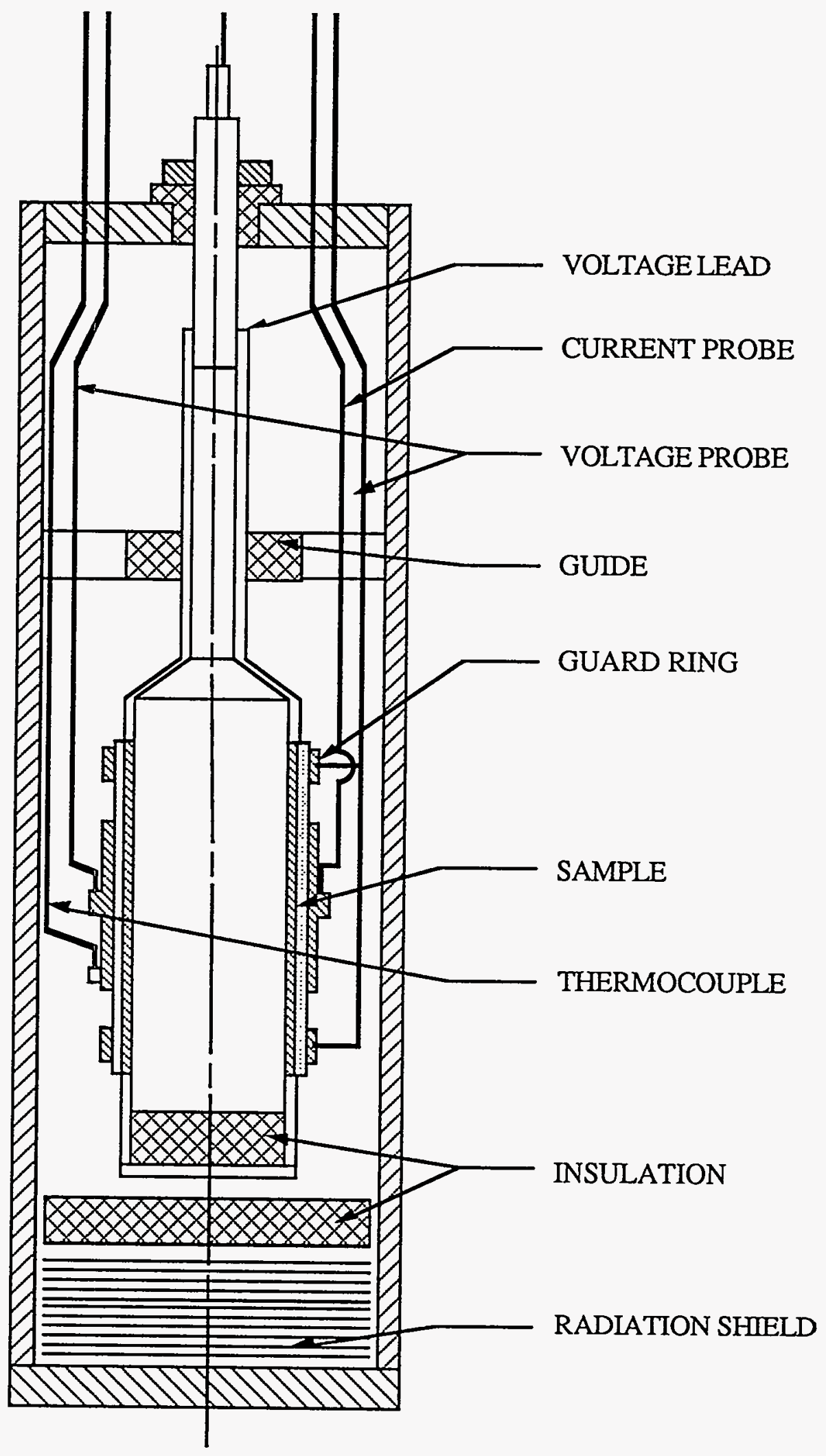

Figure 5-1. FFTF IFAC-SI Conceptual Design 


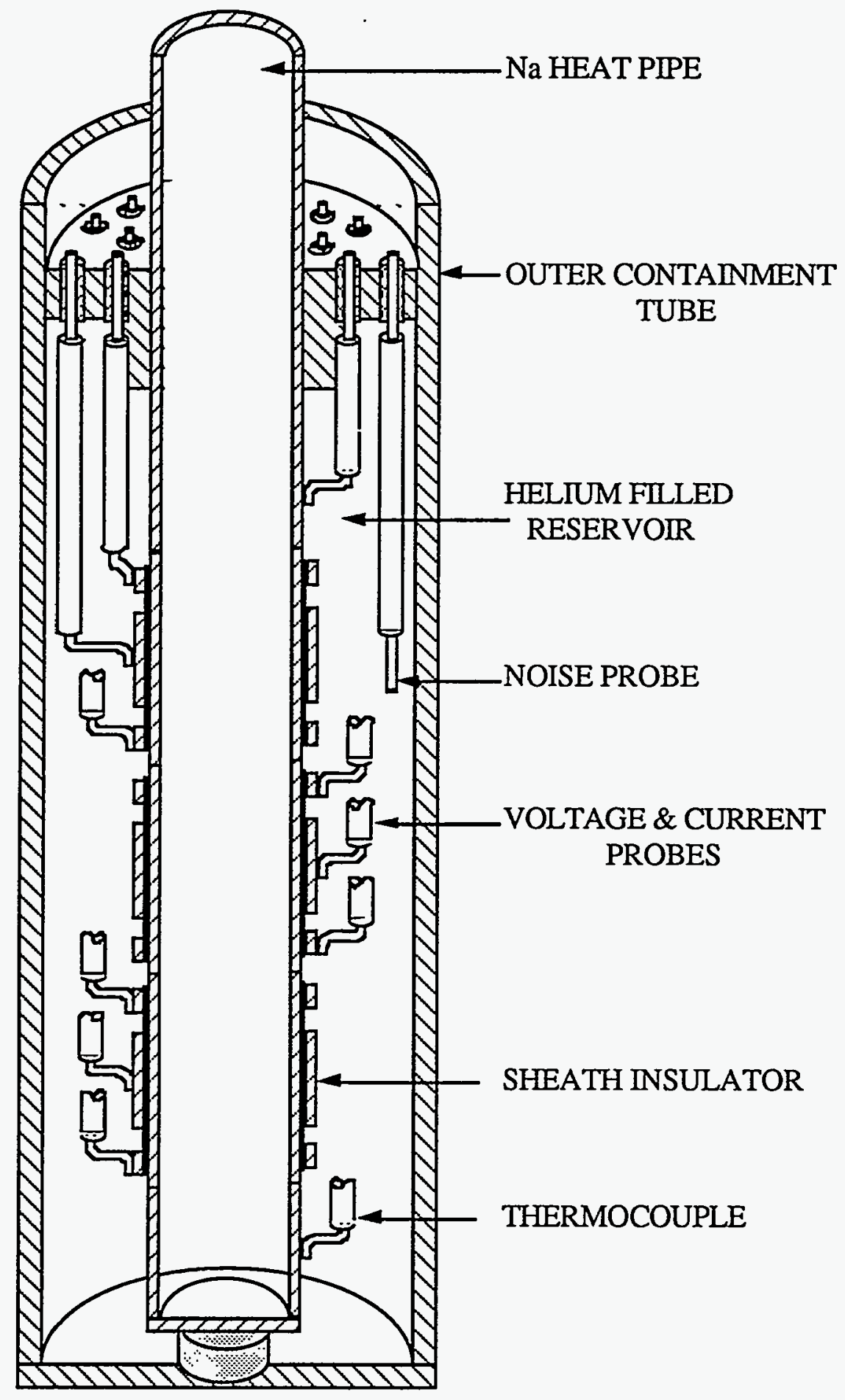

Figure 5-2. Heat Pipe Concept for EBR-II IFAC-SI 


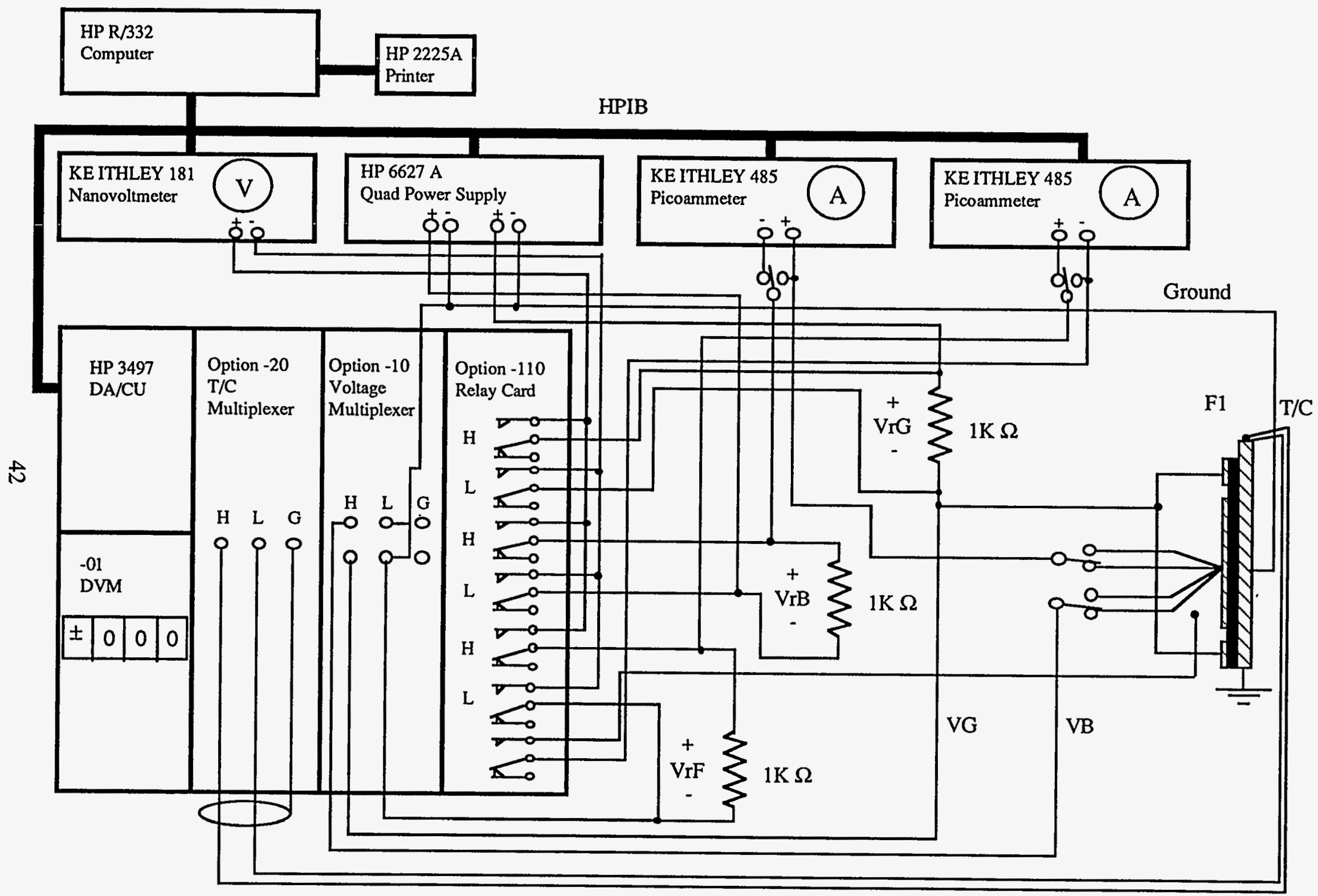

Figure 5-3. Schematic Of The IFAC-SI Measuring System 
In the SP-100 program an instrumented test capsule with 5 sheath insulators was tested in the TRIGA reactor (Ref. 5-1). The test was terminated when a leak developed in the watercooled cold finger used as part of the temperature control system. At this time, the samples had accumulated a fast neutron fluence of $6 \times 10^{20} \mathrm{n} / \mathrm{cm}^{2}(\mathrm{E}>0.1 \mathrm{MeV})$ and operated for 6450 hours at an average temperature of $1030 \mathrm{~K}$. An alumina sheath insulator (AEC/NASA-1970) had a resistivity of $2.2 \times 10^{7} \mathrm{ohm}-\mathrm{cm}$ with an applied potential of 10 volts. The resistivity of a yttria sheath insulator (SP-100-1985) was about $2.1 \times 10^{7} \mathrm{ohm}-\mathrm{cm}$ under the same operating conditions. The resistivity of the insulator samples steadily increased during irradiation in spite of an increase in the operating temperature of more than $50 \mathrm{~K}$ from the start of the irradiation. The irradiation tests indicated that alumina and yttria should last for 7 years under SP-100 conditions. Additional in-reactor testing of sheath insulators with an applied field was needed to quantify the 7-year lifetime under TFE-VP requirements.

As part of the DOE Thermionic Space Nuclear Power System Program at Rocketdyne (Ref. 5-2), sheath insulators fabricated for the TFE-VP will be tested in-reactor in Obninsk, Russia. Testing will be performed by Institute of Physics and Power Engineering (IPPE) in the BR-10 reactor. The requirements for the test article and irradiation conditions are similar to those that were established for the IFAC-SI test.

\section{$5.4 \quad$ Postirradiation Examination}

Postirradiation examination of the irradiated samples consisted of visual examination, dimensional measurements, metallography, He leak check, and electrical resistance as a function of temperature. A flow chart outlining the PIE is shown in Fig. 5-4. Leak tightness is not a requirement for sheath insulators but it was measured since it can be used to correlate to the performance of the trilayer seal.

The thermal conductivity of irradiated alumina and yttria sheath insulators was measured as part of the PIE of the K-5 capsule (Ref. 5-1). The K-5 sheath insulator irradiation test assembly was irradiated in the EBR-II reactor in the early 1970s and PIE occurred in the early $1980 \mathrm{~s}$. The total neutron fluence received by each specimen ranged from 0.6 to $1.0 \times 10^{22} \mathrm{n} / \mathrm{cm}^{2}$ $(\mathrm{E}>0.1 \mathrm{MeV})$ at a temperature of $1000 \mathrm{~K}$. The capsule consisted of 16 sheath insulator test specimens of various configurations and various additives to either strengthen the ceramic or give it better bonding characteristics to the niobium inner and outer sheaths. The additives used included $30 \%$ and $50 \%$ tungsten, $15 \%$ molybdenum, $10 \%$ lanthana, and $10 \%$ praseodymia. The thermal conductance was measured using a laser pulse thermal diffusivity technique. These measurements were made in a vacuum furnace at $1000 \mathrm{~K}$ and at room temperature. In general, the values for yttria and alumina sheath insulator, both irradiated and unirradiated, were similar.

In an Air Force funded program, which was complementary to the TFE-VP, a procedure for the thermal conductivity of UCA irradiated sheath insulators was developed by WHC. A measuring system was procured which used a pulse technique. The pulse was generated by a flash lamp that could deliver up to 3000 watts of energy. The system was installed outside the hot cell and successfully tested. Laboratory measurements of thermal diffusivity were performed 


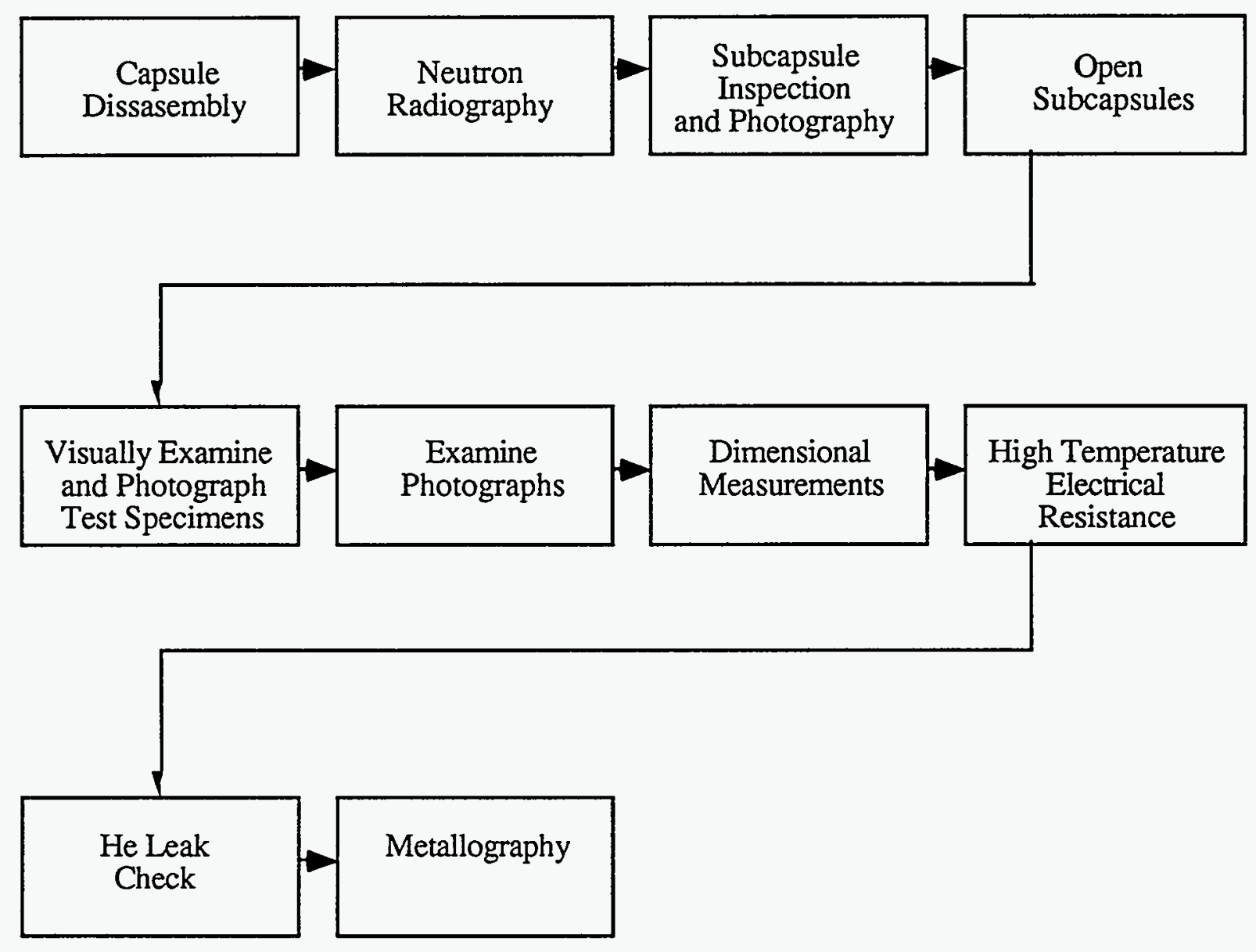

Figure 5-4. Postirradiation Examination Flow Chart

on nine unirradiated sheath insulators and a niobium control sample. The samples included three graded alumina, three alumina cermet with $10 \%$ niobium, two alumina cermet with $5 \%$ niobium and a graded yttria sheath insulator. The measured thermal conductivity of the control sample agrees within $\pm 1 \%$ of the published value for niobium. The results for the control sample and the tested sheath insulators are shown in Table 5-3. A data base was generated which would allow comparison with the thermal conductivity of irradiated samples. The requirement for irradiated sheath insulators was a thermal conductivity of greater than $0.03 \mathrm{~W} / \mathrm{cm}-\mathrm{K}$.

However the thermal conductivity of the UCA sheath insulators was never measured. Detailed information on the thermal property measurements of the unirradiated sheath insulators performed at WHC can be found in Ref. 5-3.

\section{$5.5 \quad$ Test Results}

The results of the in-reactor tests are summarized in Table 5-4. Detailed information on each of the tests can be found in Refs. 5-4 through 5-7 and in a larger body of data discussed in Section 1.7. 
Table 5-3

MEASURED THERMAL CONDUCTIVITY OF SHEATH INSULATORS

\begin{tabular}{||l|c|l|c||}
\hline \multicolumn{2}{|c|}{$1173 \mathrm{~K}$} & \multicolumn{2}{c|}{$973 \mathrm{~K}$} \\
\hline Sample & $\begin{array}{c}\text { Thermal } \\
\text { Conductivity } \\
\text { (W/cm-K) }\end{array}$ & \multicolumn{1}{|c|}{ Sample } & $\begin{array}{c}\text { Thermal } \\
\text { Conductivity } \\
\text { (W/cm-K) }\end{array}$ \\
\hline Niobium & 0.677 & Niobium & 0.703 \\
10\% Nb cermet (067-6) & 0.292 & & 0.280 \\
10\% Nb cermet (065-3) & 0.249 & $10 \%$ Nb cermet (065-3) & 0.248 \\
10\% Nb cermet (no ID) & 0.209 & $10 \%$ Nb cermet (no ID) & 0.242 \\
5\% Nb cermet (066-1) & 0.254 & $5 \%$ Nb cermet (066-1) & 0.282 \\
5\% Nb cermet (068-3) & 0.244 & $5 \%$ Nb cermet (068-3) & 0.211 \\
Graded (031069-3) & 0.180 & Graded 031069-3 & 0.192 \\
Graded (No ID) & 0.171 & Graded (no ID) & 0.120 \\
Graded (short) & 0.170 & & Graded yttria (Y-4) \\
Graded yttria (Y-4) & 0.100 & \multicolumn{3}{l}{} \\
\hline
\end{tabular}

\subsubsection{UCA-1}

Visual and dimensional PIE of the graded alumina sheath insulators on the K-5 irradiation capsule indicated that the outer metallic sheaths had bowed outward at the ends, resulting in circumferential cracking in the ceramic layer. Less cracking was observed for the alumina cermet sheath insulators made with niobium spheres. The axial extent of the end cracks for the graded and cermet sheath insulators was about 2 to $4 \mathrm{~mm}$ for samples 12.7 and $57.1 \mathrm{~mm}$ in length. It was concluded that since the cracks only extended a small fraction of the length, it would be possible to modify the sheath insulator ends to accommodate the effect. Analytic results showed that the problem could be alleviated by beveling the metal components at the ends of the sheath insulators.

This was the approach taken with the UCA-1 test samples, where three different stress relief configurations were tested, two on the graded alumina sheath insulators and one on the alumina cermets. The test specimen designs are shown in Fig. 5-5. Visual examination of the irradiated samples revealed that all the graded alumina and graded yttria had a continuous circumferential crack in the ceramic layer, whereas the alumina cermet samples were crack-free. The crack pattern was similar to the circumferential cracks seen in the K-5 graded alumina samples. The two stress relief configurations tested on the graded alumina sheath insulators did not solve the cracking problem.

Measurements of the electrical resistance as a function of temperature was performed on all the sheath insulators and only the alumina sheath insulators had acceptable resistance at high temperature. Measurements were taken during the rise to $1173 \mathrm{~K}$ and during the return to room 
Table 5-4

SHEATH INSUALTOR IN-REACTOR TEST SUMMARY

a

\begin{tabular}{|c|c|c|c|c|c|c|c|c|c|}
\hline TEST & MATERIAL AND & FLUENCE & TEMPERATURE & PIE & DIMENSIC & VAL PIE & PIE & PIE & PIE \\
\hline $\mathbf{S} / \mathbf{N}$ & PROCESS & $\mathrm{n} / \mathrm{cm}^{2}$ & IRRADIATION & VISUAL & RADIAL & AXIAL & RESISTANCE & He LEAK RATE & METALLOGRAPHY \\
\hline & & & & & & & Ohms & Std cc/sec & \\
\hline UCA-1 & FFTF 9/86 - 10/87 & 8164 hours & & & & & & & \\
\hline AL-1 & AL2O3-GRADED & $3.50 \mathrm{E}+22$ & $1109 \mathrm{~K}$ & Circum cracks at ends & $0.58 \%$ & & $3650(1173 \mathrm{~K}-1 \mathrm{~V})$ & $>10-4$ & Cracks penetrale1.3mm into ceramic \\
\hline AL-2 & AL2O3-GRADED & $3.30 \mathrm{E}+22$ & $1110 \mathrm{~K}$ & Cincum cracks at ends & $0.58 \%$ & & $1370(1173 \mathrm{~K}-1 \mathrm{~V})$ & $5 \times 10-5$ & No circumferential crack in center \\
\hline ALN-1 & AL2O3-GRADED & $6.90 \mathrm{E}+22$ & $1135 \mathrm{~K}$ & Circum cracks at ends & $1.16 \%$ & & $4590(1173 \mathrm{~K}-1 \mathrm{~V})$ & $>10-4$ & \\
\hline AA-1 & AL203-GRADED & $3.60 \mathrm{E}+22$ & $1112 \mathrm{~K}$ & Circum cracks at ends & $0.43 \%$ & & $38(1073 \mathrm{~K}-1 \mathrm{~V})$ & $5 \times 10-5$ & \\
\hline AA-2 & AL2O3-GRADED & $3.30 \mathrm{E}+22$ & $1104 \mathrm{~K}$ & Circum cracks at ends & $0.58 \%$ & & $8.1 \times 10+5(1173 \mathrm{~K}-1 \mathrm{~V})$ & $7.5 \times 10-5$ & Cracks penetrate $1.3 \mathrm{~mm}$ into ceramic \\
\hline AAN-1 & AL2O3-GRADED & $3.80 \mathrm{E}+22$ & $1114 \mathrm{~K}$ & Circum cracks at ends & $0.58 \%$ & & $540(1173 \mathrm{~K}-1 \mathrm{~V})$ & $2.6 \times 10.6$ & \\
\hline ALH-1 & AL2O3-GRADED & $3.60 \mathrm{E}+22$ & $1115 \mathrm{~K}$ & Circum cracks at ends & & & & & \\
\hline $\mathrm{Y}-1$ & Y2O3-GRADED & $3.10 \mathrm{E}+22$ & $1104 \mathrm{~K}$ & Circum cracks at ends & $0.30 \%$ & & $10(1173 \mathrm{~K}-1 \mathrm{~V})$ & $4.3 \times 10-8$ & Crack extends full length \\
\hline $\mathrm{Y}-2$ & Y2O3-GRADED & $3.70 \mathrm{E}+22$ & $1112 \mathrm{~K}$ & Circum cracks at ends & $0.43 \%$ & & $8(1173 \mathrm{~K}-1 \mathrm{~V})$ & $1.1 \times 10.7$ & Circumferential crack in center \\
\hline $\mathrm{Y}-3$ & Y2O3-GRADED & $6.80 \mathrm{E}+22$ & $1133 \mathrm{~K}$ & Circum cracks at ends & $0.58 \%$ & & $3(1173 \mathrm{~K}-1 \mathrm{~V})$ & $8.5 \times 10-8$ & \\
\hline TEA-1 & AL2O3-CERMET 25\% & $3.10 \mathrm{E}+22$ & $1090 \mathrm{~K}$ & No cracks & $0.48 \%$ & $0.70 \%$ & 27 at RT (1V) & $1.1 \times 10.7$ & No Cracks \\
\hline TEA-2 & AL2O3-CERMET 25\% & $7.00 \mathrm{E}+22$ & $1137 \mathrm{~K}$ & No cracks & $0.58 \%$ & $0.85 \%$ & 1460 at RT (1V) & $1.3 \times 10.7$ & \\
\hline TEA-3 & AL2O3-CERMET 25\% & $3.50 \mathrm{E}+22$ & $1111 \mathrm{~K}$ & No cracks & $0.43 \%$ & $0.60 \%$ & 50 at RT (1V) & $5 \times 10-5$ & \\
\hline TEYAG-1 & YAG-CERMET $25 \%$ & $3.40 \mathrm{E}+22$ & $1096 \mathrm{~K}$ & No cracks & $0.30 \%$ & & $220(1174 \mathrm{~K}-1 \mathrm{~V})$ & 1 & No Cracks \\
\hline TEYAG-2 & YAG-CERMET 25\% & $6.60 \mathrm{E}+22$ & $1130 \mathrm{~K}$ & No cracks & $0.15 \%$ & & 2900 at RT (IV) & 1 & \\
\hline TEYAG-4 & YAG-CERMET 25\% & $3.40 \mathrm{E}+22$ & $1106 \mathrm{~K}$ & No cracks & $0.30 \%$ & & $150(1173 \mathrm{~K}-1 \mathrm{~V})$ & $1.0 \times 10-2$ & \\
\hline UCA-2 & FFTF 11/87 - 1/89 & 8040 hours & & & & & & & \\
\hline 317 & AL2O3-GRADED & $3.70 \mathrm{E}+22$ & $1114 \mathrm{~K}$ & No cracks & $1.41 \%$ & $0.94 \%$ & $7.7 \times 10+6(1196 \mathrm{~K}-7.5 \mathrm{~V})$ & $9.2 \times 10-5$ & No cracks \\
\hline 336 & AL2O3-GRADED & $5.80 \mathrm{E}+22$ & $1128 \mathrm{~K}$ & No cracks & $1.15 \%$ & $0.62 \%$ & $8.2 \times 10+6(1209 \mathrm{~K}-7.5 \mathrm{~V})$ & $5.4 \times 10-7$ & No cracks \\
\hline 345 & Y2O3-GRADED & $3.40 \mathrm{E}+22$ & $1117 \mathrm{~K}$ & No cracks & $0.58 \%$ & $0.44 \%$ & $4.62 \mathrm{E}+05(873 \mathrm{~K}-7.5 \mathrm{~V})$ & & \\
\hline 346 & Y2O3-GRADED & $5.90 \mathrm{E}+22$ & $1128 \mathrm{~K}$ & No cracks & $0.58 \%$ & $0.28 \%$ & $69(1207 \mathrm{~K}-7.5 \mathrm{~V})$ & $1 \times 10-8$ & No cracks \\
\hline 333 & YAG-GRADED & $3.80 \mathrm{E}+22$ & $1113 \mathrm{~K}$ & No cracks & $0.15 \%$ & $0.32 \%$ & $23(1214 \mathrm{~K}-7.5 \mathrm{~V})$ & $4.1 \times 10-4$ & \\
\hline 334 & YAG-GRADED & $5.60 \mathrm{E}+22$ & $1130 \mathrm{~K}$ & No cracks & $0.15 \%$ & $0.32 \%$ & $49(1210 \mathrm{~K}-7.5 \mathrm{~V})$ & $1.6 \times 10-4$ & \\
\hline TA8 & AL2O3-CERMET 10\% & $3.70 \mathrm{E}+22$ & $1109 \mathrm{~K}$ & No cracks & $1.09 \%$ & $1.51 \%$ & $3.0 \times 10+6(1197 \mathrm{~K} \cdot 7.5 \mathrm{~V})$ & $2.7 \times 10-6$ & No cracks \\
\hline TA9 & AL2O3-CERMET $10 \%$ & $6.00 \mathrm{E}+22$ & $1121 \mathrm{~K}$ & No cracks & $1.15 \%$ & $1.41 \%$ & $7.6 \times 10+6(1209 \mathrm{~K}-7.5 \mathrm{~V})$ & $1.2 \times 10-4$ & No cracks \\
\hline TY2 & Y2O3-CERMET $10 \%$ & $3.40 \mathrm{E}+22$ & $1112 \mathrm{~K}$ & No cracks & $0.51 \%$ & $0.56 \%$ & $37(1210 \mathrm{~K}-7.5 \mathrm{~V})$ & $2.8 \times 10-4$ & \\
\hline TY5 & Y2O3-CERMET 10\% & $6.20 \mathrm{E}+22$ & $1122 \mathrm{~K}$ & No cracks & $0.58 \%$ & $0.56 \%$ & $31(1213 \mathrm{~K}-7.5 \mathrm{~V})$ & $2.9 \times 10-4$ & \\
\hline UCA-3B & EBR-II 5/91 - 2/92 & 2640 hours & & & & & & & \\
\hline 1380 & AL2O3-GRADED & $1.60 \mathrm{E}+22$ & $1070 \mathrm{~K}$ & No cracks & & & & & \\
\hline 1383 & AL2O3-GRADED & $1.80 \mathrm{E}+22$ & $1070 \mathrm{~K}$ & No cracks & & & & & \\
\hline $065-1$ & AL2O3-CERMET 10\% & $1.60 \mathrm{E}+22$ & $1070 \mathrm{~K}$ & No cracks & & & & & \\
\hline $065-4$ & AL2O3-CERMET 10\% & $1.70 \mathrm{E}+22$ & $1070 \mathrm{~K}$ & No cracks & & & & & \\
\hline $066-2$ & AL203-CERMET 5\% & $1.80 \mathrm{E}+22$ & $1070 \mathrm{~K}$ & No cracks & & & & & \\
\hline $066-3$ & AL2O3-CERMET 5\% & $1.70 \mathrm{E}+22$ & $1070 \mathrm{~K}$ & No cracks & & & & & \\
\hline
\end{tabular}



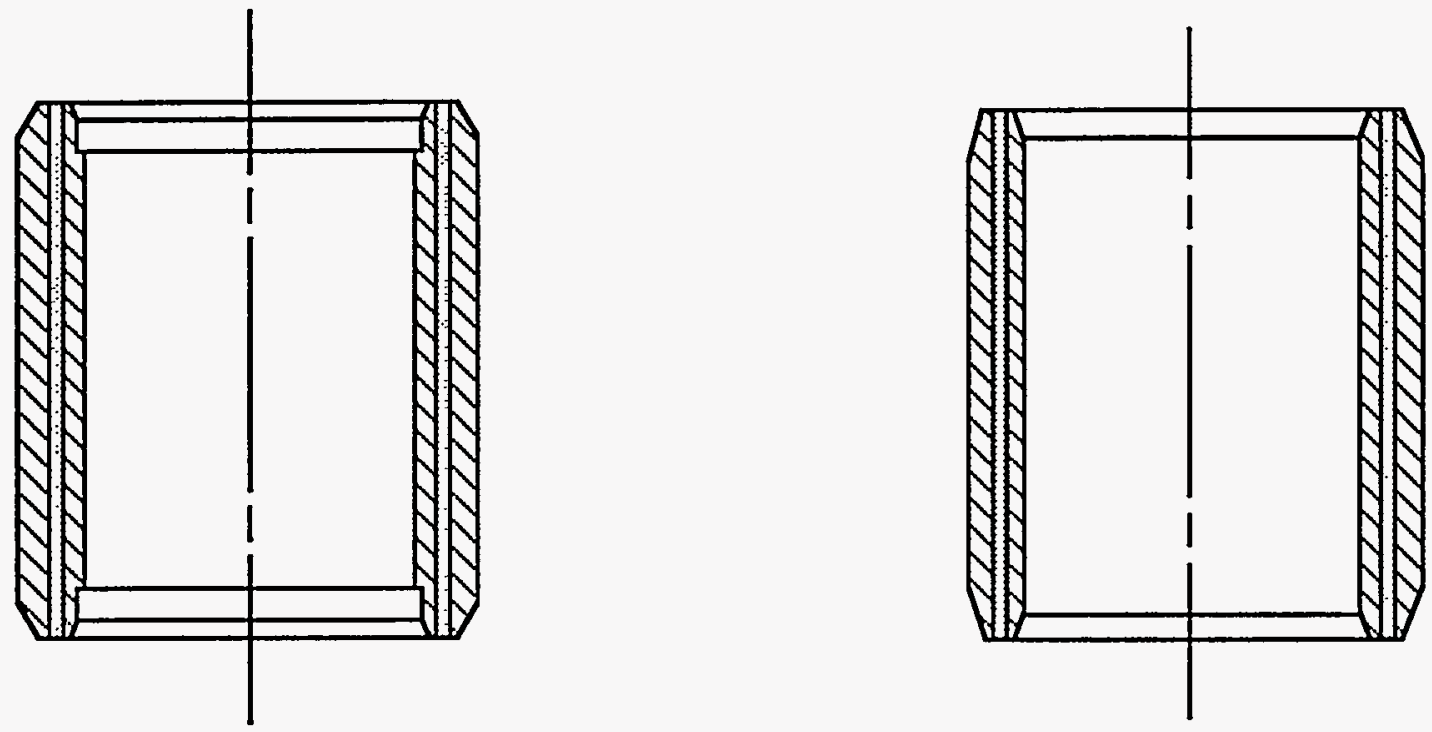

Graded Alumina Stress Relief

Graded Alumina Alternate Stress Relief
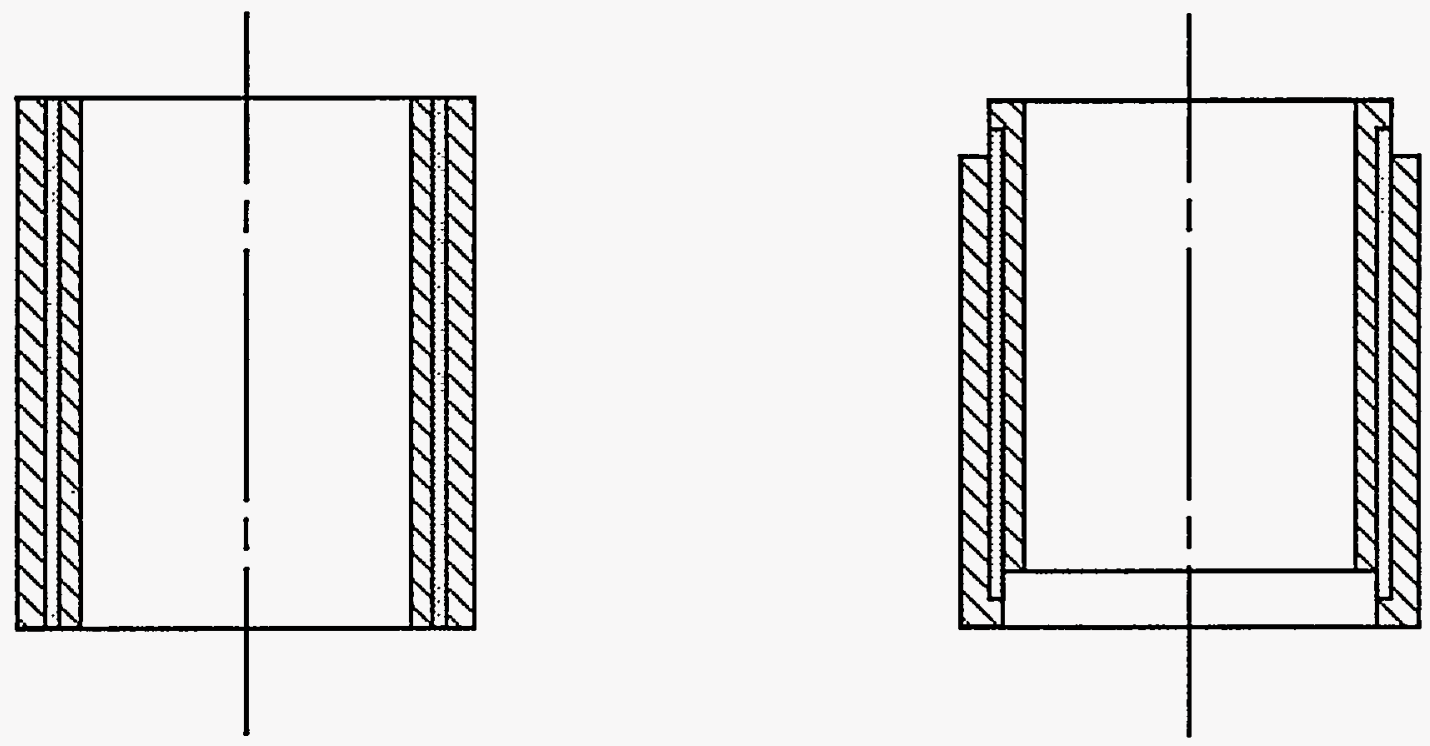

Graded Alumina and Yttria and YAG Cermet

Alumina Cermet

Restrain End

Figure 5-5. UCA-1 Test Sample Configuration 
temperature. The measurements were done under a positive pressure of high purity He and with an applied potential of one volt.

With the exception of the YAG cermet all the sheath insulators were He leak tight. As reported in Section 3, the YAG sheath insulators, either graded or cermet, could not be fabricated without cracks in the insulating layer; this was the cause of the leakage paths.

Of the fifteen UCA-1 samples, seven were selected for metallographic examination to obtain information on:

o Extent of the insulator cracking.

o Distortion of the ends.

o Bonding between insulator and niobium.

o Changes in the microstructure as a result of neutron fluence.

Photomicrographs from five of the surfaces examined are shown in Figs. 5-6 through 510. The metallography results were generally positive. The TE-YAG-1 sample (Fig. 5-6) had excellent bonding of the cermet to the niobium metal. Metal spheres within the cermet showed no interaction or extensive migration that would result in bridging.

The Y-2 sample (Fig. 5-7) showed excellent bonding of the ceramic to the niobium metal with the transition zone from metal to ceramic similar to the as-fabricated condition. The circumferential crack observed at the ends extended the full length of the sample. This axial crack is inconsistent with the helium leak measurement for Y-2 that indicated no detectable leak. It is believed that the initial circumferential crack had extended the length of the sample from the cutting, mounting, and polishing of the metallographic specimen.

Samples Al-1 and AA-2 (Figs. 5-8 and 5-9) showed excellent bonding of the ceramic to the niobium metal. The circumferential crack in the alumina layer only extended 1 to $2 \mathrm{~mm}$ into the ceramic. The appearance and extent of the cracks at both ends of the sample were similar. Change in the alumina microsturcture was limited to some microcracking at the grain boundaries.

Sample TEA-1 (Fig. 5-10) showed distortion of the ends but with no cracking of the cermet. Overall performance of the cermet appeared similar to the YAG sample with excellent bonding of the cermet to the metal and no apparent migration or bridging of the metal spheres.

\subsection{2 $\underline{\mathrm{UCA}-2}$}

In UCA-2 a new end configuration was tested on the graded sheath insulators to alleviate the circumferential cracking at the ends. In the step-end configuration the outer niobium sheath and the graded ceramic layers are recessed from the ends of the inner niobium mandrel. Figure 5-11 is a schematic of the end configurations used in UCA-2. 

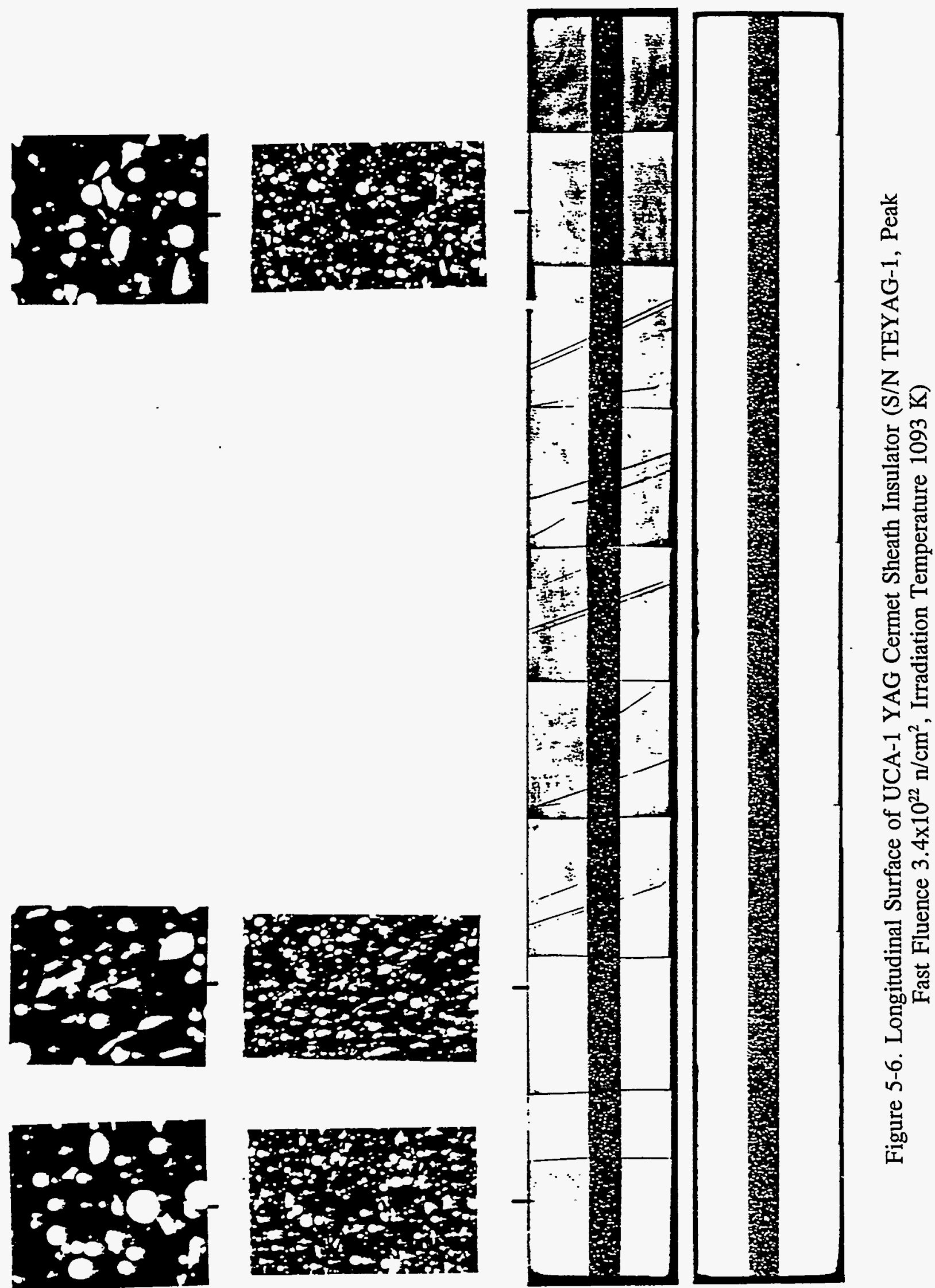


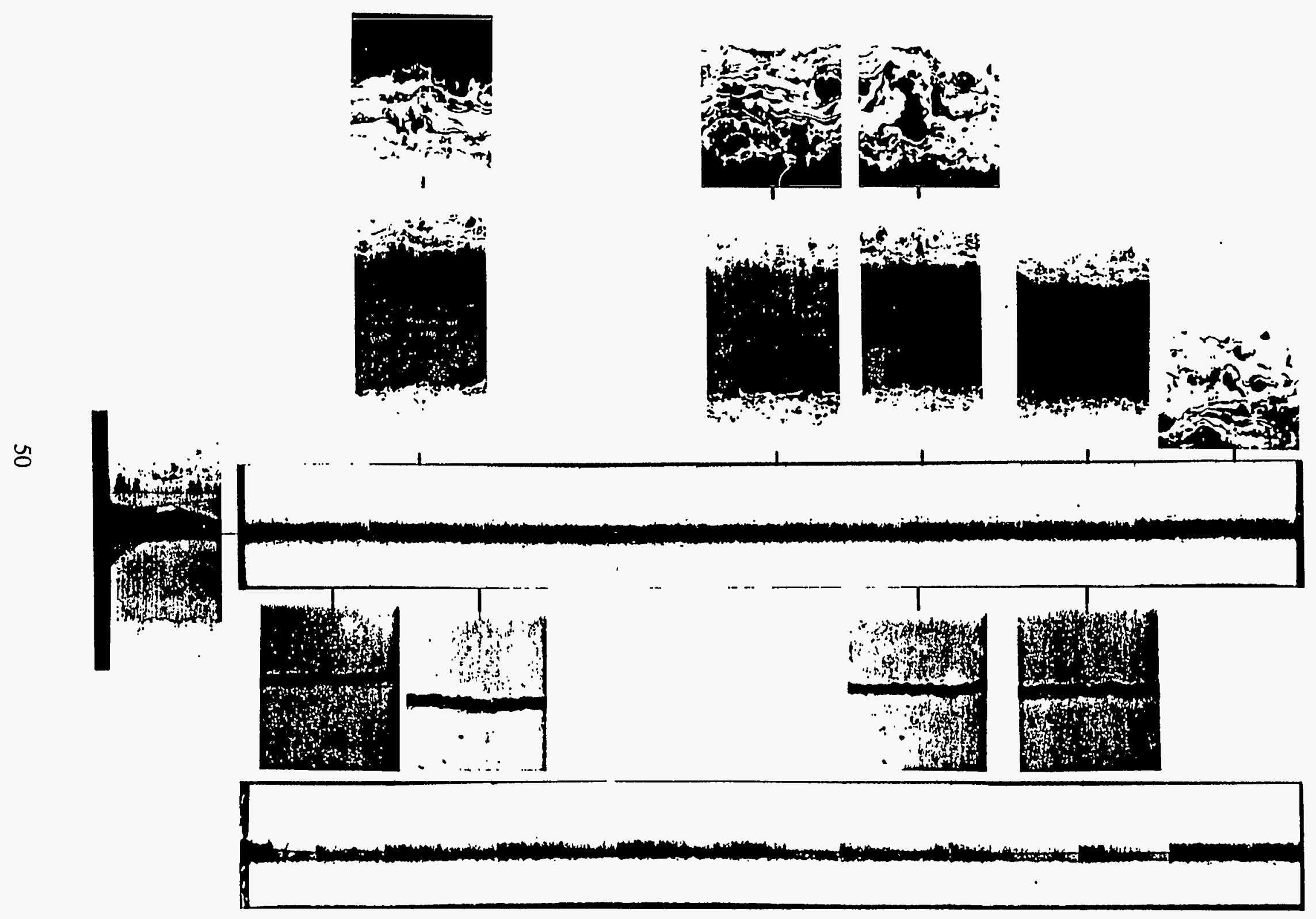

Figure 5-7. Longitudinal Surface of UCA-1 Graded Yttria Sheath Insulator (S/N T-2, Peak Fast Fluence $3.7 \times 10^{22} \mathrm{n} / \mathrm{cm}^{2}$, Irradiation Temperature $1112 \mathrm{~K}$ ) 


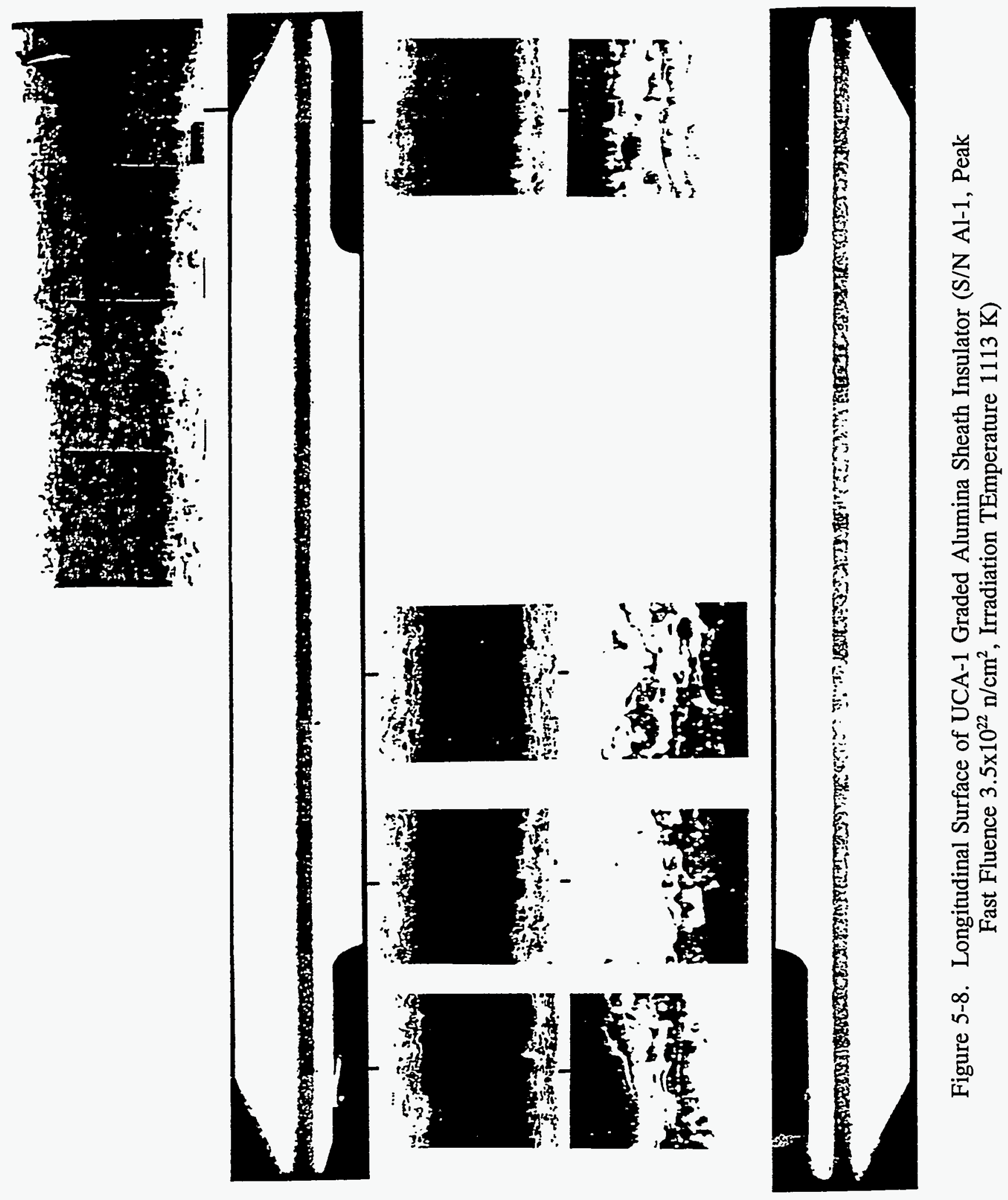




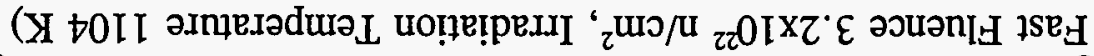

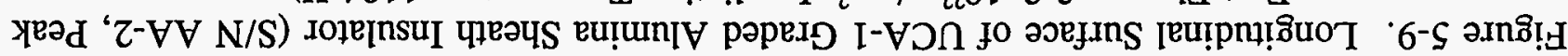

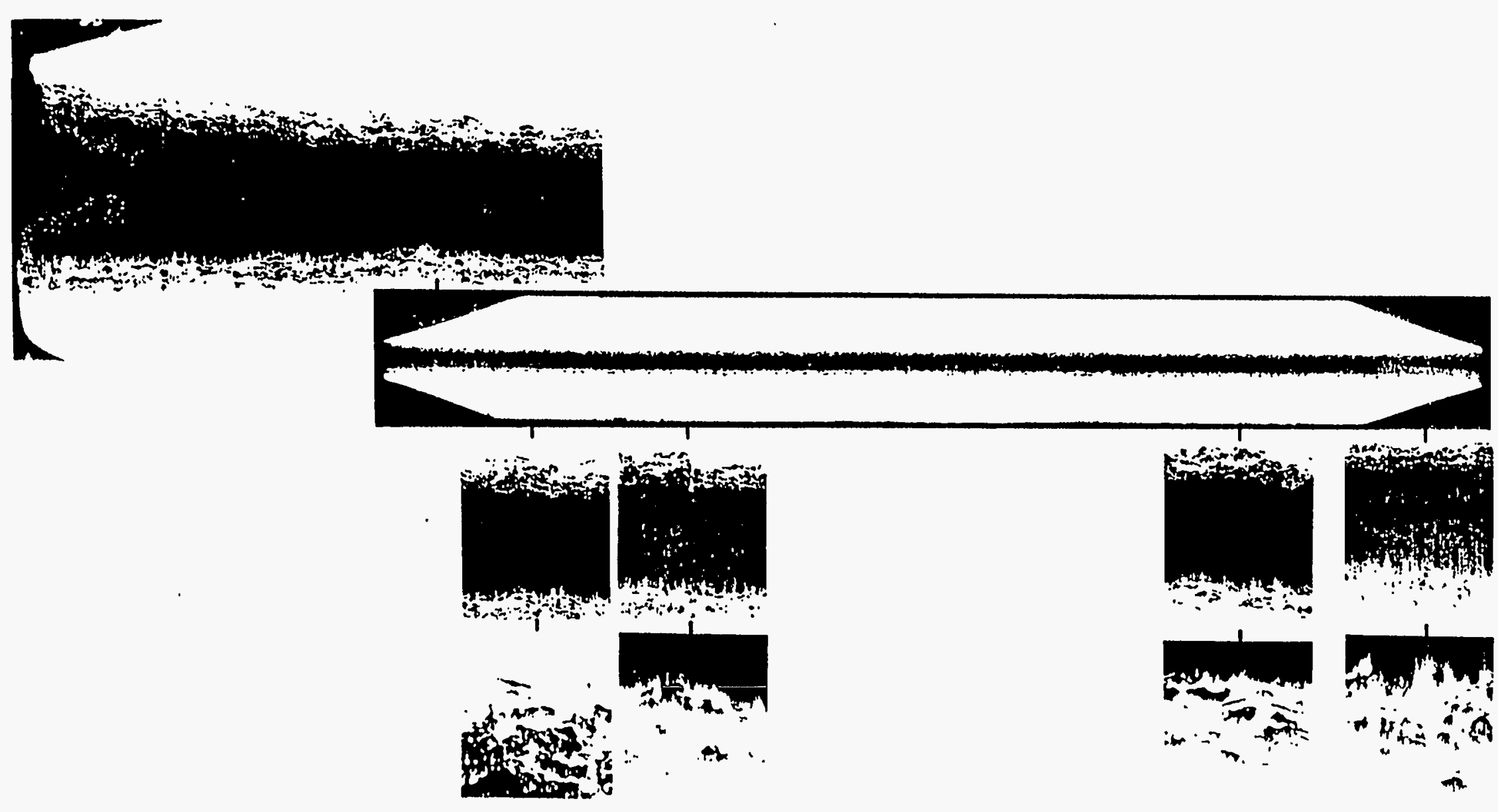



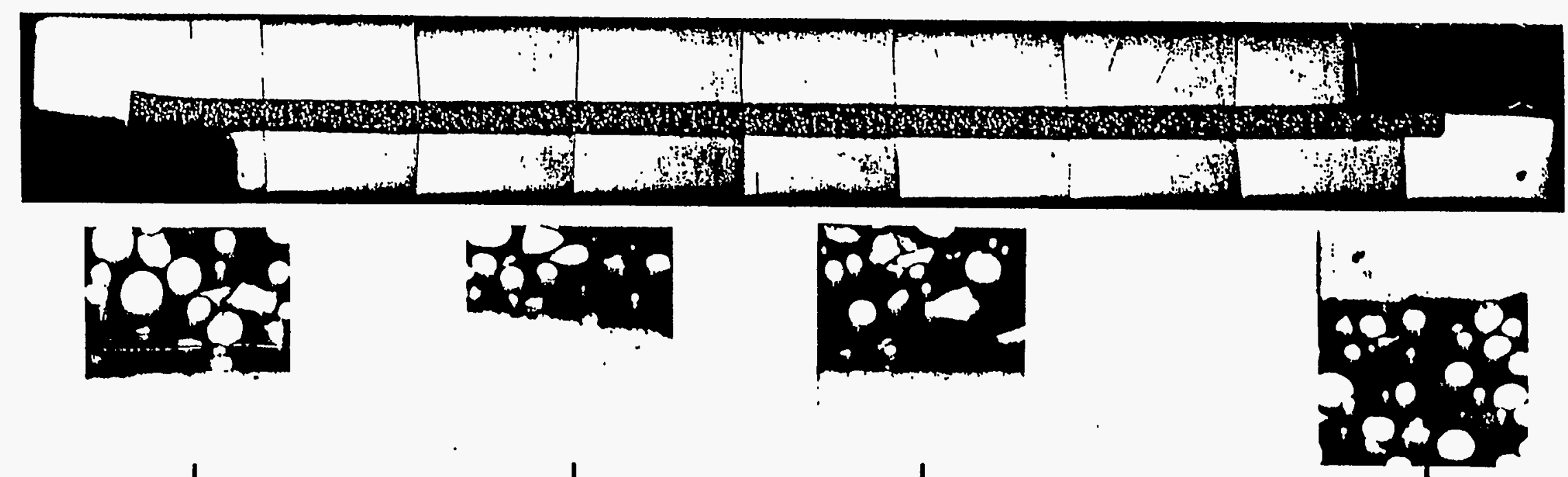

u

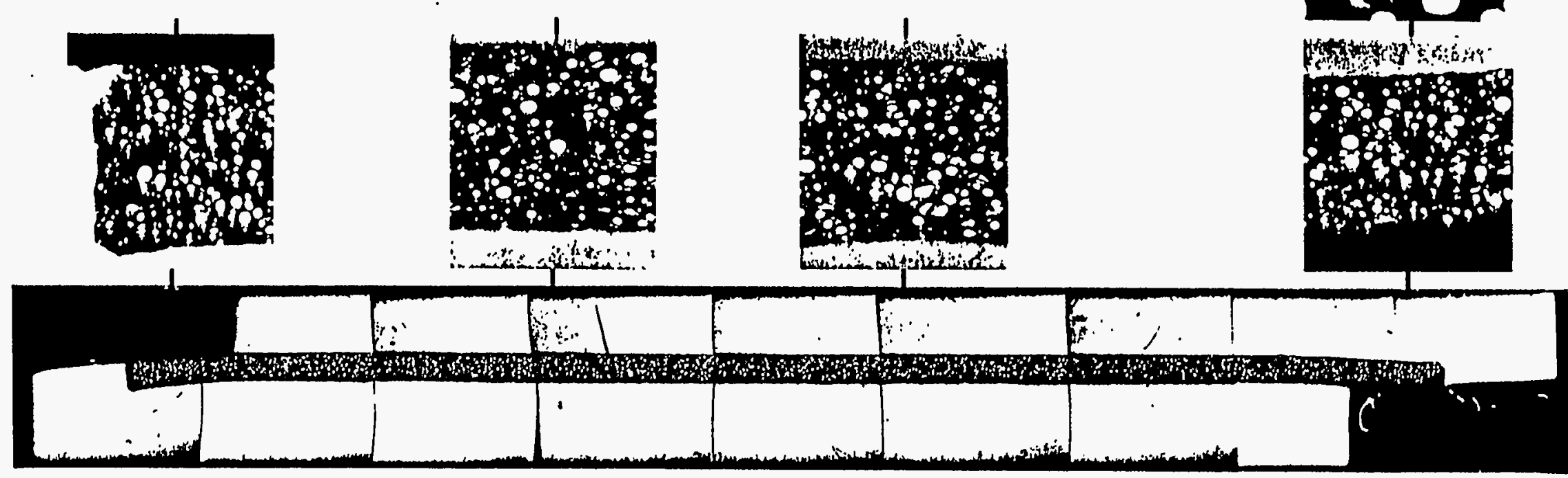

Figure 5-10. Longitudinal Surface of UCA-1 Alumina Cermet Sheath Insulator (S/N TEA-1, Peak Fast Fluence $3.1 \times 10^{22} \mathrm{n} / \mathrm{cm}^{2}$, Irradiation Temperature $1093 \mathrm{~K}$ ) 


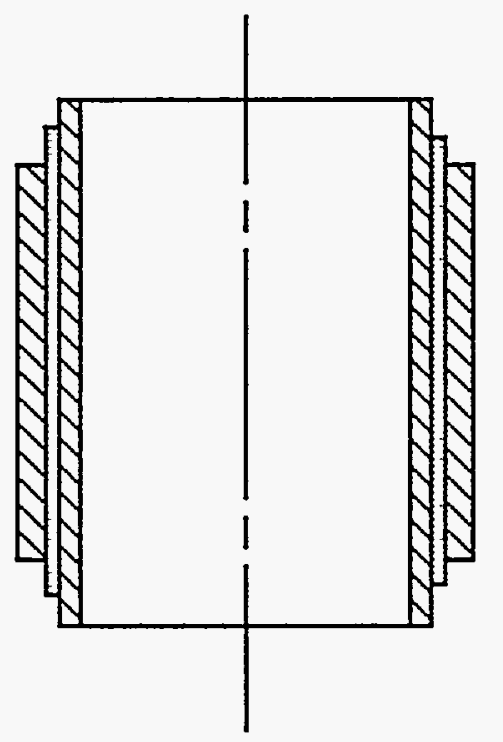

Graded Alumina, Yttria and YAG Step End

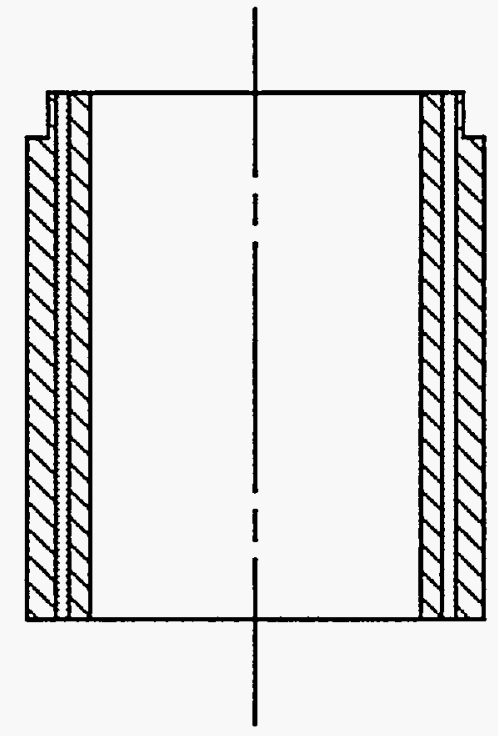

Alumina and YAG Cermet Step-Square End

Figure 5-11. UCA-2 Test Sample Configuration

Visual PIE of the sheath insulators showed that the sheath insulators were intact. The graded alumina sheath insulators with the step-end configuration did not show any circumferential cracks indicating that the step-end configuration was effective. The step-end configuration was selected as the reference end configuration for the UCA-3 and IFAC-SI irradiation tests.

Electrical resistance measurements were taken during the rise to $1070 \mathrm{~K}$ and during the return to room temperature with an applied potential of 7.5 volts. The graded alumina and alumina cermet samples had high resistance values at temperature, indicating no major changes in resistance due to irradiation. One of the graded yttria samples was only tested to $873 \mathrm{~K}$ because of a mishap during testing that resulted in the oxidation of the sample. At this temperature the resistance of the sample was $6.6 \times 10^{5} \mathrm{ohms}$, which was very good for yttria. The second graded yttria sample and the two yttria cermets had resistances of $400 \mathrm{ohms}$ and lower at $1070 \mathrm{~K}$, below the minimum requirement for the sheath insulator. The graded YAG samples also had resistance values at $1070 \mathrm{~K}$ below the minimum requirement.

He leak tightness was performed on all the samples except the oxidized graded yttria sample. All the samples were leak tight to some degree with the best results obtained for the graded alumina samples.

Five of the ten UCA-2 sheath insulators were selected for metallographic examination. The two graded alumina samples examined, one of which is shown in Fig. 5-12, showed excellent bonding of the ceramic to the metal with no cracking in the graded transition region. 

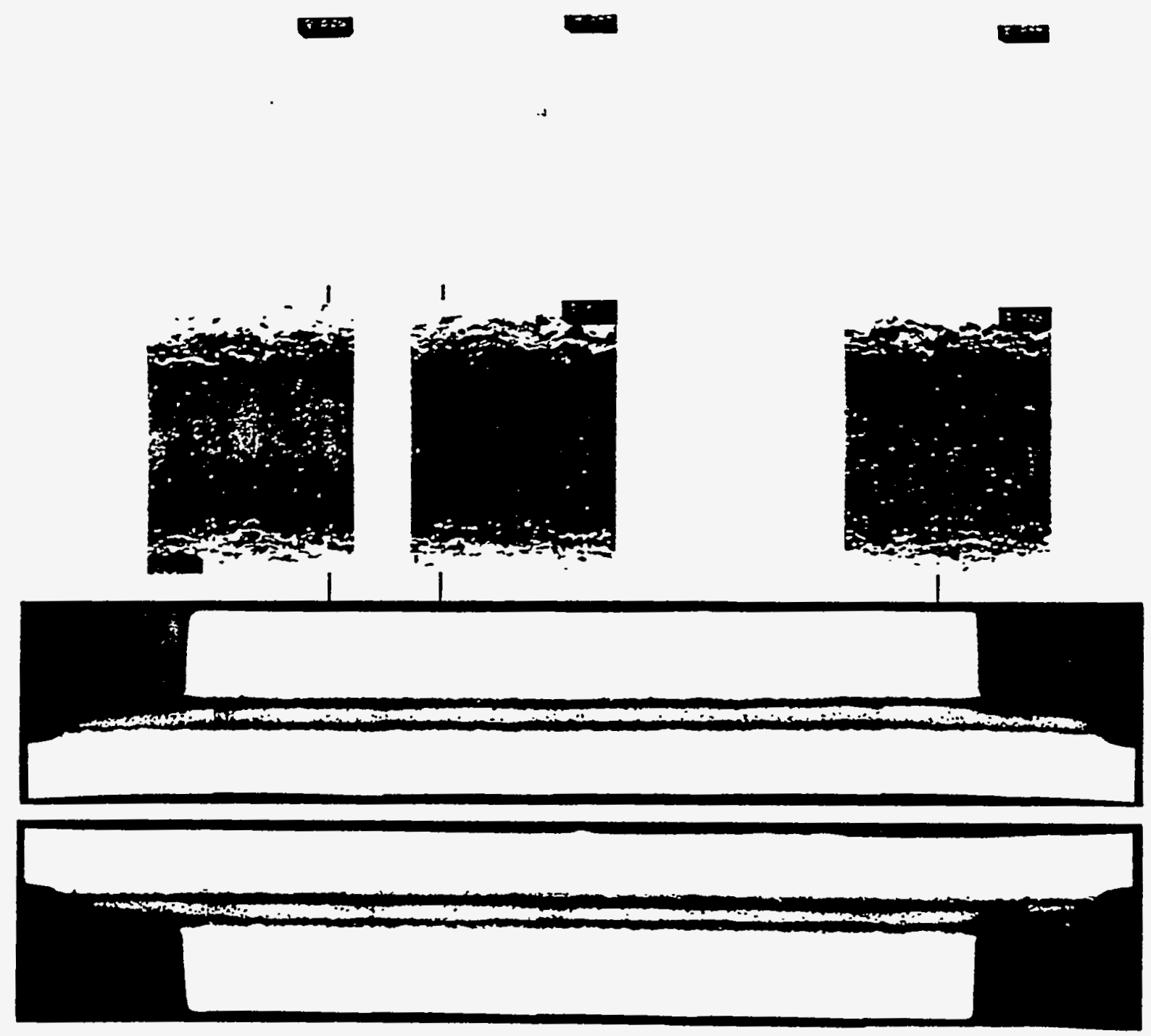

Figure 5-12. Longitudinal Surface of UCA-2 Graded Alumina Step End Sheath Insulator (S/N 336, Peak Fast Fluence $5.8 \times 10^{22} \mathrm{n} / \mathrm{cm}^{2}$, Irradiation Temperature $1128 \mathrm{~K}$ ) 
There was no axial crack at either end of the ceramic. The microstructure of the two samples was essentially the same as the preirradiated microstructure. The UCA-1 graded alumina microstructure was characterized by microcracking at the grain boundaries with laminar porosity oriented along the axis of the sample, quite the opposite of the UCA-2 samples. The differences between UCA-1 and UCA-2 in this regard are not fully understood. Both UCA-1 and UCA-2 samples were fabricated in the same way and both were exposed to similar neutron fluence. In the UCA-1 samples the outer sheath was made of $\mathrm{Nb}-1 \% \mathrm{Zr}$ and in the UCA-2 samples the outer sheath was made of pure niobium. However, this difference was probably not responsible for the difference in microstructure.

The graded yttria sheath insulator (Fig. 5-13) with the step-end configuration had axial cracks, with the cracks starting at each end and extending about $1 / 8$ of inch into the ceramic. At the graded transition region there was excellent bonding of the ceramic to the metal. The microstructure was very similar to the microstructure of the UCA-1 graded yttria and which in turn was very similar to the preirradiation microstructure.

The two alumina cermet sheath insulators, one of which is shown in Fig. 5-14, showed excellent bonding of the cermet to the metal with no cracking at the interface. There was no cracking of the cermet, no interactions between the matrix and the metal

particles, and no apparent migration or bridging of the metal particles.

UCA-2 results were so encouraging for the graded alumina and alumina cermet sheath insulators that alumina was switched from a backup to the reference material in either of the two configurations, graded or cermet.

\subsubsection{UCA-3}

The UCA-3 irradiation test consisted of six test samples; two graded alumina, two alumina cermet with $5 \% \mathrm{Nb}$ and two alumina cermet with $10 \% \mathrm{Nb}$. The sample configuration, shown in Fig. 5-15, consisted of step ends, TFE-VP prototypic dimensions and included the $\mathrm{Nb}-1 \% \mathrm{Zr}$ outer sheath tube. The outer sheath tube was nickel brazed to the outer niobium sheath of the sheath insulator. Terminal nondestructive examinations included visual examination and neutron radiography at three orientations of the sample capsules. The radiography showed no changes as a result of the irradiation. The sample capsules are presently in storage at EBR-II.

\subsubsection{H-Series}

Graded alumina sheath insulators were also tested in the H-series TFE irradiation program. Table 5-5 summarizes the testing history of the six H-series TFEs tested in the TFEVP. Graded alumina sheath insulators have experience over 20,000 real-time test hours in the TRIGA reactor and there have been no indications of sheath insulator failure. 

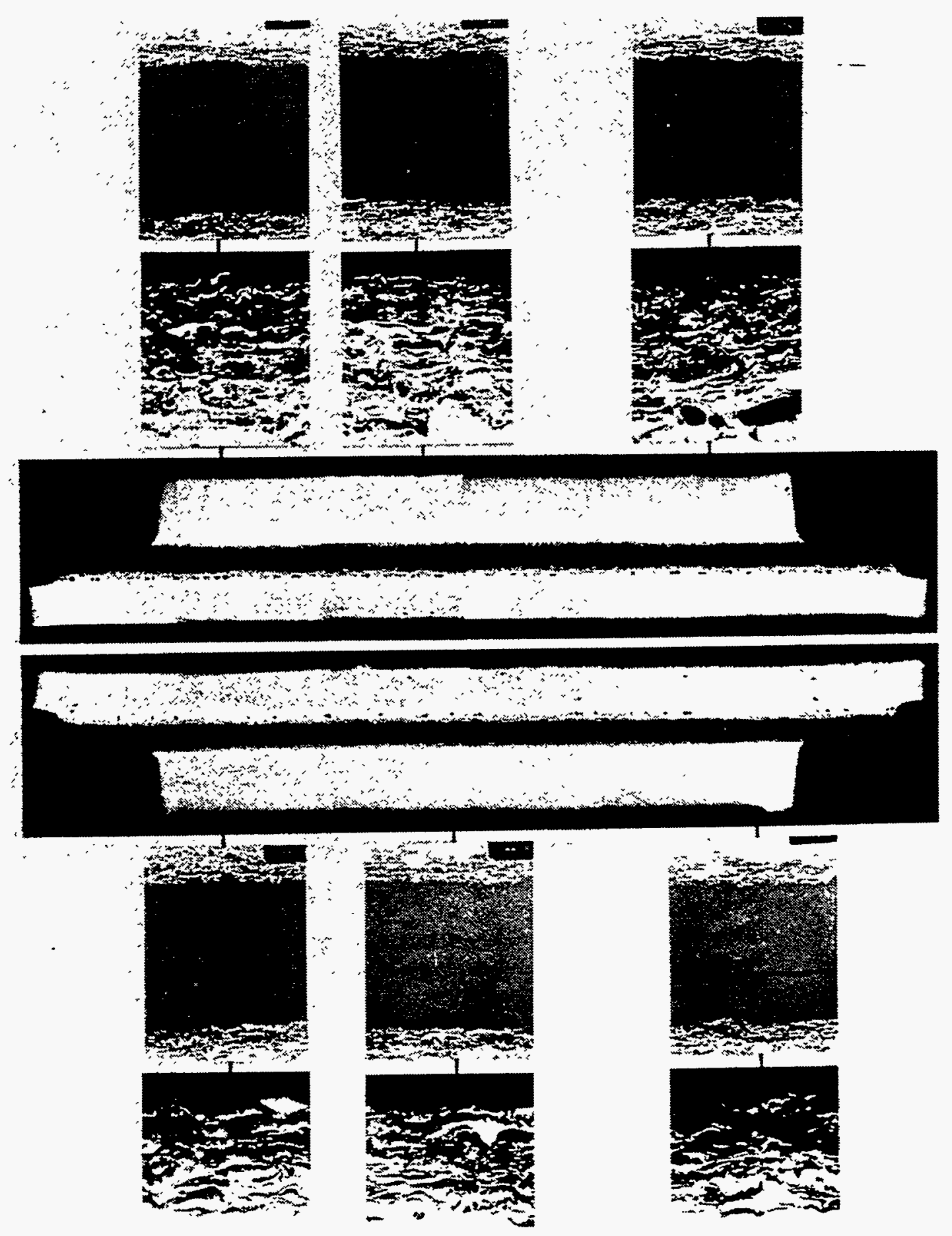

Figure 5-13. Longitudinal Surface of UCA-2 Graded Yttria Step End Sheath Insulator (S/N 336, Peak Fast Fluence $5.9 \times 10^{22} \mathrm{n} / \mathrm{cm}^{2}$, Irradiation Temperature $1128 \mathrm{~K}$ ) 

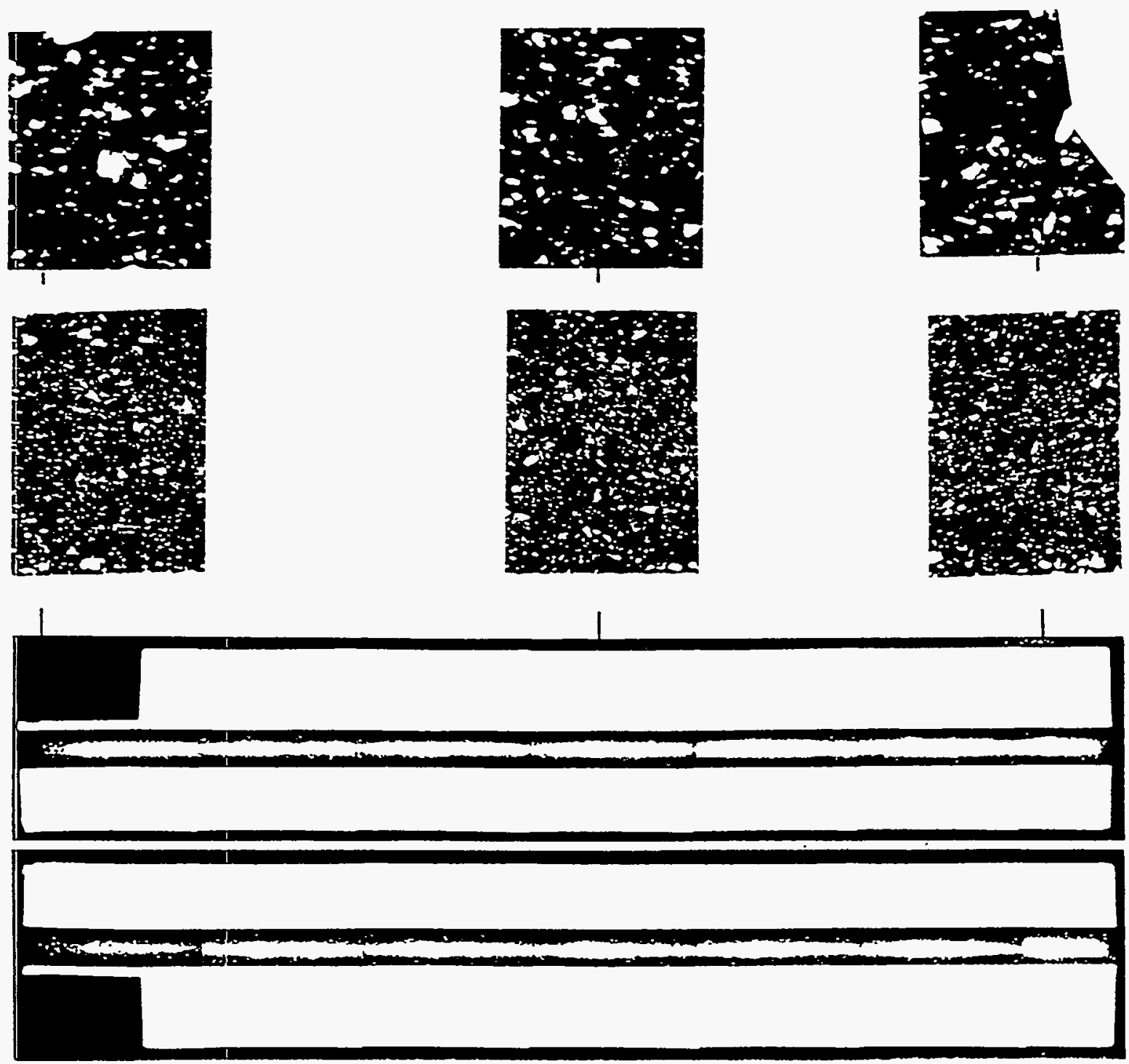

Figure 5-14. Longitudinal Surface of UCA-2 Alumina Cermet $(10 \% \mathrm{Nb})$ Square End Sheath Insulator (S/N TA9, Peak Fast Fluence $6.0 \times 10^{22} \mathrm{n} / \mathrm{cm}^{2}$, Irradiation Temperature $1121 \mathrm{~K}$ ) 


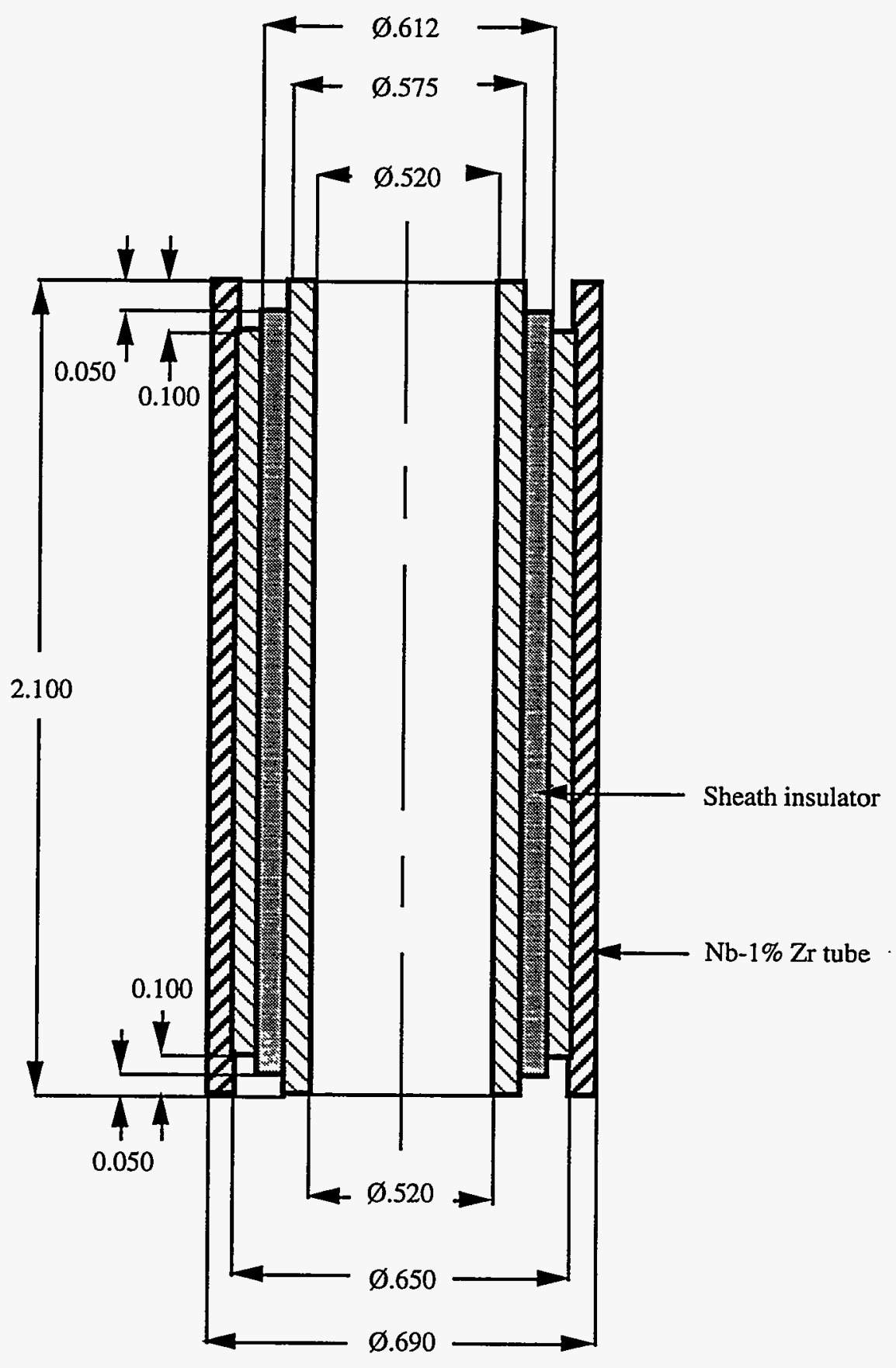

Figure 5-15. UCA-3 Test Sample Configuration 
Table 5-5

SUMMARY OF H-SERIES TFE TESTING

\begin{tabular}{||l|c|c|c|c|c|c||}
\hline \multicolumn{1}{|c|}{ Test } & $1 \mathrm{H} 1$ & $1 \mathrm{H} 2$ & $1 \mathrm{H} 3$ & $3 \mathrm{H} 1$ & $3 \mathrm{H} 5$ & $6 \mathrm{H} 1$ \\
\hline Sheath Insulators & 1 & 1 & 1 & 2 & 3 & 5 \\
Material & Yttria & Alumina & Alumina & Alumina & Alumina & Alumina \\
Start & $9 / 88$ & $3 / 90$ & $8 / 89$ & $5 / 91$ & $9 / 92$ & $4 / 93$ \\
End & $12 / 90$ & $3 / 92$ & $4 / 92$ & $3 / 93$ & $10 / 93$ & $10 / 93$ \\
Hours & 17,166 & 14,000 & 20,020 & 14,167 & 9,041 & 4,316 \\
Fast Fluence & $6.4 \times 10^{20}$ & $1.4 \times 10^{21}$ & $2.4 \times 10^{21}$ & $1.6 \times 10^{21}$ & $9.3 \times 10^{20}$ & $5.1 \times 10^{20}$ \\
& $\mathrm{n} / \mathrm{cm}^{2}$ & $\mathrm{n} / \mathrm{cm}^{2}$ & $\mathrm{n} / \mathrm{cm}^{2}$ & $\mathrm{n} / \mathrm{cm}^{2}$ & $\mathrm{n} / \mathrm{cm}^{2}$ \\
End of Test & Loss of output & Internal short & Heater failure & Heater failure & $\begin{array}{c}\text { Testing } \\
\text { terminated }\end{array}$ & $\begin{array}{c}\text { Testing } \\
\text { terminated }\end{array}$ \\
\hline
\end{tabular}




\section{INSULATOR SEAL SPECIFICATION}

\subsection{Materials/Design}

The TFE-VP reference sheath insulator specifications are summarized below:

\section{$\underline{\text { Reference Sheath Insulator }}$}

Insulator material: Polycrystalline alumina.

Design: Trilayer.

Fabrication: Plasma sprayed graded or slip cast cermet and gas pressure bonded.

Table 6-1 summarizes the sheath insulator development effort.

Table 6-1

SHEATH INSULATOR DEVELOPMENT EFFORT

\begin{tabular}{|c|c|c|c|c|c|c|c|c|c|c|}
\hline \multirow[b]{2}{*}{ Material } & \multirow[b]{2}{*}{ Design } & \multirow{2}{*}{$\begin{array}{l}\text { Electrical } \\
\text { Properties }\end{array}$} & \multirow{2}{*}{$\begin{array}{l}\text { Neutron } \\
\text { Stability }\end{array}$} & \multirow[b]{2}{*}{ Fabricability } & \multicolumn{6}{|c|}{ Test Matrix (Number of Specimens) } \\
\hline & & & & & UCA-1 & UCA-2 & UCA-3 & $\begin{array}{c}\text { TFE- } \\
1 \mathrm{H} 1,1 \mathrm{H} 2,1 \mathrm{H} 3, \\
3 \mathrm{H} 1,3 \mathrm{H} 5,6 \mathrm{H} 1\end{array}$ & $\begin{array}{l}\text { SP-100 } \\
\text { Fueled } \\
\text { Emitter }\end{array}$ & Ex-Reactor \\
\hline Alumina & Graded & Good & Good & Good & 7 & 2 & 2 & 12 & 9 & 31 \\
\hline Alumina & Cermet & Good & Good & Good & 3 & 2 & 4 & & & 52 \\
\hline Alumina & Sapphire & Good & & Difficult & & & & & & 2 \\
\hline Yttria & Graded & Poor & Good & Good & 3 & 2 & & 1 & & 21 \\
\hline Yuria & Cermet & Poor & Good & Good & & 2 & & & & 9 \\
\hline YAG & Graded & Good & Good & Difficult & & 2 & & & & 4 \\
\hline YAG & Cermet & Good & Good & Difficult & 2 & & & & & 1 \\
\hline
\end{tabular}

\subsection{Fabrication Process Description Reference Sheath Insulator}

The insulator in the sheath insulator is an aluminum oxide-matrix composite with niobium powder as the second phase. Two types of aluminum oxide-matrix composite insulators can be used: a graded alumina-niobium configuration or an alumina-niobium cermet. The graded configuration uses alumina-niobium layers of different compositions between the two niobium cylinders forming the sheath insulator. Those layers closest to the niobium cylinders have a high niobium content. The middle layer is pure alumina and is the electrical insulating layer. The graded structure minimizes the stresses resulting from the thermal expansion difference between the alumina and the niobium.

In the cermet, niobium powder is mixed uniformly throughout the alumina matrix. Addition of niobium powder to the alumina increases the fracture strength of the oxide, and provides for a good bond between the alumina and the niobium cylinders. The cermet better matches the coefficient of thermal expansion of niobium than pure alumina. 


\subsubsection{Materials}

The reference materials selected for the sheath insulator are:

Insulator Polycrystalline aluminum oxide (Linde A or Linde B from Union Carbide for the graded structure and A39SG from Alcoa for the cermet).

Metal Niobium rod and tube.

Niobium powder $\quad(<10 \mu \mathrm{m}$ FSSS Hermann C. Starck $)$.

\subsubsection{Processing}

Machining of niobium and aluminum oxide-matrix composite should be done with sulfur free cutting fluids.

Niobium parts should be solvent and acid cleaned to remove hydrocarbons and oxides.

For the plasma sprayed process, the surface of the niobium mandrel to be plasma sprayed should be conditioned by grit blasting with ALCOA tabular alumina. Typical plasma spraying parameters are specified as follows:

o Gun current setting 400 amps

- Gun distance from work piece 2 to 3 inches

o Torch gas Argon at $70 \mathrm{CFH}$

- Powder carrier gas Argon

For the cermet process, cermet tubes are fabricated by slip casting the alumina niobium mixture. The alumina and niobium powders are ball-milled together in water with an organic dispersant and drain cast in plaster molds. Typical casting parameters are specified as follows:

o Total solids content

- Organic dispersant

o Dispersant content

o Milling time
43 volume percent

Darvan C

$4.4 \mathrm{mg} / \mathrm{g}$ of alumina

18 hours

The drying procedure was found to be critical to the successful production of cermets. Too aggressive drying tends to crack the green castings. When thoroughly dry the cylinders are sintered at $1250^{\circ} \mathrm{C}$ in vacuum.

After sintering, the cermet cylinders are machined using conventional carbide cutting tools.

Gas pressure bonding of the graded and cermet sheath insulators should be done following the temperature-pressure-time cycle outlined in Fig. 6-1. 


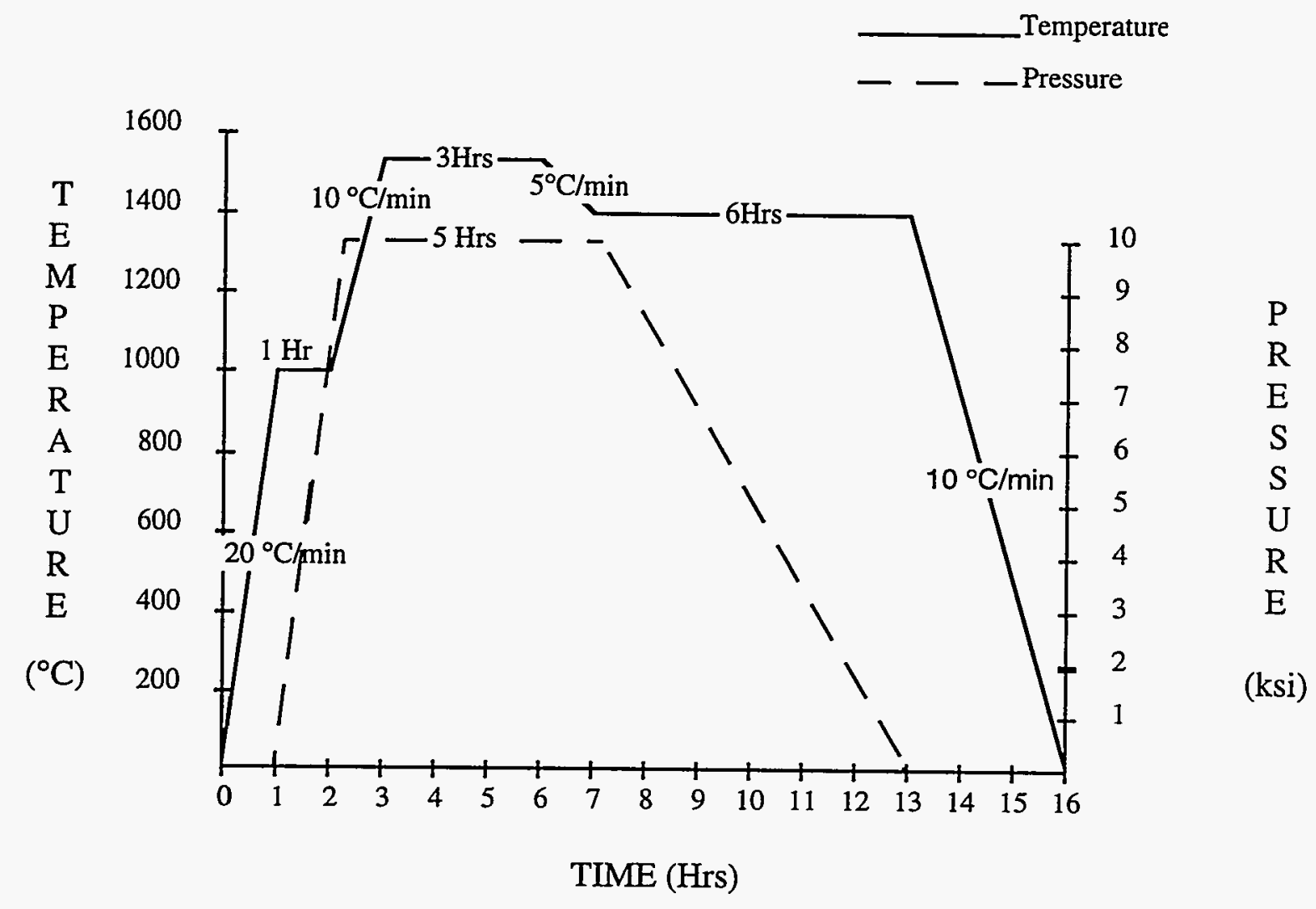

Figure 6-1. Gas Pressure Bonding Cycle

\subsubsection{Acceptability of Sheath Insulators}

The sheath insulator should pass the following acceptability criteria:

1) Dimensions should be acceptable.

2) Room temperature electrical resistance should be greater than $1,000,000$ ohms.

3) High temperature electrical resistance should be greater than 1,000 ohms.

4) Number of cracks should be less than 25 . 


\section{REFERENCES}

1-1 General Atomics Report GA-C18062, GES Baseline System Definition and Characterization Study, Final Report for the Period December 1984 through July 1985; Prepared under JPL Contract 956472, August 9, 1985.

1-2 General Atomics Report GA-A18182 (1985), SP-100 Thermionic Technology Program Annual Integrated Technical Progress Report for the Period Ending September 30, 1985, by GA Technologies, Rasor Associates, Inc., Space Power, Inc. and Thermo Electron Corporation, General Atomics, San Diego, CA, November 1985.

1-3 General Atomics Report GA-A18915 (1987), Thermionic Irradiations Program Final Report, General Atomics, San Diego, CA.

1-4 Cone, V. P. and J. Dunlay (1987), Thermionic Technology Program Fiscal Year 1986 and Final Technical Report, Thermo Electron Report No. TE4400-227-87.

1-5 Hatch, G. L. (1988), Thermionic Technology Program: Thermionic Converter Performance Final Report, NSR-25-25, E-533-003-B053188 (DOE Contract No. DE-ACO3-86SF15954).

2-1 Yoshimura, M., and H.K. Bowen (1981), Electrical Breakdown Strength of Alumina at High Temperatures, J. Am. Ceram. Soc., 64, 404.

2-2 Touloukian, Y.S., R.W. Powell, C.Y. Ho, and P.G. Klemens (1970), Thermophysical Properties of Matter, Vol. 2: Thermal Conductivity of Nonmetallic Solids, Plenum, NY.

3-1 Poirier, V.L. (1971), Topical Report on Irradiation of Metal/Ceramic Sheath Insulators, Thermo Electron Report No. TE 4122-42-72.

3-2 Clinard, F.W. (1979), Ceramics for Application Fusion Systems, J. Nucl. Mater., 85-86, 393.

3-3 Touloukian, Y.S., R.K. Kirby, R.E. Taylor and T.Y.R. Lee (1977), Thermophysical Properties of Matter, Vol.13: Thermal Expansion of Nonmetallic Solids, Plenum, NY.

3-4 Bates, J.L. and J.E. Garnier (1981), Electrical Conductivity of $\mathrm{MgAl}_{2} \mathrm{O}_{4}$ and $\mathrm{Y}_{2} \mathrm{O}_{3}$, Comm. of Am. Ceram. Soc., C-138.

3-5 Brook, R.L., J. Yee, and F.A. Kroger (1971), Electrochemical Cells and Electrical Conduction of Pure and Doped $\mathrm{Al}_{2} \mathrm{O}_{3}$, J. Am. Ceram. Soc. $\underline{54}, 444$.

3-6 Bauer, A.W. and J.L. Bates (1974), An Evaluation of Electrical Insulators for Fusion Reactors, Battelle Report BMI-1930. 
3-7 Gupta, T.K. and J. Valentich (1971), Thermal Expansion of Yttrium Aluminum Garnet, J. Am. Ceram. Soc. $\underline{54}, 355$.

3-8 Lin-Liu, Y.R. and L.D. Woolf (1986), Site Percolation and Electrical Breakdown in Cermets, GA Technologies Report GA-D18628.

3-9 Thermionic Technology Program: Fiscal Year 1986 - Final Report, Thermo Electron Corporation, Contract DE-AC03-86SF15955-1 (1987), Waltham, MA.

3-10 Final Technical Report: Thermionic Technology Program, Thermo Electron Corporation, Report No. TE4430-0190 (1990), Waltham, MA.

4-1 Kroger, F.A. (1984), Electrical Properties of a $\mathrm{Al}_{2} \mathrm{O}_{3}$, Advances in Ceramics, Vol. 10, Structure and Properties of $\mathrm{MgO}$ and $\mathrm{Al}_{2} \mathrm{O}_{3}$ Ceramics, pp. 1-15, (The American Ceramic Society).

5-1 Ranken, W.A, and A.R. Veca (1987), Irradiation Test Results on Thermionic Fuel Element Sheath Insulators, Space Nuclear Power Systems, M.S. El-Genk and M.D. Hoover, eds., Orbit Book Co., Malabar, FL, (1988).

5-2 Thermionic Space Nuclear Power System Program, Rocketdyne Division of Rockwell International, DOE Contract DE-RP03-92SF19138.

5-3 Cannon, N.S. (1991), Thermal Property Measurements of Unirradiated Thermionic Fuel Element (TFE) Sheath Insulators, WHC-SP-0711.

5-4 Lawrence, L.A., N.S. Cannon and K.E. Ard (1990), Irradiation and Examination of the Thermionic Fuel Element (TFE) Verification Program UCA-1 Samples, WHC-SP-0585.

5-5 Lawrence, L.A., K.E. Ard and D.M. Paxton (1991), Irradiation and Examination of the Thermionic Fuel Element (TFE) Verification Program UCA-2 Samples, WHC-SP-0656.

5-6 Paxton, D.M. and L.A.Lawrence (1991), Irradiation and Nondestructive Examination (NDE) of the Thermionic Fuel Element (TFE) Verification Program UFAC SC3-2 Seal Insulator Samples, WHC-SP-0674.

5-7 Lawrence, L.A. and D.M.Paxton (1993), Irradiation and Examination of the Thermionic Fuel Element (TFE) Verification Program UCA-3 Samples, WHC-SP-1055. 


\section{APPENDIX A}

\section{RESISTANCE REQUIREMENT}

The resistance requirement for the sheath insulator should be such as to limit the total power dissipated in the insulator to $0.1 \%$ of the total TFE power. The system design assumptions used to calculate the resistance requirement were:

- Converters per TFE

$$
\mathrm{N}=12
$$

- Converter voltage

Nominal

Maximum

$$
\begin{aligned}
& V_{\text {cell }}=0.49 \text { volts } \\
& V_{\text {cell }}=0.63 \text { volts }
\end{aligned}
$$

- TFE current

$$
I_{\text {cell }}=140 \mathrm{amps}
$$

- TFE voltage

$\mathrm{V}_{\mathrm{TFE}}=5.9$ volts

- TFE power

$$
\mathrm{P}_{\mathrm{TFE}}=829 \text { watts }
$$

o Temperature

$\mathrm{T}_{\max }=1070 \mathrm{~K}$

In the reactor converter system design the TFEs will be connected in a series and parallel configuration with a maximum of two TFEs connected in series. In such an arrangement the output voltage limit per TFE has been set to a maximum of 15 volts, nominal 11.8 volts.

During initial startup of the reactor an open circuit voltage of up to 1.5 volts per converter can be generated during short periods of time. With careful control of the startup procedures, the open circuit voltage can be controlled so that it does not exceed the maximum TFE output voltage limit of 15 volts.

To calculate the sheath insulator minimum resistance requirement, the following parameters were used, assuming 2 TFEs are connected in series:

- $\quad \mathrm{V}_{\max }=15$ volts

o $\quad P_{\max }=1658$ watts

- $\quad \mathrm{N}_{\max }=24$

The equivalent circuit for the sheath insulator calculations is:

$$
\text { A-1 }
$$




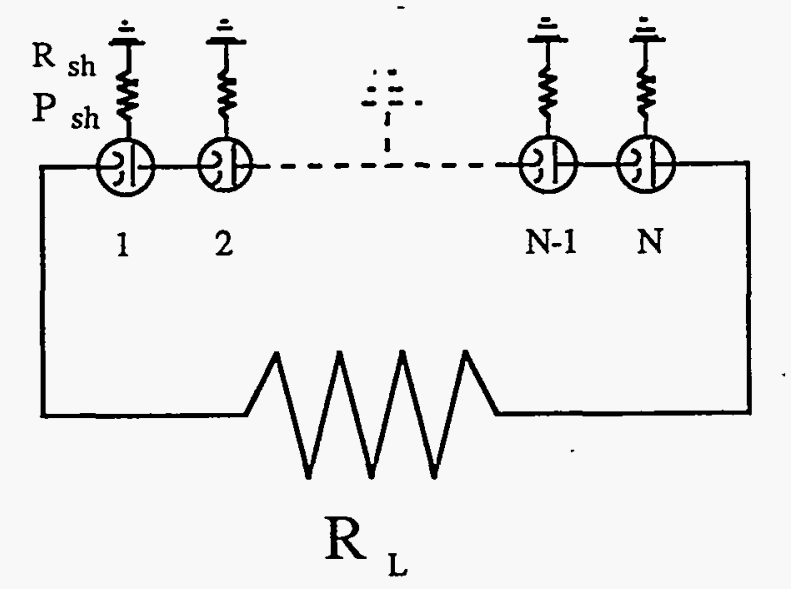

If the allowed total power dissipated by the sheath insulator $\left(\mathrm{P}_{\text {Tsh }}\right)$ is not to exceed $0.1 \%$ of the maximum total TFE power $\left(\mathrm{P}_{\max }\right)$, then:

$$
\begin{array}{ll}
0 & \mathrm{P}_{\mathrm{Tsh}}=0.001 \mathrm{P}_{\mathrm{MAX}} \\
0 & \mathrm{P}_{\mathrm{Tsh}}=\mathrm{P}_{\mathrm{sh}}\left(\mathrm{N}_{\mathrm{MAX}}\right) \\
0 & \mathrm{P}_{\mathrm{sh}}=\left(\mathrm{V}_{\mathrm{CELL}}\right)^{2} / \mathrm{R}_{\mathrm{sh}} \\
0 & \mathrm{~V}_{\mathrm{CELL}}=\mathrm{V}_{\mathrm{MAX}} / 2 \\
0 & \mathrm{R}_{\mathrm{Sh}}=\left(\mathrm{V}_{\mathrm{MAX}}\right)^{2 * \mathrm{~N}_{\mathrm{MAX}} / 4 *(0.001) * \mathrm{P}_{\mathrm{MAX}}}
\end{array}
$$

The resistance requirement for the sheath insulator for the TFE-VP is only 814 ohms. The resistivity requirement for the insulator in an sheath insulator with a $1000 \mathrm{ohms}$ resistance has been calculated and is given in Fig. A-1. 


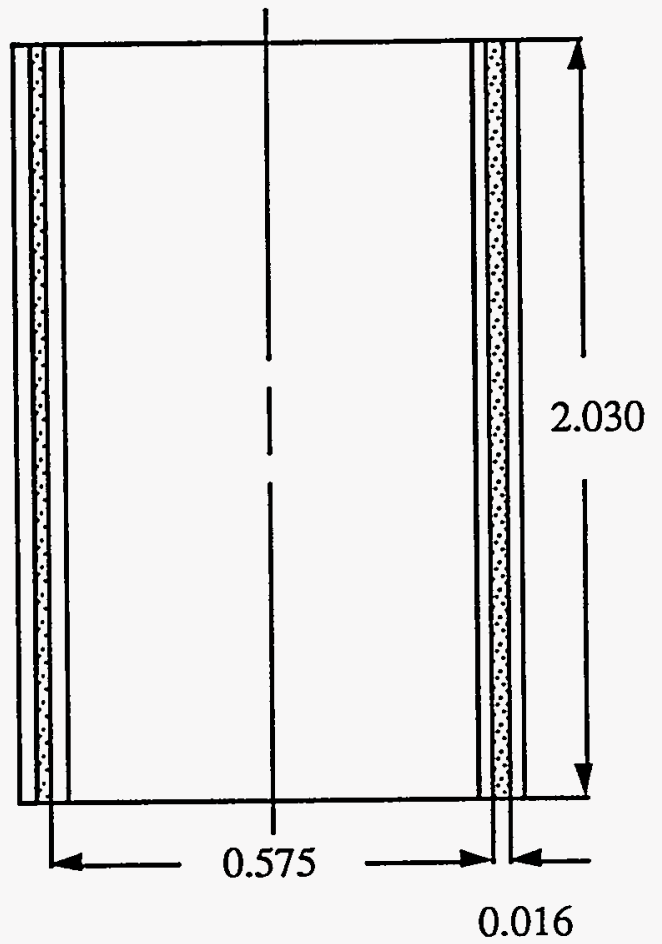

$$
\begin{aligned}
& A=3.77 \text { in }^{2}=24.32 \mathrm{~cm}^{2} \\
& L=0.016 \text { in }=0.041 \mathrm{~cm} \\
& \mathrm{r}=5.16 \times 10^{5} \mathrm{ohm}-\mathrm{cm}
\end{aligned}
$$

Figure A-1. Resistivity Requirements for the TFE-1H1 Sheath Insulator Design 


\section{APPENDIX B}

\section{B.1 CERMET FABRICATION DEVELOPMENT REPORT}

The TFE sheath insulator development program at ThermoElectron Technologies Corporation (TTC) concentrated on the fabrication of trilayer sheaths through more traditional ceramic forming processes, including dry pressing, filter pressing and slip casting.

The general approach to fabrication of the sheath trilayers was to form a free standing ceramic tube which could be sandwiched between inner and outer niobium sheath tubes. The three concentric tubes were then bonded together at high temperature and pressure in a Hot Isostatic Press (HIP). The resulting trilayers could then be machined to form electrical test specimens, trilayers seals, thermionic collector assemblies, etc. A number of types of free standing precursor ceramic cylinders were investigated: fully dense polycrystalline material, single crystal, or a partially dense polycrystalline piece which could be densified during the bonding procedure. For the polycrystalline case, the starting material might be a single phase ceramic, a mixture of ceramic phases or a continuous ceramic matrix with dispersed metal particles. This ceramic matrix with metal particles is referred to as a cermet. The metal particles can perform two functions in the cermet. The metal inclusions can toughen and strengthen the matrix and enhance the metal-to-ceramic interface by providing a large number of small areas of metal to metal bonding. Too many or poorly dispersed metal particles, however, can create electrical short circuits.

Successful cermet sheath insulators were developed by Thermo Electron in thermionic technology programs during the 1960's and early 1970's. These trilayers utilized an insulating layer composed of a cermet of an alumina matrix reinforced with 30 volume percent niobium metal spheres. The Thermionic Technology Program (TTP) attempted to recover this technology (Ref. B-1) for applications in programs such as TFE-VP. To obtain the 30 to 50 micrometer niobium spheres, niobium powder was first passed through a plasma torch in an argon atmosphere. The irregular particles were removed and the remaining spheres tumbled in a wax-coated jar. The waxed niobium particles were then mixed with alumina powder to coat them totally. The resulting mixture was then isostatically pressed into tubes which were fired, machined and finally pressure bonded to form trilayers. The key to this fabrication process is to find the combination of wax and alumina powder which will assure that the niobium particles are well coated with alumina particles. A random distribution of 30 volume percent of a conducting phase dispersed in an insulator is expected to form a short circuit path. A successful cermet at this metal content must, therefore, have an ordered structure with the metal spheres having much more tendency to be separated than would be the case for a random distribution. The need for properly coating the spheres with the alumina particles is obvious. This critical step was never consistently reproduced during the TTP effort although many combinations of powder and adherent were investigated. This work concluded that slurry processing was a better approach to achieving highly dispersed niobium particles.

The development of trilayers for thermionic applications continued at TTC in the TFEVP. Pure ceramic as well as cermet insulating layers were investigated. The enhancement of the ceramic-to-metal bond by the incorporation of niobium particles is illustrated in Figure B-1. 
The test specimens for this experiment were thin disks of the test material pressure bonded to niobium rods which could be clamped to the jaws of a tensile testing machine. The bond was loaded under tension until the specimen failed at the recorded stresses. The pure ceramic materials failed cleanly at the interface, while the cermets failed in a mixed interface/bulk mode. Substantial strengthening by the metal additions is quite apparent with fine niobium powder (less than 10 micrometers) providing substantially more enhancement than the spheres. At only a few volume percent metal addition, the fine powder provided nearly as much bond strength as $25 \%$ spherical additions. The metal particles were later shown to strengthen and toughen the bulk of the cermet as well as the ceramic-to-metal bond. Table B-1 lists the strength and toughness for alumina cermets with various amounts of niobium spheres as well as sub ten micrometer niobium powder. The niobium powder was air classified to remove the particles greater than ten micrometers. Solid rods of the materials were densified within a niobium shell using the usual bonding scheme. The specimens were then sliced into thin disks and fractured by a multiple point bending method. The difference between the spheres and the irregular particles is striking. Addition of large spherical particles enhances neither the strength nor the toughness, while the fine powder doubles the strength with $10 \%$ or more addition. The increase in fracture toughness in even more dramatic. The advantage of the cermet concept over the use of pure ceramic, especially using fine powder, is apparent from these data although the electrical consequences of the metallic inclusions were not initially known. Since both pure ceramic and cermet trilayers were necessary for testing, the preferred fabrication process would allow both types of materials to be produced.

The bulk of the early effort concentrated on techniques to form an aqueous suspension (slip) of ceramic (or mixed ceramic and metal) powder(s) into a thin, free standing tube suitable for pressure bonding to form a niobium clad trilayer sheath. Dry pressing of ceramic and mixed powders was also investigated as well as pressure bonding of single crystal sapphire $\left(\mathrm{Al}_{2} \mathrm{O}_{3}\right)$ tubes directly to niobium sheaths. The general procedure to produce trilayers was the same for all materials and forming processes. An insulator was first fabricated and then machined into a thin walled ( 0.020 inches thick or less) tube approximately 0.62 inches outside diameter by 2.25 inches long. This cylinder was then totally encapsulated in niobium by electron beam welding of the inner and outer niobium sheath tubes surrounding the ceramic. The sealed assembly was then bonded by a HIP procedure at $1550^{\circ} \mathrm{C}$ in 10,000 psi argon. The stresses in the ceramic layer during the bonding operation can be very high and depend upon the time/temperature/pressure cycle utilized. Cracking of the ceramic can occur during cooling due to thermal expansion mismatch or during the pressure release due to the different elastic moduli of the materials. Various bonding cycles were tried early in the program to eliminate or minimize cracking in the final product. The bonding cycle that became known as the "standard cycle" is shown in Fig.B-2. This cycle was used for the majority of trilayers bonded at TTC and appears to minimize cracking to the extent possible. The largest reduction in the tendency to crack, however, was found to be by the minimization of the thickness of the inner niobium sheath tube. This was particularly true for the plasma sprayed materials. The HIP process was controlled manually, so the cycle shown in Fig.B-2 can only be considered nominal with run-to-run variations occurring. The various forming techniques were utilized for each of the materials of interest and the resulting cylinders bonded into trilayers as described above. 


\section{B.2 FABRICATION PROCESSES}

\section{B.2.1 Dry Pressing}

Solid rods of ceramic materials can be isostatically pressed by loading powder into a rubber mold and placing the sealed form into a fluid which can be pumped to high pressure. The solid rod can be machined into tube form after a heat treatment. Hollow tubes can be pressed directly, but the fixturing is much more complicated. The key to successful dry pressing is the nature of the starting powder. The pressability and strength of the pressed piece can be enhanced by the addition of significant amounts of organic binders and lubricants. These organic materials must be burned out prior to bonding the trilayer. This burnout is best accomplished in an oxidizing environment. Pure ceramic materials will withstand such a burnout cycle, but the niobium in a cermet will not. Burnout of the cermets in a vacuum system will eliminate the bulk of the organic materials, but the probability of residual carbon is high. Therefore it was decided that dry pressing experiments would be performed without organic additives.

Powders of all three candidate materials were tested for feasibility of dry pressing without additives. The powders used for these tests were:

1) Alumina - type A-39 Superground supplied by Alcoa, Bauxite, AR, marketed as $99.9 \%$ pure. The particle size of the lot was given as 90 volume percent less than 1.25 micrometers, $50 \%$ less than 0.44 micrometers, and $10 \%$ less than 0.19 micrometers. Specific surface area $7.5 \mathrm{~m}^{2} / \mathrm{g}$.

2) Yttria - produced by Molycorp Inc., White Plains, NY, marketed as $99.99 \%$ pure. Coulter size 4.8 micrometers, FAPS 1.29 micrometers. Specific surface area $10.8 \mathrm{~m}^{2} / \mathrm{g}$.

3) YAG - "sinterable powder" supplied by Trans-Tech Inc., Adamstown, MD, sold as greater then $99.5 \%$ pure. Average particle size $2-3$ micrometers.

4) Niobium - initial powder supplied by Cabot Corporation, Boyertown, PA. The powder was then air classified by Alpine American Co., Natick, MA, into two size fractions at ten micrometers. The less than 10 micrometer fraction was used for these cermets.

Initial uniaxial pressing of pellets of the powders indicated that each of the oxides could be pressed into coherent disks. A higher purity alumina powder, Alcoa A-49 Superground, would not press at all. Cylinders of the powders were then pressed at $30-40 \mathrm{ksi}$ in an isostatic press. The green densities achieved by the isostatic pressing were about $60 \%$, slightly higher than those produced by the uniaxial tests. To produce the cylinders, a perforated brass cylinder was lined with a latex tube. One end was sealed with a silicone plug, and powder was loaded into the rubber-lined tube. The second end was stoppered, the rubber bag pulled over the ends and sealed by twisting with wire. The loaded assembly was then immersed in the pressing fluid and pumped up to the specified pressure. The rods formed in this manner were irregular 
in cross section but were solid and well pressed. After moderate temperature firing in air, 1225 ${ }^{\circ} \mathrm{C}$ for alumina and $1450{ }^{\circ} \mathrm{C}$ for yttria and YAG, the cylinders were strong and could be machined into the necessary thin-walled tubes.

The desirability of the inclusion of fine niobium powder in the ceramic matrix lead to efforts to dry press cermets in a similar fashion. The ceramic and niobium powders were mixed in a number of ways. Mixing techniques included simply tumbling for many hours, milling in a ball mill and mixing in a Szegvari Attritor with alumina balls. The resulting mixtures were isostatically pressed into rods as described previously. Examination of the fractured cross sections of these pressed cermet rods showed isolated areas of alumina devoid of niobium. Passing the mixed powder through a 200 mesh sieve prior to pressing greatly enhanced the homogeneity of the pressed material. After bonding into trilayers, about half of the $\mathrm{Al}_{2} \mathrm{O}_{3} / 10 \% \mathrm{Nb}$ cermets fabricated by this method were electrically short circuited at room temperature. The same composition produced by slip casting from the same raw materials showed no tendency to short circuit, so the tendency for the $\mathrm{Nb}$ powder to agglomerate apparently could not be overcome by the dry mixing procedures. Figure B-3 compares the particle distribution in a trilayer produced by dry mixing and dry pressing to that produced by wet milling and slip casting. Both samples contain 10 volume percent niobium powder taken from the same lot, although the dry processed specimen appears to have coarser powder. The milling procedure either reduced the niobium particle size or broke up agglomerates which gave the appearance of larger particles in the dry pressed powder. Examination of the cross sections of the dry pressed pieces showed no obvious continuous niobium paths, but the trilayers exhibited virtually zero electrical resistance at room temperature. When cut into smaller sections, each piece is individually short circuited indicating generally poor dispersion of the powder with many continuous pathways being formed.

Wet milling of the ceramic and metal powders (such as for slip casting) obviously forms a more uniform dispersion. A well dispersed powder for dry pressing might be produced by first forming an aqueous suspension and then drying it in a manner to avoid settling of the dense niobium particles. This would require the material to transform quickly from a well mixed viscous state to a rigid condition. Spray drying the slip to form small spherules of the mixed powders was one method investigated. The lack of the necessary equipment in-house and the difficulty of supplying the slip to a outside vendor made this technique unsuitable for the small scale test that was desired. A freeze drying technique was used to try to utilize the advantages of wet processing to produce a pressable cermet powder. The well dispersed slip was rapidly frozen by immersion in liquid nitrogen. The frozen material was then transferred to a small freeze drying apparatus to sublime the water from the mixture. A dispersed mixture could be formed in this manner, but the large amount of powder necessary to press a cylinder was never produced. The success of materials formed directly from the aqueous slips led to the discontinuation of dry pressing efforts. 


\section{B.2.2 Layered Structures}

An alternative to a cermet insulating layer containing a large volume fraction metal particles is a layered structure of varying composition. If a thin layer of pure ceramic were placed between cermet layers, the result might have the mechanical advantages of a cermet while retaining the excellent electrical resistance of the pure ceramic layer. The final structure would be similar to the graded plasma sprayed trilayers developed by GA. Two methods were used to produce layered structures from aqueous suspensions. Tape casting and slurry spraying can both yield greenware that can be bonded into trilayers. Slurry spraying involves coating a niobium mandrel by spraying it with alternating layers of slurries of pure ceramic and ceramic/niobium mixture(s). After pressing the multiple layered structure in a cold isostatic press, an outer niobium sheath was added and the assembly bonded in the normal way. Planar layered structures fabricated in a similar fashion were bonded and tested for fracture strength. The bond strength was considerably enhanced compared with pure ceramic material as seen in Figure B-1. A trilayer containing about $25 \%$ niobium produced by this method had a cracked center ceramic layer when completed. Apparently the pure ceramic layer behaved similarly to being bonded directly to the niobium sheaths without the intervening cermet layers.

Tape casting involves the production of thin flexible sheets of powder dispersed in a binder phase. A slurry of the powder(s) in an organic solvent with acrylic binder is formed into thin sheets with a doctor blade. When dry, these "tapes" are quite flexible. Tapes of various composition can be alternately wrapped around a niobium mandrel. The binder must then be burnt out prior to sealing the niobium sheaths for hot pressing. Acrylic binders allegedly can be decomposed completely without oxygen while leaving no residual carbon. Controlled burnout experiments at TTC, however, indicated that this was not the case. Traces of binder were always left in the powder after burnout in a non-oxidizing environment. Given the large initial concentration of acrylic necessary to produce the flexible tapes and the prospect of a certain fraction of it remaining undecomposed, this method of cermet production was not pursued further.

\section{B.2.3 Single Crystal Sapphire}

Single crystal alumina (sapphire) has an extremely high electrical resistivity and has been studied extensively. Success in the fabrication of taper seals from sapphire led to the evaluation of the possibility of using this material as the insulating layer of the sheath trilayer. Sapphire tubes machined to the proper dimensions were supplied by O'Keefe Ceramics, Woodland Park, CO. Bonding to niobium sheaths using the standard HIP cycle led to cracked insulators in the trilayers. When the niobium sheaths were etched away, the sapphire tube was heavily cracked, having a shattered appearance. It was unclear when this fracture was taking place and whether it was due to thermal stresses or directly to the applied pressure in the hot press. Additional bonding cycles were run at $1550^{\circ} \mathrm{C}$ to determine what bonding pressure might be tolerated by the sapphire. The HIP cycles were similar to that shown in Figure B-2 but with the pressure reduced to $2000 \mathrm{psi}$ and finally to only $300 \mathrm{psi}$. In all cases the sapphire 
was severely cracked after bonding. Cracking at only 300 psi bonding pressure should discount the possibility that fracture occurs during depressurization due to the differential elastic modulus. The sapphire tubes apparently could not tolerate the stresses produced by cooling from the bonding temperature.

The original sapphire crystals had been grown in a cylindrical shape but had to be machined on both the inner and outer surfaces to meet the specifications for bonding to niobium sleeves. The diamond grinding left the surfaces scratched, giving the tubes the appearance of frosted glass. Surface flaws are well known to severely weaken single crystals. Removal of surface flaws by thermal or chemical polishing has been shown to increase the strength of single crystals by up to an order of magnitude. Etched fibers have reached strengths approaching theoretical levels. Such dramatic strengthening cannot be expected for the relatively massive single crystals used for the trilayers, but even a marginal enhancement might be sufficient to allow the crystals to survive the bonding cycle. A process to etch the sapphire tubes in molten borax was developed. The excess borax was easily removed by dilute nitric acid. Tubes etched at $1000^{\circ} \mathrm{C}$ for 20 minutes became transparent although a number of etch pits were formed. Samples etched for 10 minutes and 15 minutes exhibited less severe pitting and were bonded to niobium sheaths in a standard cycle. No decrease in the density of cracks was noted for the etched crystals compared with those bonded in the as-machined condition. Again the success in fabrication of other materials led to the discontinuation of effort in this phase of the program as the down selection process progressed.

\section{B.2.4 Forming Processes}

The two primary methods of forming cylinders directly from the aqueous suspensions were slip casting and filter pressing. Slip casting is a traditional ceramic method in which a suspension is poured into a porous mold. Capillary forces draw the liquid out of the suspension leaving a layer of solid material deposited on the mold surface. As time passes, this deposited layer grows thicker. At the desired thickness, the excess slurry is drained from the center leaving a hollow tube in the plaster mold. The piece shrinks slightly as it dries allowing easy removal from the mold. Filter pressing is basically an accelerated form of slip casting in which the capillary forces are supplemented by an externally applied pressure. The filter pressing apparatus developed at TTC was essentially a punch and die set which can be loaded into a hydraulic press. The punch is hollow and has a porous metal end which contacts the slurry and acts as a filter. After pouring the slurry into the die the filter/punch is inserted and pressed in at several thousand psi. The applied pressure forces the liquid through the porous metal disk and out the hollow plunger leaving a solid cylinder of material. When all the excess liquid has been removed, the die is disassembled and the ceramic rod removed. After drying, the piece can be sintered or may be isostatically pressed to further densify prior to heat treatment.

Filter Pressing: The filter pressing process was initially developed to form rods from highly viscous slips which were unsuitable for slip casting. Pieces slip cast from very viscous slips tend to crack during drying, so an alternative forming process was needed. At this point 
YAG was being produced by mixing yttria and alumina powders together in stoichiometric proportions. After the high temperature processing, the materials were reacted to form the single phase garnet. The yttria powder used in the early stages of this program could not be formed into low viscosity suspensions, so attempts to produce both yttria and YAG led to high viscosity slips. Later in the program a sinterable YAG powder was acquired, and the need to react yttria and alumina was eliminated. This powder was found to form fluid slips quite readily.

The filter pressing method described above was generally able to produce viable ceramic cylinders, but the results were mixed. Cermet materials were also filter pressed after ball milling the ceramic and niobium powders together. The green density of the filter pressed rods tended to be the same as for slip castings of the same material, i.e. approximately $43 \%$ for yttria, $60 \%$ for YAG (from YAG powder) and $55 \%$ for alumina cermets. The densities of the pressed pieces were essentially proportional to the original solids content of the slips with YAG readily forming a 50 volume percent solids slip while yttria slips could be produced with only about $30 \%$ solids content. The green density of the cylinders was increased in some cases by isostatic pressing of the dried piece. After sintering, the rods could be machined to form the tubes necessary for trilayer bonding. Trilayers formed by this method showed the same general trends as those fabricated by other methods. Pure alumina trilayers were always cracked after bonding, alumina/ $\mathrm{Nb}$ cermets were often intact, yttria trilayers never cracked and YAG trilayers were also always cracked with the cermets showing reduced cracking compared with the pure ceramic. No correlation between the green density of the original casting and the ultimate results could be found.

After it became apparent that filter pressing offered no advantage over slip casting, the process was abandoned in favor of casting. Filter pressing has a number of disadvantages compared with slip casting although both utilize the same starting materials and preparation of the slip. Even though filter pressing is an accelerated process, it is still much slower than slip casting. The water removed from the filter pressing must all be removed through the end of the punch which has a very small area while a casting has water removed over the entire mold surface. The water must also pass through the already deposited material which for the filter pressing is the entire length of the rod but is only the wall thickness of a hollow casting. A casting will form in approximately 3-5 minutes while a filter pressing can take over an hour. This large forming time is of particular concern for the cermets. The high density of niobium will eventually lead to segregation by gravity. The effects of this tendency will be dependent upon the slip viscosity and the size and shape of the niobium particles, but the problem is best avoided by minimization of the forming time. The filter pressing time could be significantly reduced by increasing the area of the filter. Attempts to filter press using an isostatic press and a porous metal tubular filter were unsuccessful as the pressed piece could never be removed from the filter without breaking.

Slip casting was also preferred from a practical point of view. Many plaster molds can easily be made and as many castings as desired formed at one time from a batch of slip. Filter pressings had to be made one at a time as only one automatic hydraulic press was available. 
A fraction of the slip was removed from the mill and vacuum de-aired while the remaining slip continued to mill as the first piece was pressed. In this manner, a batch of four filter pressings could take an entire day to fabricate with each subsequent cylinder having more accumulated milling time as a slip. Slip casting was also more consistent with viable castings forming with nearly every attempt. The filter pressing technique often failed when either the porous metal filter plugged up or the finely milled particles came out with the liquid. Maintenance and repair of the filter pressing apparatus was also substantial compared with the simplicity of slip casting.

Slip Casting: The majority of the successful trilayers fabricated in this program were formed by slip casting. This method could be used to form cylinders of all three candidate materials, with or without the niobium particles to create cermets. The mechanical advantage of adding niobium to alumina is quite apparent from Figure B-1 and Table B-1. Some of the early cermets contained large amounts of the large niobium spheres as previously described. When the mechanical property data were obtained, the superiority of irregularly shaped, finer particles was apparent and the use of spheres was abandoned. The large spheres also presented a greater probability of niobium segregation during processing as the settling rate of particles in a given fluid is proportional to the square of the diameter. After this time, the cermet fabrication program concentrated on materials containing $5 \%$ and $10 \%$ niobium powder by volume. The ten percent addition of powder nearly maximized the bond and matrix strengths but was believed to be marginal from an electrical standpoint. Addition of five volume percent niobium was expected to show little tendency to short circuit but still significantly strengthen the material.

A number of ceramic powders were tested at various times in the program for their ability to form suitable slips. Different powders were found to behave very differently when forming aqueous suspensions. The powders used for most of the slip casting experiments described here were the best found for slip casting and are the same as those listed in the dry pressing section with the exception that additional types of niobium powders were tested as the program progressed. All three ceramic materials were formed by ball milling the powders in water using Darvan $\mathrm{C}$ as a dispersant. Darvan $\mathrm{C}$ is an aqueous solution of an ammonium polyelectrolyte marketed by L.T. Vanderbilt Co., Norwalk, CT. This organic dispersant is often chosen when deflocculants containing alkali metals are considered undesirable. Some of the early alumina slips had an addition of $2 \%$ yttria to reduce the viscosity, but this practice was stopped when it was suspected that reactions involving the yttria might be leading to the formation of pyrophoric niobium dust which caused electrical short circuits on the ends of the trilayers.

The preferred compositions of the slips were found by experimentation and reference to slip casting literature. Too low solids content in the slip often leads to cracking as the casting dries. As more solids are incorporated into the slip, higher concentrations of deflocculant are needed to maintain low viscosity. Higher solids content slips also tend to cast to a higher green density. The compositions of the slips are therefore a compromise between the casting and drying properties and possible contamination from high deflocculant 
concentration. Each material was able to form a fluid slip at very different solids concentration while keeping the concentration of the dispersant solution at less than 5 milligrams per gram of ceramic powder. The Trans-Tech YAG powder formed the densest slips with 50 volume percent powder forming a fluid suspension with about $3 \mathrm{mg}$ Darvan $\mathrm{C}$ per gram YAG. Alcoa's A-39 SG powder formed 43 volume percent solid slips at approximately $4.4 \mathrm{mg} / \mathrm{g}$ while the Molycorp yttria powder could be incorporated at only about $27 \%$ at similar dispersant concentration. Alumina slips with $50 \%$ solids could easily be produced, but the necessary Darvan concentration increased dramatically. Cermets containing 5 or 10 volume percent (solids basis) niobium powder could be formed from each of these powders using similar dispersant concentrations based upon the weight of the ceramic component.

Of the three candidate materials, yttria appeared to be the most compatible with bonding to the niobium sheaths. Even though only about 30 volume percent powder could be incorporated into the slip and the as-cast green density was only $43 \%-45 \%$, the slip cast tubes could be processed into final trilayers. A solid casting technique was developed in order to allow the cast cylinders to be isostatically pressed to a higher green density. Instead of draining the liquid from the mold to form a hollow cylinder, additional slip was continuously supplied to the mold from a reservoir until a solid cylinder was cast. By pressing the cylinder after drying, the green density could be increased to nearly $60 \%$. Little difference could be seen between the drain cast and the solid cast samples with a little more shrinkage occurring during bonding of the lower density hollow cast specimens. Due to the ease of manufacture, drain casting of hollow tubes became the standard process. The drying process for the solid cast cylinders was a particular problem with many samples cracking.

After the standard bonding cycle, the yttria layer was fully dense and crack-free. The consistent production of uncracked yttria trilayers was believed to be due to exceptionally good agreement between the thermal expansion coefficients of niobium and yttria over the temperature range of the bonding cycle (up to $1550^{\circ} \mathrm{C}$ ). Yttria/ $\mathrm{Nb}$ cermets could also be produced but were made in very limited quantities since the mechanical enhancement of the niobium inclusions did not seem necessary and such additions can only reduce the electrical resistivity which for yttria is not nearly as high as for YAG or alumina. The yttria cermets were also crack-free and did indeed exhibit lower high temperature resistivity than the pure yttria trilayers. Development of yttria trilayers at TTC was discontinued when the electrical tests indicated that the material always broke down after some time at high temperature with an applied voltage.

Pure YAG and YAG/Nb cermets were readily formed by slip casting. These castings had very good green density due to the high solids content of the slips. Trilayers containing a pure YAG layer always exhibited large numbers of radial cracks after bonding. This cracking occurred when using pre-reacted YAG powder as well as when mixing alumina and yttria to form the garnet. The method of forming the original ceramic structure (slip casting, dry pressing, plasma spray, etc.) appeared to have little or no influence on the outcome. The different bonding cycles were also ineffective in eliminating the cracks. Production of YAG cermets containing 10 volume percent niobium powder reduced the number of cracks in a 
typical trilayer, but not a single crack-free specimen was ever bonded. When bonded at 1300 ${ }^{\circ} \mathrm{C}$, the YAG cermets showed very few cracks but were not fully dense. The same batch of starting material bonded at $1550^{\circ} \mathrm{C}$ were fully dense but contained many more cracks. This indicated that there was probably a problem at high temperature. Thermal expansion data acquired during this program showed that the thermal expansion coefficient of YAG matched that of niobium at moderate temperatures but appeared to be increasing rapidly above $1400{ }^{\circ} \mathrm{C}$. This mismatch was believed to be the cause of the cracking. As the trilayer cooled, the YAG layer contracted more rapidly than the inner niobium sheath tube creating a tensile hoop stress in the ceramic.

Cladding the YAG in a material of higher thermal expansion would create very different stresses than those created by niobium. YAG specimens bonded to vanadium using the standard cycle were very different. Instead of the usual radial cracks extending through the thickness of the ceramic layer, the material contained circumferential cracks apparently created by the inner vanadium sheath trying to contract away from the YAG layer as it cooled. Bonding YAG between an outer vanadium sheath and an inner niobium sheath led to both modes of failure. Both circumferential and radial cracks were seen in these specimens. The stresses created by thermal mismatch can be quite substantial with niobium appearing to be a reasonable but not quite good enough match with YAG. Niobium is the collector material for the thermionic converters so it must be used for the inner sheath of the trilayer. The best prospects for a YAG trilayer with niobium sheaths appears to be a $10 \%$ cermet, but the final assembly will probably contain a few cracks unless further refinements of the bonding cycle can reduce the thermally induced stresses.

\section{B.2.5 Alumina Cermet Development}

Most of the cermets fabricated into final trilayers were alumina containing 5 or 10 volume percent niobium powder produced by slip casting. When vacuum fired to approximately $1250{ }^{\circ} \mathrm{C}$, the cast cermet cylinders were about $65 \%-70 \%$ dense and could be machined into thin walled tubes using carbide tools. After the mechanical advantage of adding irregular powders rather than spheres became clear, all cermets were produced incorporating niobium powder and the spheroidization and separation process was abandoned. Initially the niobium powder was obtained by separating the less than 10 micrometer fraction from the asreceived powder as previously described. No particle size analysis is available for this powder. An example of a $10 \% \mathrm{Nb}$ cermet using this powder was shown in Figure D-3B. Numerous alumina cermets were cast containing this powder. Most of these cylinders were for process development purposes, but at least thirteen (five $10 \% \mathrm{Nb}$ and eight $5 \% \mathrm{Nb}$ ) were bonded to niobium to produce trilayers. With the ends cut off to expose the layered structure, the specimens were ground and polished with diamond paste to examine for cracks, porosity, etc. Among the specimens examined from this group of cermets, not a single crack was seen in the as-bonded condition. All trilayers exhibited very high resistance at room temperature after the ends were removed and polished. It was found, however, that grinding the $5 \% \mathrm{Nb}$ trilayers on a coarse diamond impregnated bronze wheel could create cracks. No cracks were seen prior to grinding on this wheel, and more cracks were seen as the specimens were further ground. 
Cracks were seen on all samples that were ground in this manner and on no other specimens. It is unknown whether this grinding would also crack the $10 \% \mathrm{Nb}$ cermets and its use was discontinued. Generally, the cermets produced from this $\mathrm{Nb}$ powder could be considered crack-free in the as-bonded state.

Figure B-4 illustrates the type of cracks seen in the bonded trilayers. Such radial cracks are the only type noted in alumina or cermet trilayers; circumferential cracks or separation of the ceramic-to-metal bond wer not seen in niobium-clad sheaths. The only circumferential cracking ever seen in the as-bonded condition was in attempts to bond to vanadium sheath tubes. This type of cracking, while not desired, should offer minimal impedance to heat transfer and is indicative of the nature of the stresses induced during the bonding cycle.

The use of larger, but still irregularly shaped particles, was investigated when the availability of powder from which to extract the fine fraction became questionable. Niobium powder which had previously had the less than ten micrometer fraction removed by air elutriation was sieved through 500 mesh. The resulting powder should have been primarily between 10 and 31 micrometers although no size analysis was performed. Several dozen alumina cermets containing 5 and 10 volume percent of this powder were slip cast. Eighteen of these castings were fabricated to the bonded trilayer stage, only one of which was $5 \% \mathrm{Nb}$. Several of these trilayers were fabricated with $\mathrm{Nb} / 1 \% \mathrm{Zr}$ sheaths rather than the standard pure niobium. An example of a $10 \%$ niobium cermet with this larger powder is shown in Figure B-5. The particles are notably larger than in the previously presented micrographs.

The cermet layers bonded to the $1 \%$ zirconium sheaths were all cracked after the bonding procedure with typically 2-4 radial cracks seen on each polished end. One crack was noted in one of the $10 \% \mathrm{Nb}$ cermets bonded to pure niobium sheath tubes while all others appeared uncracked. The single $5 \%$ niobium cermet produced with this $\mathrm{Nb}$ powder contained a larger number ( $>6$ ) cracks. One $10 \%$ specimen was found to be short circuited at room temperature after bonding. A one millimeter long section cut from the end of this trilayer was a short circuit as was the next $4 \mathrm{~mm}$ long section. After removing a total of about 5 millimeters from one end of the trilayer, the remaining length was $10^{10}$ ohms or greater at room temperature. This type of failure may be attributable to segregation of the large niobium particles during the slurry stage of the fabrication process. If the particles did indeed settle significantly during the casting process, the bottom end of the casting would have a higher concentration of niobium particles with the additional particles tending to be the largest in the mixture. The ends of the casting were not indexed so it is uncertain whether the short circuited end of the trilayer was the top or the bottom of the casting. No as-bonded short circuits were found when the finer niobium particles were included, so attributing this behavior to the larger particle size would appear to be reasonable. The mechanical results using the larger powder were similar to those with the finer powder. Both powders could be easily incorporated into the slip by ball milling and the resulting slurry cast into hollow cylinders. After sintering and machining, the cylinders could be bonded to niobium sheath tubes with few or no cracks.

Electrical testing was indicating that cermets with the finer niobium powder were 
probably more stable at high temperature, so new sources for the fine powder were sought. A batch of niobium powder promised to be less than ten micrometers was ordered from Hermann C. Starck Berlin, GmbH. When received, the powder was documented as having a Fisher SubSieve Size (FSSS) of 5.6 micrometers. A batch each of 5\% and 10\% niobium in alumina cermets were slip cast. Two bonded trilayers of each composition were produced. No cracking was noted for any of these trilayers, but one of the $10 \%$ specimens was shorted at room temperature similarly to the specimen containing the larger niobium particles. The short circuited section of the trilayer was found to be within one-tenth of an inch from the end, again indicating possible segregation of the niobium particles. Microscopic examination of this lot of "fine" niobium powder (H.C. Starck lot 090490) showed a significant number of large particles to be present.

The niobium powder was passed through a 400 mesh ( 37 micrometer) sieve to remove the largest particles. About 90 weight percent of the powder passed the sieve. Examination of the two sieved fractions showed that the largest particles were indeed removed. A particle size analysis (laser diffraction) of the sieved powder is shown in Figure B-6. A significant fraction (25\%) is seen to be 20 micrometers or larger. This sieved powder was used to slip cast alumina cermets with both five and ten percent $\mathrm{Nb}$ addition. Two $10 \%$ and six $5 \%$ samples were bonded to produce trilayers. Examples of cermets produced using this sieved powder are shown in Figure B-7. Of the specimens polished for microscopic examination, one of four $5 \%$ niobium samples was cracked while both $10 \%$ trilayers were fully intact. These results continued the trend that alumina cermets containing ten percent niobium powder survive the bonding process without cracking, while five percent niobium cermets tend to exhibit a few cracks in some fraction (less than one-half) of the bonded specimens. Subsequent electrical testing indicated that the ten percent niobium cermets were stable at $1300 \mathrm{~K}$ for only a few hours with $7.5 \mathrm{Vdc}$ applied. A source of truly fine niobium powder was sought in an attempt to return to the favorable electrical behavior seen in the earlier cermets containing the finest niobium particles.

The same supplier (H.C. Starck) agreed to provide niobium powder to be $100 \%$ less than 25 micrometers and $95 \%$ less than 10 micrometers. Upon receipt, this powder (lot 151090) was microscopically examined. A number of large particles in the 25 micrometer range were seen, but the number was not too great and the powder generally appeared considerably finer than the previous lot 090490 . The particle size distribution for this new lot of powder as determined by laser diffraction is shown in Figure B-8. The powder is distinctly finer than the previous lot. shown in Figure B-6. Nearly $90 \%$ of the particles are 10 micrometers or less and only a few percent are greater than 20 micrometers. About 75 cylinders of alumina cermets containing this powder were slip cast. Sixteen $5 \% \mathrm{Nb}$ and thirteen $10 \% \mathrm{Nb}$ trilayers were completed through the bonding stage.

Eleven trilayers of each composition were polished and examined for cracks. Examples of trilayers containing $\mathrm{Nb}$ lot 151090 are shown in Figures B-9 and B-10. The niobium particles appear to be finer than those in any of the other cermets produced. The dispersion of the particles looks very uniform with good particle separation, especially in the $5 \% \mathrm{Nb}$ 
specimens. One of the $5 \% \mathrm{Nb}$ specimens was found to have one crack after bonding and all others were intact. After an outgassing procedure at $1250^{\circ} \mathrm{C}$, three more of the $5 \% \mathrm{Nb}$ trilayers were seen to have 1-3 cracks on the ends. All three of the trilayers that cracked during outgassing were bonded in a single HIP run while three other $5 \%$ trilayers cast from the same batch of slip but HIP'ed separately survived both bonding and outgassing uncracked. Apparently an occurrence during TTC HIP Cycle 276 created unusually high stresses in the trilayers during the bonding cycle. Comparison of the HIP records to those from HIP Cycle 277 which produced three intact $5 \% \mathrm{Nb}$ cermet trilayers from the same slip batch revealed no obvious event that might account for the difference. The hot press was operated manually, so there were always cycle-to-cycle variations although the nominal cycle was kept constant. The nominal bonding cycle is apparently marginal for producing $5 \% \mathrm{Nb}$ cermets with relatively minor variation resulting in all the samples cracking rather than all samples remaining intact. The mechanical results using this niobium powder were similar to other fine niobium powders. Ten volume percent addition of niobium powder to alumina leads to uncracked trilayers while $5 \%$ addition produces weaker trilayers which are often intact but contain a few cracks in many cases.

Near the end of the program, several alumina slip castings were produced containing 7.5 and 14 volume percent niobium powder from lot 151090 which was quite successful at the $10 \%$ level. The fourteen percent addition was to press the limit of niobium inclusion without short circuiting, while the $7.5 \%$ was to test the strengthening (as determined by cracking) of an intermediate niobium content. Five trilayers of $7.5 \%$ composition and two $14 \%$ specimens were eventually bonded. The seven and one-half percent samples were uncracked in the asbonded condition. Only one of these specimens was outgassed and tested. Both fourteen percent trilayers were less than five ohms at room temperature as bonded. One of these trilayers was cut into eleven sections approximately $5 \mathrm{~mm}$ long each. Eight of these sections exhibited less than $100 \mathrm{ohms}$ each at room temperature while the other three sections were each greater than $2 \times 10^{7} \mathrm{ohms}$. The high resistance sections were from the center portion of the trilayer indicating that the short circuiting was probably not due to concentration of the niobium by gravimetric segregation. The large area of low resistance suggests that fourteen percent niobium addition is simply too much to disperse safely by ball milling in an aqueous slip.

\section{D.2.6 Other Materials}

A number of materials beside the original three candidates and their cermet analogues were fabricated for testing as sheath insulators at TTC. Many of these were ceramic/ceramic composites. The goal was to reinforce a ceramic matrix by inclusion of a second ceramic phase (powder or fibers) much as the niobium particles strengthen the cermet matrices but without the potential electrical side effects of the inclusion of conducting particles. The results of much of this work are summarized in the TTP final report, Ref. B-2.

The addition of chromium oxide (chromia, $\mathrm{Cr}_{2} \mathrm{O}_{3}$ ) to $\mathrm{YAG}$ was seen to greatly strengthened the material, but crack-free composite trilayers were never produced. Some of 
the strongest materials tested were alumina with silicon nitride $\left(\mathrm{Si}_{3} \mathrm{~N}_{4}\right)$ added. This material was not pursued strongly in the TFE-VP program due to probable incompatibility of the silicon containing material with the cesium vapor environment.

Aluminum oxynitride (AlON) was considered promising due to its spinel structure which tends to be very resistant to radiation damage. Fully dense AlON tubes were supplied by Raytheon Corporation, Lexington, MA. This material was found to need a platinum barrier between itself and the niobium sheaths in order to not break down quickly during electrical testing. The AlON layer often shattered during the bonding cycle leading to abandonment of this material as possible sheath insulator. $\mathrm{YAG} / \mathrm{Nb}$ cermet trilayers were seen to crack considerably less than pure YAG, but even the near maximum addition of $10 \%$ niobium could not eliminate cracking totally. Since chromium oxide additions had been shown to strengthen YAG, a ternary mixture of YAG, chromium oxide and niobium powder seemed a very viable candidate. Cylinders of this composition were slip cast, but the castings tended to be more fragile than other types. No samples of this type were ever processed as far as bonding to form sheath trilayers. Ternary mixtures of alumina, chromia and niobium were also slip cast but again never reached the state of bonded trilayers.

\section{B.2.7 Conclusions}

The development of fabrication processes for the three candidate materials was generally quite successful. The fabrication of high niobium content cermets by coating spheres in wax and fine alumina powder, i.e. the 1960's technology, could never be consistently reproduced. Cermets containing lesser quantities of finer, irregularly shaped niobium particles were shown to be stronger and tougher than the cermets with niobium spheres. Isostatic dry pressing was found to be a viable process for pure ceramic materials, but dry mixing was not adequate to blend the ceramic and niobium powders together. The resulting dry pressed cermets were found to be short circuited after bonding. Methods requiring large amounts of organic additives, such as tape casting, were concluded to be inappropriate for cermets due to probable residual contamination after vacuum firing. Single crystal alumina (sapphire) tubes could not be bonded to niobium sheaths without cracking. Attempts to strengthen the machined sapphire tubes by polishing in molten borax appeared to have no effect on the cracking.

All three of the candidate oxides could be formed into an aqueous slip as either pure ceramic or as a cermet mixed with niobium powder by ball milling the powders with water and Darvan C. The slips formed in this manner could be drain cast into hollow cylinders or could be formed into solid rods by solid casting or filter pressing. No advantage could be found to forming solid rods, so slip casting of hollow tubes was chosen as the preferred fabrication process due to its simplicity and high yield. When alumina (or alumina/ $\mathrm{Nb}$ ) castings are fired to approximately $1250^{\circ} \mathrm{C}$, the resulting material can be machined with carbide tools to form the thin walled tubes required for sheath trilayers. YAG, yttria and their cermets can similarly be machined after firing to about $1450^{\circ} \mathrm{C}$. The machining is not trivial but should be achievable by any experienced machinist with a little practice and patience. 
The standard bonding cycle illustrated in Figure B-2 was found to yield good results. All three materials were densified and bonded to the niobium sheath tubes when hot pressed to $10,000 \mathrm{psi}$ at $1550{ }^{\circ} \mathrm{C}$ in argon. The results of bonding were similar regardless of the fabrication method of the ceramic (or cermet) cylinder. Yttria trilayers always survived the process without cracking, probably due to excellent agreement of thermal expansion coefficients. Addition of niobium to form yttria cermets appears unnecessary. YAG and $\mathrm{YAG} / \mathrm{Nb}$ cermet trilayers always exhibit cracking during the bonding cycle with the cermets having fewer cracks. The cracking is worse at higher bonding temperature indicating that thermal expansion mismatch with niobium at high temperature is problematic. The lower bonding temperature, however, was not sufficient to fully densify the YAG/Nb layer.

The addition of niobium powder to alumina to form cermets was very successful in producing trilayer sheath insulators. Alumina/ $\mathrm{Nb}$ cermets containing five to fourteen volume percent niobium powder were slip cast and bonded to niobium sheaths. The particle size of the niobium powder was critical to the performance of the trilayers. At ten percent addition, even large niobium particle (10-31 micrometers) were rather effective in strengthening the matrix enough to survive the bonding cycle, but the electrical consequences of including larger particles at the $10 \%$ level are unacceptable with a few specimens short circuited as-bonded and others failing rapidly at high temperature under an applied voltage. At five percent niobium addition, the results were mixed. A fraction (roughly $40 \%$ ) of the specimens contained a few cracks as-bonded or developed cracks during subsequent grinding or heat treatment. The number of cracks seen in any specimen was rather low, typically one to five. The five percent $\mathrm{Nb}$ cermets appeared to have superior electrical stability at high temperature and were never found to be short circuited in the as-bonded state regardless of the type of niobium powder used. Cermet trilayers containing fourteen percent niobium particles were short circuited as bonded with multiple conduction paths in each trilayer. A limited number of $7.5 \% \mathrm{Nb}$ cermets indicated that this composition survives the bonding process uncracked.

The best alumina cermets were produced using the finest niobium powder. Not a single crack was ever noted for a $10 \% \mathrm{Nb}$ cermet when using the finer niobium powders, i.e. the original air classified powder or either of the Starck lots. A very effective particle size distribution was that shown in Figure B-8 for the Hermann C. Starck niobium powder lot 151090. A somewhat coarser niobium powder (Starck lot 090490) illustrated in Figure B-6 had similar efficacy in the reduction of cracking, but samples produced with this powder exhibited unstable electrical behavior.

\section{B.3 ELECTRICAL TESTING AT TTC}

While most of the ex-reactor electrical testing of the trilayer sheath insulators was performed at Rasor Associates, a number of specimens were electrically tested at TTC. These tests were often short term and were used primarily as screening tests to determine which types of specimens warranted long term, more accurate testing at RAI. Some specimens were briefly tested as proof testing prior to use as samples for in-reactor tests such as UCA and the IFACSI test vehicle. The test specimens were prepared as simple trilayer cylinders rather than 
having machined guard rings like the ex-reactor samples at RAI. The straight cylinders were easier to prepare and measure and could later be machined to various geometries for use as collectors or in-core test specimens. While the lack of guard rings might allow electrical conduction mechanisms in addition to bulk conduction, the measured resistance values will always be equal to or lower than the true bulk resistance of the trilayer. As a result, no poor insulators could be interpreted as acceptable due to the lack of surface guard rings.

The lengths of the test specimens were typically between 0.75 and 2.0 inches. The thickness of the insulating layer also varied from sample to sample, so the resistivity values were not known precisely. The data are therefore reported as resistance in ohms with the resistivity in ohm-cm typically $500 \mathrm{~cm}$ times the reported resistance. The trilayers were heated internally by a concentric tungsten tube which was electron bombardment heated by an internal filament. Temperatures were monitored by optical pyrometry of the outer $\mathrm{Nb}$ sheath and/or by thermocouples wire wrapped to the outer sheath. Substantial temperature gradients occurred along the length of the longer specimens due to the heating method, so the test temperatures must be considered nominal values.

Two bombardment heaters were mounted inside a glass bell jar which was evacuated to the $10^{-7}$ torr range during the tests. The system was pumped only by sorption and ion pumps to avoid the possibility of contamination from pump oils. The inner niobium sheaths of the specimens were grounded to the system by niobium spacer rings which isolated the outer sheath of each sample. A $7.5 \mathrm{Vdc}$ power supply was connected to the each specimen by a tantalum wire wrapped around the outer sheath. The current through each trilayer was monitored as the voltage drop over a resistor in series with the test article. This resistor was typically $100 \mathrm{ohms}$ and limited the current to $75 \mathrm{~mA}$. For a high resistance sample the current was very low and the full 7.5 volts was applied across the trilayer. Lower resistance specimens, however, would have somewhat less than $7.5 \mathrm{Vdc}$ applied due to substantial voltage drop across the series test resistor.

The results of the electrical testing at TTC are summarized in Table B-2. Initially, the tests were performed near the nominal TFE operating temperature of $1100 \mathrm{~K}$. When it became apparent that real time testing for short periods might yield little useful information, the test temperature was increased to the accelerated value of about $1300 \mathrm{~K}$. Samples with a six digit prefix, i.e. the first thirteen listed in the table, were formed by filter pressing followed by isostatic pressing. The remaining samples were slip cast except for the sapphire sheaths and sample 025B-1 which was dry pressed.

It should be noted that both sapphire samples, all YAG and YAG cermet samples and samples 066-1,068-1, 068-2 and 068-3 were known to be cracked at the time of this testing. The sapphire layers were literally shattered with many cracks while each of the $5 \% \mathrm{Nb}$ cermets was seen to have 1 to 3 cracks on each polished end. The cracks do not appear to compromise the electrical stability in vacuum, but the sapphire samples were seen to have little temperature dependence of the electrical resistance, i.e. a low apparent activation energy, compared with the alumina cermet specimens. 
Testing of the filter pressed trilayers generally indicated that cermets containing 10 volume percent or more niobium spheres were unstable at high temperature and immediately or quickly went to low resistance values. Even one of the $5 \% \mathrm{Nb}$ sphere cermets was observed to fail immediately at $1100 \mathrm{~K}$. This was probably due to the initial niobium particle distribution being very nearly a short circuit as a result of settling of the large, dense $\mathrm{Nb}$ spheres during the filter pressing process. Filter pressed trilayers containing fine niobium powder exhibited much better behavior. Alumina with 5\% and YAG with $10 \%$ niobium showed stable resistance through the test periods of 14 to 22 days. Pure YAG trilayers also exhibited stable resistance for up to 47 days, but their resistance was slightly lower than that of the YAG $10 \% \mathrm{Nb}$ cermets. This result was unexpected and may have been due to the density of cracks in each type of material. The conduction mechanism may be a surface process occurring through the cracks rather than true bulk conduction. Such a mechanism could explain the relative resistance of pure YAG and YAG cermet as well as the relative temperature insensitivity of the resistance of the sapphire trilayers. The sole yttria specimen tested at TTC (025B-1) was seen to quickly degrade. Its final resistance of only 15 ohms was the lowest resistance observed for any specimen at high temperature. Similar results were found for yttria at RAI for guarded specimens.

The test results for the slip cast insulators reinforce the conclusion that the type of niobium particles incorporated in the cermet was critical to electrical stability. All alumina cermets containing 5 to 10 percent niobium powder from Starck lot 151090 or from the original lot of elutriated, less than 10 micrometer powder were stable at $1300 \mathrm{~K}$ throughout their test periods. The longest test cycle was 100 days for sample 085-1. Alumina cermets containing other niobium powder exhibited mixed electrical results. Niobium particles of nominal 10-31 micrometer size produced some cermets that were shorted at room temperature as bonded, others that degraded to low resistance at test temperature as well as specimens that were quite stable. The $10 \% \mathrm{Nb}$ cermets of the $04 \mathrm{X}$-X series (six samples tested) as well as 057-1 all failed within a few days with some failing within minutes. Other $10 \%$ cermets (056$\mathrm{X}$ ) with the same powder appeared stable as did the $5 \% \mathrm{Nb}$ cermet $054 \mathrm{~A}-1$. Two of these cermets, 056-6 and 054A-1, were among the longest tested specimens with up to 50 days at $1300 \mathrm{~K}$. Although the processing of each batch was nominally the same, there appeared to be significant batch to batch variation when using these larger niobium powders with specimens within each batch behaving similarly. It is probably possible to produce viable cermets with such powder, but the necessary process parameters are not known. Apparently, subtle differences in the process (slip viscosity perhaps) could alter the results from quite good to very poor.

Niobium powder from Starck lot 090490 showed poor results even after sieving through 400 mesh to remove any excessively large particles. The particle size distribution was shown in Figure B-6 and does not appear to be a particularly coarse powder although it does contain considerably more particles greater than 10 micrometers than does lot 151090 (see Figure B-8) which proved quite successful. Alumina cermets produced with $10 \%$ of the unsieved powder yielded one specimen short circuited as bonded, and the one sample tested at high temperature (059-2) went to low resistance very rapidly. The sieved powder gave mixed results. Two - 
specimens produced with $10 \%$ sieved powder each failed within 4 days while the only $5 \%$ specimen tested was taken off test after seven stable days at $1300 \mathrm{~K}$.

The electrical failures at high temperature were somewhat reversible. After initially degrading to a low resistance, the trilayer could be returned to high resistance by a high temperature anneal (ca. $1250^{\circ} \mathrm{C}$ ) without applied voltage. With the voltage reapplied at the test temperature, the resistance would again degrade in a short time. This cycle could sometimes be repeated several times with the degradation time decreasing each cycle. This implies that failure may be due to electrolytic migration of atoms which can be reversed to some extent by diffusion at high temperature. Low resistance "failed" samples behaved metallically with the resistance decreasing slightly when cooled. The room temperature resistance was typically one half the final value at high temperature. Attempts to isolate and examine the point failure(s) by sectioning the specimen were never successful with the failed section often being removed by the kerf of the diamond wafering blade.

Some specimens were seen to initially exhibit low resistance that could be permanently recovered by high temperature annealing in the test stand. This process must have outgassed components which could form a conductive film across the ends of the trilayer at the normal test temperature. It became standard practice to outgas the trilayers for four hours at $1250^{\circ} \mathrm{C}$ after cutting off the ends to expose the insulating layer prior to electrical testing. After this high temperature outgassing at approximately $10^{-7}$ torr, the ends of the trilayers could be seen to be covered by a film. After mechanically cleaning this film, the samples were ready for testing.

The room temperature electrical resistance was found to be an excellent indicator of cracked specimens. Room temperature resistance was measured similarly to the high temperature values except that a $10,000 \mathrm{ohm}$ resistor was placed in series with the specimen with $7.5 \mathrm{Vdc}$ applied. With a voltmeter of microvolt precision, a voltage drop across the resistor of essentially zero indicated that the sample was $10^{10} \mathrm{ohms}$ or greater. Any appreciable voltage drop could be interpreted to calculate the trilayer resistance. For uncracked trilayers, the room temperature resistance was always greater than $10^{10} \mathrm{ohms}$. Cracked specimens tended to polarize, that is, the current (voltage cross resistor) would start at some value when the voltage was applied and drop over time to a value near zero. This effect was seen to various degrees for all cracked specimens with the initial voltage varying from tens of microvolts to tens of millivolts and the time of measurable decay from seconds to hours. The magnitude of this effect was largest when the samples had been recently cleaned and rinsed but perhaps not thoroughly dried. The polarization was not seen (at least not of measurable magnitude) when the sample was at room temperature in the evacuated electrical test system. This suggests that the effect is due to moisture in the cracks. Polishing the ends of the trilayers to examine for cracks is very time consuming and appears to be unnecessary. A simple test to sort cracked trilayers could easily be developed based upon the polarization effect discussed above.

Conclusions of the ex-reactor (screening) testing can be summarized as follows. Alumina cermets containing 5 to 10 volume percent niobium particles can be readily slip cast and 
bonded into trilayers. These trilayers appear to be stable at $1300 \mathrm{~K}$ with $7.5 \mathrm{Vdc}$ applied. Yttria trilayers quickly degrade to low resistance under the same conditions. YAG and YAG/Nb cermets also appear to be electrically stable but are always cracked from the bonding process. The key to strong, stable cermets is the inclusion of the proper niobium powder. When the number of particles greater than 10 micrometers is not too great, the resulting alumina cermets have high resistivity and are stable at $1300 \mathrm{~K}$ for at least hundreds of hours. Inclusion of larger niobium particles leads to mixed results with some samples short circuited as bonded and others seemingly as stable as those with the finer particles. The precise point at which a niobium powder presents problems is unknown, but the distribution shown in Figure B-8 is greatly superior to that shown in Figure B-6. No cermet made with powder from lot 151090 was seen to degrade at $1300 \mathrm{~K}$. Cracking appears to have little or no effect upon the high temperature resistivity in vacuum but is readily detected by ambient testing.

\section{B.4 FABRICATION OF CERMET TRILAYERS}

Slip casting of aqueous slurries was chosen as the preferred method to fabricate the cermet cylinders for bonding to form trilayer sheath insulators. The alumina and niobium powders are ball milled together in water with an organic dispersant and drain cast in plaster molds. The general procedure for producing slip cast cermet trilayers is essentially the same as that for fabricating pure ceramic trilayers. The steps involved are:
1) Formulation
2) Milling
3) Casting
4) Drying
5) Firing
6) Machining
7) Encapsulation
8) Bonding
9) Rough machining
10) Outgassing

Formulating the batch consists of determining the niobium and total solids content of the slip. As discussed earlier, viable niobium content is in the five to ten volume percent range. This niobium content is based upon the final dense material, not the aqueous slip. For example, a ten percent cermet contains one part niobium powder to nine parts A-39 alumina powder by volume, or 1:4.2 by weight. The amount of water in the batch of slip is determined by the desired solids content. A total solids content of 43 volume percent was determined to produce good castings although solids contents as low as $37 \%$ appear to produce good trilayers as well. Solids contents significantly greater than $43 \%$ require disproportionately larger concentrations of dispersant. The amount of Darvan $\mathrm{C}$ required to produce a slip of suitable viscosity was found to vary from batch to batch for unknown reasons. For a $43 \%$ solids slip, an initial dispersant content of 4.4 milligram Darvan $C$ per gram of alumina powder was usually sufficient to combine the powders into a fluid slip. The addition of niobium powder did not appear to require additional dispersant. 
The powders are intimately mixed by ball milling the slip for approximately eighteen hours. Additional size reduction may also occur during this period. The mill jar volume should be about three or four times the slip volume to be milled. A $1750 \mathrm{ml}$ mill jar is suitable for approximately $400 \mathrm{ml}$ slip which is sufficient to cast six or more cylinders of TFE dimensions. The jar was filled approximately half full of three-quarter inch grinding cylinders. A convenient method to introduce the powder is to first mix the distilled water and Darvan in the jar with the grinding cylinders. About half of the mixed powder is added and the mixture milled for a few minutes. The remaining powder can be incorporated in two or three more batches, milling briefly between additions. The slip is then milled for approximately 18 hours at $60-70 \%$ of the critical speed. Critical speed for a mill jar is defined as:

$$
\mathrm{RPM}_{\text {crit }}=266 / \mathrm{SQRT}(\mathrm{D}) \quad \mathrm{D}=\text { diameter in inches }
$$

This is the angular velocity at which the grinding media do not tumble properly due to centrifugal forces and must not be approached during actual milling. At the end of this milling time the grinding cylinders should be tumbling freely, but the viscosity may need to be adjusted for casting. Experience is the best judge of proper viscosity, but the rule of thumb is that the slip should flow freely, perhaps similar to cold heavy cream. If the slip is too viscous at this point, add two or three more drops Darvan $\mathrm{C}$ and mill fifteen to twenty minutes.

Prepare the plaster molds by blocking the bottom end of the openings. A strip of wide masking tape works well. Remove the mill jar from the rollers and immediately drain the slip into a $1000 \mathrm{ml}$ beaker straining through a coarse sieve to remove any dried material which might flake off the rim of the jar. De-air the slip by evacuating in a bell jar, pumping only until the initial foaming subsides. Back-fill the vacuum system and immediately pour the slip into the prepared molds. Let cast until the desired wall thickness forms. Three to five minutes is a typical casting time, but this can vary significantly depending upon the exact condition of the slip and dryness of the molds. Additional slip may be added to the molds during casting as the fluid level drops if a long tapered section is objectionable. When the walls have cast to the proper thickness, drain the excess slip by unblocking the bottom of the molds. Dispose of the remaining slip in the approved manner. After drying in the mold for four hours, the cylinders should slip easily out of the molds when tapped on the tabletop.

The drying procedure was found to be critical to the successful production of cermets. Too aggressive drying tends to crack the green castings. These cracks are often not evident until after sintering. A generally safe drying procedure is several days at room temperature followed by several hours at $70^{\circ} \mathrm{C}$. Drying at higher temperature tends to lead to cracks. When thoroughly dry, the cylinders are ready for sintering. For alumina cermets, $1250^{\circ} \mathrm{C}$ is a good sintering temperature. At this temperature, the material gains enough strength to be machined but does not become too hard. A few percent linear shrinkage takes place during this process. The niobium tends to increase the maximum temperature at which a machinable material can be produced. A pure alumina casting fired to $1250^{\circ} \mathrm{C}$, for example, would probably be too hard to machine while a $10 \%$ cermet might be machinable as high as $1300^{\circ} \mathrm{C}$. The dry castings are placed in the vacuum furnace standing on end. Leaving the pieces under the roughing pump at room temperature for a couple of days may decrease the time needed for the heating cycle. After switching over to a diffusion pump, the cermets are slowly heated 
keeping the pressure at $10^{-4}$ torr or less. It may take as long as twenty hours to heat a large number of cylinders when keeping the pressure at this level. The final sintering temperature is held for thirty minutes and the furnace cooled at a moderate rate.

After sintering, the cylinders are examined for cracks and are ready for machining. When properly produced, the cermet cylinders can be machined using conventional carbide cutting tools without excessive wear. If the cermets are too hard, however, the tools will wear quickly and must be sharpened frequently. The first step is to turn the cylinder to fit the nearest size collet. The piece is mounted in a three jaw chuck and roughly aligned since the cylinders will be neither perfectly straight nor round. The cylinders are then bored through when snugly chucked in the collet. The boring bar should be as large and stiff as possible as chattering can result in fracture of the cermet. Working with a mandrel and sleeve, the inside and outside diameters are slowly worked down to their final dimensions. The thin walled tube is cut off to length after all other machining is complete. A layer of thin plastic shim stock is always inserted between the cermet cylinder and the sleeve or mandrel. This allows a snug fit while facilitating removal of the piece and preventing abrasion of the mandrel. The final surfaces are never touched by steel tools to prevent contamination by abrasion.

After machining, the tubes are inspected for defects such as air bubbles or agglomerates of niobium particles. Inspection at about 10-30x magnification is sufficient to detect most defects, but acceptance is largely subjective as qualities such as niobium dispersion are difficult to quantize. The accepted cylinders are then cleaned of loose particles by blowing with clean nitrogen. After assembling the cleaned cermets between inner and outer niobium sleeves, the niobium ends of the encapsulated cermet package are electron beam welded to form a hermetic assembly. The welds are leak tested by mass spectrometer He leak detection. The trilayer packages are pumped down in a bell jar to a few millitorr pressure. The chamber is then backfilled with helium and allowed to permeate the specimens. Each weld is then tested by passing over the sniffer attachment of the leak detector. No measurable He rate should be detected.

Before hot pressing, the trilayer cylinders are wrapped in a number of layers of refractory metal foils to act as sacrificial getters. After wrapping, the cylinders are loaded in the hot press and bonded with the time/temperature/pressure cycle previously described. The cylinders will be slightly out of round and perhaps not straight after bonding. After removing the getter foils, the ends of the trilayer package are cut off with a diamond wheel to expose the trilayer structure. The inner and outer surfaces are then bored and turned to nominal dimensions for possible short term electrical testing. This machining trues the surfaces and centers the insulating layer to the extent possible. With the ends of the trilayer exposed, the trilayers can be outgasses at $1250^{\circ} \mathrm{C}$ for four hours to rid them of potential surface contaminating components. Subsequent machining forms the sheaths into test specimens. 


\section{B.5 REFERENCES}

(1) Thermionic Technology Program: Fiscal Year 1986 - Final Report, Thermo Electron Corporation, DOE Contract DE-AC03-86SF15955-1, Waltham, Massachusetts, 1987.

(2) Final Technical Report: Thermionic Technology Program, Thermo Electron Corporation Report, TE4430-0190, Waltham, Massachusetts, 1990. 
Table B-1

STRENGTH AND TOUGHNESS ENHANCEMENT OF ALUMINA BY NIOBIUM PARTICLE ADDITIONS

\begin{tabular}{||c|c|c||}
\hline \hline \multicolumn{3}{|c|}{ Mechanical Properties of TTC Alumina Cermet } \\
\hline Composition & Strength & Toughness \\
\hline $0 \% \mathrm{Nb}$ & $29200 \mathrm{psi}$ & $2.87\left(\mathrm{MN} / \mathrm{m}^{3 / 2}\right)$ \\
$5 \% \mathrm{Nb}$ spheres & $32400 \mathrm{psi}$ & $3.10\left(\mathrm{MN} / \mathrm{m}^{3 / 2}\right)$ \\
$10 \% \mathrm{Nb}$ spheres & $29850 \mathrm{psi}$ & $2.58\left(\mathrm{MN} / \mathrm{m}^{3 / 2}\right)$ \\
$15 \% \mathrm{Nb}$ spheres & $30050 \mathrm{psi}$ & $2.79\left(\mathrm{MN} / \mathrm{m}^{3 / 2}\right)$ \\
$20 \% \mathrm{Nb}$ spheres & $33040 \mathrm{psi}$ & $2.71\left(\mathrm{MN} / \mathrm{m}^{3 / 2}\right)$ \\
$5 \% \mathrm{Nb}$ powder & $45680 \mathrm{psi}$ & $8.13\left(\mathrm{MNN} / \mathrm{m}^{3 / 2}\right)$ \\
$10 \% \mathrm{Nb}$ powder & $63130 \mathrm{psi}$ & $12.35\left(\mathrm{MN} / \mathrm{m}^{3 / 2}\right)$ \\
$15 \% \mathrm{Nb}$ powder & $57760 \mathrm{psi}$ & $9.01\left(\mathrm{MN} / \mathrm{m}^{3 / 2}\right)$ \\
$20 \% \mathrm{Nb}$ powder & $55870 \mathrm{psi}$ & \\
\hline
\end{tabular}




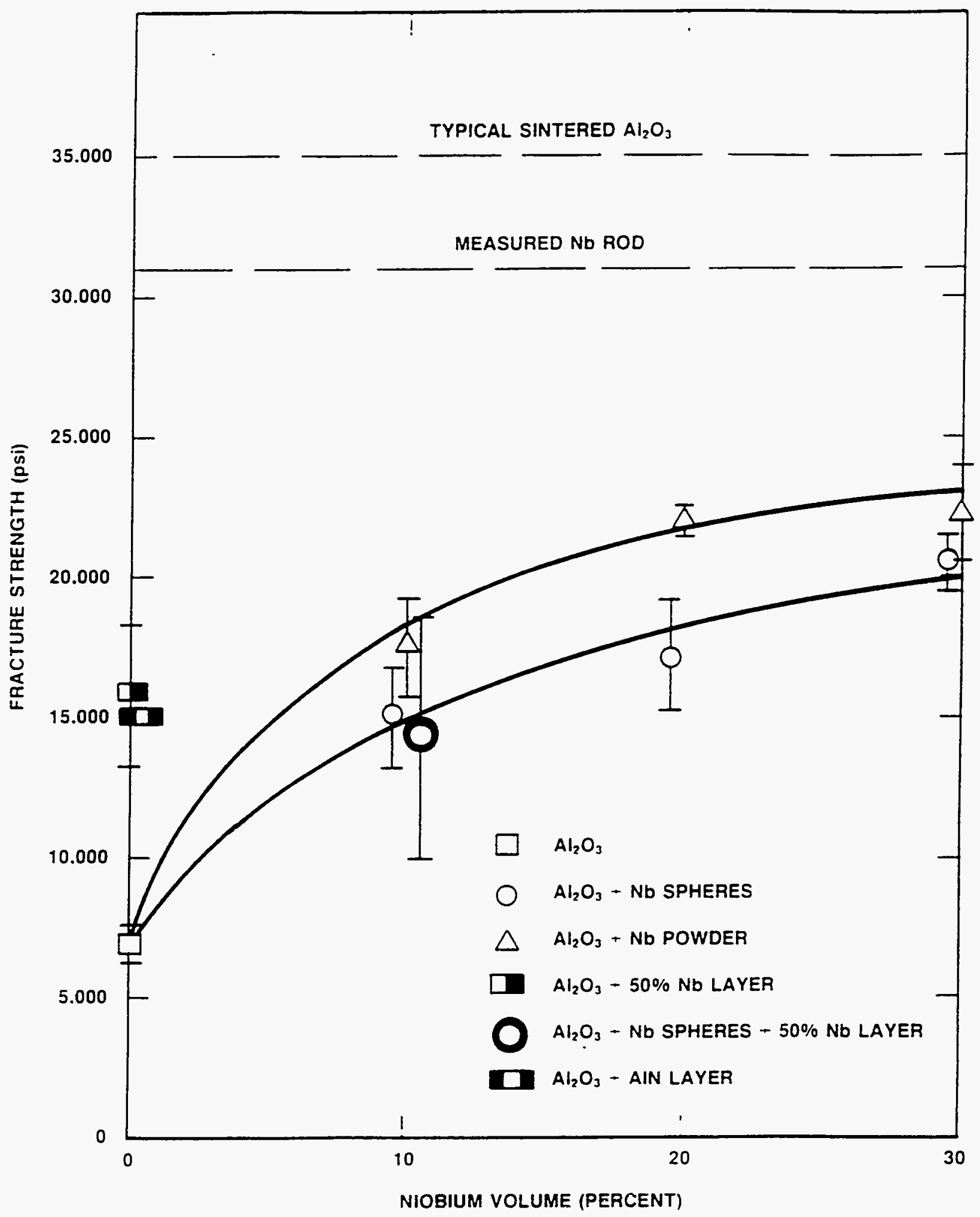

Figure B-1. Strengthening of Ceramic-to-Niobium Bond Using the Cermet Concept 


\section{NOMINAL CERMET BONDING CYCLE Heater Turned Off at Approximately 800 Minutes Pressure Bled to Ambient at Room Temperature}

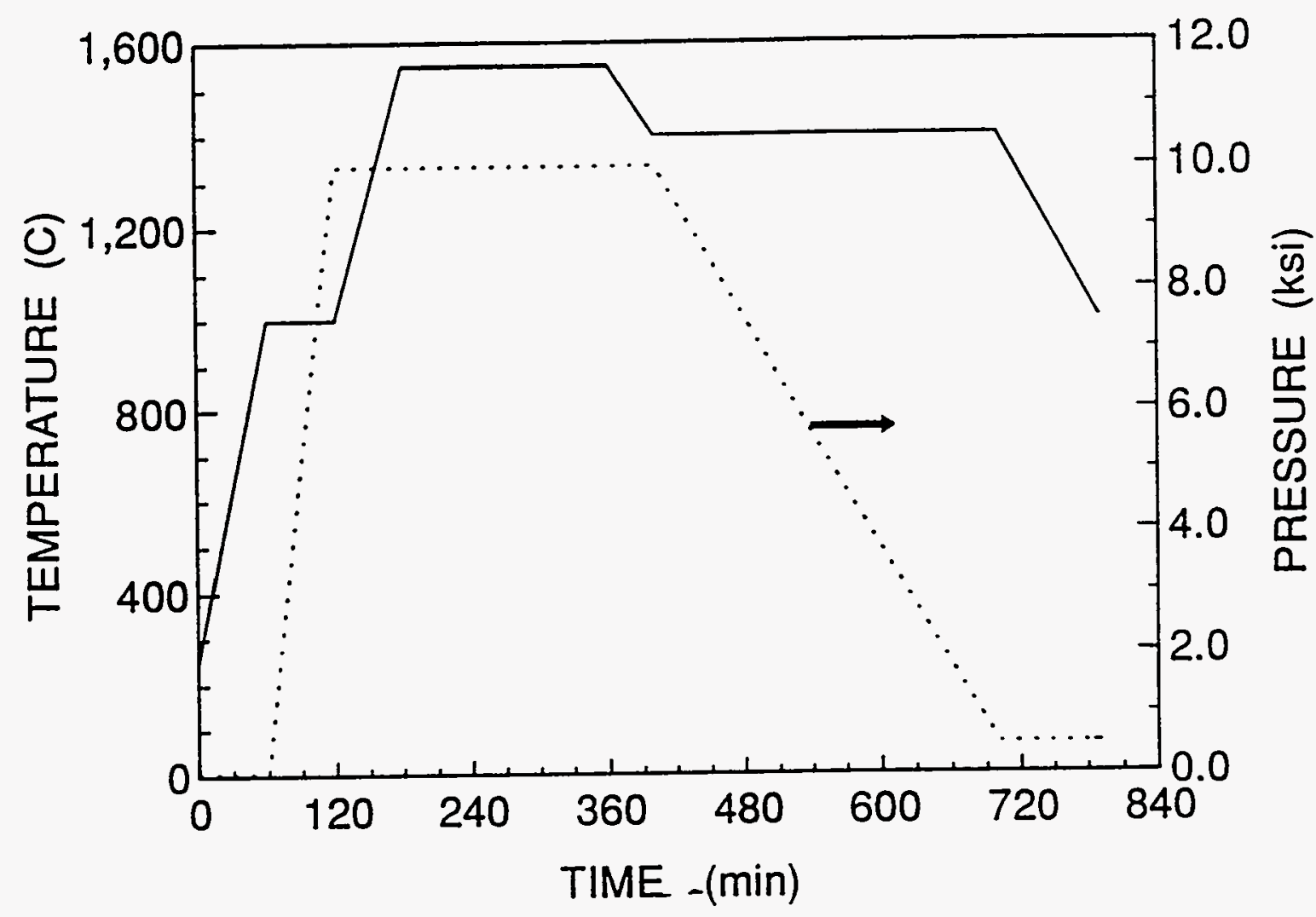

Figure B-2. Standard Bonding Cycle for Sheath Trilayers at TTC 


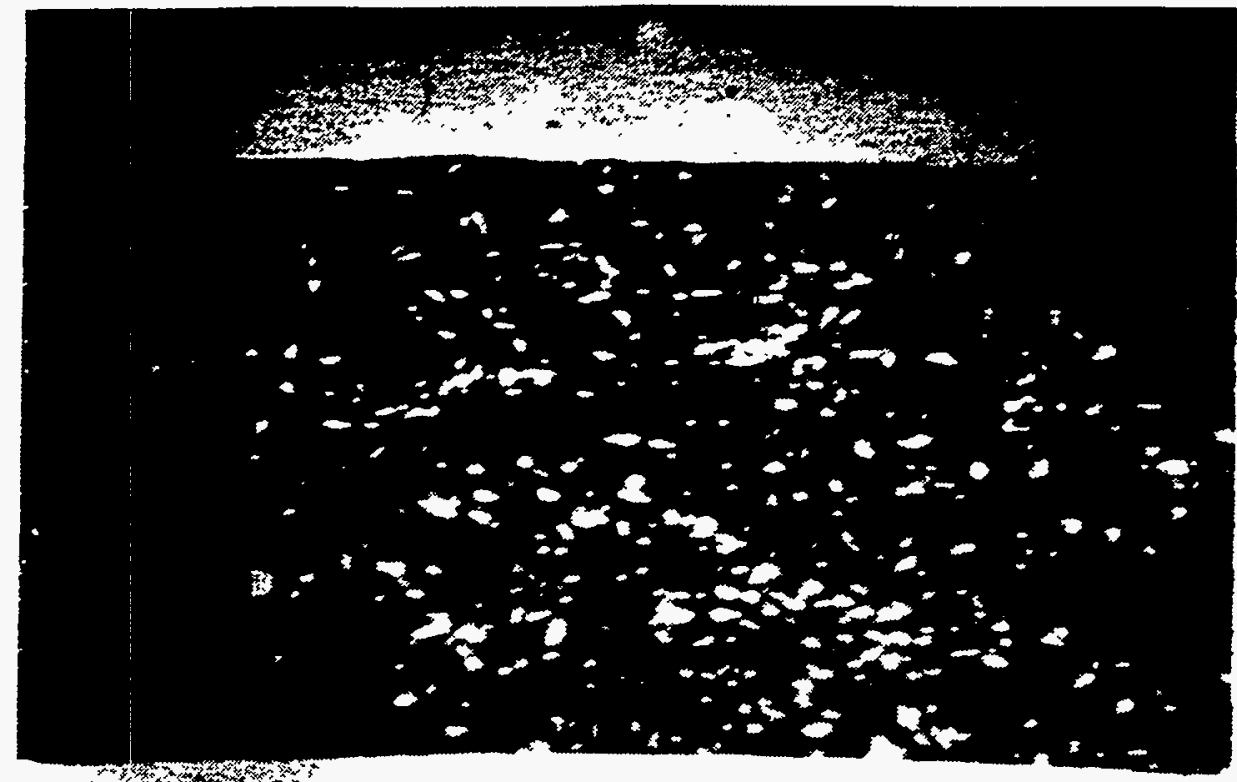

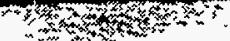
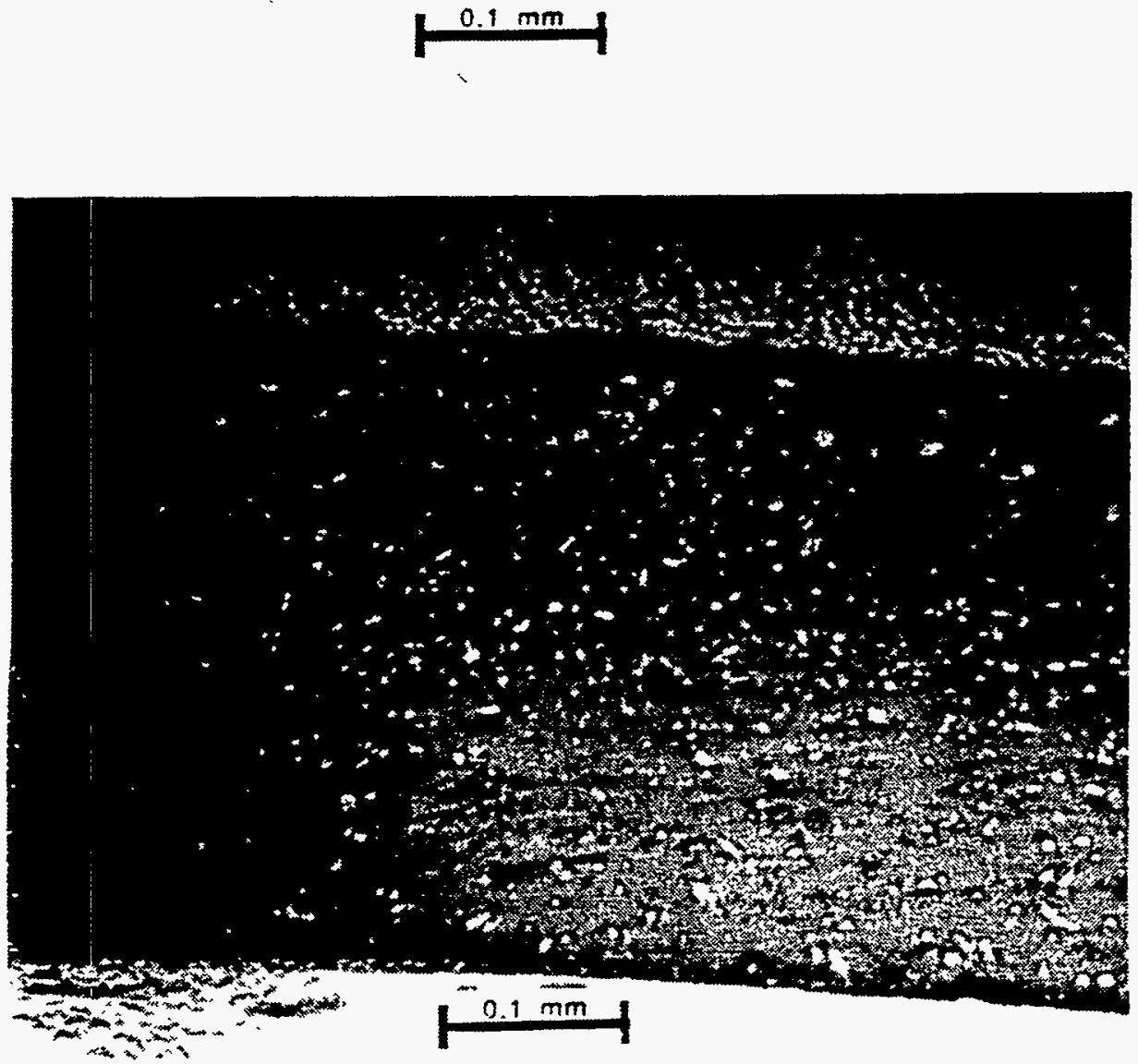

Figure B-3. Alumina Cermets with 10 Volume Percent Niobium Particles A) Dry Mixed and Pressed. B) Wet Milled and Slip Cast. Approximately $200 \mathrm{x}$. 
A

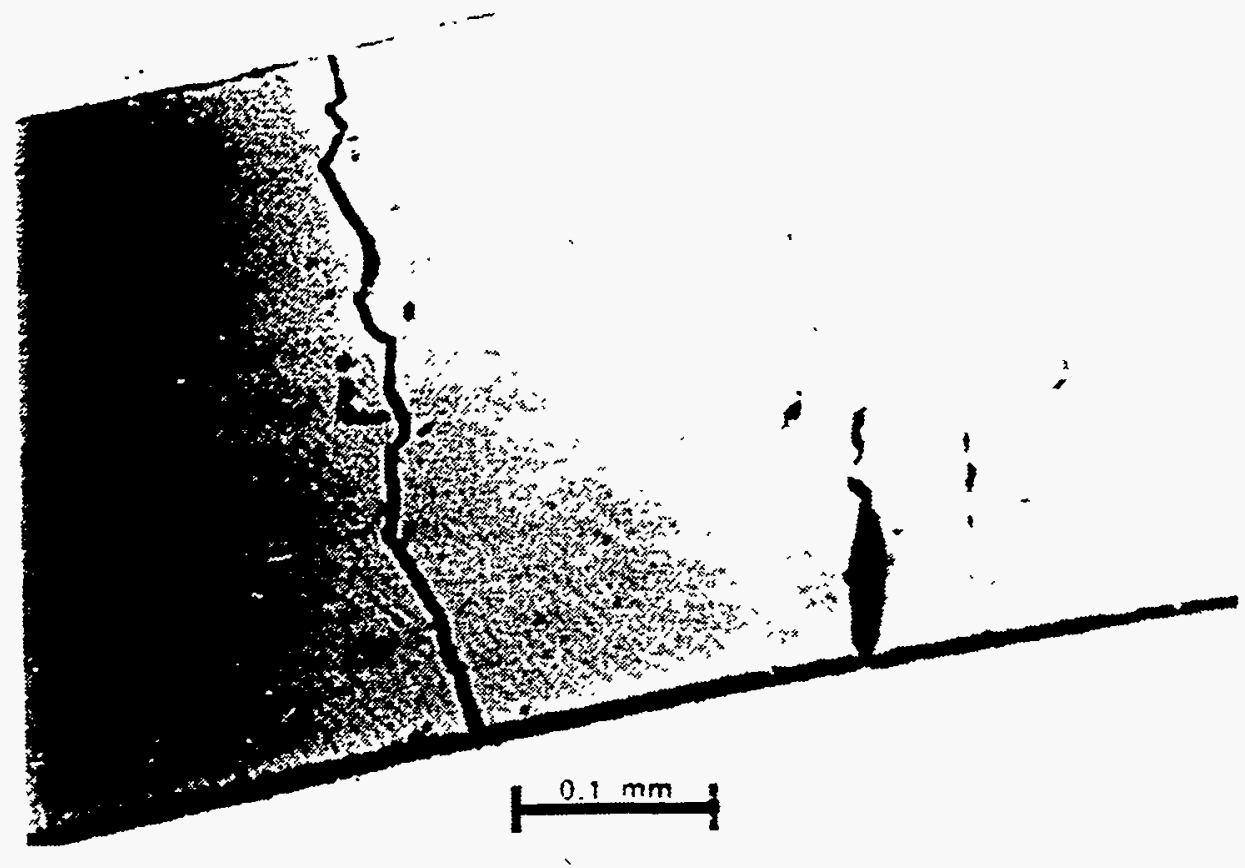

B

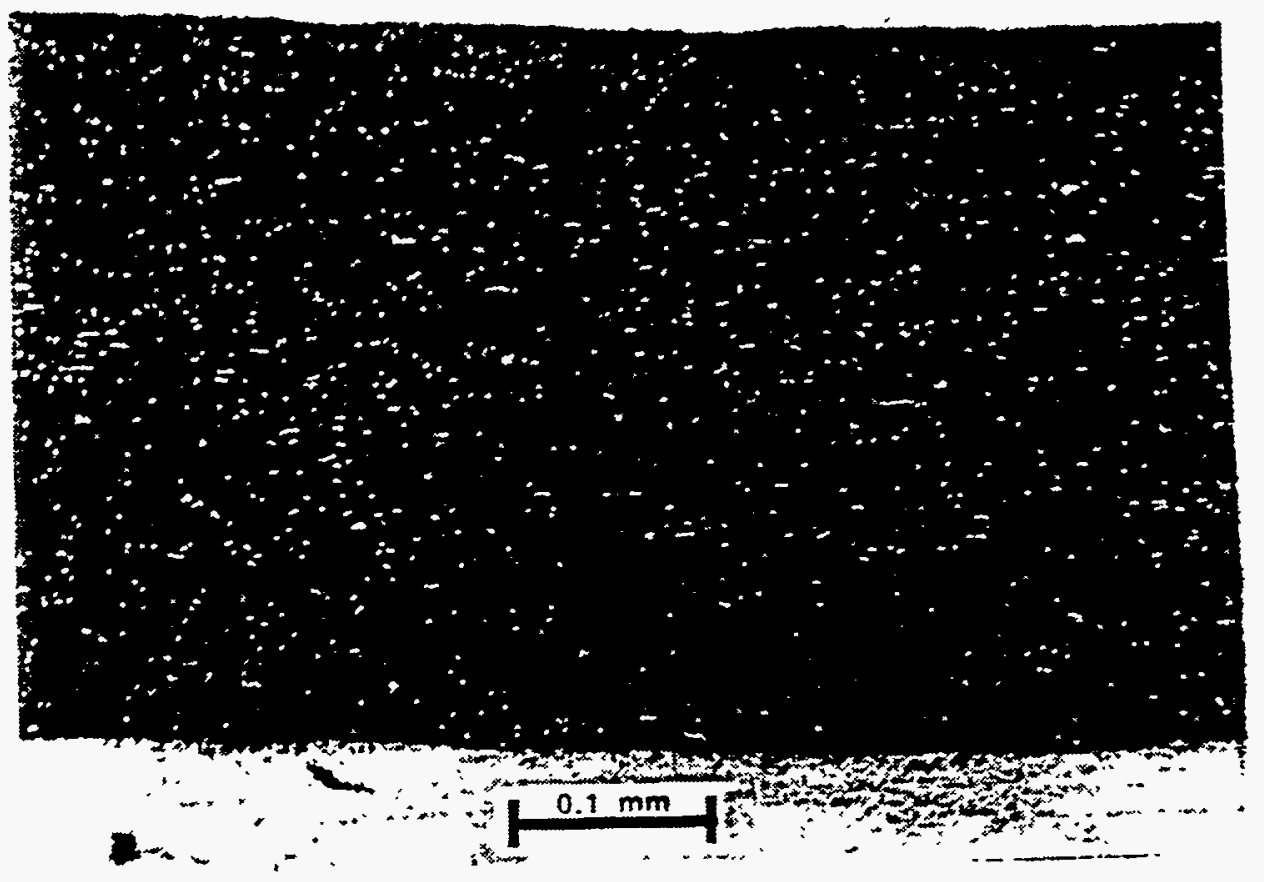

Figure B-4. Typical Radial Cracks Seen in Niobium-Clad Trilayer Sheaths. A) Pure Alumina. B) Alumina with $5 \%$ Niobium. Approximately 200x. 


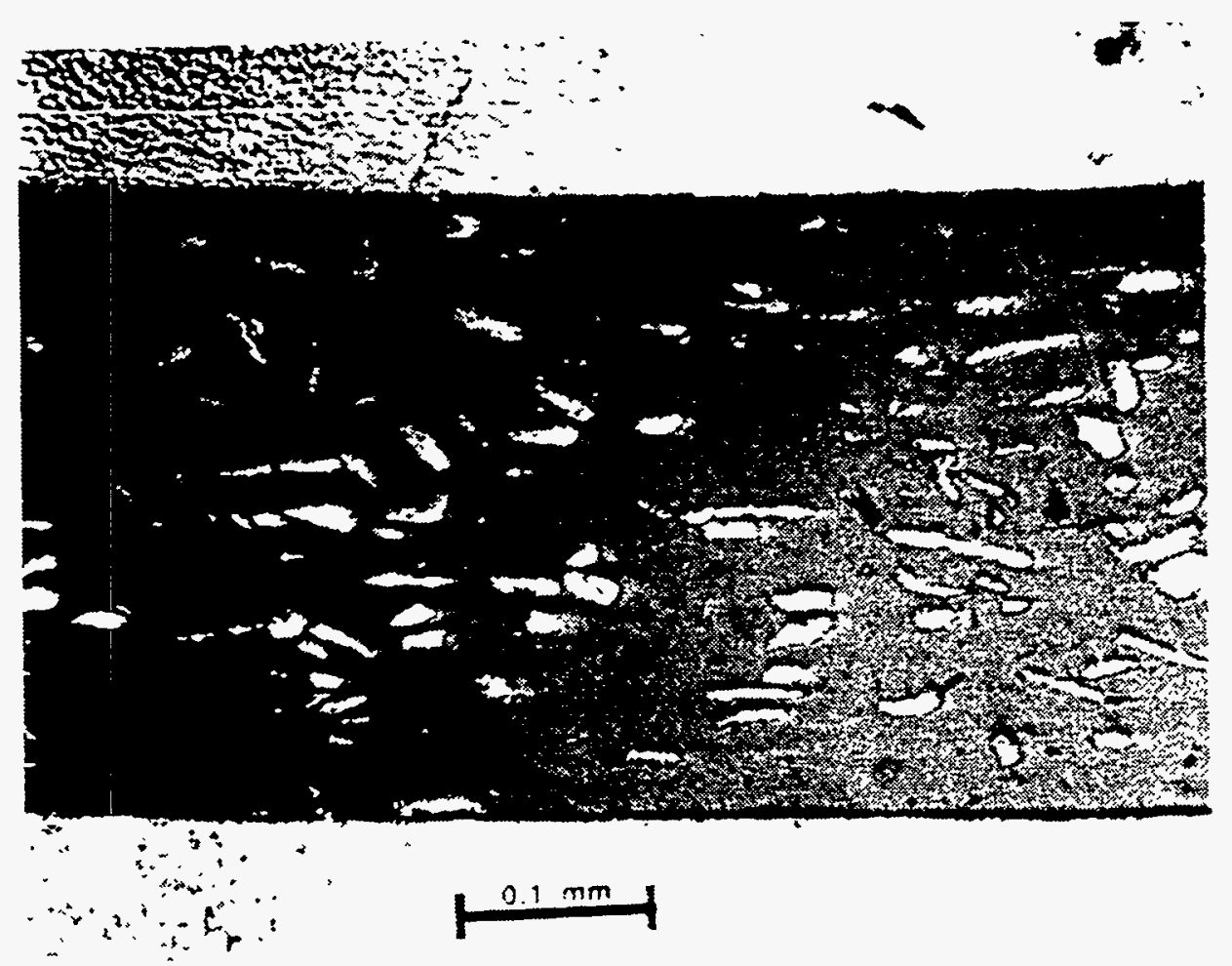

Figure B-5. Alumina Cermet Containing 10 Volume Percent Large Niobium Particles. Approximately 200x.

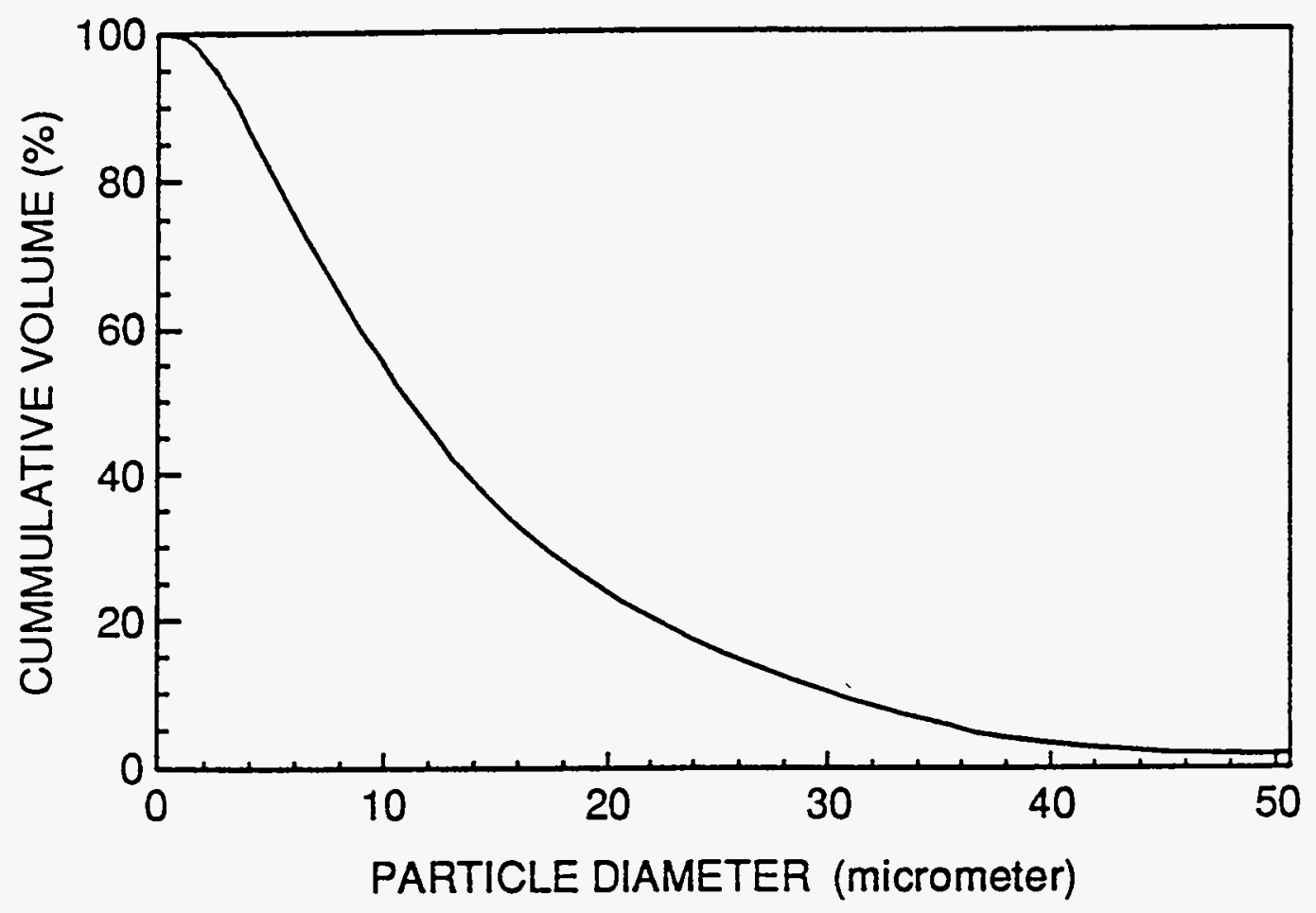

Figure B-6. Particle Size Analysis of Niobium After Sieving Through 400 Mesh 

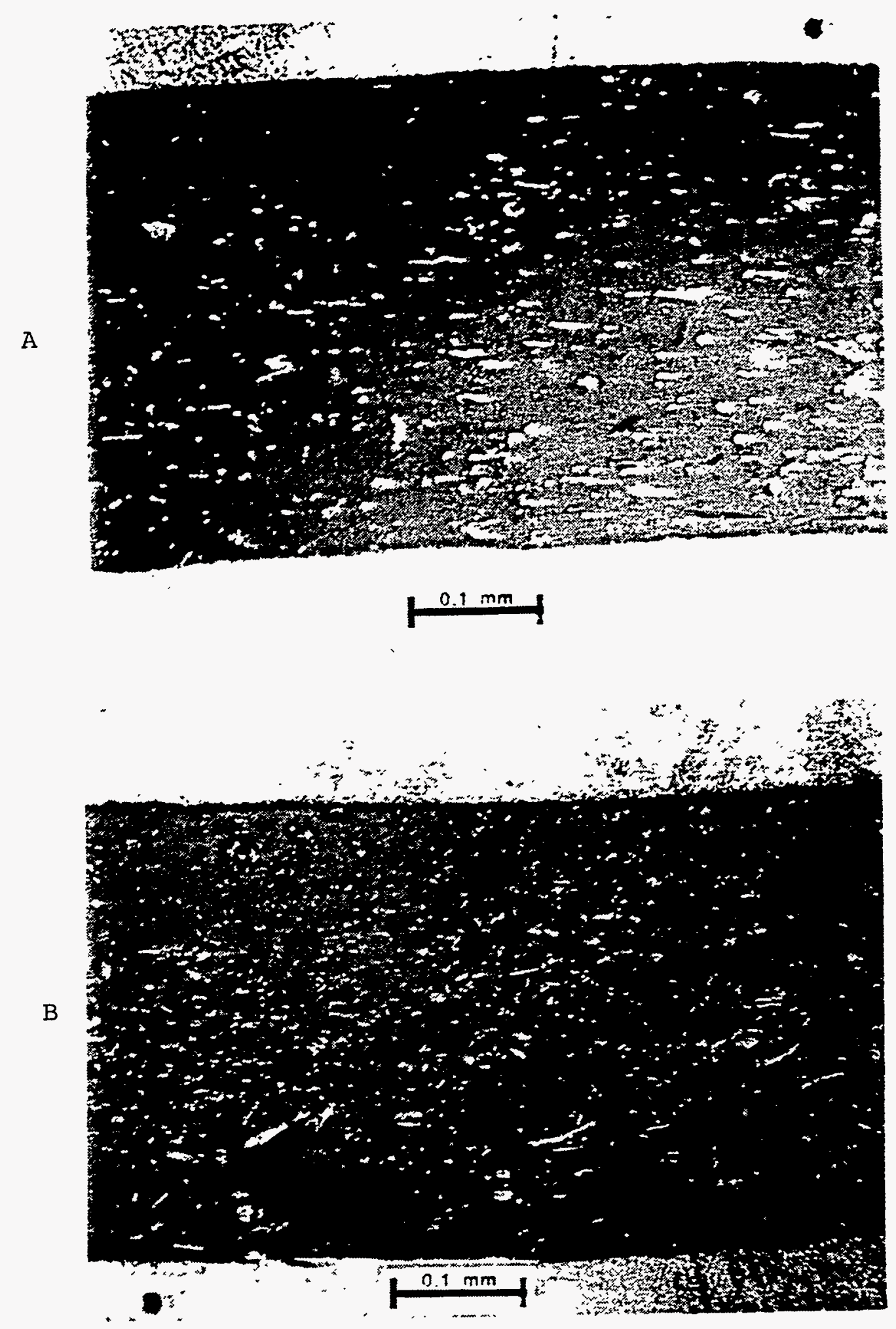

Figure B-7. Alumina Cermet Trilayers Made with Niobium Powder Lot $\# 090490$. A) $5 \% \mathrm{Nb}$. B) $10 \% \mathrm{Nb}$. Approximately $200 \mathrm{x}$. 


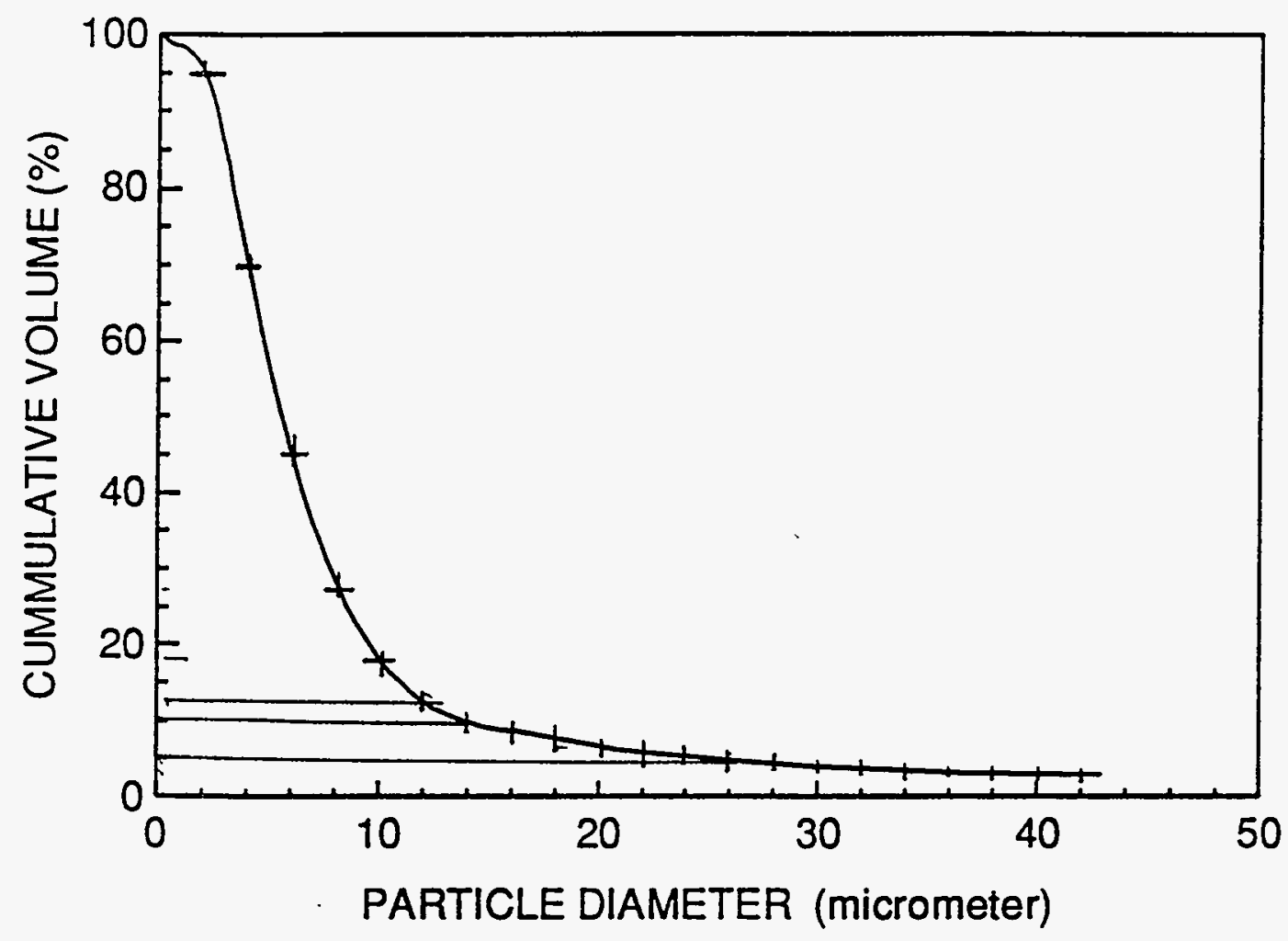

Figure B-8. Particle Size Analysis of Niobium Lot \#151090 

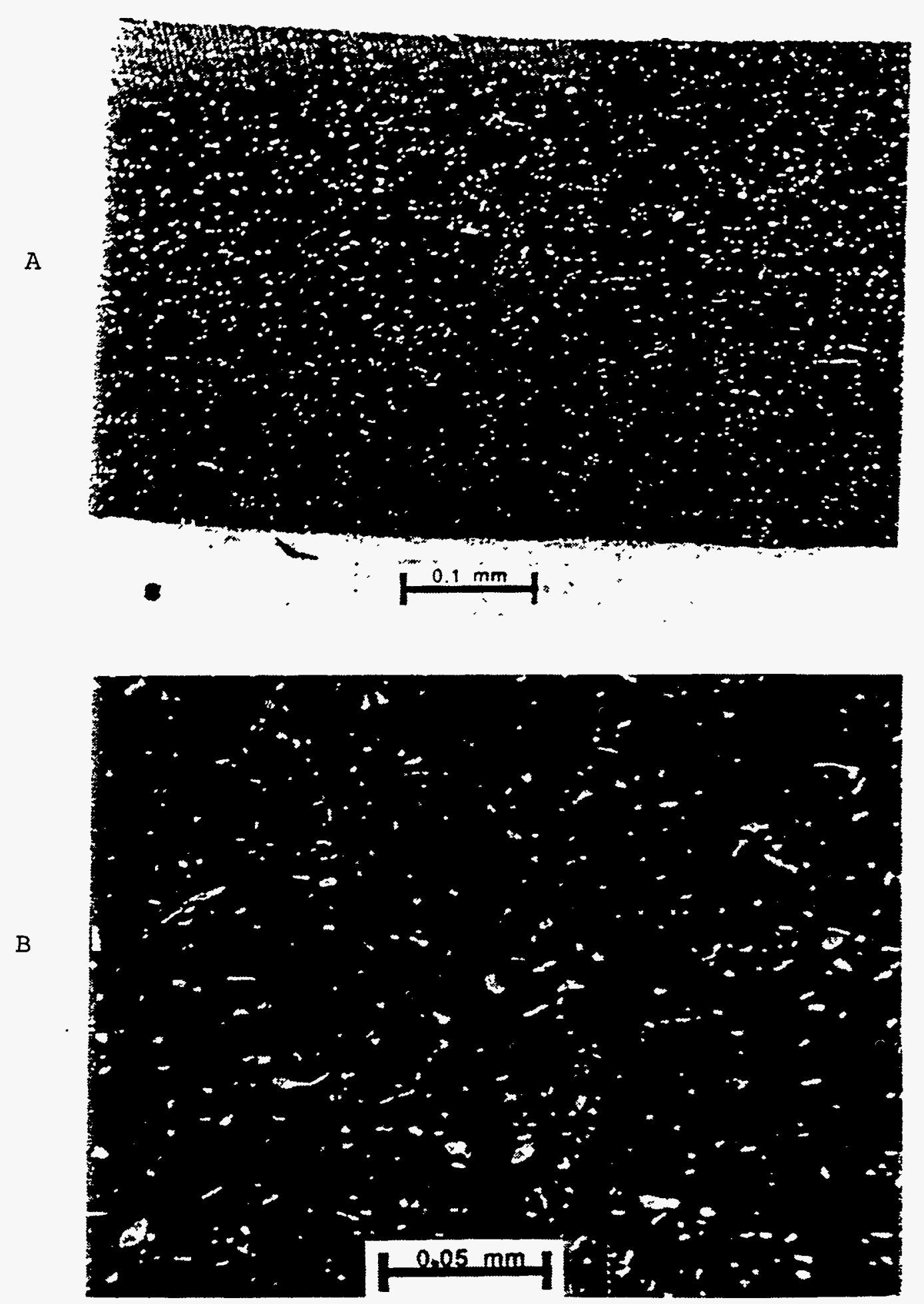

Figure B-9. Alumina Cermet Containing Five Volume Percent Niobium Lot \#151090 A) Approximately 200x. B) Approximately 520x. 

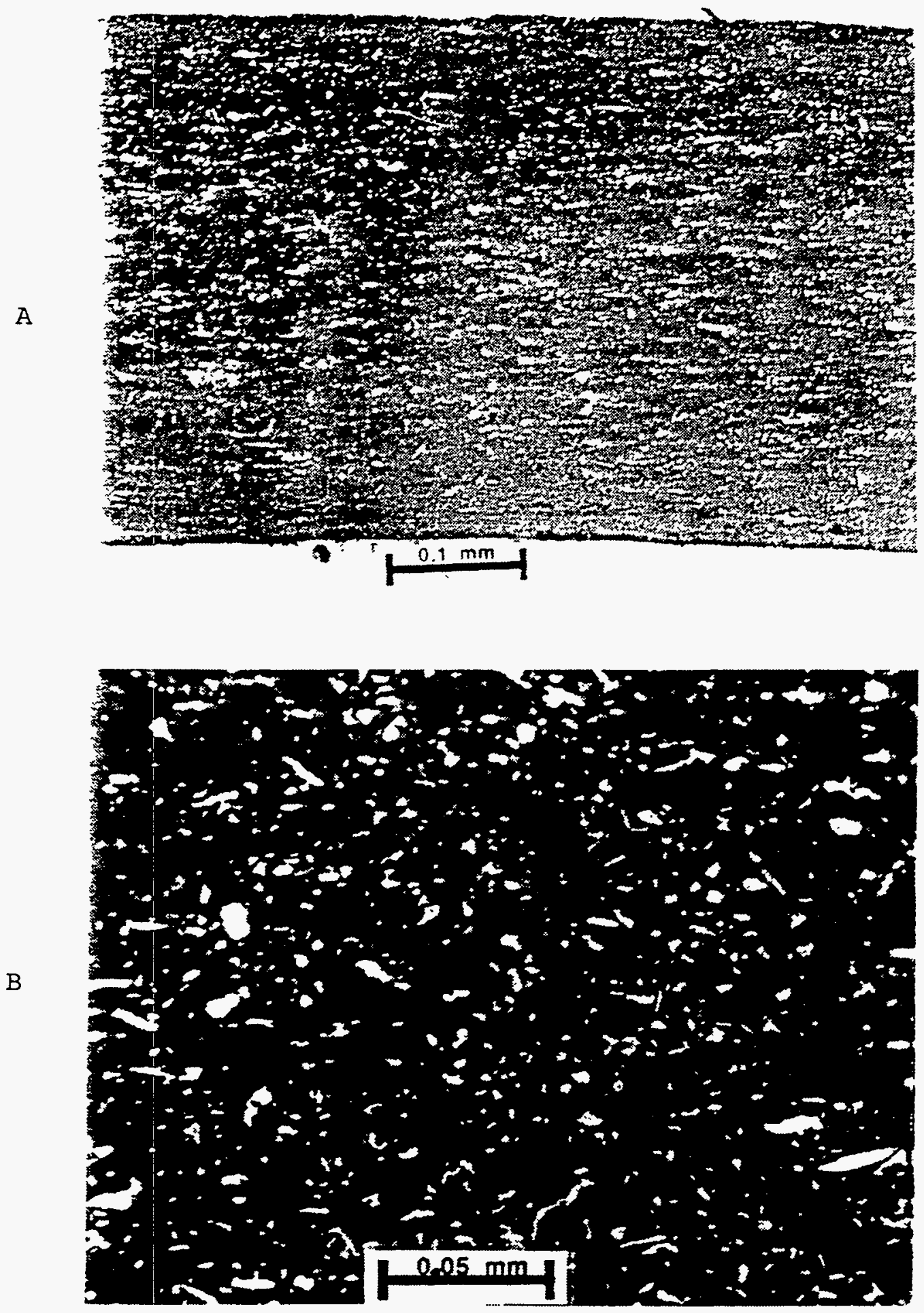

Figure B-10. Alumina Cermet Containing Ten Volume Percent Niobium Lot \#151090. A) Approximately 200x. B) Approximately 520x. 
Table B-2

$\omega$

\begin{tabular}{|c|c|c|c|c|c|c|}
\hline & & ALL TRILAYER TESTS & AT TTC WERE & PERFORMED AT $7.5 \mathrm{Vdc}$ & & \\
\hline & & & & FINAL & APPARENT & \\
\hline & & TEST & TEST & TEST TEMPERATURE & ACTIVATION & \\
\hline SAMPLE \# & COMPOSITION & TEMPERATURE (K) & TIME (hrs) & RESISTANCE (ohms) & ENERGY (eV) & COMMENTS \\
\hline \multirow[t]{2}{*}{ 101188-01A } & Alumina 5\% Niobium Cermet & 1090 & 170 & $1.3 \mathrm{ES}$ & & Test terminated \\
\hline & Large Niobium Spheres & & & & & \\
\hline \multirow[t]{2}{*}{ 101188-01B } & Alumina 5\% Niobium Cermet & 1090 & 1 & 165 & & Immediate failure \\
\hline & Large Niobium Spheres & & & & & \\
\hline \multirow[t]{2}{*}{ 102788-01 } & Alumina 5\% Niobium Cermet & 1100 & 530 & $2.6 \mathrm{ES}$ & & Test terminated \\
\hline & \multicolumn{2}{|c|}{ Less Than 10 Micrometer Niobium } & & & & \\
\hline \multirow[t]{2}{*}{$110788-01$} & Alumina $10 \%$ Niobium Cermet & 1090 & 530 & $\leadsto 2.9 \mathrm{ES}$ & & Test terminated \\
\hline & \multicolumn{2}{|c|}{ Less Than 10 Micrometer Niobium } & & & & \\
\hline \multirow[t]{2}{*}{$111488-01$} & Alumina $10 \%$ Niobium Cermet & 1090 & 38 & N/A & & Failure. Resistance not recorded \\
\hline & Large Niobium Spheres & & & & & \\
\hline \multirow[t]{2}{*}{$111688-01 \mathrm{~A}$} & Alumina $15 \%$ Niobium Cermet & 1090 & 1 & 1200 & & Immediate failure \\
\hline & Large Niobium Spheres & & & & & \\
\hline
\end{tabular}




\begin{tabular}{|c|c|c|c|c|c|}
\hline \multirow[t]{2}{*}{$111688-01 \mathrm{~B}$} & Alumina $15 \%$ Niobium Cermet & 1100 & 1 & 2300 & Immediate failure \\
\hline & Large Niobium Spheres & & & & \\
\hline \multirow[t]{2}{*}{$111688-01 \mathrm{C}$} & Alumina $15 \%$ Niobium Cermet & 1080 & 150 & 4200 & Terminated. Low, stable resistance \\
\hline & Large Niobium Spheres & & & & \\
\hline \multirow[t]{2}{*}{ 111688-01D } & Alumina $15 \%$ Niobium Cermet & 1120 & 1 & 300 & Immediate failure \\
\hline & Large Niobium Spheres & & & & \\
\hline \multirow[t]{2}{*}{ 050189-01 } & YAG $10 \%$ Niobium Cermet & 1100 & 336 & $8.8 \mathrm{E} 4$ & Test terminated \\
\hline & \multicolumn{2}{|c|}{ Less Than 10 Micrometer Niobium } & & & \\
\hline \multirow[t]{2}{*}{ 050189-02 } & YAG $10 \%$ Niobium Cermet & 1090 & 336 & $1.3 \mathrm{E} 5$ & Test terminated \\
\hline & \multicolumn{2}{|c|}{ Less Than 10 Micrometer Niobium } & & & \\
\hline 051089-01 & YAG & 1100 & 336 & $2.2 \mathrm{E} 4$ & Test terminated \\
\hline 051089.02 & YAG & 1090 & 1130 & $3.4 \mathrm{E} 4$ & Test terminated \\
\hline Sapphire 1 & Single Crystal Alumina & 1250 & 750 & $3.0 \mathrm{E} 6$ & Very little temperature dependence \\
\hline Sapphire 2 & Single Crystal Alumina & 1250 & 750 & $3.0 \mathrm{E} 6$ & Very little temperature dependence \\
\hline \multirow[t]{2}{*}{ 021B-1 } & Alumina $10 \%$ Niobium Cermet & 1300 & 450 & 9.0E5 & Test terminated \\
\hline & \multicolumn{2}{|c|}{ Less Than 10 Micrometer Niobium } & & & \\
\hline
\end{tabular}




\begin{tabular}{|c|c|c|c|c|c|c|}
\hline & & & & & & \\
\hline & & & & & 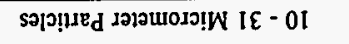 & \\
\hline \multirow[t]{2}{*}{ 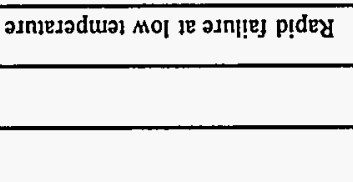 } & & $00 \mathrm{I}$ & $\mathrm{I}$ & $00 \mathrm{II}$ & 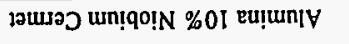 & $39-060$ \\
\hline & & & & & Sэ|ग!มี & \\
\hline \multirow[t]{2}{*}{ 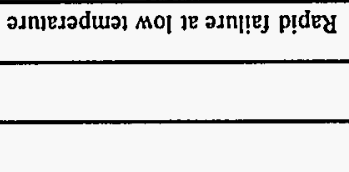 } & & $00 \varepsilon$ & $I$ & 0011 & 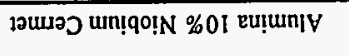 & 89-010 \\
\hline & & & & & 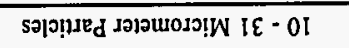 & \\
\hline \multirow[t]{2}{*}{$\begin{array}{ll}\text { ant!ey } \\
\end{array}$} & & 081 & 001 & 00\&I & 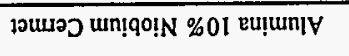 & $\tau \cdot 0+0$ \\
\hline & & & & \multicolumn{2}{|c|}{ 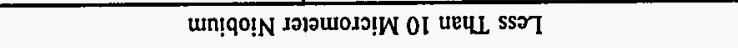 } & \\
\hline \multirow{2}{*}{ 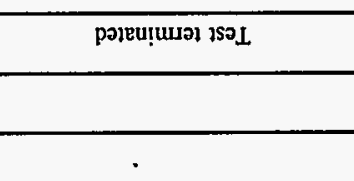 } & & $\$ 90.6$ & OSt & OOEI & 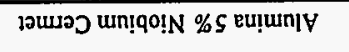 & $\forall Z-6 £ 0$ \\
\hline & & & & \multicolumn{2}{|c|}{ 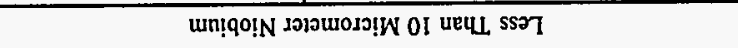 } & \\
\hline \multirow[t]{2}{*}{ 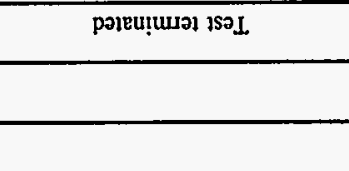 } & & $990^{\circ} I$ & 005 & 0821 & 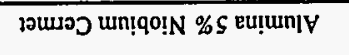 & $\forall \downarrow \varepsilon 0$ \\
\hline & & & & \multicolumn{2}{|c|}{ 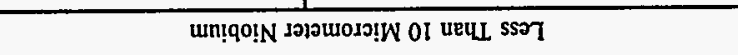 } & \\
\hline 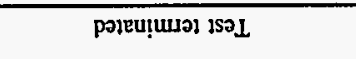 & & $9 \mathrm{~g} 0^{\circ} \mathrm{S}$ & 005 & 0ॄ£ı & 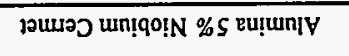 & $\mathrm{I}-\varepsilon \varepsilon 0$ \\
\hline \multirow[t]{2}{*}{ ann!ए:y } & & SI & $\mathrm{ZI}$ & 0821 & 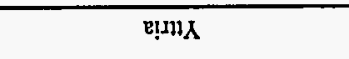 & $\mathrm{I}-\mathrm{gsz0}$ \\
\hline & & & & \multicolumn{2}{|c|}{ 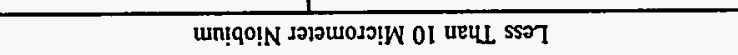 } & \\
\hline 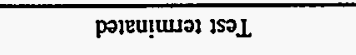 & & $\$ 90^{\circ} \mathrm{L}$ & 0st & 0โદI & 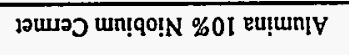 & $z-9120$ \\
\hline \multirow[t]{3}{*}{ SLNaWWOJ } & 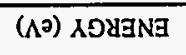 & (surप0) JDNVISISGY & (S」Y) $\exists W I L$ & 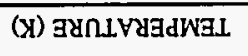 & NOLLISOdWOJ & HETdWVS \\
\hline & NOLLVALכV & IXกIVAGJWWGL LSEL & ISAI & ISGI & & \\
\hline & INGYYddY & TVNII & & & & \\
\hline
\end{tabular}




\begin{tabular}{|c|c|c|c|c|c|}
\hline $041-1$ & Alumina $10 \%$ Niobium Cermet & 1300 & 64 & 43 & Failure \\
\hline & $10-31$ Micrometer Particles & & & & \\
\hline \multirow[t]{2}{*}{$043 \mathrm{~A}-1$} & Alumina $10 \%$ Niobium Cermet & 1100 & 24 & 275 & Failure \\
\hline & $10-31$ Micrometer Particles & & & & \\
\hline \multirow[t]{2}{*}{ 043A-2 } & Alumina $10 \%$ Niobium Cermet & 1300 & 4 & 60 & Rapid failure \\
\hline & 10-31 Micrometer Particles & & & & \\
\hline \multirow[t]{2}{*}{$054 \mathrm{~A}-1$} & Alumina $5 \%$ Niobium Cermet & 1300 & 1100 & $2.0 \mathrm{E} 6$ & Test terminated \\
\hline & 10 - 31 Micrometer Particles & & & & \\
\hline \multirow[t]{2}{*}{$056-3$} & Alumina $10 \%$ Niobium Cermet & 1100 & 240 & $2.0 \mathrm{E} 7$ & Test Terminated \\
\hline & $10-31$ Micrometer Particles & & & & \\
\hline \multirow[t]{2}{*}{$056-6$} & Alumina $10 \%$ Niobium Cermet & 1300 & 1200 & $7.0 \mathrm{E} 5$ & Test Terminated \\
\hline & $10-31$ Micrometer Particles & & & & \\
\hline \multirow[t]{2}{*}{$057-1$} & Alumina $10 \%$ Niobium Cermet & 1300 & 24 & 150 & Failure \\
\hline & 10 - 31 Micrometer Particles & & & & \\
\hline \multirow[t]{2}{*}{$059-2$} & Alumina $10 \%$ Niobium Cermet & 1300 & 1 & 82 & Rapid Failure \\
\hline & Niobium Lot\# 090490 & & & & \\
\hline & & & & & \\
\hline & & & & & \\
\hline & & & & & \\
\hline & & & & & \\
\hline
\end{tabular}




\begin{tabular}{|c|c|c|c|c|c|c|}
\hline & & & & & 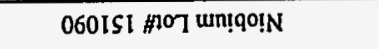 & \\
\hline \multirow{2}{*}{ 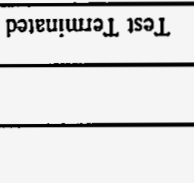 } & $\iota^{\prime} \mathfrak{\varepsilon}$ & şs' & ZL & 00EI & 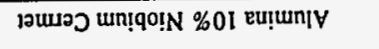 & $\varepsilon-\angle 90$ \\
\hline & & & & & O60ICI tho7 unigoin & \\
\hline \multirow[t]{3}{*}{ 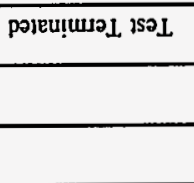 } & $1 \cdot b$ & $\varsigma \boxminus 0^{\circ} \varepsilon$ & & & 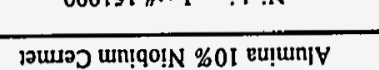 & $7-190$ \\
\hline & & & & & & 0.0 \\
\hline & & & & & 060 ISI HOO un! & \\
\hline \multirow[t]{2}{*}{ poseu! } & $0, b$ & $\varsigma \exists 07$ & $\overline{\tau L}$ & $00 \varepsilon I$ & 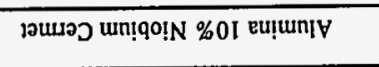 & $i-\angle 90$ \\
\hline & & & & & 060ISI \#ROT un!qo!N & \\
\hline \multirow[t]{2}{*}{ pəseu!umaL /SOL } & & Sas'L & $0 \varepsilon s$ & $\overline{00 E I}$ & 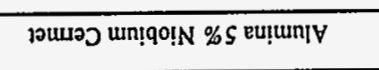 & $\mathrm{I}-990$ \\
\hline & & & & & 060ISI \#107 un!qO!N & \\
\hline \multirow[t]{2}{*}{ 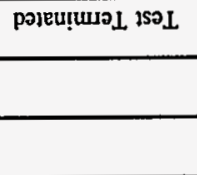 } & $50^{\circ} 7$ & sas'z & $\overline{0 \varepsilon S}$ & $00 \varepsilon$ & 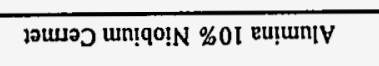 & $\varepsilon-\varsigma 90$ \\
\hline & & & & & 4ร5พ 00t- 06t060 tho7 un!qo!N & \\
\hline \multirow[t]{3}{*}{ 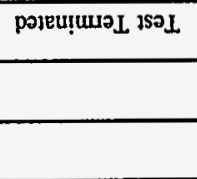 } & & SaI' $\varepsilon$ & 891 & $00 \varepsilon I$ & 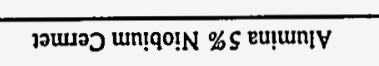 & $1-290$ \\
\hline & & & & & & \\
\hline & & & & & 4saw 00b- $06+060$ fno7 un!qo!N & \\
\hline \multirow[t]{2}{*}{ anniled } & & 001 & $8 b$ & 00EI & 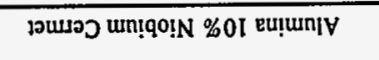 & $\tau-190$ \\
\hline & & & & & 455W 00t- 06t060 \#107 un!q0!N & \\
\hline asn!!es p!dey & & 00I & 8 & OOEI & 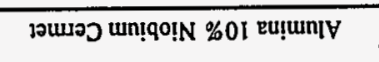 & $\mathrm{I}-\mathrm{I} 90$ \\
\hline \multirow[t]{3}{*}{ SINAWWOJ } & 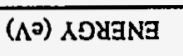 & (suryo) gJNVLSISad & (SI4) IWIL & 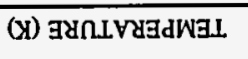 & NOLLISOdWOJ & \#gרWVS \\
\hline & NOLIYALJY & 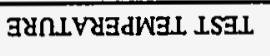 & LSEI & LSGI & & \\
\hline & LNGXYddY & TYNH & & & & \\
\hline
\end{tabular}




\begin{tabular}{|c|c|c|c|c|c|c|}
\hline \multirow[t]{2}{*}{ 068-1 } & Alumina $5 \%$ Niobium Cermet & 1300 & 120 & $2.5 \mathrm{ES}$ & & Test Terminated \\
\hline & Niobium Lot\# 151090 & & & & & \\
\hline \multirow[t]{2}{*}{ 068-2 } & Alumina $5 \%$ Niobium Cermet & 1300 & 72 & $3.5 \mathrm{E} 5$ & 2.5 & Test Terminated \\
\hline & Niobium Lot" 151090 & & & & & \\
\hline \multirow[t]{2}{*}{ 068-3 } & Alumina 5\% Niobium Cermet & 1300 & 144 & $3.0 \mathrm{ES}$ & 3.4 & Test Terminated \\
\hline & Niobium Lot/ 151090 & & & & & \\
\hline \multirow[t]{2}{*}{$068-4$} & Alumina 5\% Niobium Cermet & 1300 & 72 & $4.0 \mathrm{ES}$ & 3.9 & Test Terminated \\
\hline & Niobium Lot" 151090 & & & & & \\
\hline \multirow[t]{2}{*}{$068-5$} & Alumina 5\% Niobium Cermet & 1300 & 72 & $4.0 \mathrm{ES}$ & 3.8 & Test Terminated \\
\hline & Niobium Lot" 151090 & & & & & \\
\hline \multirow[t]{2}{*}{$068-6$} & Alumina 5\% Niobium Cermet & 1300 & 96 & 4.0E5 & 3.7 & Test Terminated \\
\hline & Niobium Lot" 151090 & & & & & \\
\hline \multirow[t]{2}{*}{$085-1$} & Alumina $7.5 \%$ Niobium Cermet & 1300 & 2400 & $1.5 \mathrm{ES}$ & & Test Terminated \\
\hline & Niobium Lot\# 151090 & & & & & \\
\hline & & & & & & \\
\hline & & & & & & \\
\hline & & & & & & \\
\hline & & & & & & \\
\hline & & & & & & \\
\hline
\end{tabular}


NSR-31 / 88-0998

E-561-043-B-061490

\section{APPENDIX C}

TFE SHEATH INSULATOR

TEST PROCEDURE

Prepared by:

TONY WITT and J-L DESPLAT

Rasor Associates, Inc.

253 Humboldt Court

Sunnyvale, CA 94089

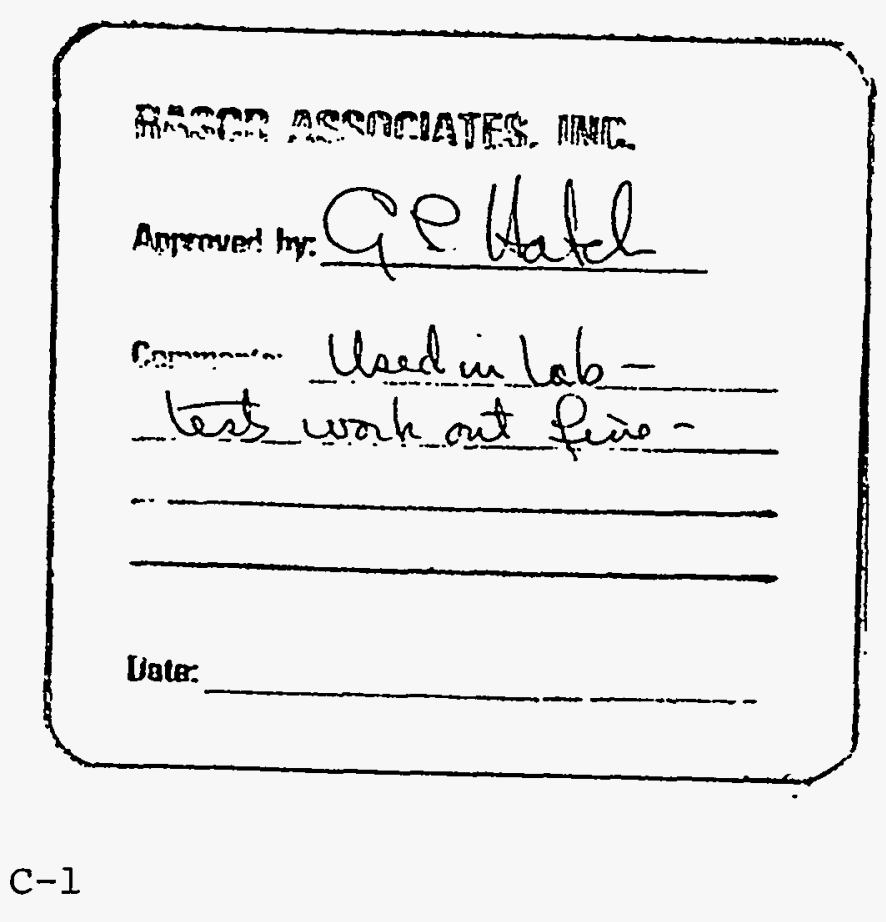


OUTLINE

PAGE

I. GENERAL COMMENTS $\ldots \ldots \ldots \ldots \ldots \ldots \ldots \ldots \ldots \ldots \ldots \ldots .$.

A. PURPOSE OF DOCUMENT $\ldots \ldots \ldots \ldots \ldots \ldots \ldots \ldots \ldots \ldots \ldots \ldots$

B. FUNCTION OF SHEATH INSULATORS $\ldots \ldots \ldots \ldots \ldots \ldots .$.

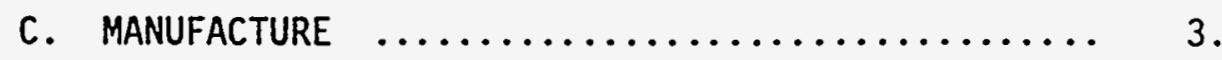

D. TEST PROCEDURE $\ldots \ldots \ldots \ldots \ldots \ldots \ldots \ldots \ldots \ldots \ldots . \ldots \ldots$.

II. SHEATH INSULATOR TEST PROTOCOL $\ldots \ldots \ldots \ldots \ldots \ldots \ldots .20$.

A. GENERAL REQUIREMENTS $\ldots \ldots \ldots \ldots \ldots \ldots \ldots \ldots \ldots . \ldots \ldots$.

B. CleAning $\ldots \ldots \ldots \ldots \ldots \ldots \ldots \ldots \ldots \ldots \ldots \ldots \ldots \ldots \ldots \ldots \ldots \ldots \ldots .$.

C. MOUNTING $\ldots \ldots \ldots \ldots \ldots \ldots \ldots \ldots \ldots \ldots \ldots \ldots \ldots \ldots \ldots \ldots$

D. OVEN ASSEMBLY $\ldots \ldots \ldots \ldots \ldots \ldots \ldots \ldots \ldots \ldots \ldots \ldots \ldots \ldots \ldots \ldots$

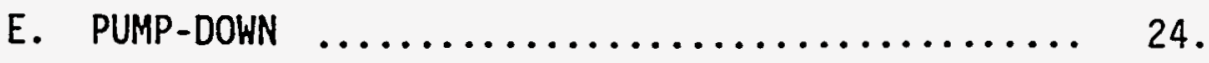

F. HEAT-UP $\ldots \ldots \ldots \ldots \ldots \ldots \ldots \ldots \ldots \ldots \ldots \ldots \ldots \ldots \ldots \ldots \ldots \ldots \ldots$

G. RESISTANCE VS TEMPERATURE $\ldots \ldots \ldots \ldots \ldots \ldots \ldots \ldots . \ldots \ldots$.

H. LIFE-TESTING $\ldots \ldots \ldots \ldots \ldots \ldots \ldots \ldots \ldots \ldots \ldots \ldots \ldots \ldots \ldots \ldots \ldots$ 


\section{GENERAL COMMENTS}

\section{A. Purpose of Document}

The primary purpose of this document is to place under one cover all procedures required to test out-of-core and evaluate trilayer sheath insulators used in the TFE-VP. The actual test protocol constitute a major portion of this document.

\section{B. Function of Sheath Insulators}

The function of the sheath insulator in a TFE is to electricaliy isolate the collector electrode from the liquid metal coolant. Any electrical leakage through this path represents power loss in the thermionic converter system and must be minimized. These insulators operate at approximately $1100 \mathrm{~K}$ and must retain electrical insulating properties throughout the entire 7 year lifetime. The sheath insulator also act as thermal conductors for the converter waste heat so thermal integrity between the layers of the sheath structure is vital. The purpose of the ex-reactor testing at RAI is to confirm the viability of insulator materials and configurations for this application. The effects of temperature and voltage are studied by long term testing at or above the operating temperature with the application of a constant DC potential. The electrical resistance of specimens is monitored as a function of time to check for degradation due to electrolysis or other effects.

\section{Manufacture}

Insulator trilayers wi11 be manufactured by GA and TTC. Each company wi.11 employ the fabrication processes which they have developed, but final specifications must meet those established by the TFE-VP. 
A11 trilayer sheath insulators to be tested at RAI will have a guard ring on each end to minimize measurement of end effects. Guard rings will be fabricated according to established procedures. A schematic of a test specimen with guard rings is shown in Fig. 1.

Normal overall sample length is $0.75^{\prime \prime}$. However, this dimension is not critical and could be shortened, if desired, in order to increase oven capacity.

The inside diameters of the inner niobium sheath and of the ceramic layer are vital and must not deviate from specifications if test fixture is to function properly.

Outer niobium layer of each specimen will be scribed with unique identifying 1 abel.

Samples intended for life testing will be cleaned according to procedures established by the manufacturers, wrapped in 1 int-free packing material and placed in a rigid container for shipment to RAI.

Documentation describing each specimen should accompany a11 shipments.

\section{RAI Test Procedure}

The test oven configuration to be used for sheath insulator lifetesting is illustrated in Fig. 2. Heating is accomplished by passing AC current through a tantalum winding surrounding the samples. This winding is isolated from the samples by a molybdenum shield as seen in the diagram. Furthermore, to keep to a minimum metal evaporation from the shield itself, an alumina tube is placed between the samples and the cylindrical shield.

All parts with 1ine-of-sight view of the specimens are made of molybdenum, niobium, tungsten-rhenium alloys, or alumina. 


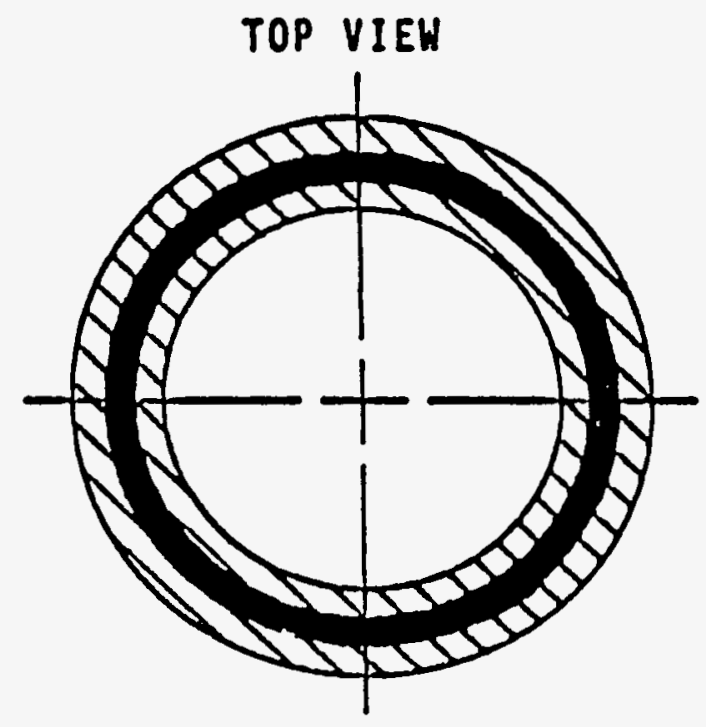

CROSS SECTION

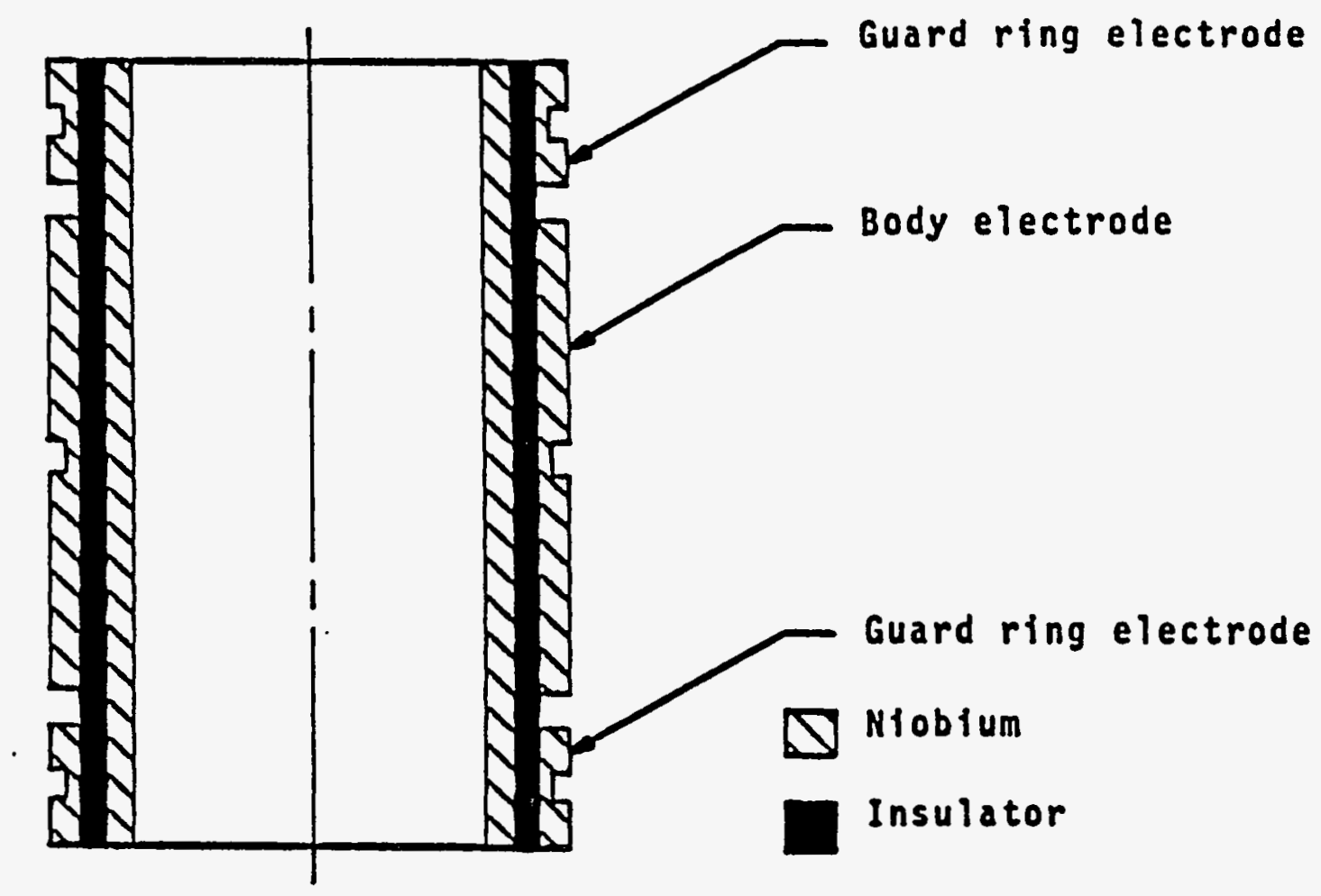

Fig. 1 TFE sheath insulator configuration 


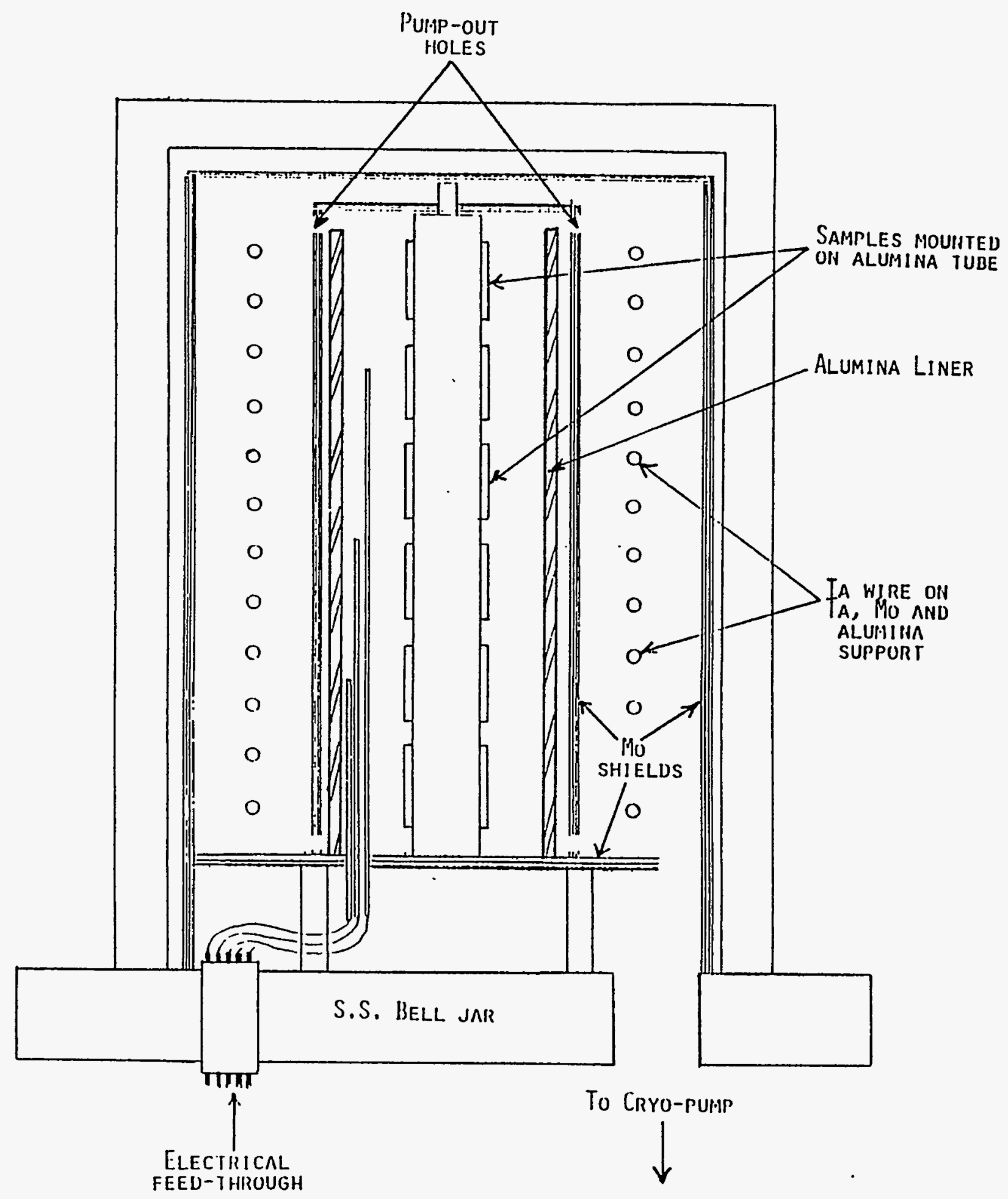

Fig. 2 Isothermal oven design concept 
A schematic of the samples stacked on the alumina tube is shown in Fig. 3. Each of three ovens may accommodate 5-6 samples with the body and guard ring resistivities independentiy monitored.

The specimens are separated by niobium spacer rings. These rings contact only the inner niobium sheath to form a common ground for the electrical measurements. The thermocouples are spot-welded onto thin tantalum tabs, themselves spot-welded to these spacers. Detail of the spacer/sample configuration is shown in Fig. 4.

The four (maximum) thermocouples are type C (W/5\% Re vs. $\mathrm{H} / 26 \% \mathrm{Re}$ ), made from matched pairs of bare alloy wires. The absolute accuracy of the temperature measurements with these thermocouples is estimated to be $\pm 5^{\circ} \mathrm{C}$, al though the reproducibility of any reading is about $\pm 1^{\circ} \mathrm{C}$. Connections to extension grade wire are made near room temperature. The number and precise placement of thermocouples will depend upon the number of specimens being tested.

The electrical leads are brought through the stainless steel base plate by ceramic-insulated feedthroughs which terminate near the base. Niobium wires are spot-welded to the feedthrough wires and brought up to the samples through holes in the stack of molybdenum shields. All niobium wires are insulated with high purity alumina tubes.

When configured as illustrated, the heaters can heat the central region to the maximum test temperature of $1270 \mathrm{~K}$. Temperature controllers maintain each oven temperature constant within $1^{\circ} \mathrm{C}$, as seen in Fig. 5 .

A fan is mounted, oriented downward, above the be11 jar to cool it by convection. The surface temperature of the bell jar is considerably reduced by the use of this fan. With the samples at $1250 \dot{K}$, the outer surface temperature is approximately $150^{\circ} \mathrm{C}$, which is considered low enough to create minimal safety hazards. 
$E-561-043-B-061490$

NSR-31/88-0998

8.

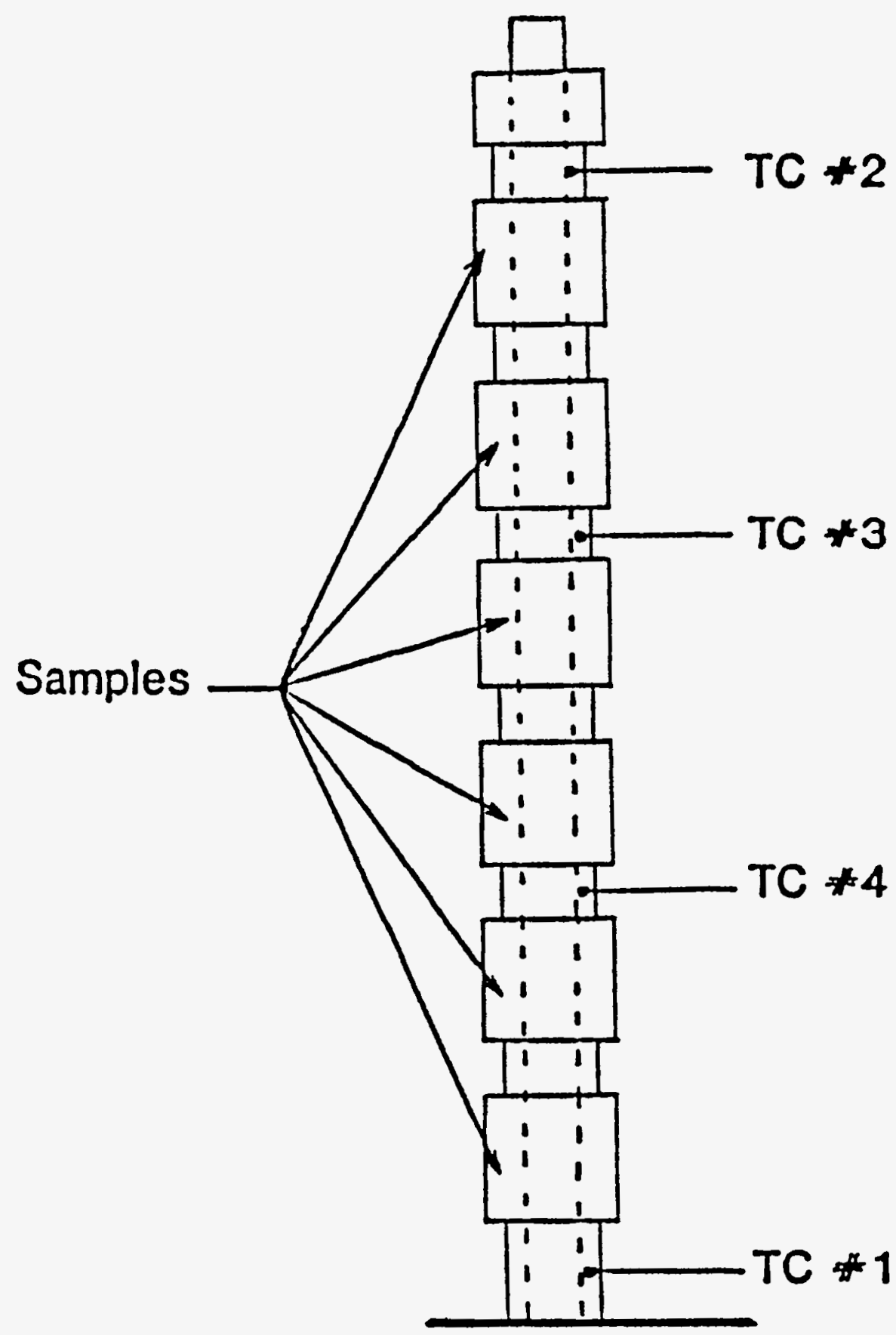

Fig. 3 Sample and thermocouple arrangement 
$E-561-043-B-061490$

NSR-31/88-0998

9.

NIOBIUM

U///A Insulator sample
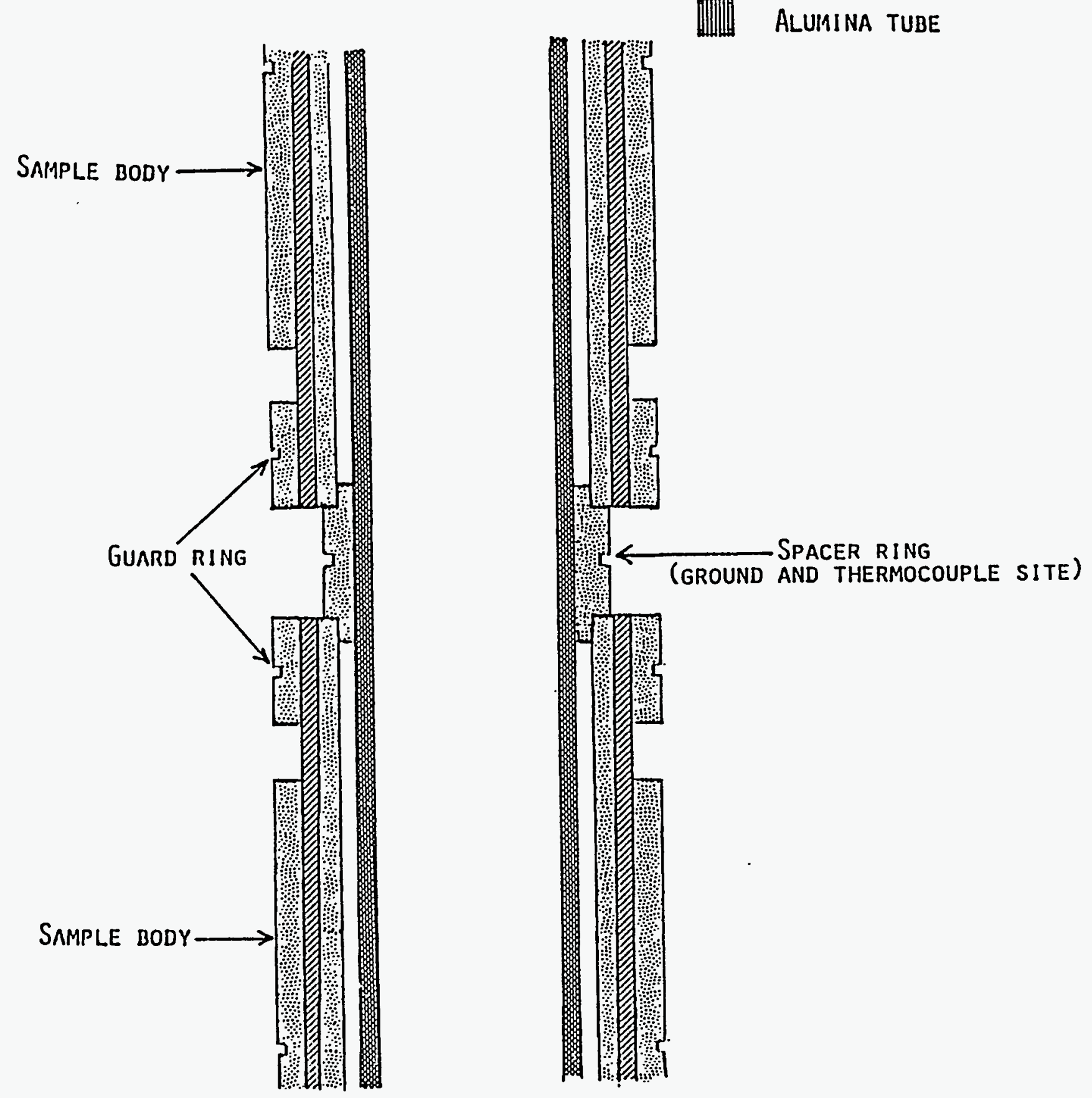

Fig. 4 Detail of sample/spacer configuration 


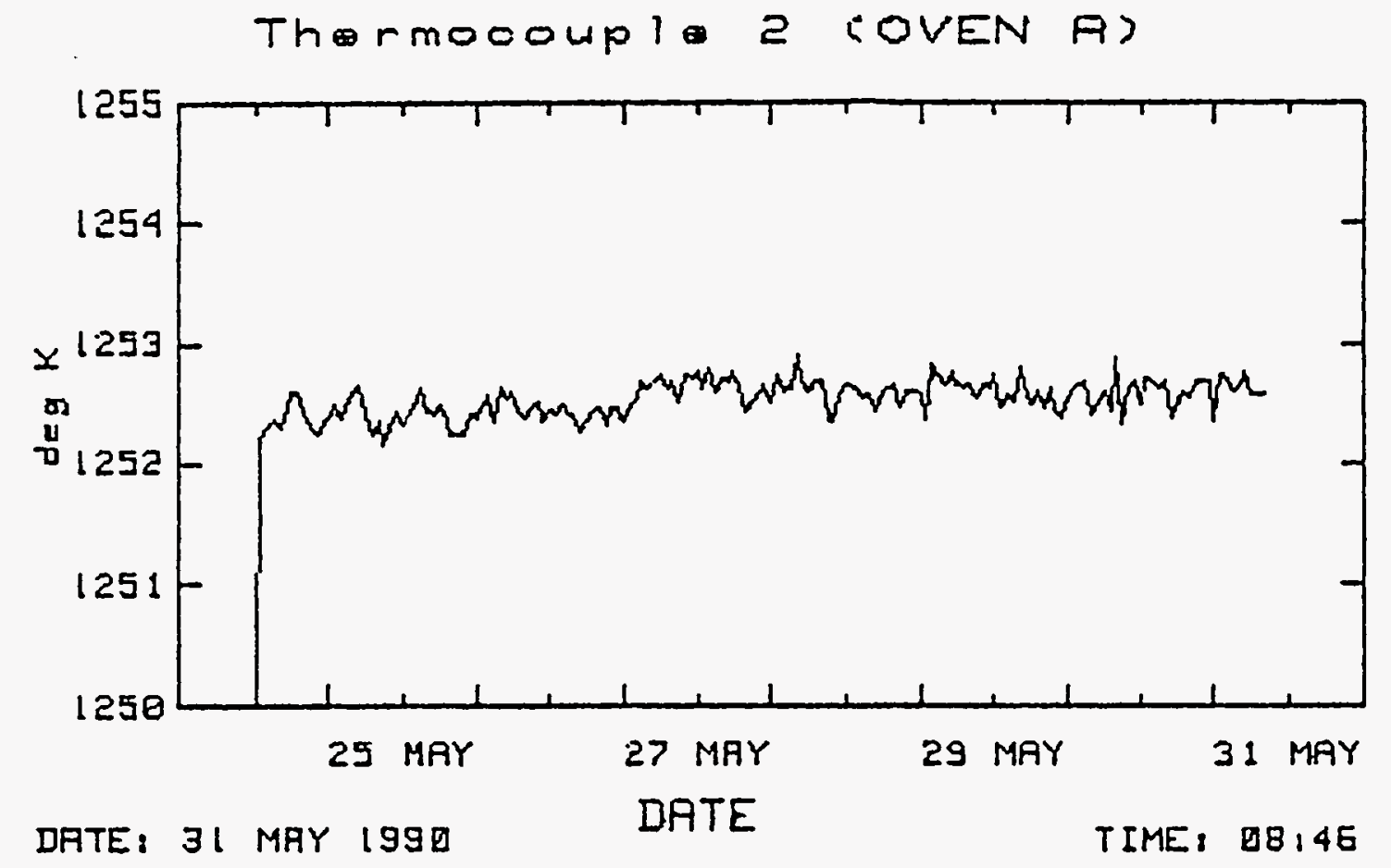

Fig. 5 Typical temperature evolution over a week, showing less than $1^{\circ} \mathrm{C}$ peak-to-peak variation. 
The enclosure at the base of the oven between the stainiess steel plate and the stack of molybdenum shields reaches a temperature of about $700 \mathrm{~K}$ with the specimen area at $1100 \mathrm{~K}$. This volume contains non-refractory materials such as stainiess steel and copper.

The temperature measured along the oven axis shows random variations from oven to oven of about $\pm 15 \mathrm{~K}$ over the length of five samples at an average temperature of $1250 \mathrm{~K}$. Since the construction of the three ovens is the same, variations of the temperature distribution along the oven axes probably do not reflect real temperature differences, but rather differences in thermal contact, local alloy composition, or noise component. The average temperature is used as the real temperature for each oven, and is considered accurate to $\pm 10 \mathrm{~K}$.

The primary sources of possible sample contamination are those materials with line-of-sight access to the specimens in addition to impurities in or on the samples prior to testing. Even though the use of guard rings will minimize errors due to surface conduction on the sample ends, the possibility of contamination from surrounding materials should be eliminated to the extent possible.

The materials in near proximity to the ceramic trilayers are tungsten-rhenium alloys, tantalum, molybdenum, niobium and alumina. At equilibrium, all of these materials are at temperatures near that of the samples. At the maximum testing temperature of $1270 \mathrm{~K}$, the most volatile material is molybdenum with an evaporation rate of $3.5 \times 10^{-18} \mathrm{~g} / \mathrm{cm}^{2} / \mathrm{s}$. If the entire metallic vapor product of the exposed molybdenum shields $\left(25 \mathrm{~cm}^{2}\right)$ were to deposit solely upon the ceramic region of one insulator end, about a year would be required to form a monolayer. These evaporation rates are, therefore, negligible and the oven materials themselves are not expected to be a potential source of contamination. Impurities in these materials, however, may be of concern as potential contaminants. Such impurities may be inherent in the original processing of materials or might originate from the oven 
assembly process. Assembly and outgassing protocol will be established in an effort to minimize contamination of the system with solvents, fingerprints, etc. Outgasing is particularly critical to remove the water from the oven walls, which could otherwise contribute to the transport of metal through a water vapor cycle. This is best accomplished by letting the temperature of the oven enclosures rise above $200 \mathrm{C}$ during the initial pump-down.

The test ovens are continuousiy pumped with a cryo-pump to keep gaseous species to a minimum. Each of the three ovens is evacuated through 1$3 / 8$ " diameter tubing through the base plate. An air-operated right angle valve isolates each oven from a common chamber which is located directly above the pump. These valves contain Viton seals and bonnet gaskets and operate at less than $50^{\circ} \mathrm{C}$ with the ovens at temperature. A diagram of the pumping system is seen in Fig. 6. The total pressure is monitored in this common chamber by a cold cathode vacuum gauge. This pressure is at the extreme low end of the instrument's range so the pressure is no higher than the indicated level of approximately $1 \times 10^{-7}$ torr.

The pressure cannot be monitored directly in the oven chamber so inference must be drawn from the monitored value. The flow conductance between the pump and the base of the oven chamber should be quite high. Conductance within the chamber, however, might be considerably lower. A series of 1/4" holes is punched around the upper and lower circumference of the inner set of molybdenum shields (see Fig. 2) to allow flow between the sample area and the heater coil region. The holes are located such that there is no direct 1 ine-of-sight between the samples and the hot tantalum heating wire. The total area of opening between these two volumes is approximately 1-1/2 square inches. Flow between the heater winding space and the base of the chamber (i.e. the pump) is accommodated by an opening approximately $3 / 8^{\prime \prime}$ wide and 2-1/2" long between the edge of the stack of molybdenum shields at the base and the outer cylindrical shields. There are additional openings between these volumes through cut-outs for the feed-through wires and areas of loose fit. The total open area is greater than one square inch. The pressure in the sample region is estimated to be higher than the value measured in the chamber above the pump by perhaps an order of magnitude. 


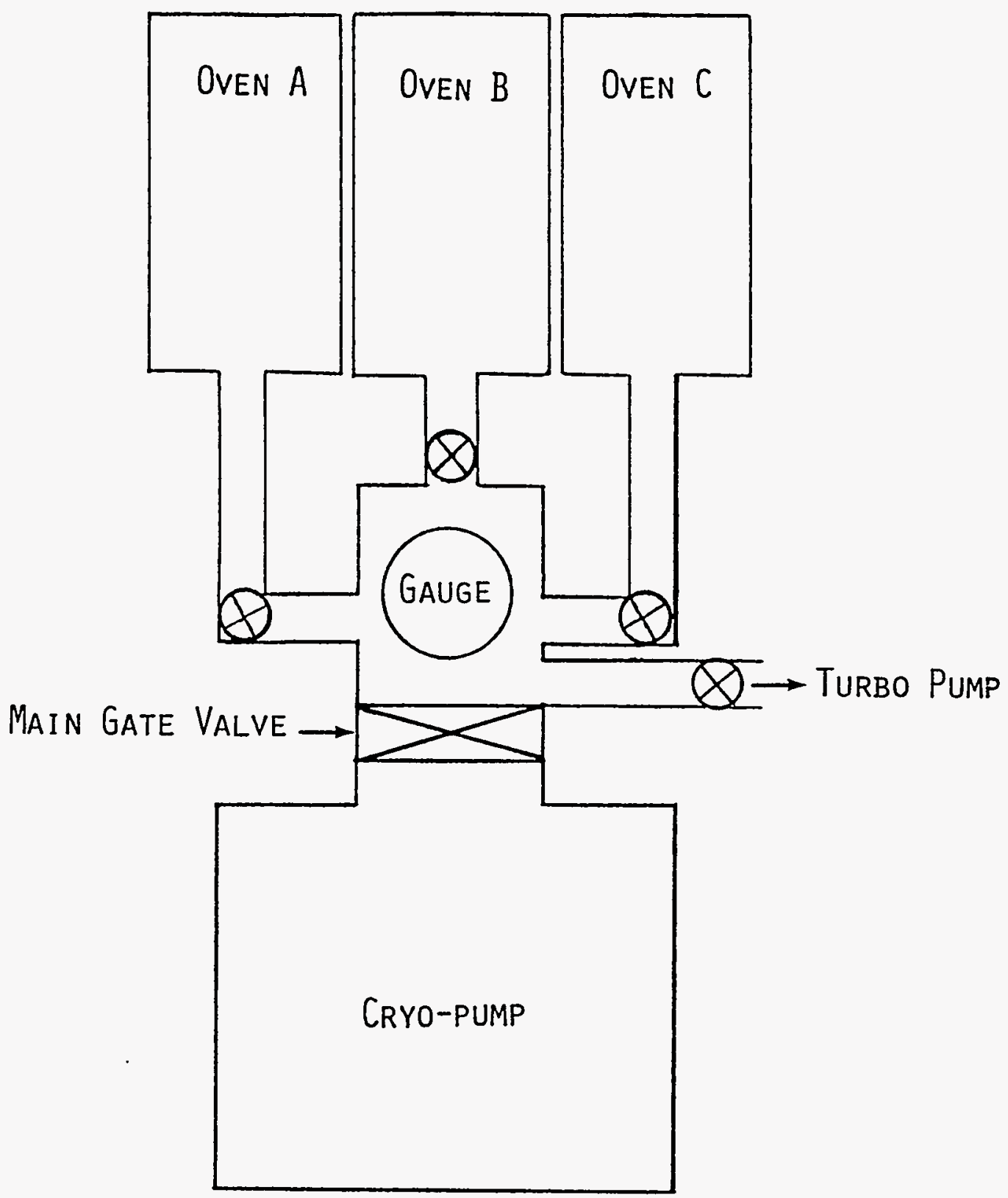

Fig. 5 TFE vacuum arrangement 
With the oven at temperature and a stable vacuum established, a constant $D C$ voltage is applied to the samples. The current is measured and the sample resistance defined as the voltage to current ratio. The two guard rings on each sample are shorted and the combination defined as the guard ring of that sample. A schematic of the electrical connections is shown in Fig. 7. A schematic of measurement system is given in Fig. 8.

A typical data printout and weekly plot are shown in Fig. 9. Each printout gives all temperatures, applied voltage and resistance for each sample body and guard ring in each oven.

Although great efforts are taken to prevent artifacts across the ends of insulators, surface conduction can alter the performance of the insulator. Guard-rings are thus $\mathrm{placed}$ around the two ends so as to prevent artifacts. Each of the guards are monitored along with the central insulator. Tests show that the body of the sample can still be effectively measured as highly resistive even when the guard rings are much more conductive. If the guard ring becomes too conductive, however, more potential will drop over other parts of the system and the voltage across the guard ring will be reduced. This will reduce the effectiveness of the guarding of the measurement of the sample body by allowing current to flow between the body and guard electrodes.

Due to limitations on the present data acquisition system, the electrical current through the guard rings is measured by a different method from that used for the sample bodies. A 100 ohm resistor is wired in series with each pair of guard rings. The voltages across these resistors are measured directly by the data scanner and interpreted as the current through the guard rings. The precision of the voltmeter is one microvolt which corresponds to 10 nanoamps. Guard ring resistances above about $10^{8}$ ohms are, therefore, not accurate but do represent approximate minimum values. The 100 ohm resistors limit the current through the guard rings as well as serving as current measuring shunts. This current limitation will prevent a runaway situation. As the guard rings become more conductive, a larger fraction of 
E-561-043-B-061490 NSR-31/88-0998

15.

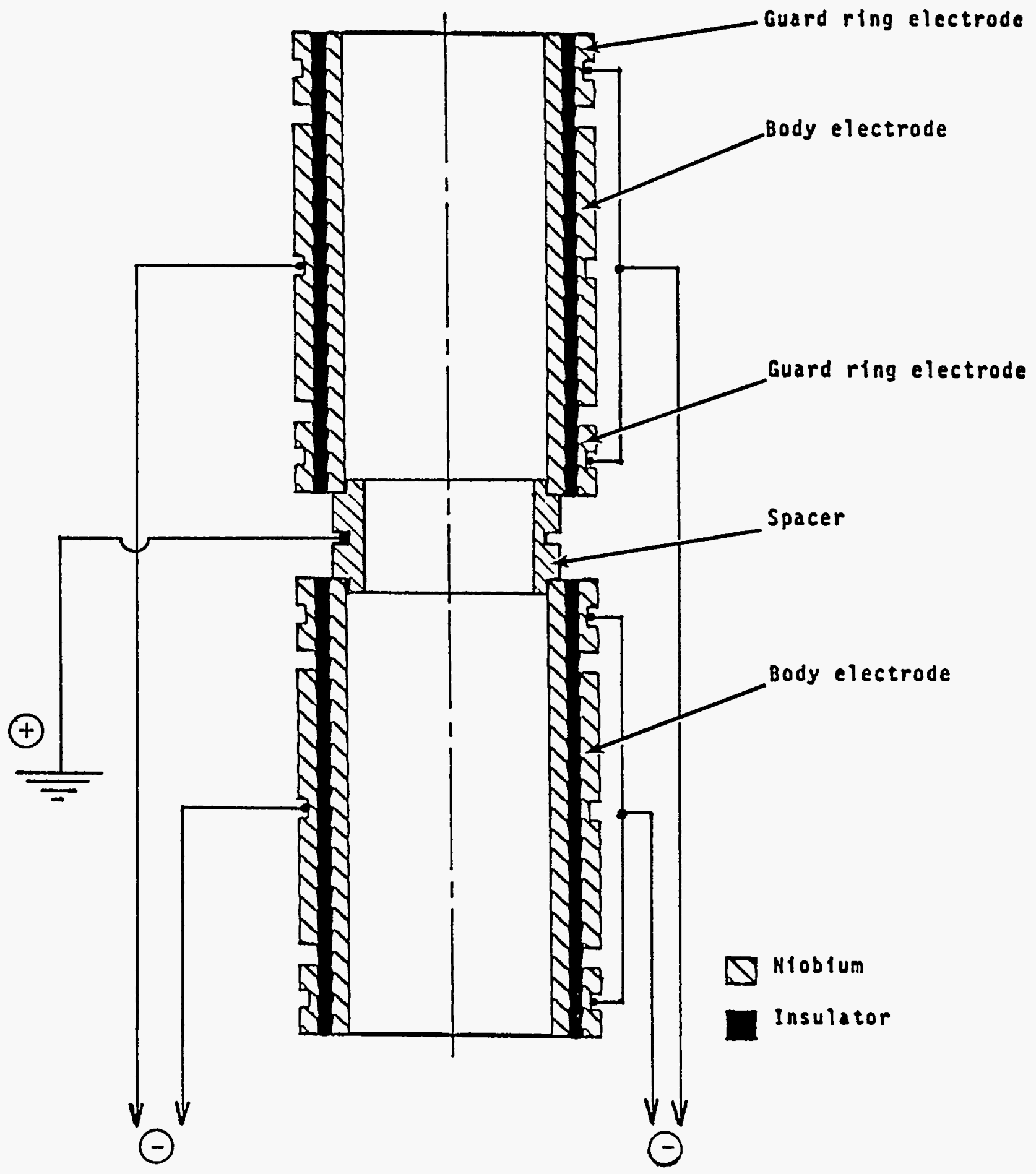

Fig. 7 Schematic of electrical connections 


\section{E-561-043-B-061490}

NSR-31/88-0998

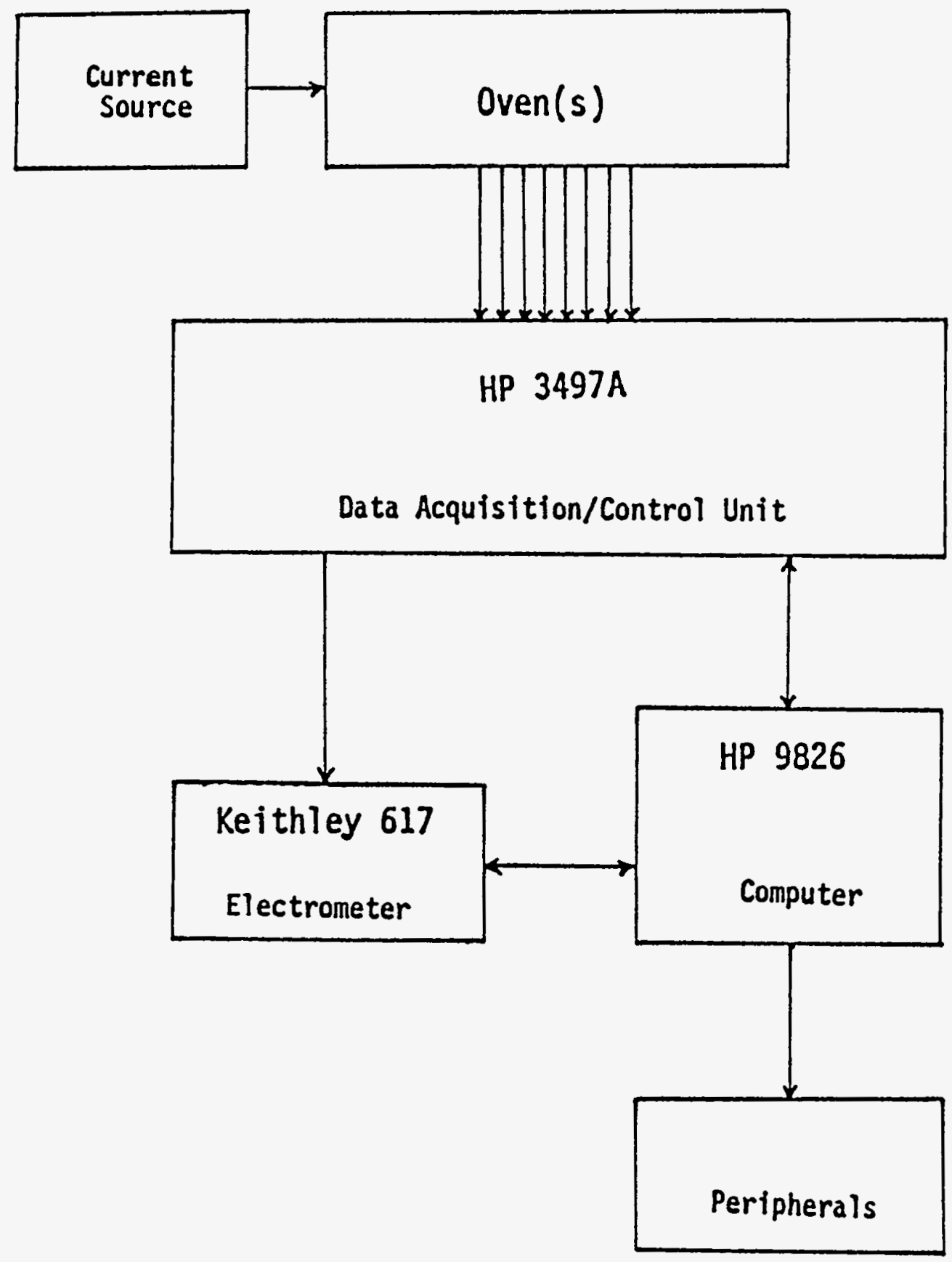

16.

TFE Data Acquisition System

A11 IEEE-488 Interfaced

Fig. 8 Schematic diagram of data acquisition system 


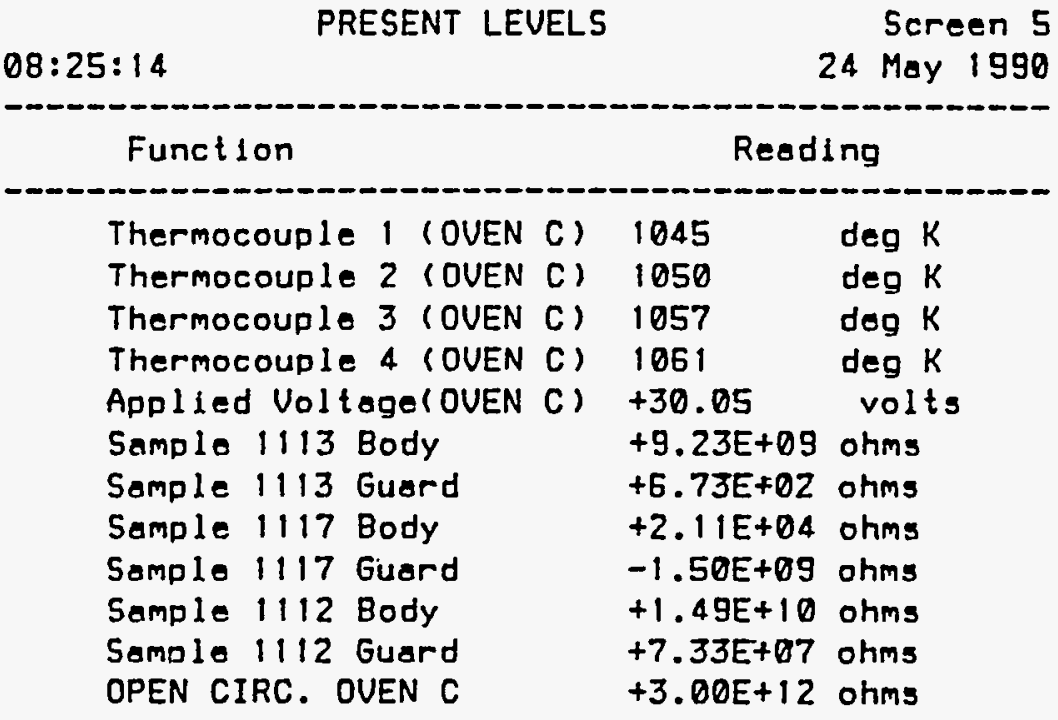

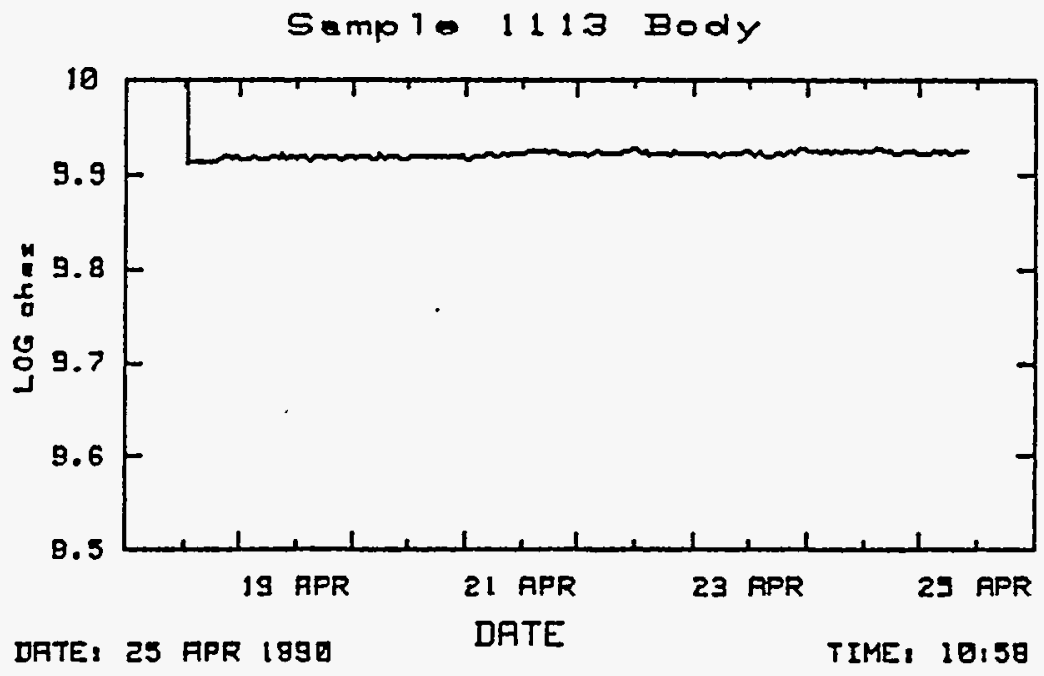

Fig. 9 Example of data printout and sample resistance plot 
the applied voltage will drop over the resistor while the potential across the guard ring will decrease. This should tend to prevent the guard ring from being driven to total failure by the applied voltage by limiting the current to 0.1 amp at the normal test potential of 7.5 volts.

The currents through the sample bodies are measured by an electrometer operated in the current mode. This method is more precise than the shunt resistor measurements so it is being utilized to monitor the body resistances rather than the less important guard-ring measurements. The applied voltage is normally switched directly to the samples. When measurements are to be made, the electrometer is switched in series with the sample by means of relays with the data acquisition unit. The results are relayed to the computer over the IEEE bus. Each sample is switched sequentially to the electrometer until all channels have been sampled. The electrometer system also limits the current through the samples during the measurement period. The switching procedure involves putting 200 ohms in series with the sample so the current flowing through the electrometer is limited to $38 \mathrm{~mA}$ at $7.5 \mathrm{~V}$. Twenty milliamps is the upper measurement limit of the electrometer so the software is written to terminate testing at $19 \mathrm{~mA}$. This is done by opening a relay which disconnects the offending test sample from the voltage source. The sample current may exceed this limit between data scans, but the sample will be taken offline as soon as the high current is detected by the next scan. Therefore, a specimen body witl never be exposed to current exceeding $19 \mathrm{~mA}$ for more than the scan period of three minutes.

Data sampling currentiy occurs every three minutes and includes sample body and guard ring currents as well as applied voltage and temperatures. A11 data are retained in memory for eight hours and are available for plotting or listing. Each hour the data are written to disk. These hourly data are available in memory for one week before being overwritten. Each data diskette contains the hourly data for one week. These catalogued data may later be read and listed or plotted as functions of time (date). This data acquisition is continued over the time span of the 
experiment which may terminate at the time of failure (resistance reduced to hundreds of ohms or less) or by design after a pre-determined time period.

Samples that have failed are removed from the oven and retained for possibie post-test analysis. The region of failure can be located in the failed specimens which exhibit high conductivity when cooled to room temperature. Any region of low resistance will exhibit localized heating when current is passed through the specimen. The failed specimen can be immersed in a volatile fluid and the conductive regions are identified by localized boiling. Such samples can be sectioned and the failure zone examined microscopically and analytically. Unfortunately, most specimens showing low resistance at high temperature have extremely high resistances when cooled to room temperature. This makes isolation of the failed region quite difficult, if such a region actually exists. Techniques for post-test analysis as well as development of an experimental matrix to validate accelerated testing are currently being pursued. 
II. SHEATH INSULATOR TEST PROTOCOL

\section{A. General Requirements}

This protocol shall be followed for all life-test samples at RAI. Slight variation of test parameters might be specified for short-term tests, but sample preparation and mounting procedures sha11 be adhered to for all tests.

A1l handling of samples and interior oven parts must be done wearing clean, nylon inspection gloves.

All spot welds in the oven chamber (current leads, thermocouples, oven supports, etc.) shall be made with clean tungsten electrodes. № copper electrodes.

After the initial cleaning, the bell jar shall be in place at all times when work is not being performed on the oven.

No spot welds shall be made to the trilayers themselves. Contacts will be made by twisting wires around circumference of niobium cladding. These wires may then be spot welded to the leads within the oven.

The oven must always be isolated from cryo-pump before opening to atmospheric pressure. The "ON" position for the pneumatic valves represents an open condition. Allow one minute after switching for valves to open or close.

\section{B. Cleaning}

1. Upon receipt from the supplier, each sample will be visually inspected. Any anomalies shall be noted along with proper sample identification in the TFE notebook. 
2. Each sample shall be cleaned by soaking in high purity acetone followed by alcohol rinse. Gently agitate during soaking period. Do not use ultrasound on samples. Dry with bottled nitrogen. These samples are now referred to as "clean" samples.

3. Wires and electrodes shall be cleaned ultrasonicalty in acetone followed by an alcohol rinse prior to use. Wrap a clean piece of niobium wire around each guard ring and sample body. A groove is machined in each electrode for this purpose. Twist the wires tightiy. Spot weld the two guard ring leads of each sample together using tungsten electrodes.

4. All removable oven parts shall be cleaned prior to each test cycle. Clean in acetone using ultrasound when feasible. Rinse all parts with alcohol. Blow dry with bottled nitrogen.

5. Clean spacer rings similarly. Wrap niobium wire around notch in each spacer but do not tighten at this time.

6. A11 parts that were cleaned in solvents (samples, spacers and oven parts) shal1 be outgassed overnight at $100^{\circ} \mathrm{C}$ into a turbopump to remove volatile organics.

\section{Mounting}

1. Clean alumina spacers shall be placed below the samples to center them in the heated zone. The length of this spacer will depend upon the number of samples being tested.

2. Samples shall be alternated with spacer rings. Maximum number of samples is five in each Oven $A$ and $B$ and six in Oven $C$.

3. Orient samples such that inscribed identification label is right side up. 
4. With all samples and guard rings in place, be sure that the leads coming off the samples are dressed to eliminate potential shorting.

5. Attach thermocouples to spacer rings by twisting beneath the niobium wires around middle of spacers. Check orientation of each thermocouple by gently heating the junction and measuring output. Output will be positive w.r.t. polarity markings on feedthrough if properly wired. Check the data acquisition system corresponding temperature readings.

6. Wire all spacer rings together and spot weld to ground wire. Be certain that neither the ground wire nor its insulator tube is touching any of the other wires or insulators.

7. Spot weld each guard and body lead to a feedthrough wire using tungsten electrodes. Visualiy inspect to be sure that insulators are not touching any grounded metal surface within the oven.

8. The continuity of each connection from the different guards and bodies will be checked with an ohmmeter between these sample parts and the outside pins of the corresponding feedthroughs.

9. The channel assignments for the sample measurements are as follows:

Oven A: Guards

$\begin{array}{lr}20-24 & \\ \text { Bodies } & 40-44 \\ \text { Thermocouples } & 0-3\end{array}$

Oven B: Guards

$$
\begin{array}{lr}
25-29 & \\
\text { Bodies } & 45-49 \\
\text { Thermocouptes } & 4-7
\end{array}
$$

Oven C: Guards

$$
\begin{array}{lr}
\text { Bodies } 30-35 & 50-55 \\
\text { Thermocouples } & 8-11
\end{array}
$$


10. Check the current through the samples at $7.5 \mathrm{~V}$ to test for gross short circuits. Currents will typically not be measurable at room temperature.

11. A dated sketch of the set up shall be inserted in the notebook. This sketch will include:
a. Tocation of each sample
b. location and channel number used for thermocouples
c. channel number used for guard and body
d. color of wire used for each measurement

12. Update data acquisiton software to reflect the new sample ID's and their locations.

13. The data acquisition system proper operation will be checked according to the following procedure:

For each sample body and guard, a known resistor is connected between the corresponding outside pin of the appropriate feedthrough and the + (ground, brown wire) of the voltage source. The value of this resistor is chosen to be at least ten times smaller than the resistance being checked and should have a $5 \%$ or better precision. The reading provided by a new scan should indicate the value of this resistor within $10 \%$.

\section{Oven Assembly}

1. Gently blow dust and particles away with a dry gas.

2. $\mathrm{Place} \mathrm{Al}_{2} \mathrm{O}_{3}$ shield then inner molybdenum shields around samples. Be sure cylinder is aligned firmly by tabs on baseplate. Place stack of shieids on top.

3. Bolt heater coil in place checking for even clearance between heating wire and inner shields. Adjust inner shield cylinder, if necessary. 
4. Attach leads to terminal blocks with stainless steel bolts. Be sure terminal blocks are securely attached to copper current feedthroughs. Tighten set screws if not firmly in place.

5. Test heater coil for short to ground. Make adjustments to correct any short circuit.

6. Lower outer molybdenum cylinders around heater and top with stack of shields.

7. Replace copper gasket.

8. Carefully place bell jar over assembled oven. Align loosely with several bolts.

9. Check again for short circuit between heater coil and ground before tightening.

10. Bolt down bell jar flange as for any knife edge-copper seal.

11. Re-check sample currents at $7.5 \mathrm{~V}$ for obvious short circuits. If any currents greater than $10^{-6}$ amps are measured at 7.5 volts, examine the sample in questions to detect potential shorts.

\section{E. Pump-Down}

1. Attach turbo pump to common roughing valve.

2. Open pneumatic oven gate valve and roughing valve to bell jar. Be sure oven is isolated from cryo-pump by closing main gate valve.

3. Switch on turbo and backing pumps.

4. Allow to pump to $10^{-5}$ torr range. Isolate from turbo pump by closing roughing valve. 
5. Isolate all other operating ovens by closing corresponding pneumatic valves.

6. Open oven to cryo-pump through main gate valve and allow to pump to equilibrium pressure reading of about $4 \times 10^{-7}$ torr.

F. Heat-Up

1. Apply the test voltages to all samples with data acquisition a]gorithm running.

2. Turn on temperature controller with oven power off and Variac set to zero. Adjust set point to $400 \mathrm{C}$.

3. Toggle relay switch to "RUN" position. Amber indicator lamp should light. Switch oven power on. Red indicator will turn on.

4. STowly increase Variac to approximately $35 \%$. Watch ammeter to keep current at less than 7 amps. Let temperature increase to setpoint of $400^{\circ} \mathrm{C}$.

5. Increase setpoint to $600^{\circ} \mathrm{C}$ and Variac setting at $45 \%$.

6. Increase Variac to $60 \%$.

7. Increase setpoint by $50^{\circ} \mathrm{C}$ at $10-15$ minute intervals until the test temperatures are reached.

8. Continue monitoring sample currents until they appear stable over a one half hour period. Stability is based upon general trends rather than noise.

9. Turn off applied voltage and continue outgassing at the test temperatures until pressure gauge returns to approximately $4 \times 10^{-7}$ torr. When stable, open other ovens to cryo-pump. 
10. Plot temperature vs time and current vs time for each sample during the heating period. Label plots and retain for files.

\section{G. Resistance vs Temperature}

1. Turn on applied voltage and record data at the test temperatures.

2. Reduce setpoint $50^{\circ} \mathrm{C}$, let stabilize for one half hour and record data.

3. Repeat $50^{\circ} \mathrm{C}$ steps down to $500^{\circ} \mathrm{C}$. Let stabilize for one half hour at each temperature and print data. Terminate at higher temperature if all currents fall below measureable levels of $10^{-7}$ amps for guard rings and $5 \times 10^{-10}$ amsp for sample bodies. Decrease Variac setting if necessary to retain good temperature control. Fig. 10 shows a typical temperature scan.

4. Repeat procedure for $100^{\circ} \mathrm{C}$ temperature increases back to initial test temperatures.

H. Life-Testing

1. Reduce setpoint to designated life test temperature.

2. Be sure voltage is applied and data acquisition program is running.

3. Periodically view data to ensure that all samples and fuses are operational and that the data acquisition is functioning properly.

4. Change data diskette each Wednesday afternoon at 4:00 p.m. At this time also: 
Thermooouple 2 [OVEN $A$ ?

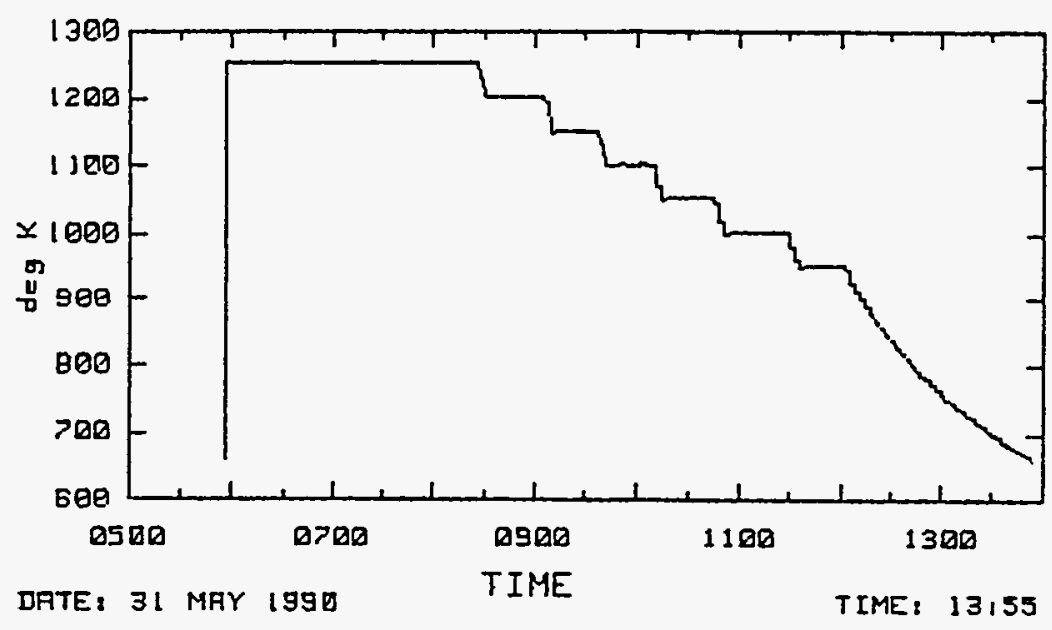

Samp 1 a 1108 Body

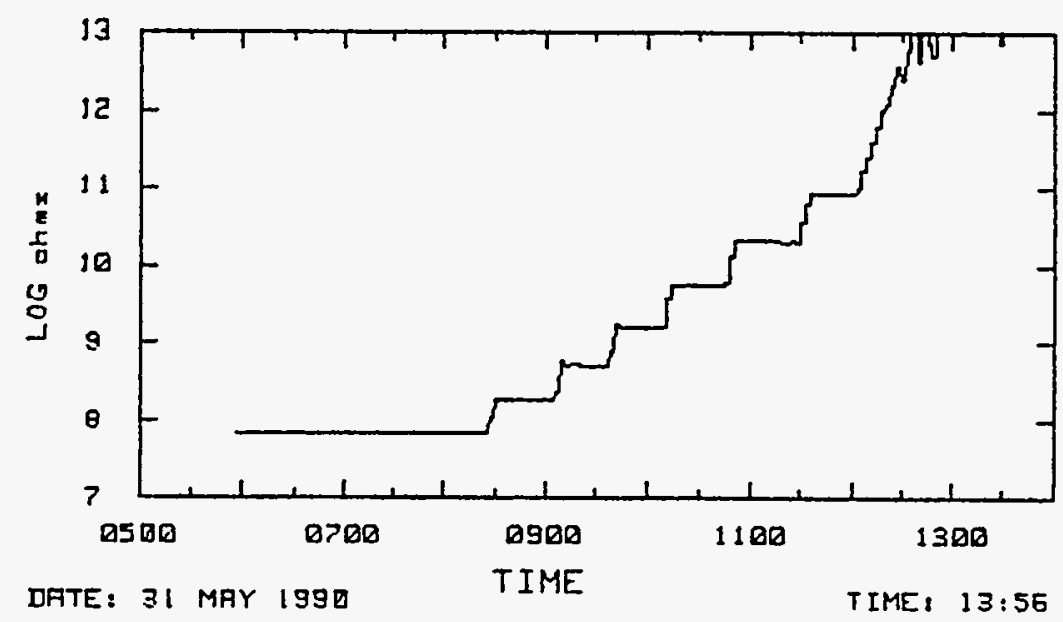

Fig. 10 Example of a temperature scan 
a. PAUSE the data acquisition algorithm. Measure voltage directly across each sample between ground and terminal strip on the side of teststand to ensure that all relays have remained closed. CONTINUE acquisition program.

b. Print weekly stripchart for voltages, currents and temperatures. Use the default parameters for axis 7 imits to maintain consistency. Note the measured voltages and place the data plots in the TFE file. 
APPENDIX D

SHEATH INSULATOR EX-REACTOR TEST SUMMARY

\begin{tabular}{|c|c|c|c|c|c|c|c|c|}
\hline SERIAL NUMBER & MATERIAL & PROCESS & TEMPERATURE & POTENTIAL & TIME (HOURS) & RESISTANCE END & ACTIVATION ENERGY & COMMENTS \\
\hline Y1 & YTTRIA & GA GRADED & $1100 \mathrm{~K}$ & $15 \mathrm{~V}$ & 354 & $<100$ & & Failed, carbon contamination \\
\hline Y2 & YTTRIA & GA GRADED & $1030 \mathrm{~K}$ & $10 \mathrm{~V}$ & 838 & $<100$ & & Failed, carbon contamination \\
\hline 245 & ALUMINA & GA GRADED & $1130 \mathrm{~K}$ & $10 \mathrm{~V}$ & 2267 & $4.00 \mathrm{E}+08$ & & Heater failure \\
\hline 244 & YTTRIA & GA GRADED & $1060 \mathrm{~K}$ & $10 \mathrm{~V}$ & 16 & $<100$ & & Failed, carbon contamination \\
\hline 247 & YAG & GA GRADED & $1120 \mathrm{~K}$ & $10 \mathrm{~V}$ & 500 & $2.80 \mathrm{E}+03$ & & Test terminated \\
\hline 250 & ALUMINA & GA GRADED & $1094 \mathrm{~K}$ & $10 \mathrm{~V}$ & 7031 & $3.00 \mathrm{E}+08$ & $2.15 \mathrm{eV}$ & Test terminated \\
\hline 251 & ALUMINA & GA GRADED & $1094 \mathrm{~K}$ & $10 \mathrm{~V}$ & 7031 & $2.00 \mathrm{E}+08$ & $2.15 \mathrm{eV}$ & Test terminated \\
\hline 252 & ALUMINA & GA GRADED & $1094 \mathrm{~K}$ & $10 \mathrm{~V}$ & 4752 & $7.10 \mathrm{E}+08$ & $2.15 \mathrm{eV}$ & Test terminated \\
\hline 253 & YTTRIA & GA GRADED & $1120 \mathrm{~K}$ & $10 \mathrm{~V}$ & 28 & $<100$ & & Failed, carbon contamination \\
\hline 254 & YTTRIA & GA GRADED & $1120 \mathrm{~K}$ & $10 \mathrm{~V}$ & 339 & $<100$ & & Failed, carbon contamination \\
\hline 255 & YAG & GA GRADED & $1096 \mathrm{~K}$ & $10 \mathrm{~V}$ & 6931 & $1.10 \mathrm{E}+04$ & $1.92 \mathrm{eV}$ & Test terminated \\
\hline 317 & ALUMINA & GA GRADED & $1020 \mathrm{~K}$ & $10 \mathrm{~V}$ & 24 & $2.00 \mathrm{E}+08$ & & UCA-2 Sample S/N 317 \\
\hline 333 & YAG & GA GRADED & $1050 \mathrm{~K}$ & $10 \mathrm{~V}$ & 24 & $2.00 E+03$ & & UCA-2 Sample S/N 333 \\
\hline 334 & YAG & GA GRADED & $1020 \mathrm{~K}$ & $10 \mathrm{~V}$ & 24 & $2.00 \mathrm{E}+03$ & & UCA-2 Sample S/N 334 \\
\hline 346 & YTTRIA & GA GRADED & $1050 \mathrm{~K}$ & $10 \mathrm{~V}$ & 24 & $6.00 \mathrm{E}+05$ & & UCA-2 Sample S/N 346 \\
\hline 467 & YTTRIA & GA GRADED & $995 \mathrm{~K}$ & $10 \mathrm{~V}$ & 792 & $5.70 \mathrm{E}+04$ & & Heater failure \\
\hline 471 & YTTRIA & GA GRADED & $1050 \mathrm{~K}$ & $10 \mathrm{~V}$ & 792 & $5.90 \mathrm{E}+04$ & & Heater failure \\
\hline 472 & YTTRIA/ALUMINA & GA GRADED & $1110 \mathrm{~K}$ & $10 \mathrm{~V}$ & 792 & $3.70 \mathrm{E}+04$ & & Heater failure \\
\hline 473 & YTTRIA/CERIA & GA GRADED & $1090 \mathrm{~K}$ & $10 \mathrm{~V}$ & 168 & $1.25 \mathrm{E}+02$ & & Failed, shorted \\
\hline 474 & YTTRIA/ZIRCONIA & GA GRADED & $970 \mathrm{~K}$ & $10 \mathrm{~V}$ & 792 & $1.10 \mathrm{E}+04$ & & Heater failure \\
\hline 735 & ALUMINA & GA GRADED & $1100 \mathrm{~K}$ & $7.5 \mathrm{~V}$ & 360 & $1.00 \mathrm{E}+08$ & $1.93 \mathrm{eV}$ & Vacuum failure \\
\hline 736 & ALUMINA & GA GRADED & $1100 \mathrm{~K}$ & $7.5 \mathrm{~V}$ & 360 & $1.00 \mathrm{E}+08$ & $2.5 \mathrm{eV}$ & Vacuum failure \\
\hline 737 & ALUMINA & GA GRADED & $1100 \mathrm{~K}$ & $7.5 \mathrm{~V}$ & 360 & $1.00 \mathrm{E}+08$ & $2.5 \mathrm{eV}$ & Vacuum failure \\
\hline 738 & ALUMINA & GA GRADED & $1100 \mathrm{~K}$ & $7.5 \mathrm{~V}$ & 360 & $1.00 \mathrm{E}+08$ & $2.5 \mathrm{eV}$ & Vacuum failure \\
\hline 739 & ALUMINA & GA GRADED & $1100 \mathrm{~K}$ & $7.5 \mathrm{~V}$ & 360 & $1.00 \mathrm{E}+08$ & $2.1 \mathrm{eV}$ & Vacuum failure \\
\hline 740 & ALUMINA & GA GRADED & $1250 \mathrm{~K}$ & $7.5 \mathrm{~V}$ & 1560 & $1.08 E+08$ & $2.76 \mathrm{eV}$ & Test terminated \\
\hline 741 & ALUMINA & GA GRADED & $1250 \mathrm{~K}$ & $7.5 \mathrm{~V}$ & 1560 & $1.11 \mathrm{E}+08$ & $2.79 \mathrm{eV}$ & Test terminated \\
\hline 742 & YTTRIA & GA GRADED & $1250 \mathrm{~K}$ & $7.5 \mathrm{~V}$ & 2256 & $3.67 \mathrm{E}+02$ & $2.28 \mathrm{eV}$ & Failed, short \\
\hline 743 & YTTRIA & GA GRADED & $1250 \mathrm{~K}$ & $7.5 \mathrm{~V}$ & 2256 & $9.23 \mathrm{E}+02$ & $2.27 \mathrm{eV}$ & Failed, short \\
\hline 744 & YTTRIA & GA GRADED & $1250 \mathrm{~K}$ & $7.5 \mathrm{~V}$ & 2256 & $3.20 \mathrm{E}+01$ & $2.4 \mathrm{eV}$ & Failed, short \\
\hline 745 & YTTRIA & GA GRADED & $1250 \mathrm{~K}$ & $7.5 \mathrm{~V}$ & 2256 & $6.00 \mathrm{E}+01$ & $2.4 \mathrm{eV}$ & Failed, short \\
\hline 1108 & ALUMINA & GA GRADED & $1250 \mathrm{~K}$ & $7.5 \& 30 \mathrm{~V}$ & 3696 TOTAL & $6.93 E+07$ & $2.41 \mathrm{eV}$ & Test terminated \\
\hline 1109 & ALUMINA & GA GRADED & $1250 \mathrm{~K}$ & $7.5 \& 30 \mathrm{~V}$ & 3696 TOTAL & $6.60 \mathrm{E}+07$ & $2.41 \mathrm{eV}$ & Test terminated \\
\hline 1110 & ALUMINA & GA GRADED & $1150 \mathrm{~K}$ & $7.5 \mathrm{~V}$ & 1440 & $5.77 \mathrm{E}+07$ & & Furnace problems \\
\hline 1111 & ALUMINA & GA GRADED & $1150 \mathrm{~K}$ & $7.5 \mathrm{~V}$ & 1440 & $7.50 \mathrm{E}+08$ & & Furnace problems \\
\hline 1112 & ALUMINA & GA GRADED & $1050 \mathrm{~K}$ & $7.5 \& 30 \mathrm{~V}$ & 3696 TOTAL & $1.54 \mathrm{E}+10$ & & Test terminated \\
\hline 1113 & ALUMINA & GA GRADED & $1050 \mathrm{~K}$ & $7.5 \& 30 \mathrm{~V}$ & 3696 TOTAL & $9.58 \mathrm{E}+09$ & & Test terminated \\
\hline 1114 & YTTRIA & GA GRADED & $1250 \mathrm{~K}$ & $7.5 \mathrm{~V}$ & 312 & $<100$ & & Test terminated \\
\hline 1115 & YTTRIA & GA GRADED & $1250 \mathrm{~K}$ & $7.5 \mathrm{~V}$ & 528 & $<100$ & & Test terminated \\
\hline 1116 & YTTRIA & GA GRADED & $1150 \mathrm{~K}$ & $7.5 \& 30 \mathrm{~V}$ & 2208 TOTAL & $<100$ & & Test terminated \\
\hline 1117 & YTTRIA & GA GRADED & $1050 \mathrm{~K}$ & $7.5 \& 30 \mathrm{~V}$ & 3696 TOTAL & $2.13 E+04$ & & Test terminated \\
\hline 1342 & YTTRIA & GA GRADED & $1270 \mathrm{~K}$ & $7.5 \mathrm{~V}$ & 960 & $4.00 \mathrm{E}+01$ & & Failed, short \\
\hline
\end{tabular}


APPENDIX D

SHEATH INSULATOR EX-REACTOR TEST SUMMARY

\begin{tabular}{|c|c|c|c|c|c|c|c|c|}
\hline SERIAL NUMBER & MATERIAL & PROCESS & TEMPERATURE & POTENTIAL & TIME (HOURS) & RESISTANCE END & ACTIVATION ENERGY & COMMENTS \\
\hline 1343 & YTTRIA & GA GRADED & $1170 \mathrm{~K}$ & $7.5 \& 30 V$ & 2232 TOTAL & $7240 / 7.5 \mathrm{~V}$ & & Failed, short \\
\hline 1344 & YTTRIA & GA GRADED & $1070 \mathrm{~K}$ & $7.5 \& 30 \mathrm{~V}$ & 2472/TOTAL & $4.20 \mathrm{E}+04$ & & Failed, short \\
\hline 1345 & ALUMINA & GA GRADED & $1270 \mathrm{~K}$ & $7.5,30,50 \& 100 \mathrm{~V}$ & 6048/TOTAL & $6.9 \mathrm{E}+7 / 100 \mathrm{~V}$ & 3.01 & Test terminated \\
\hline 1346 & ALUMINA & GA GRADED & $1170 \mathrm{~K}$ & $7.5,30,50 \& 100 \mathrm{~V}$ & 6048/TOTAL & $1.3 \mathrm{E}+9 / 100 \mathrm{~V}$ & 2.86 & Test terminated \\
\hline 1347 & ALUMINA & GA GRADED & $1070 \mathrm{~K}$ & $7.5,30 \& 50 \mathrm{~V}$ & 4560/TOTAL & $2.06 \mathrm{E}+10 / 50 \mathrm{~V}$ & 2.32 & Test terminated \\
\hline $1348-\mathrm{A}$ & ALUMINA & GA GRADED & $1270 \mathrm{~K}$ & $7.5,30,50 \& 100 \mathrm{~V}$ & 6048 TOTAL & $1.4 \mathrm{E} 7 / 100 \mathrm{~V}$ & 3 & Test terminated \\
\hline $1348-B$ & ALUMINA & GA GRADED & $1170 \mathrm{~K}$ & $7.5,30,50 \& 100 \mathrm{~V}$ & 6048 TOTAL & $1.4 \mathrm{E} 9 / 100 \mathrm{~V}$ & 3 & Test terminated \\
\hline $1348-\mathrm{C}$ & ALUMINA & GA GRADED & $1070 \mathrm{~K}$ & $7.5,30,50 \& 100 V$ & 4560 TOTAL & $2.04 \mathrm{E} 10 / 50 \mathrm{~V}$ & 2.84 & Test terminated \\
\hline 1685 & ALUMINA & GA GRADED & $1270 \mathrm{~K}$ & $100 \mathrm{~V}$ & 9048 & $3.90 \mathrm{E}+08$ & 0.57 (Surface Cond.) & Test terminated \\
\hline 1686 & ALUMINA & GA GRADED & $1170 \mathrm{~K}$ & $100 \mathrm{~V}$ & 9048 & $3.50 \varepsilon+09$ & 2.99 & Test terminated \\
\hline 1687 & ALUMINA & GA GRADED & $1070 \mathrm{~K}$ & $100 \mathrm{~V}$ & 8160 & $2.80 \mathrm{E}+10$ & 0.33 (Surface Cond.) & Test terminated \\
\hline $1705 \mathrm{~A}$ & ALUMINA & GA GRADED & $1270 \mathrm{~K}$ & $100 \mathrm{~V}$ & 9048 & $5.70 \mathrm{E}+08$ & 2.38 & Test terminated \\
\hline $1705 \mathrm{~B}$ & ALUMINA & GA GRADED & $1170 \mathrm{~K}$ & $100 \mathrm{~V}$ & 9048 & $4.90 E+07$ & 2.38 & Test terminated \\
\hline $1705 \mathrm{C}$ & ALUMINA & GA GRADED & $1070 \mathrm{~K}$ & $100 \mathrm{~V}$ & 9048 & $1.30 \mathrm{E}+09$ & 2.42 & Test terminated \\
\hline $1-24-1$ & ALUMINA & CERMET & $1100 \mathrm{~K}$ & $10 \mathrm{~V}$ & 48 & & & Failed, short \\
\hline $1-24-1$ & ALUMINA & CERMET & $1100 \mathrm{~K}$ & $10 \mathrm{~V}$ & 48 & & & Failed, short \\
\hline $1-36-3$ & ALUMINA & CERMET & $1100 \mathrm{~K}$ & $10 \mathrm{~V}$ & 48 & & & Failed, short \\
\hline $1-36-5$ & ALUMINA & CERMET & $1100 \mathrm{~K}$ & $10 \mathrm{~V}$ & 48 & & & Failed, short \\
\hline AL-1 & ALUMINA & CERMET $10 \%$ & $1130 \mathrm{~K}$ & $10 \mathrm{~V}$ & 96 & $<100$ & & Failed, short \\
\hline AL-2 & ALUMINA & CERMET $10 \%$ & $1130 \mathrm{~K}$ & $10 \mathrm{~V}$ & 2602 & $3.00 \mathrm{E}+07$ & & Heater failure \\
\hline $\mathrm{AL}-4$ & ALUMINA & CERMET $10 \%$ & $1086 \mathrm{~K}$ & $10 \mathrm{~V}$ & 4752 & $7.10 \mathrm{E}+08$ & $2.15 \mathrm{eV}$ & Test terminated \\
\hline$Y-0$ & YTTRIA & SLIP CAST & $1130 \mathrm{~K}$ & $10 \mathrm{~V}$ & 1253 & $<300$ & & Failed, short \\
\hline $001-1$ & YTTRIA & CERMET $10 \%$ & $1074 \mathrm{~K}$ & $7.5 \mathrm{~V}$ & & 50 & $1.62 \mathrm{eV}$ & Failed, short \\
\hline $001-2$ & YTTRIA & CERMET $10 \%$ & $1074 \mathrm{~K}$ & $7.5 \mathrm{~V}$ & & 50 & $1.63 \mathrm{eV}$ & Failed, short \\
\hline $001-3$ & YTTRIA & CERMET $10 \%$ & $1074 \mathrm{~K}$ & $7.5 \mathrm{~V}$ & & 50 & $1.61 \mathrm{eV}$ & Failed, short \\
\hline $082688-001$ & YTTRIA & SLIP CAST & $1250 \mathrm{~K}$ & $7.5 \mathrm{~V}$ & 2496 & 52.9 & & Failed, short \\
\hline $082688-002$ & YTTRIA & SLIP CAST & $1250 \mathrm{~K}$ & $7.5 \mathrm{~V}$ & 2496 & 8.32 & & Failed, short \\
\hline $082688-003$ & YTTRIA & SLIP CAST & $1250 \mathrm{~K}$ & $7.5 \mathrm{~V}$ & 2496 & 7.01 & & Failed, short \\
\hline $082688-004$ & YTTRIA & SLIP CAST & $1250 \mathrm{~K}$ & $7.5 \mathrm{~V}$ & 2496 & 15.4 & & Failed, short \\
\hline $100588-001$ & ALUMINA & CERMET $10 \%$ & $1250 \mathrm{~K}$ & $7.5 \mathrm{~V}$ & 2496 & 278 & & Failed, short \\
\hline $100588-002$ & ALUMINA & CERMET $10 \%$ & $1250 \mathrm{~K}$ & $7.5 \mathrm{~V}$ & 2496 & $1.48 \mathrm{E}+04$ & & Failed, short \\
\hline $101188-01 \mathrm{~A}$ & ALUMINA & CERMET 5\% & $1090 \mathrm{~K}$ & $7.5 \mathrm{~V}$ & 171 & $1.30 \mathrm{E}+05$ & & Test terminated \\
\hline $101188-01 B$ & ALUMINA & CERMET 5\% & $1090 \mathrm{~K}$ & $7.5 \mathrm{~V}$ & 1 & $1.65 E+02$ & & Immediate failure \\
\hline $102788-01$ & ALUMINA & CERMET 5\% & $1100 \mathrm{~K}$ & $7.5 \mathrm{~V}$ & 530 & $2.60 \mathrm{E}+05$ & & Test terminated \\
\hline $110788-01$ & ALUMINA & CERMET $10 \%$ & $1090 \mathrm{~K}$ & $7.5 \mathrm{~V}$ & 530 & $2.90 \mathrm{E}+05$ & & Test terminated \\
\hline $111088-001$ & ALUMINA & CERMET $10 \%$ & $1250 \mathrm{~K}$ & $7.5 \mathrm{~V}$ & 2496 & $1.17 \mathrm{E}+07$ & $2.69 \mathrm{eV}$ & Test terminated \\
\hline $111088-002$ & ALUMINA & CERMET $10 \%$ & $1250 \mathrm{~K}$ & $7.5 \mathrm{~V}$ & 2496 & $1.11 \mathrm{E}+07$ & $2.68 \mathrm{eV}$ & Test terminated \\
\hline $111488-01$ & ALUMINA & CERMET $10 \%$ & $1090 \mathrm{~K}$ & $7.5 \mathrm{~V}$ & 38 & & & Failed, short \\
\hline $111688-01 \mathrm{~A}$ & ALUMINA & CERMET $15 \%$ & $1100 \mathrm{~K}$ & $7.5 \mathrm{~V}$ & 1 & $1.20 \mathrm{E}+03$ & & Failed, short \\
\hline $111688-01 B$ & ALUMINA & CERMET 15\% & $1080 \mathrm{~K}$ & $7.5 \mathrm{~V}$ & 1 & 2300 & & Failed, short \\
\hline $111688-01 C$ & ALUMINA & CERMET $15 \%$ & $1120 \mathrm{~K}$ & $7.5 \mathrm{~V}$ & 150 & 4200 & & Failed, short \\
\hline $111688-01 \mathrm{D}$ & ALUMINA & CERMET 15\% & $1130 \mathrm{~K}$ & $7.5 \mathrm{~V}$ & 1 & $3.00 \mathrm{E}+02$ & & Failed, short \\
\hline
\end{tabular}


APPENDIX D

SHEATH INSULATOR EX-REACTOR TEST SUMMARY

\begin{tabular}{|c|c|c|c|c|c|c|c|c|}
\hline SERIAL NUMBER & MATERIAL & PROCESS & TEMPERATURE & POTENTIAL & TIME (HOURS) & RESISTANCE END & ACTIVATION ENERGY & COMMENTS \\
\hline $050189-01$ & YAG & CERMET 10\% & $1100 \mathrm{~K}$ & $7.5 \mathrm{~V}$ & 336 & $8.80 \mathrm{E}+04$ & & Test terminated \\
\hline 050189-02 & YAG & CERMET $10 \%$ & $1090 \mathrm{~K}$ & $7.5 \mathrm{~V}$ & 336 & $1.30 \mathrm{E}+05$ & & Test terminated \\
\hline $051089-01$ & YAG & SLIP CAST & $1100 \mathrm{~K}$ & $7.5 \mathrm{~V}$ & 336 & $2.20 \mathrm{E}+04$ & & Test terminated \\
\hline $051089-02$ & YAG & SLIP CAST & $1090 \mathrm{~K}$ & $7.5 \mathrm{~V}$ & 1130 & $3.40 \mathrm{E}+04$ & & Test terminated \\
\hline Sapphire 1 & ALUMINA & SINGLE CRYSTAL & $1250 \mathrm{~K}$ & $7.5 \mathrm{~V}$ & 750 & $3.00 \mathrm{E}+06$ & & No temp. dependance \\
\hline Sapphire 2 & ALUMINA & SINGLE CRYSTAL & $1250 \mathrm{~K}$ & $7.5 \mathrm{~V}$ & 750 & $3.00 \mathrm{E}+06$ & & No temp. dependance \\
\hline 021B-1 & ALUMINA & CERMET $10 \%$ & $1300 \mathrm{~K}$ & $7.5 \mathrm{~V}$ & 450 & $9.00 \mathrm{E}+05$ & & Test terminated \\
\hline 021B-2 & ALUMINA & CERMET $10 \%$ & $1310 \mathrm{~K}$ & $7.5 \mathrm{~V}$ & 450 & $7.00 \mathrm{E}+05$ & & Test terminated \\
\hline 025B-1 & YTTRIA & SLIP CAST & $1280 \mathrm{~K}$ & $7.5 \mathrm{~V}$ & 12 & 15 & & Failed, short \\
\hline $033-1$ & ALUMINA & CERMET 5\% & $1330 \mathrm{~K}$ & $7.5 \mathrm{~V}$ & 500 & $5.00 \mathrm{E}+05$ & & Test terminated \\
\hline 033-2A & ALUMINA & CERMET 5\% & $1270 \mathrm{~K}$ & $7.5,30,50 \& 100 V$ & $5568 /$ Total & $4.12 E+5 / 100 V$ & $2.5 \mathrm{eV}$ & Test terminated \\
\hline 033-2B & ALUMINA & CERMET 5\% & $1170 \mathrm{~K}$ & $7.5,30,50 \& 100 V$ & $6048 /$ Total & $1.40 \mathrm{E}+7 / 100 \mathrm{~V}$ & $2.0 \mathrm{eV}$ & Test terminated \\
\hline 033-2C & ALUMINA & CERMET 5\% & $1070 \mathrm{~K}$ & $7.5,30 \& 50 \mathrm{~V}$ & $4560 /$ Total & $3.01 \mathrm{E}+9 / 50 \mathrm{~V}$ & & Test terminated \\
\hline $034 \mathrm{~A}$ & ALUMINA & CERMET 5\% & $1280 \mathrm{~K}$ & $7.5 \mathrm{~V}$ & 500 & $1.00 \mathrm{E}+06$ & & Test terminated \\
\hline $039-1 \mathrm{~A}$ & ALUMINA & CERMET 5\% & $1270 \mathrm{~K}$ & $7.5,30,50 \& 100 \mathrm{~V}$ & $6048 /$ Total & $1.10 \mathrm{E}+6 / 100 \mathrm{~V}$ & $2.2 \mathrm{eV}$ & Test terminated \\
\hline 039-1B & ALUMINA & CERMET 5\% & $1170 \mathrm{~K}$ & $7.5,30,50 \& 100 V$ & $6048 /$ Total & $1.90 \mathrm{E}+7 / 100 \mathrm{~V}$ & $2.5 \mathrm{eV}$ & Test terminated \\
\hline 039-1C & ALUMINA & CERMET 5\% & $1070 \mathrm{~K}$ & $7.5,30 \& 50 \mathrm{~V}$ & $4560 /$ Total & $3.66 \mathrm{E}+9 / 50 \mathrm{~V}$ & & Test terminated \\
\hline $039-2 \mathrm{~A}$ & ALUMINA & CERMET 5\% & $1300 \mathrm{~K}$ & $7.5 \mathrm{~V}$ & 450 & $9.00 \mathrm{E}+05$ & & Test terminated \\
\hline $040-2$ & ALUMINA & CERMET $10 \%$ & $1300 \mathrm{~K}$ & $7.5 \mathrm{~V}$ & 100 & $1.80 \mathrm{E}+02$ & & Failed, short \\
\hline 040-6B & ALUMINA & CERMET $10 \%$ & $1100 \mathrm{~K}$ & $7.5 \mathrm{~V}$ & 1 & $3.00 \mathrm{E}+02$ & & Failed, short \\
\hline $040-6 C$ & ALUMINA & CERMET $10 \%$ & $1100 \mathrm{~K}$ & $7.5 \mathrm{~V}$ & 1 & $1.00 \mathrm{E}+02$ & & Failed, short \\
\hline $041-1$ & ALUMINA & CERMET $10 \%$ & $1300 \mathrm{~K}$ & $7.5 \mathrm{~V}$ & 64 & $4.30 \mathrm{E}+01$ & & Failed, short \\
\hline $043 \mathrm{~A}-1$ & ALUMINA & CERMET $10 \%$ & $1100 \mathrm{~K}$ & $7.5 \mathrm{~V}$ & 24 & $2.75 E+02$ & & Failed, short \\
\hline $043 \mathrm{~A}-2$ & ALUMINA & CERMET $10 \%$ & $1300 \mathrm{~K}$ & $7.5 \mathrm{~V}$ & 4 & $6.00 \mathrm{E}+01$ & & Failed, short \\
\hline $054 \mathrm{~A}-1$ & ALUMINA & CERMET 5\% & $1300 \mathrm{~K}$ & $7.5 \mathrm{~V}$ & 1100 & $2.00 \mathrm{E}+06$ & & Test terminated \\
\hline $056-3$ & ALUMINA & CERMET $10 \%$ & $1100 \mathrm{~K}$ & $7.5 \mathrm{~V}$ & 240 & $2.00 \mathrm{E}+07$ & & Test terminated \\
\hline $056-6$ & ALUMINA & CERMET $10 \%$ & $1300 \mathrm{~K}$ & $7.5 \mathrm{~V}$ & 1200 & $7.00 \mathrm{E}+05$ & & Test terminated \\
\hline $057-1$ & ALUMINA & CERMET $10 \%$ & $1300 \mathrm{~K}$ & $7.5 \mathrm{~V}$ & 24 & $1.50 \mathrm{E}+02$ & & Failed, short \\
\hline $059-2$ & ALUMINA & CERMET 10\% & $1300 \mathrm{~K}$ & $7.5 \mathrm{~V}$ & 1 & $8.00 \mathrm{E}+01$ & & Failed, short \\
\hline $061-1$ & ALUMINA & CERMET $10 \%$ & $1300 \mathrm{~K}$ & $7.5 \mathrm{~V}$ & 8 & 100 & & Failed, short \\
\hline $061-2$ & ALUMINA & CERMET 10\% & $1300 \mathrm{~K}$ & $7.5 \mathrm{~V}$ & 48 & 100 & & Failed, short \\
\hline $062-1$ & ALUMINA & CERMET 5\% & $1300 \mathrm{~K}$ & $7.5 \mathrm{~V}$ & 168 & $3.10 \mathrm{E}+05$ & & Test terminated \\
\hline $065-3$ & ALUMINA & CERMET $10 \%$ & $1300 \mathrm{~K}$ & $7.5 \mathrm{~V}$ & 530 & $2.50 \mathrm{E}+05$ & 4.05 & Test terminated \\
\hline $066-1$ & ALUMINA & CERMET 5\% & $1300 \mathrm{~K}$ & $7.5 \mathrm{~V}$ & 530 & $7.50 \mathrm{E}+05$ & & Test terminated \\
\hline $067-1$ & ALUMINA & CERMET 10\% & $1300 \mathrm{~K}$ & $7.5 \mathrm{~V}$ & 72 & $2.00 \mathrm{E}+05$ & 4 & Test terminated \\
\hline $067-2$ & ALUMINA & CERMET $10 \%$ & $1300 \mathrm{~K}$ & $7.5 \mathrm{~V}$ & 72 & $3.00 \mathrm{E}+05$ & 4.1 & Test terminated \\
\hline $067-3$ & ALUMINA & CERMET $10 \%$ & $1300 \mathrm{~K}$ & $7.5 \mathrm{~V}$ & 72 & $2.50 \mathrm{E}+05$ & 3.7 & Test terminated \\
\hline $068-1$ & ALUMINA & CERMET 5\% & $1300 \mathrm{~K}$ & $7.5 \mathrm{~V}$ & 120 & $2.50 \mathrm{E}+05$ & & Test terminated \\
\hline $068-2$ & ALUMINA & CERMET 5\% & $1300 \mathrm{~K}$ & $7.5 \mathrm{~V}$ & 72 & $3.50 \mathrm{E}+05$ & 2.5 & Test terminated \\
\hline $068-3$ & ALUMINA & CERMET 5\% & $1300 \mathrm{~K}$ & $7.5 \mathrm{~V}$ & 144 & $3.00 \mathrm{E}+05$ & 3.4 & Test terminated \\
\hline $068-4$ & ALUMINA & CERMET 5\% & $1300 \mathrm{~K}$ & $7.5 \mathrm{~V}$ & 72 & $4.00 \mathrm{E}+05$ & 3.9 & Test terminated \\
\hline $068-5$ & ALUMINA & CERMET $5 \%$ & $1300 \mathrm{~K}$ & $7.5 \mathrm{~V}$ & 72 & $4.00 \mathrm{E}+05$ & 3.8 & Test terminated \\
\hline
\end{tabular}




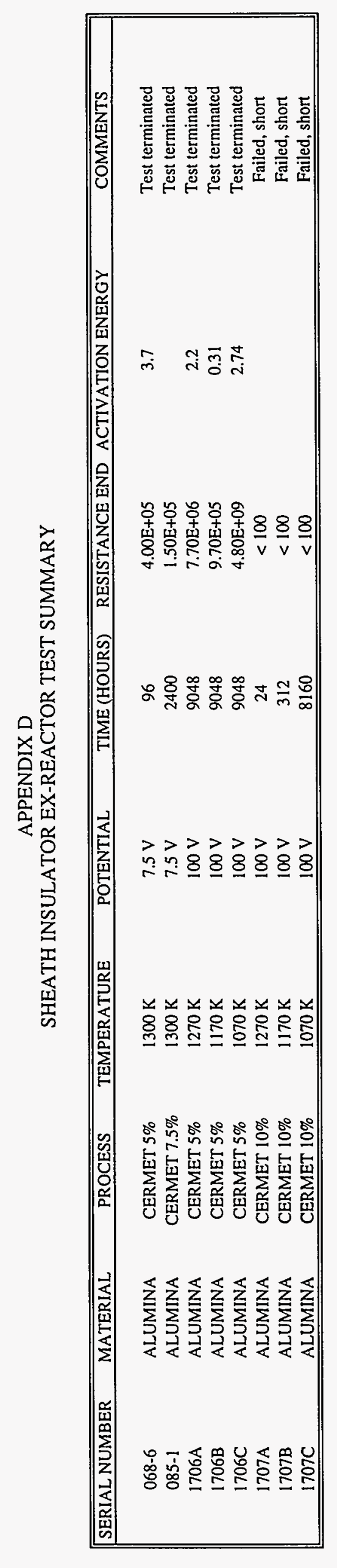

